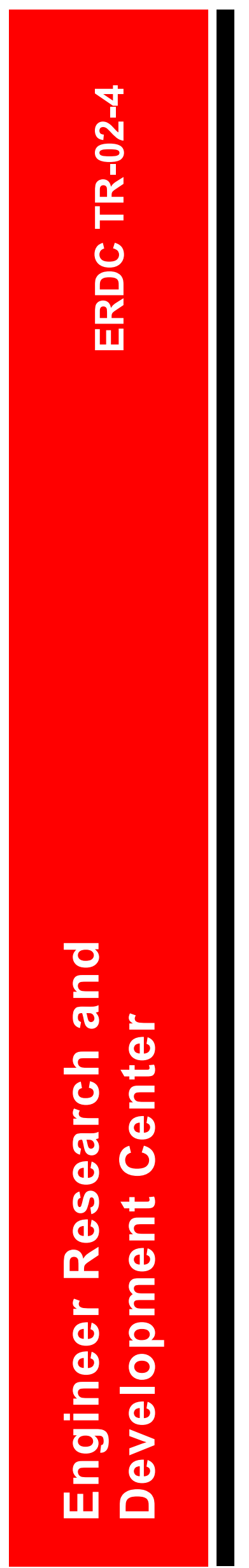

\title{
Tributary Refinements to the Chesapeake Bay Model
}

Carl F. Cerco, Billy H. Johnson, and Harry V. Wang

April 2002

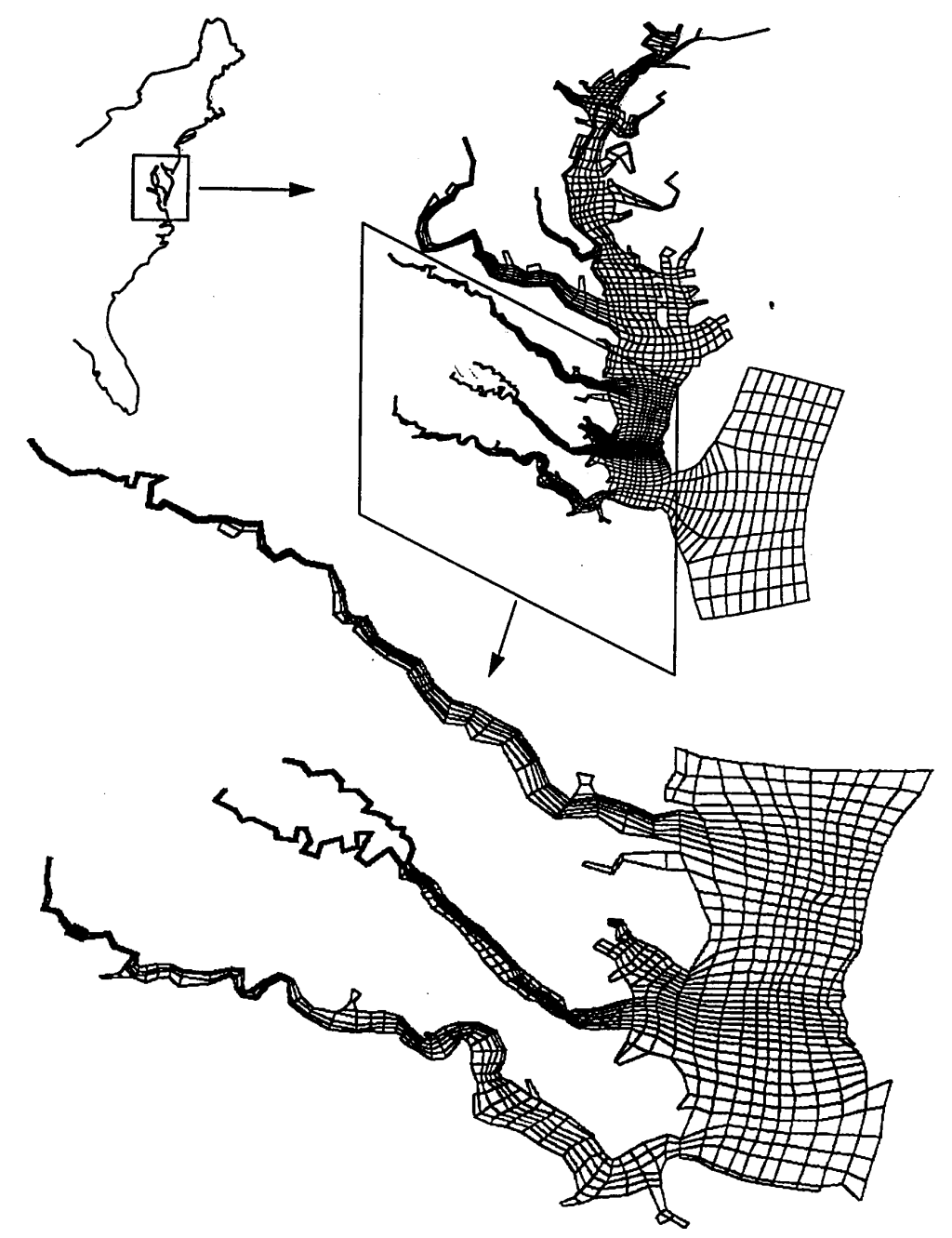

Approved for public release; distribution is unlimited. 
The contents of this report are not to be used for advertising, publication, or promotional purposes. Citation of trade names does not constitute an official endorsement or approval of the use of such commercial products.

The findings of this report are not to be construed as an official Department of the Army position, unless so designated by other authorized documents. 
ERDC TR-02-4

April 2002

\section{Tributary Refinements to the Chesapeake Bay Model}

by Carl. F. Cerco

Environmental Laboratory

U.S. Army Engineer Research and Development Center 3909 Halls Ferry Road

Vicksburg, MS 39180-6199

Billy H. Johnson

Coastal and Hydraulics Laboratory

U. S. Army Engineer Research and Development Center 3909 Halls Ferry Road

Vicksburg, MS 39180-6199

Harry V. Wang

Virginia Institute of Marine Science

P.O. Box 1346

Route 1208, Greate Road

Gloucester Point, VA 23062-1346

Final report

Approved for public release; distribution is unlimited 


\section{Contents}

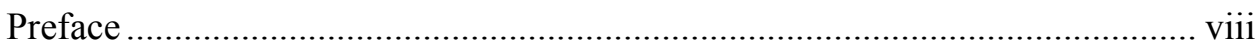

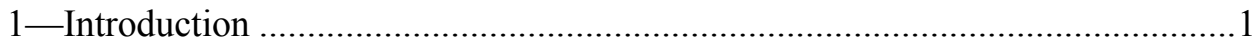

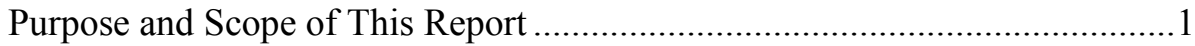

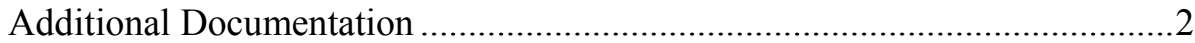

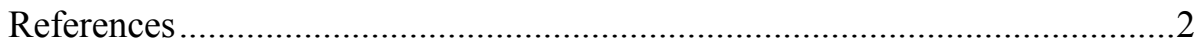

2-Validation and Application of the Second-Generation Three-Dimensional Hydrodynamic Model of Chesapeake Bay ....................................................

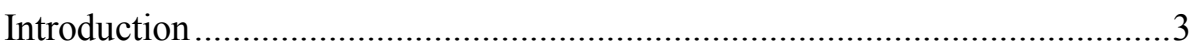

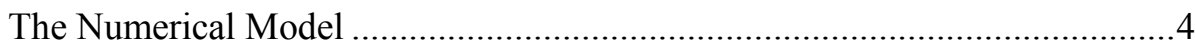

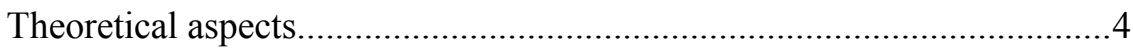

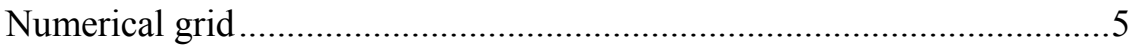

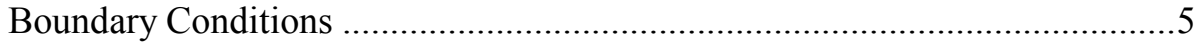

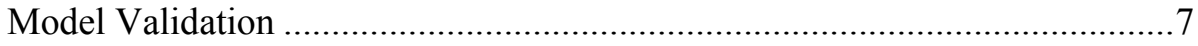

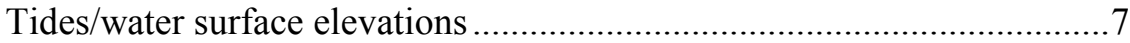

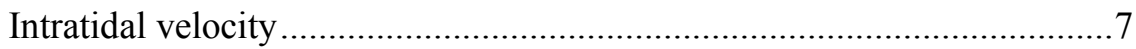

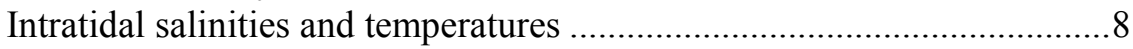

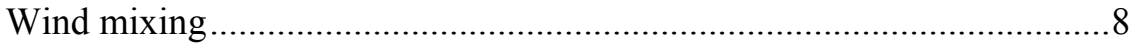

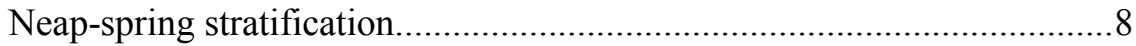

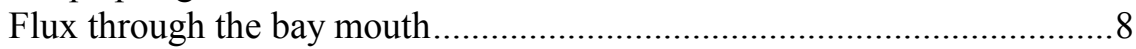

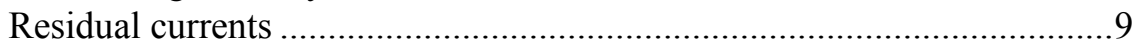

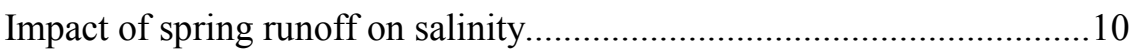

Seasonal salinity transects and vertical profiles ...................................... 10

Hydrodynamic Simulation for 1985-94 ...................................................11

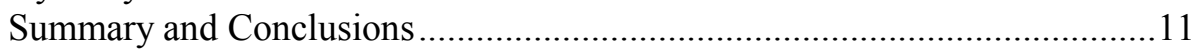

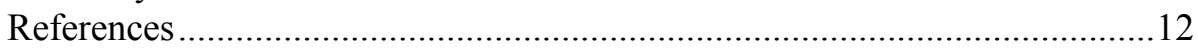

3-Tributary Refinements to the Chesapeake Bay Model ..................................46

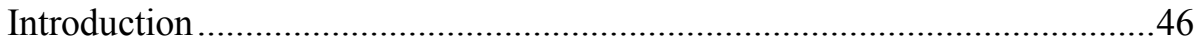

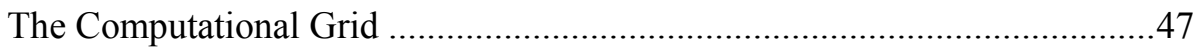

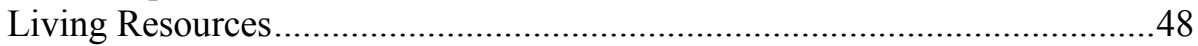

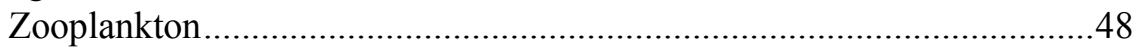

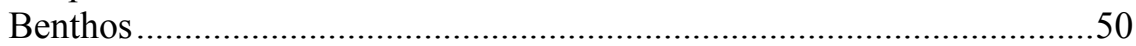

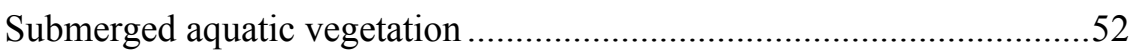

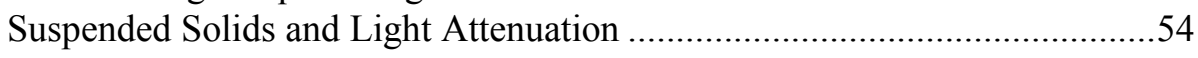

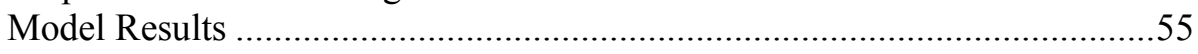




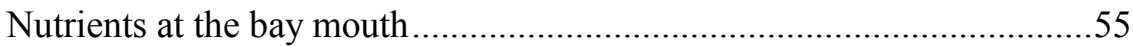

Dissolved oxygen in the lower tributaries...........................................58

Phosphorus and chlorophyll in the tidal fresh James River ....................60

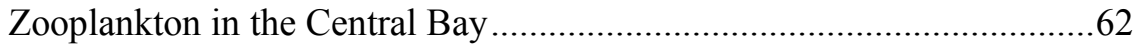

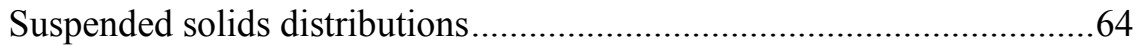

Submerged aquatic vegetation in the lower bay......................................66

Benthos in the river-estuarine transition regions.....................................66

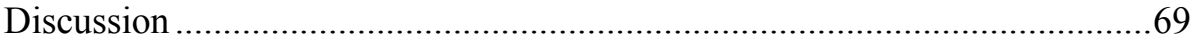

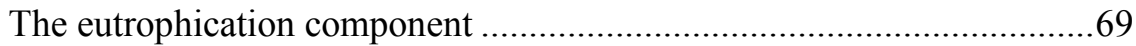

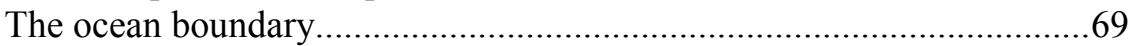

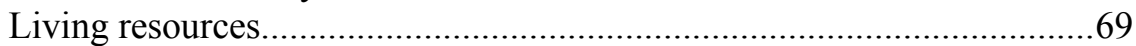

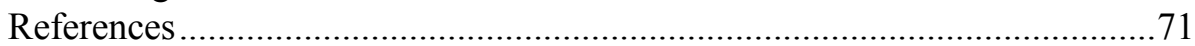

4-Phytoplankton Kinetics in the Chesapeake Bay Eutrophication Model ...........73

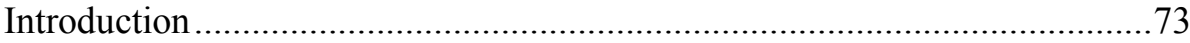

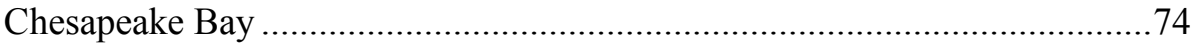

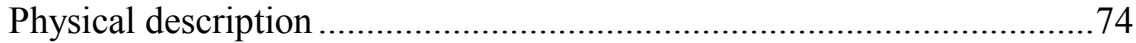

Bottom-water hypoxia …..............................................................74

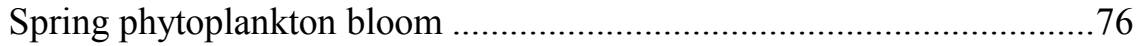

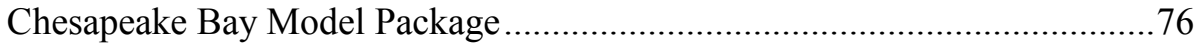

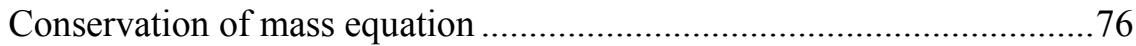

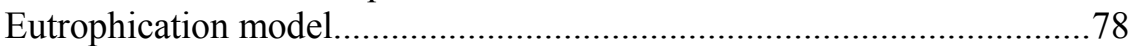

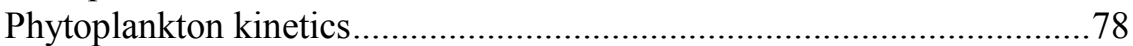

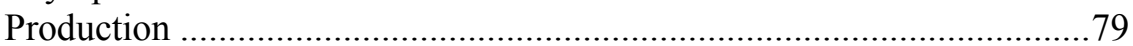

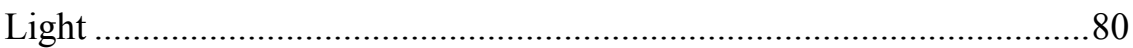

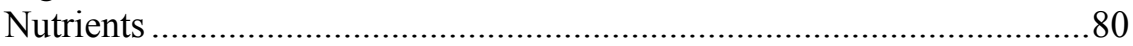

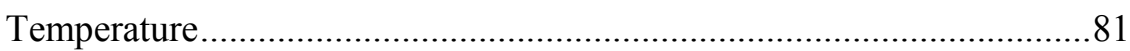

Combining effects of light, nutrients, and temperature ............................82

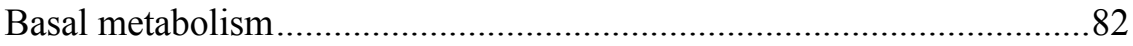

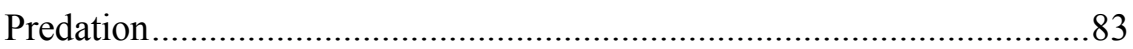

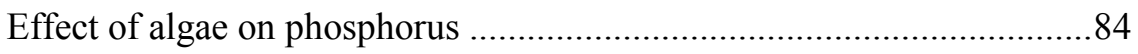

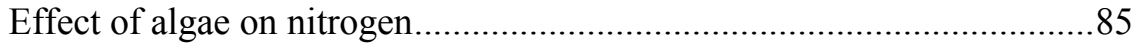

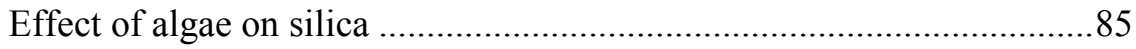

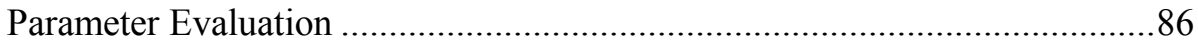

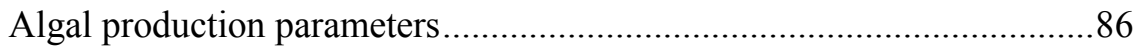

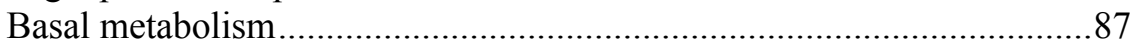

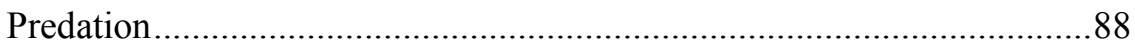

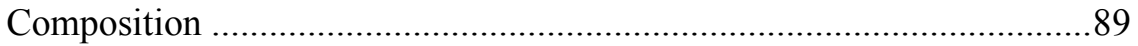

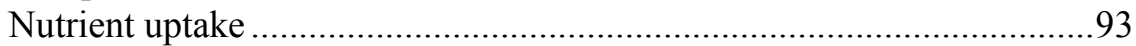

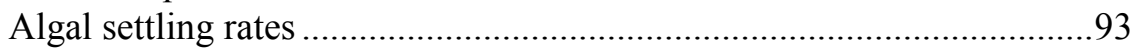

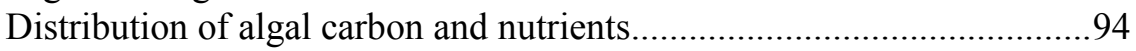

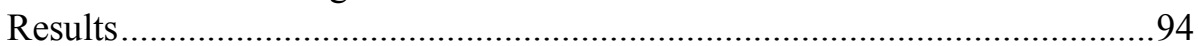

Spatial distribution of phytoplankton and nutrients ...............................95

Temporal distribution of phytoplankton and nutrients..........................100

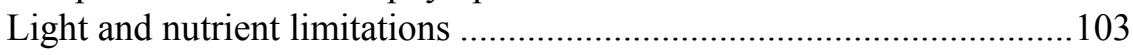

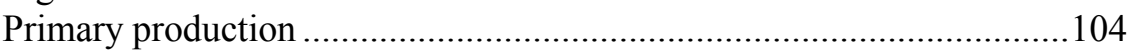

Primary production measures in Chesapeake Bay ...............................105

Comparison with observations..........................................................107

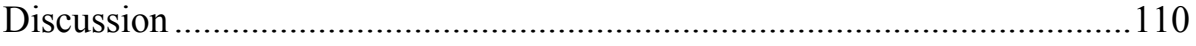

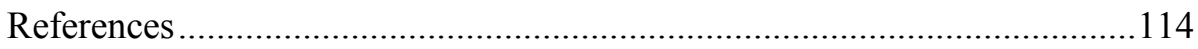


5-Systemwide Submerged Aquatic Vegetation Model for Chesapeake Bay ....119

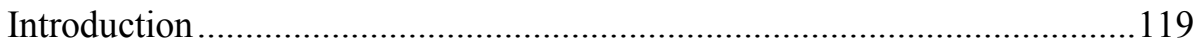

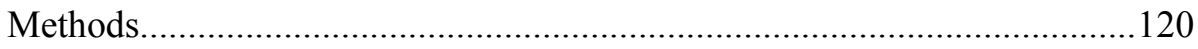

Submerged aquatic vegetation unit model ............................................120

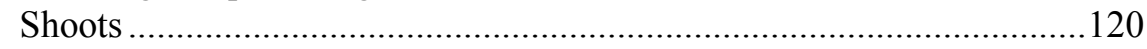

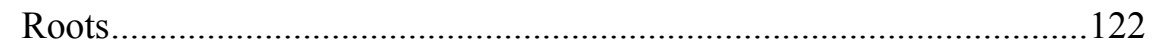

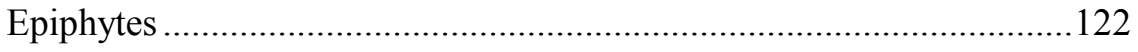

SAV composition and nutrient cycling ................................................123

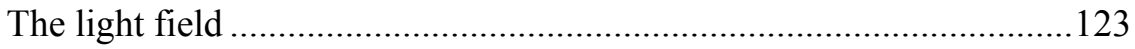

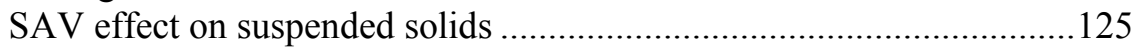

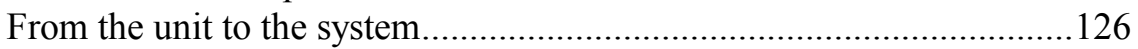

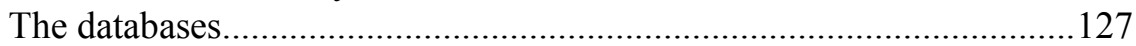

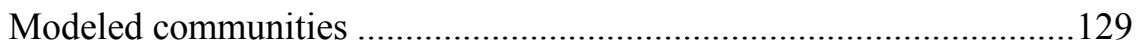

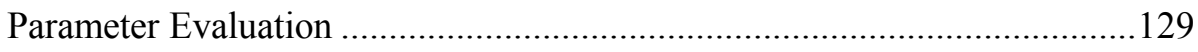

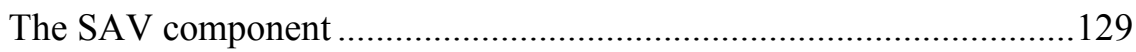

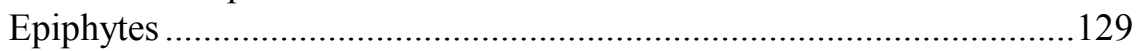

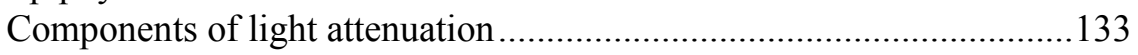

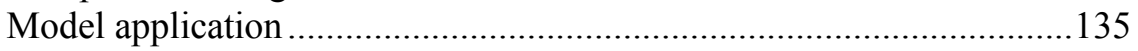

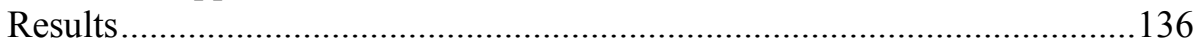

Agreement with living-resource parameters .....................................136

Effect on suspended solids.............................................................136

Spatial distribution of SAV and light attenuation ..................................136

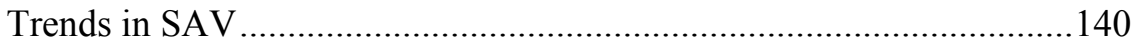

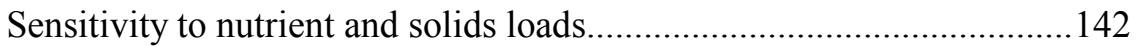

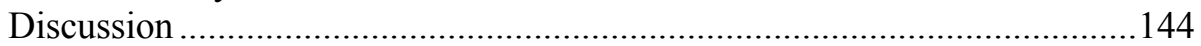

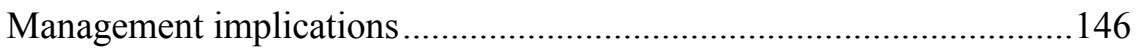

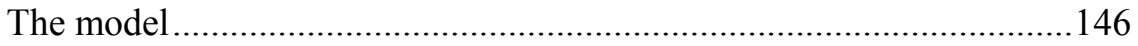

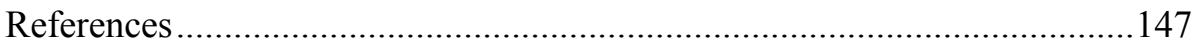

6-Nutrient and Solids Controls in Virginia's Chesapeake Bay Tributaries ......151

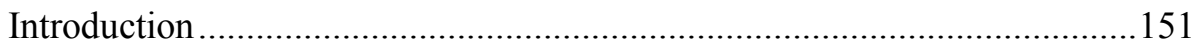

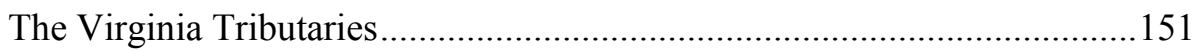

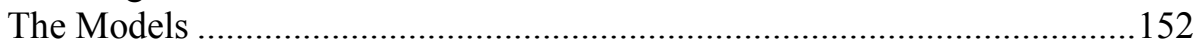

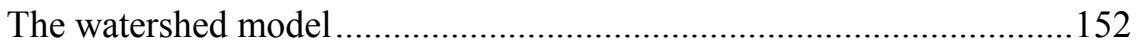

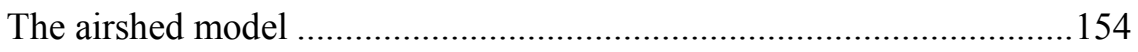

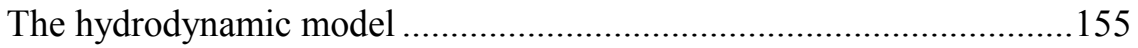

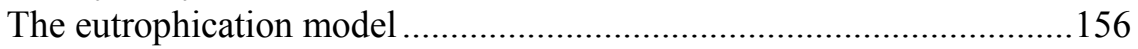

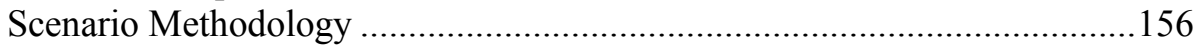

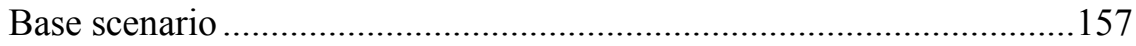

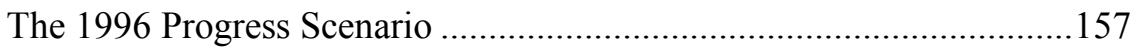

Full Voluntary Program Implementation (FVPI) ..................................157

Limit of Technology (LOT) .......................................................... 158

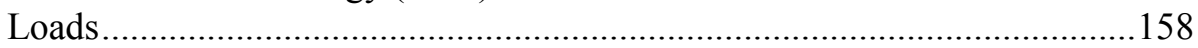

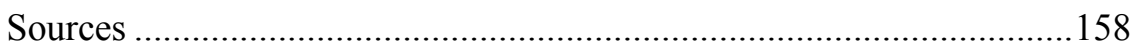

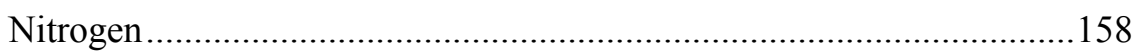

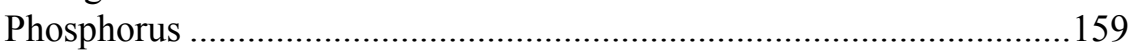

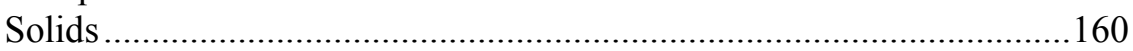

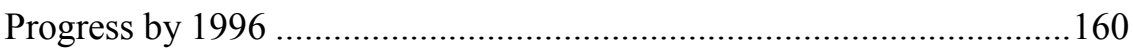

Full Voluntary Program Implementation ..........................................160 


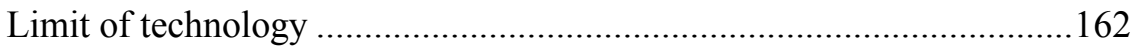

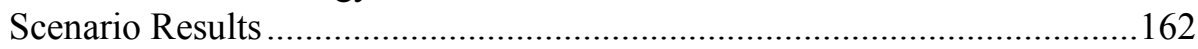

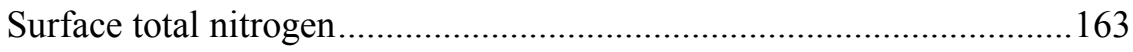

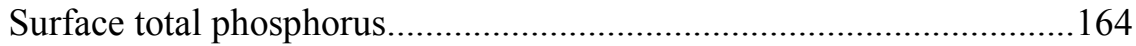

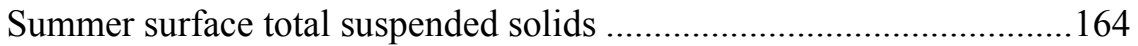

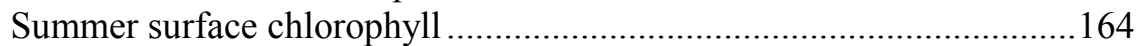

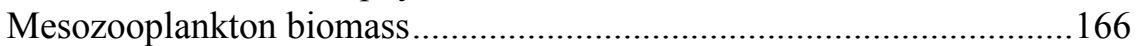

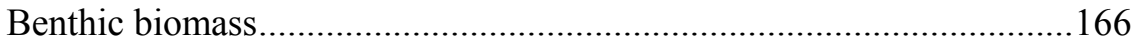

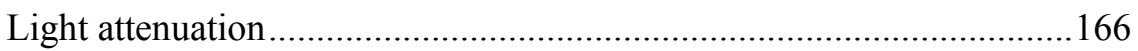

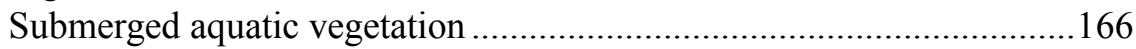

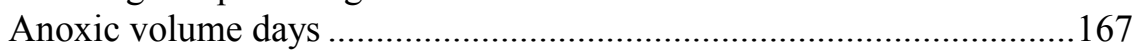

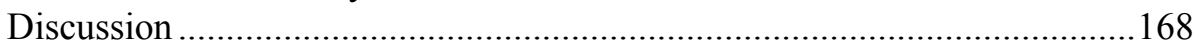

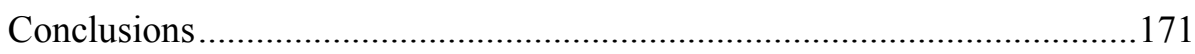

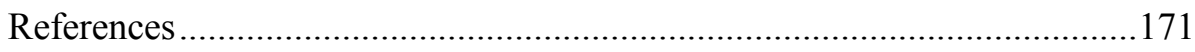

7-Incremental Improvements in Virginia Tributary Models...........................173

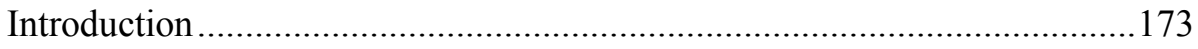

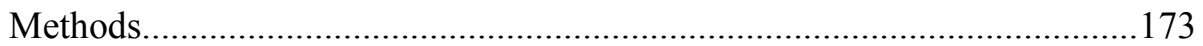

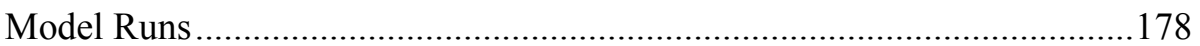

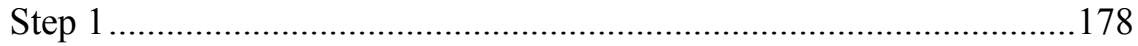

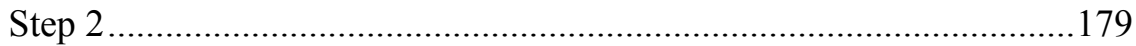

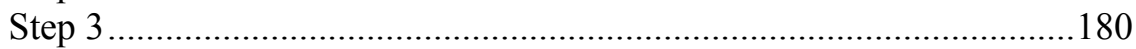

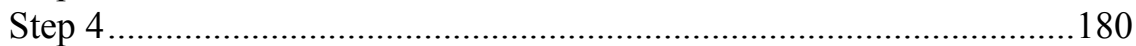

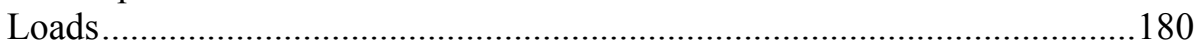

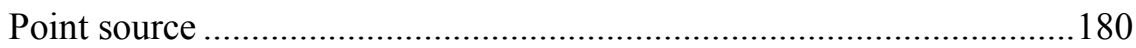

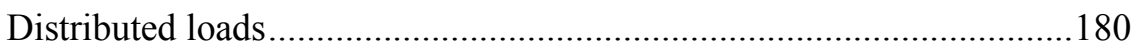

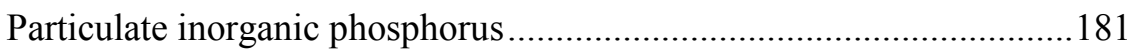

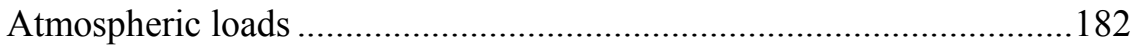

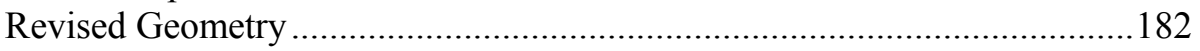

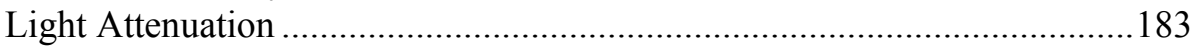

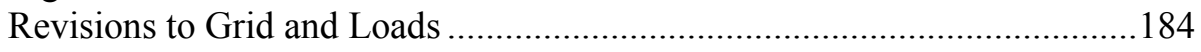

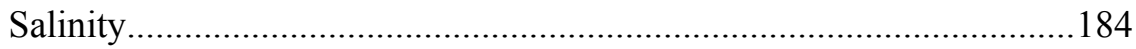

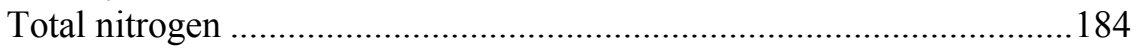

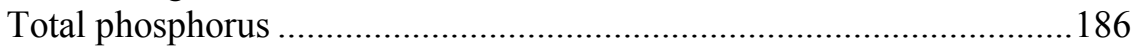

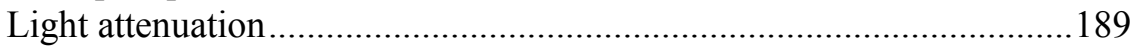

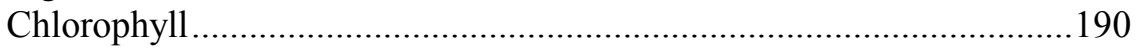

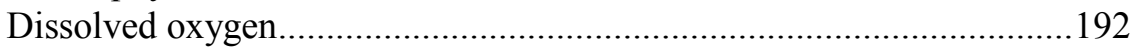

Addition of Living Resources and Solids Computations.............................193

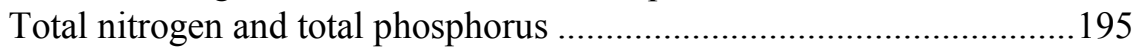

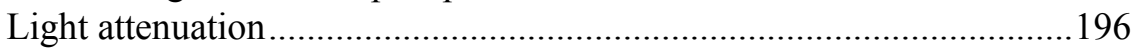

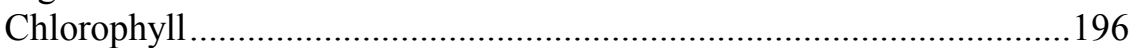

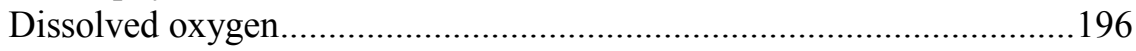

Revisions to Atmospheric and Bank Loads................................................196

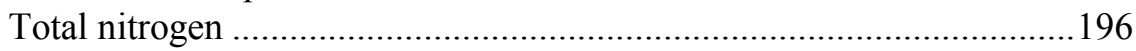

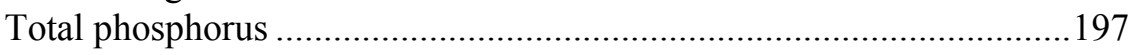

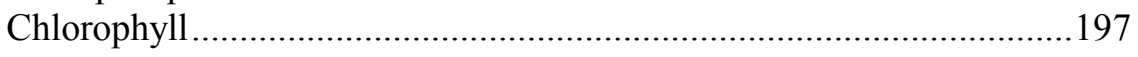

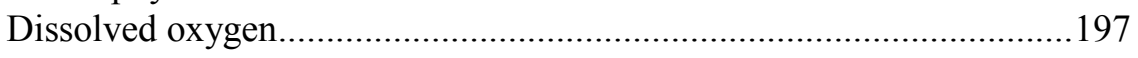

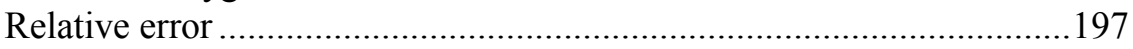

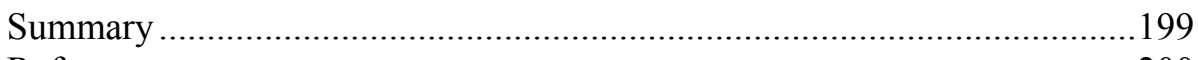

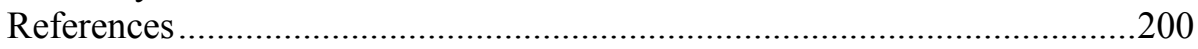




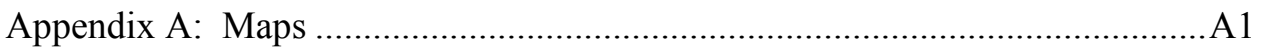

Appendix B: Tributary Calibration.................................................................. B1

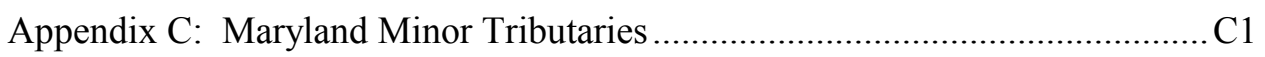

Appendix D: Particulate Inorganic Phosphorus ..................................................... 1

SF 298 


\section{Preface}

This study was sponsored by the U.S. Army Engineer District, Baltimore, and by the Chesapeake Bay Program Office, Region III, U.S. Environmental Protection Agency. Project officers were Ms. Carol Bernstein, Baltimore District, and Mr. Lewis Linker, U.S. Environmental Protection Agency.

This report assembles all documentation produced by the U.S. Army Engineer Research and Development Center (ERDC) on tributary refinements of CE-QUAL-ICM, a three-dimensional, time-variable model of eutrophication processes in the water column and benthic sediments of the Chesapeake Bay. Some of the chapters in this report were published as articles in technical journals while others remain unpublished.

The report was prepared by Dr. Carl F. Cerco, Water Quality and Contaminant Modeling Branch (WQCMB), Environmental Processes and Engineering Division (EPED), Environmental Laboratory (EL), Vicksburg, MS, ERDC; Dr. Billy H. Johnson, Estuaries and Hydroscience Division (EHD), Coastal and Hydraulics Laboratory (CHL), Vicksburg, MS, ERDC; and Dr. Harry V. Wang, Assistant Professor of Marine Science, Virginia Institute of Marine Science (VIMS), Gloucester Point, VA. Additional contributions were made as follows: Chapter 3, Dr. Mark Meyers, HydroQual, Inc., Mahwah, NJ; Chapter 5, Dr. Kenneth A. Moore, Associate Professor of Marine Science, VIMS; and Chapter 6, Messrs. Lewis Linker and Gary Shenk, U.S. Environmental Protection Agency, Chesapeake Bay Program, Annapolis, MD; Jeffrey Sweeney, University of Maryland, Chesapeake Bay Program, Annapolis, MD; and Dr. Arthur J. Butt, Virginia Department of Environmental Quality, Richmond, VA.

This work was conducted under the general supervision of Dr. Mark S. Dortch, Chief, WQCMB; Dr. Richard E. Price, Chief, EPED; Dr. Edwin A. Theriot, Director, EL; Dr. William H. McAnally, Chief, EHD; and Dr. James R. Houston, Director, CHL.

At the time of publication of this report, Dr. James R. Houston was Director of ERDC, and COL John W. Morris III, EN, was Commander and Executive Director. 
This report should be cited as follows:

Cerco, C. F, Johnson, B. H., and Wang, H. V. (2002). "Tributary refinements to the Chesapeake Bay model," ERDC TR-02-4, U.S. Army Engineer Research and Development Center, Vicksburg, MS.

The contents of this report are not to be used for advertising, publication, or promotional purposes. Citation of trade names does not constitute an official endorsement or approval of the use of such commercial products. 


\section{Introduction}

The need to manage eutrophication within Chesapeake Bay led to the development and application of the CE-QUAL-ICM model (Cerco and Cole 1993). CE-QUAL-ICM is a three-dimensional, time-variable model of eutrophication processes in the water column and benthic sediments. The model was part of a package applied to Chesapeake Bay that included a three-dimensional hydrodynamic model and a watershed model. Subsequent to validation, CE-QUALICM was employed in scenario analysis (Cerco 1995a) and in examination of long-term trends in eutrophication (Cerco 1995b).

CE-QUAL-ICM was especially suited for examination of eutrophication processes within the main stem of the bay. However, the model was less successful in modeling the major western-shore tributaries, largely because of the coarse scale of the grid in these areas. In addition, distributed loads to these tributaries lacked spatial resolution, and point-source loads were frequently set to default values. In preparation for a periodic re-evaluation of management efforts in the bay, a course of tributary refinements was specified for CE-QUAL-ICM. Among these refinements were the following:

- Increased grid resolution within the major western-shore tributaries.

- Extension of the grid beyond the mouth of the bay onto the continental shelf.

- Direct simulation of living resources including zooplankton, submerged aquatic vegetation (SAV), and benthos.

- Extension of the validation period to include contemporary data.

Concurrent with refinements to CE-QUAL-ICM, the spatial resolution of loads from the watershed model was improved and a sampling program was conducted to define the point-source loads.

\section{Purpose and Scope of This Report}

No comprehensive technical report has been published that described the tributary refinements. A number of monographs were produced, however. Several of these were published as articles in technical journals while others remain unpublished. This report assembles all documentation produced by the U.S. Army 
Engineer Research and Development Center on the tributary refinements. Each monograph is included herein as an individual chapter as follows:

- Chapter 2 - An overview of results from the hydrodynamic model

- Chapter 3 - A summary of water quality model refinements and results

- Chapter 4 - A detailed description of phytoplankton kinetics

- Chapter 5 - A description of the Submerged Aquatic Vegetation model

- Chapter 6 - A summary of management scenarios applied to the Virginia tributaries

- Chapter 7 - A statistical summary of model performance

Complete model results, in graphical form, are presented in a series of appendices. Appendix A presents maps of sample stations and of Chesapeake Bay program Segments. Appendix B presents the following results from the model: longitudinal plots, time series by program segments, time series at stations, vertical profiles, and SAV time series. Appendix C presents results from the refined Maryland minor tributaries, and Appendix D presents a data summary of the particulate inorganic phosphorus (PIP) sampling program including annual mean salinity, fixed solids concentration, particulate inorganic phosphorus concentration, particulate inorganic phosphorus as a fraction of fixed solids, and dissolved inorganic phosphorus concentration.

\section{Additional Documentation}

Additional documentation is available on the U.S. Environmental Protection Agency Chesapeake Bay Program Web site:

http://www.chesapeakebay.net/modsc.htm

This documentation includes the report "Development of a Suspension Feeding and Deposit Feeding Benthos Model for Chesapeake Bay," produced by HydroQual, Inc., under contract to the U.S. Army Engineer Research and Development Center.

\section{References}

Cerco, C. (1995a). "Response of Chesapeake Bay to nutrient load reductions," Journal of Environmental Engineering 121, 549-557. . (1995b). "Simulation of long-term trends in Chesapeake Bay eutrophication," Journal of Environmental Engineering 121, 298-310.

Cerco, C., and Cole, T. (1993). "Three-dimensional eutrophication model of Chesapeake Bay," Journal of Environmental Engineering 119, 1006-1025. 


\section{Validation and Application of the Second-Generation Three-Dimensional Hydrodynamic Model of Chesapeake Bay}

\section{Introduction}

The Chesapeake Bay (Figure 1), located on the eastern coast of the United States, is one of the largest estuaries in the world, and historically has been one of the most productive in terms of wildlife, finfish, and shellfish. However, as a result of the decline in many of the Chesapeake Bay's resources due to the introduction of excess nutrients, the Chesapeake Bay Program (CBP) was created in 1983 to restore the bay. The CBP is a partnership that includes the states of Maryland, Virginia, and Pennsylvania, the District of Columbia, the Chesapeake Bay Commission, and the U.S. Environmental Protection Agency (EPA). An integral part of the CBP's strategy was the development of numerical models to predict the impact of various nutrient control measures before the implementation of those controls.

In the late 1980's, an agreement was reached in which the EPA and the U.S. Army Corps of Engineers jointly funded the development of fully dynamic three-dimensional (3-D) hydrodynamic and water quality models of the bay. Results from that effort are published in Johnson et al. $(1991 ; 1993)$ and Cerco and Cole (1994). Although that effort was considered a great success by the bay community, it was recognized that to adequately address issues in the bay connected with the release and transport of nutrients from within the tributaries, a new study was needed in which the focus would be on the tributaries, as well as the bay proper. This effort included grid refinements, enhancement of the turbulence scheme, extending the computational domain onto the shelf, additions to the water quality model such as living resources, improvements to the hydrologic model of the watershed of the bay, and the development of a numerical model of the airshed of the bay to provide estimates of atmospheric nutrient loadings. 
The 3-D hydrodynamic model of Chesapeake Bay that provides transport to the 3-D water quality model is called CH3D (Curvilinear Hydrodynamics in $\underline{3}$ Dimensions). The second-generation model was validated by demonstrating the ability of the model to reproduce the hydrodynamics due to processes covering a wide range of temporal scales. These include tidal time scales, meteorological time scales of 2-4 days, the neap - spring tidal cycle, and longer term seasonal time scales.

After validation, the 3-D Chesapeake Bay hydrodynamic model was applied to generate a 10-year record of transport for input to the 3-D water quality model. The years simulated (1985-94) covered a wide range of environmental forcings. Hydrologically, 1985, 1988 and 1992 are considered dry years; 1986, 1987, 1990, and 1991 are considered average years; and 1989, 1993, and 1994 are considered wet years. Validation results, along with salinity and temperature results from the 10 -year simulation, are presented.

\section{The Numerical Model}

\section{Theoretical aspects}

As its name implies, $\mathrm{CH} 3 \mathrm{D}$ makes computations on a generalized curvilinear or boundary-fitted horizontal grid. However, to ensure that long-term stratification in the deep channels is maintained, the vertical grid is Cartesian. Boundary-fitted grids in the horizontal directions allow for a better representation of the boundary of the bay as well as internal features such as channels and islands.

All physics impacting circulation and mixing in water bodies such as Chesapeake Bay are included. These include the impact of freshwater inflows, tides, wind forcing, the impact of the rotation of the earth, surface heat exchange, and the effect of turbulence on the mean circulation. The vertical turbulence closure model computes the eddy viscosity and diffusivity from the kinetic energy and dissipation of the turbulence. This type of closure model is known as a k- $\varepsilon$ turbulence model. Turbulence is produced by wind stress at the surface, velocity shear in the water column, and bottom friction. Density effects due to salinity and temperature are fully coupled with the developing flow field. Thus, advection/ diffusion equations for the salinity and temperature are solved along with the conservation of mass and momentum equations for the flow field. An equation of state relates the water density to the salinity and temperature fields. Surface heat exchange is modeled through the Edinger, Brady, and Geyer (1974) concept of an equilibrium temperature.

The numerical algorithm consists of an external and an internal mode. The two-dimensional (2-D) water surface field and vertically averaged velocities are computed in the external mode, with the water surface elevations then employed in the computation of the horizontal pressure gradient in the internal mode. Terms such as the vertically averaged advection in the external mode are computed by summing up the 3-D computations over the water column. The 3-D velocities, salinity, and temperature are computed in the internal mode. The 3-D velocities are adjusted to ensure that water flux over the water column is consistent between 
the external and internal modes. The computational scheme is such that the speed of a free-surface gravity wave is removed from the stability criteria controlling the size of the computational time-step. However, other criteria remain (e.g., the advective speed of the water). Model details can be found in Sheng (1986); Johnson et al. (1991, 1993); Johnson et al. (in preparation); and Kim and Johnson (1998).

\section{Numerical grid}

The numerical grid for the second-generation Chesapeake Bay hydrodynamic and water quality models is shown in Figure 2. As can be seen, the modeled domain includes a portion of the Atlantic Ocean out to depths of about $100 \mathrm{ft}$ $(30.49 \mathrm{~m})$. The extension of the grid onto the continental shelf moves water quality boundary conditions away from the bay mouth and allows for a better computation of the exchange of flow between the bay and the shelf.

There are 2,129 computational cells in the horizontal plane of the numerical grid with cell lengths varying from about $1 \mathrm{~km}$ (in tributaries) to $5 \mathrm{~km}$ (in continental shelf). In the vertical direction there is a maximum of 20 layers with each layer being $5 \mathrm{ft}(1.52 \mathrm{~m})$ thick, except for the top layer, which varies with the tide. Thus, the total number of computational cells is 10,657 . With the numerical algorithm employed in $\mathrm{CH} 3 \mathrm{D}$, a 1-year simulation with a time step of 5 minutes requires about 15 hours on a Dec-Alpha 500-MHz work station.

\section{Boundary Conditions}

Many data are required to simulate numerically the 3-D hydrodynamics of water bodies such as Chesapeake Bay. These include water surface elevations, salinity, and temperature on the open ocean portion of the numerical grid shown in Figure 2. The water surface elevations were computed for the period of 198594 from a vertically averaged global model of the Caribbean, Gulf of Mexico, and eastern coast of the United States. This model is called ADCIRC and was developed by Westerink et al. (1992). In the ADCIRC computations, historical wind fields were applied over the modeled domain shown in Figure 3. Near-surface and near-bottom salinity and temperature data were specified on the open ocean grid at the locations shown in Figure 4. Both the near-surface and near-bottom values at locations A, C, and D are monthly climatological data taken from Lavitus (1982). The near-surface values at location B are observed data from the Field Research Facility at Duck, NC. Near-bottom values at location B were also taken from Lavitus (1982).

During model validation it was observed that the computed and observed near-bottom salinities at the bay mouth often did not match well (Figure 5). An analysis of freshwater discharges at Trenton, $\mathrm{NJ}$, on the Delaware River and observed salinity data south of the mouth of Delaware Bay revealed that the coastal salinities and the freshwater flow at Trenton correlated well with a lag of several weeks. Thus, it was decided to modify the climatological monthly salinity specified at location D (Figure 4) based on the freshwater flow released at Trenton 
3 months earlier. With this modification to the open-ocean salinity boundary condition, Figure 6 shows the improved calculation of the near-bottom salinity at the bay mouth over that shown in Figure 5.

In addition to the open-ocean boundary conditions, freshwater inflows at the fall line or head of tide are specified on each of the Chesapeake Bay tributaries. Approximately 50 percent of the total freshwater flow into Chesapeake Bay comes from the Susquehanna River. The tributary fall line flows are daily-averaged discharges published by the U.S. Geological Survey. Freshwater inflows below the fall line were taken from the CBP watershed model (Donigian et al. 1994; Linker 1996). These were distributed over the computational cells that border land along the tributaries as well as the bay proper. Figure 7 illustrates the importance of including flows below the fall line in the computation of salinities up the bay tributaries.

The remaining boundary condition data are the wind and surface heat exchange at the bay surface. Hourly values of wind data were taken from the Norfolk Airport (NFA), the Patuxent Naval Station (PAS), and the BaltimoreWashington International Airport (BWI) (Figure 1). Values for the components of the wind velocity specified at each grid point were determined by interpolating between the three sets of wind data. All of the wind data were collected over land; however, it is well known that values of the wind over the bay are different from data collected at land stations. Based on work by Goodrich (1985) and Sanford, ${ }^{1}$ the north-south and east-west components of the wind at each of the three data stations were multiplied by the factors in the following tabulation to reflect overwater winds:

\begin{tabular}{||l|l|l||}
\hline \multirow{2}{*}{ Station } & \multicolumn{2}{|c|}{ Component } \\
\cline { 2 - 3 } & N-S & E-W \\
\hline \hline NFA & 1.37 & 1.25 \\
\hline PAS & 2.05 & 1.43 \\
\hline BWI & 1.50 & 1.00 \\
\hline
\end{tabular}

Daily-averaged surface heat exchange coefficients and equilibrium temperatures for input to the hydrodynamic model were computed using meteorological data collected at the Patuxent Naval Station. These values were assumed to be constant over the entire bay.

One additional note concerning model boundary conditions relates to how the Chesapeake and Delaware Canal (C\&D Canal) is treated in the model. Based on information provided by Dr. William Boicourt of the University of Maryland (personal communication), a long-term average flow of $750 \mathrm{cfs}\left(21.24 \mathrm{~m}^{3} \mathrm{~s}^{-1}\right)$ was specified at the eastern end of the C\&D Canal. The direction of the flow was from the Chesapeake Bay toward the Delaware Bay. Thus, the C\&D Canal was treated as a river boundary with a constant outflow. In reality, time-varying flows in excess of $100,000 \mathrm{cfs}\left(2831.6 \mathrm{~m}^{3} \mathrm{~s}^{-1}\right)$ can occur through the canal. Normally the flow reverses direction every 6 hours or so as the tide changes. However, during episodic events related to large setups and setdowns in the surface waters of the two bays, large flows can continue in the same direction for 2-3 days. Thus, the

1 Personal Communication, 1997, L. P. Sanford, Horn Point Environmental Laboratories, University of Maryland, Cambridge. 
treatment of the C\&D Canal as a river with a constant outflow in the 3-D

Chesapeake Bay hydrodynamic model is a simplification.

\section{Model Validation}

In the validation of the second-generation 3-D Chesapeake Bay hydrodynamic model, it was considered crucial to demonstrate the ability of the model to reproduce the hydrodynamics produced by processes occurring over a wide range of temporal scales, e.g., the tidal time scale to seasonal periods. Thus, the following model results were compared with observed data:

- Tides/water surface elevations.

- Intratidal velocity.

- Intratidal variation of salinity and temperature.

- Wind mixing.

- Neap - spring stratification.

- Flux through the bay mouth.

- Residual currents.

- Impact of spring runoff on salinity.

- Seasonally averaged salinity transects and vertical profiles.

\section{Tides/water surface elevations}

Figures 8-10 show a comparison of computed times to both low and high water, along with the mean tide range, up the York River with data extracted from National Oceanic and Atmospheric Administration (NOAA) tide tables. As can be seen, model results compare extremely favorably with the tables. Phasing differences on the order of a few minutes and differences in the mean tide range of $5-10 \mathrm{~cm}$ are computed. Figure 11 shows a comparison of the computed and observed water surface elevations at Fort Eustis on the James River at a distance of $40 \mathrm{~km}$ above the mouth of the James (Figure 12). It can be seen that the neapspring tidal cycle, as well as the impact of meteorological forcing that results in setups and setdowns of the water surface, are reproduced well by the model.

\section{Intratidal velocity}

Velocity data were collected by the Virginia Institute of Marine Sciences during 27 May - 18 June 1985 on the James River at Fort Eustis and during 20 October - 20 November 1986 at a location about $20 \mathrm{~km}$ above the mouth of the York River (Figure 13). Figure 14 illustrates the comparison of the computed and observed components along the estuary of the tidal velocity at Fort Eustis. A similar comparison is given in Figure 15 for the York River. The phasing of the 
tidal velocities is reproduced well at both locations with magnitudes generally computed to within about 10-15 percent of the observed values.

\section{Intratidal salinities and temperatures}

Both salinity and water temperature were measured during 1986 at the York River station shown in Figure 13. Results presented in Figure 16 show that during this period both the computed and observed salinity ranged from about 22-24 ppt with the normal tidal fluctuation being about 1 ppt. As can be seen in Figure 17, computed temperatures also agree with the observed data. This is to be expected if the surface heat exchange data are accurate since water temperature is primarily a function of the surface heat exchange. Note that there is much more fluctuation in the observed data than in the model results. However, the surface heat exchange data input to the model are daily-averaged values. Thus, one would expect to see more fluctuation in the observed temperature than in the computed.

\section{Wind mixing}

Wind forcing accounts for much of the energy in Chesapeake Bay. Mixing of the surface waters into the water column occurs often and is an important process that must be captured in the hydrodynamics provided to the water quality model of Chesapeake Bay. NOAA collected data at several stations in September 1983 that captured such a mixing event. As can be seen in Figure 18, a wind event that occurred around the $20^{\text {th }}$ of the month resulted in the near-surface and near-bottom salinity at the midbay station CCA (see Figure 23) off from the mouth of the Patuxent River becoming almost uniform. It is likely that the temperature inversion that occurred a few days earlier aided the mixing process. Figure 19 shows results from the numerical model. It can be seen that the mixing event is captured well.

\section{Neap-spring stratification}

It has been observed that a neap-spring stratification pattern develops on the tributaries of Chesapeake Bay. During more energetic spring tides, greater turbulence is created, resulting in more mixing in the water column and less stratification. Figure 20 shows plots of the vertical structure of the salinity along the York River during both a neap and a spring tide. Note that during the spring tide, the water column is indeed less stratified due to increased mixing.

\section{Flux through the bay mouth}

No data existed on the magnitude of the water flux through the bay mouth during the simulation periods of the model, namely, September 1983 and 198594. However, Boicourt (1973) presents values for the net flux into and out of the bay mouth averaged over July and November 1971. The net flux $\left(\mathrm{m}^{3} / \mathrm{s}\right)$ in and out 
of the bay mouth computed for July and November 1988 is compared with Boicourt's data in the following tabulation:

\begin{tabular}{||l|l|l||}
\hline Data & Flux In & Flux Out \\
\hline \hline \multicolumn{3}{|c||}{ July } \\
\hline \hline Boicourt & 6,100 & 8,400 \\
\hline Computed & 6,400 & 8,300 \\
\hline \hline \multicolumn{3}{|c|}{ November } \\
\hline \hline Boicourt & 5,800 & 6,800 \\
\hline Computed & 7,100 & 7,900 \\
\hline
\end{tabular}

Obviously, since the observed data were not collected during the simulation period, an exact comparison cannot be made. However, since meteorological conditions are generally similar for the same month during different years, this comparison tends to increase confidence in the ability of the Chesapeake Bay hydrodynamic model to compute the proper exchange between the bay and the ocean.

\section{Residual currents}

Chesapeake Bay is classified as a partially stratified estuary. Thus, if the flow velocity is averaged over a few days, the surface velocity is directed toward the ocean with the bottom waters moving up-estuary. This circulation pattern is referred to as gravitational circulation and occurs because of the baroclinic contribution to the horizontal pressure gradient. It is important that a hydrodynamic model being used to provide transport to a water quality model reproduce the residual circulation of an estuary since these currents reflect the net transport experienced by the water quality variables.

Figure 21 was generated by Dr. Alan Blumberg of HydroQual, Inc., in Mawah, NJ. Data on water currents collected by NOAA at several locations from 1977-83 were used to generate the near-surface and near-bottom residual velocity vectors shown. Only data records at least 15 days in length were used. From Figure 21, it can be seen that the maximum residual velocities are on the order of $10 \mathrm{~cm} / \mathrm{s}$ for both near-surface and near-bottom flow. Figure 22 contains similar plots of the computed residual currents. Figures 21 and 22 provide a qualitative assessment of the ability of the model to reproduce the residual transport in Chesapeake Bay. Actual values of residual currents in $\mathrm{cm} / \mathrm{s}$ computed from the observed data were compared with model results from 1985 at several locations shown in Figure 23. These are given in the following tabulation:

\begin{tabular}{||l|l|l|l|l||}
\hline \multirow{2}{*}{ Station } & \multicolumn{2}{|c|}{ Surface } & \multicolumn{2}{c||}{ Bottom } \\
\cline { 2 - 6 } & Data & Model & Data & Model \\
\hline \hline Bay mouth & -10.7 & -10.1 & 8.2 & 6.1 \\
\hline Eastern shore & -8.5 & -7.6 & 5.3 & 4.1 \\
\hline Potomac mouth & -8.5 & -8.0 & 3.2 & 4.5 \\
\hline Patuxent mouth & -9.2 & -7.8 & 5.1 & 2.6 \\
\hline
\end{tabular}


Although this tabulation does not constitute a direct comparison between observed data and model results, these results imply that the 3-D Chesapeake Bay hydrodynamic model does compute the proper residual transport in Chesapeake Bay. Further confirmation of this is provided in Figure 24, which shows low-pass model results compared with data collected by Boicourt in September 1996 at Station CCA shown in Figure 23. It can be seen that there is excellent comparison between the data and computed results for both the near-surface and near-bottom velocities.

\section{Impact of spring runoff on salinity}

As illustrated in Figure 25, during the spring of 1993, flows from the Susquehanna River reached almost 500,000 cfs. This runoff event is one of the top ten flows ever recorded on the Susquehanna River. With such a large freshwater flow event, one would expect that much of the upper Chesapeake Bay would become almost fresh. Figure 26 shows a comparison of computed and recorded salinity at $\mathrm{CB} 3.3 \mathrm{C}$, near the Bay Bridge at Annapolis, MD. It can be seen that surface waters in the entire upper bay were indeed virtually fresh. Bottom salinities are also reproduced well except for one data point. It may be that this data point was collected in a deep hole not represented within the schematization shown in Figure 2.

\section{Seasonal salinity transects and vertical profiles}

Long-term salinity patterns in the Chesapeake Bay are determined primarily by freshwater inflows into the bay, which generally have a seasonal variation. For example, summer months tend to be dry, resulting in more salt intrusion up the bay, whereas spring months tend to be wetter, resulting in the salt being pushed down the bay. During large spring freshwater flows, stratification of the water column is greater. Since changes in water quality tend to occur over seasonal time scales, it is important that the 3-D Chesapeake Bay hydrodynamic model compute seasonally averaged salinities well. Figures 27 and 28 are near-surface and nearbottom transects, respectively, of salinity along the deep channel in the bay averaged over the spring and summer seasons for 1985-88. Note that although the absolute values of the computed salinities can differ by 2-3 ppt at some locations, the computed stratification generally agrees with the observed data. This is further substantiated in Figures 29 and 30, which show seasonally averaged vertical profiles of salinity at several locations shown in Figure 23.

All of these results demonstrate that the second-generation 3-D Chesapeake Bay hydrodynamic model is a good representation of the bay. It has been shown that the model accurately computes bay hydrodynamics resulting from processes that occur over a wide range of temporal scales. 


\section{Hydrodynamic Simulation for 1985-94}

With the hydrodynamic model having been demonstrated to be a good representation of the Chesapeake Bay, it was then applied to provide 10 years of flow fields and diffusion coefficients to the water quality model. As previously noted, the years of 1985-94 were simulated. During this period, CBP collected salinity and temperature data at 2- to 4-week intervals at multiple locations throughout the bay and its tributaries. Figures 31 and 32 show a comparison of computed salinities for the 10-year simulation at stations CB3.3C near the Bay Bridge and at CB5.2 in the midbay, respectively (Figure 23). The computed salinities plotted are 10 -day averages. Thus, high-frequency events associated with meteorological forcing on a 2- to 4-day time scale tend to be averaged out. Still, it can be seen that salinities computed over the 10 -year simulation match the observed data collected every 2 weeks quite well. Figure 33 illustrates that the model accurately computes water temperature over the 10 -year simulation.

\section{Summary and Conclusions}

A second-generation 3-D numerical hydrodynamic model of Chesapeake Bay and its tributaries has been developed to provide flow fields and diffusion coefficients to drive a 3-D water quality model of Chesapeake Bay. The numerical grid is boundary-fitted in the horizontal and Cartesian in the vertical. The grid contains in excess of 10,000 computational cells with a maximum of 20 vertical layers representing a maximum depth of $100 \mathrm{ft}(30.49 \mathrm{~m})$.

Validation of the Chesapeake Bay 3-D hydrodynamic model was conducted by demonstrating that the model accurately reproduces the bay hydrodynamics due to processes occurring over a wide range of temporal scales. For example, it was shown that the propagation of tides up the tributaries is accurately computed, along with the setups and setdowns in the water surface due to meteorological events resulting from local wind forcing as well as wind forcing over the continental shelf. Tidal velocities and salinities over the neap-spring cycle were shown to be accurately computed, along with the neap-spring stratification that occurs on bay tributaries such as the York River. Results from a simulation of September 1983 demonstrated the ability of the model to capture wind mixing events. Using data collected by Boicourt (1973), it was shown that the model accurately computes the exchange between the bay and the shelf through the mouth of the bay. Data collected by NOAA during 1977-83 were used to generate a picture of the residual transport in Chesapeake Bay. Model results agreed very well with these data. Finally, it was shown that seasonally averaged stratification in Chesapeake Bay resulting from seasonal changes in freshwater inflows was reproduced well.

The validated 3-D Chesapeake Bay hydrodynamic model was then applied to generate 10 years of hydrodynamics to drive the 3-D Chesapeake Bay water quality model. These years, 1985-94, covered a wide range of environmental forcings.

The basic conclusion is that the 3-D model is an extremely good representation of Chesapeake Bay. It accurately computes the hydrodynamics of the bay 
resulting from the different types of environmental forcings experienced by the bay over varying time scales. These include tides, meteorological forcing related to both local and nonlocal winds, turbulence generated by wind forcing, and freshwater inflows.

Further improvements planned for the model include additional grid refinement and improvements in the open ocean and C\&D Canal boundary conditions.

\section{References}

Boicourt, W. C. (1973). "Circulation of water on the continental shelf from Chesapeake Bay to Cape Hatteras,” Ph.D. diss., Johns Hopkins University, Baltimore, MD.

Cerco, C. F., and Cole, T. M. (1994). "Three-dimensional eutrophication model of Chesapeake Bay,” Technical Report EL-94-4, U.S. Army Engineer Waterways Experiment Station, Vicksburg, MS.

Donigian, A. S., Jr., Bicknell, B. R., Patwardhan, A. S., Linker, L. C., Chang, C. H., and Reynolds, R. (1994). "Chesapeake Bay Program Watershed Model Application to Calculate Bay Nutrient Loadings: Final Findings and Recommendations," Final Report, U.S. EPA Chesapeake Bay Program, Annapolis, MD.

Edinger, J., Brady, D., and Geyer, J. (1974). "Heat exchange and transport in the environment," Report 14, Department of Geography and Environmental Engineering, John Hopkins University, Baltimore, MD.

Goodrich, D. M. (1985). "On stratification and wind induced mixing in Chesapeake Bay," Ph.D. diss., State University of New York, Stony Brook.

Goodrich, D. M., and Blumberg, A. F. (1991). "The fortnightly mean circulation of Chesapeake Bay," Estuarine, Coastal and Shelf Science 32, 463-482.

Johnson, B. H., Heath, R. E., Hsieh, B. B., Kim, K. W., and Butler, H. L. (1991). "Development and verification of a three-dimensional numerical hydrodynamic, salinity, and temperature model of Chesapeake Bay; Volume 1, Main text and Appendix D," Technical Report HL-91-7, U.S. Army Engineer Waterways Experiment Station, Vicksburg, MS.

. (1993). "Validation of a three-dimensional hydrodynamic model of Chesapeake Bay," Journal of Hydraulic Engineering, ASCE, 119, 2-20.

Johnson, B. H., Kim, K. W., Wang, H. V., Martin, B. L., and Heath, R. E. "Assessment of the impact of proposed dredged material placement islands in Upper Chesapeake Bay: A three-dimensional numerical model study" (in preparation), U.S. Army Engineer Research and Development Center, Vicksburg, MS.

Johnson, B. H., Heath, R. E., Hsieh, B. B., Kim, K. W., and Martin, B. L. "Assessment of channel deepening in the Chesapeake and Delaware Canal and approach channels in Upper Chesapeake Bay: A three-dimensional numerical model study" (in preparation), U.S. Army Engineer Research and Development Center, Vicksburg, MS. 
Kim, K. W., and Johnson, B. H. (1998). "Assessment of channel deepening in the Delaware River and Bay: A three-dimensional numerical model study," Technical Report CHL-98-29, U.S. Army Engineer Waterways Experiment Station, Vicksburg, MS

Lavitus, S. (1982). "Climatological atlas of the world oceans," NOAA Paper No. 13, U.S. Department of Commerce.

Linker, L. C. (1996). “ Models of the Chesapeake Bay,” Sea Technology, September, 49-55.

Sheng, Y. P. (1986). "A three-dimensional mathematical model of coastal, estuarine, and lake currents using boundary-fitted grid," Report No. 585, A.R.A.P. Group of Titan Systems, New Jersey, Princeton, NJ.

Westerink, J. J., Luettich, R. A., Baptista, A. M., Scheffner, N. W., and Farrar, P. (1992). "Tide and storm prediction using a finite element model," Journal of Hydraulic Engineering 118, 1373-1390. 


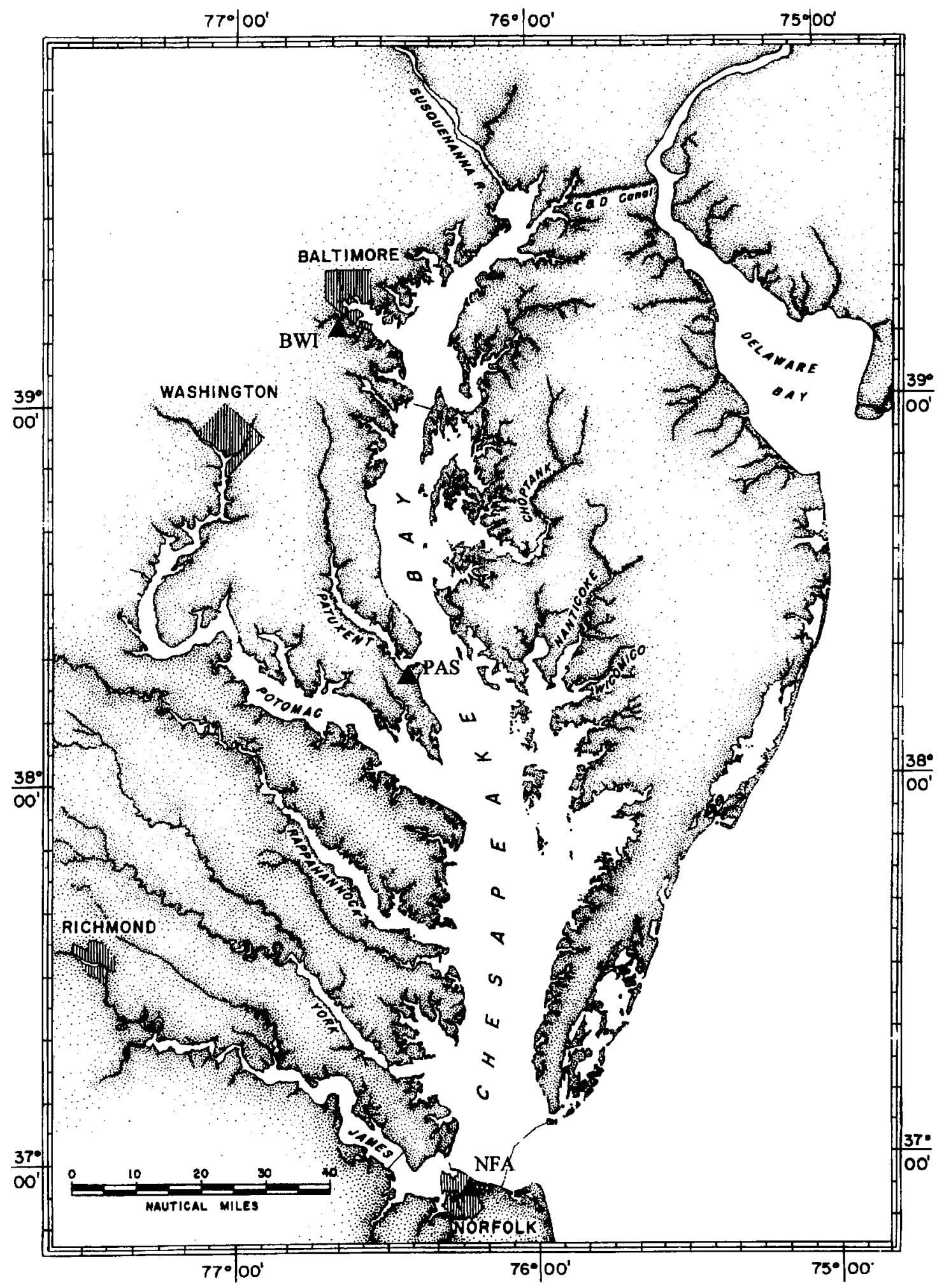

Figure 1. Chesapeake Bay 


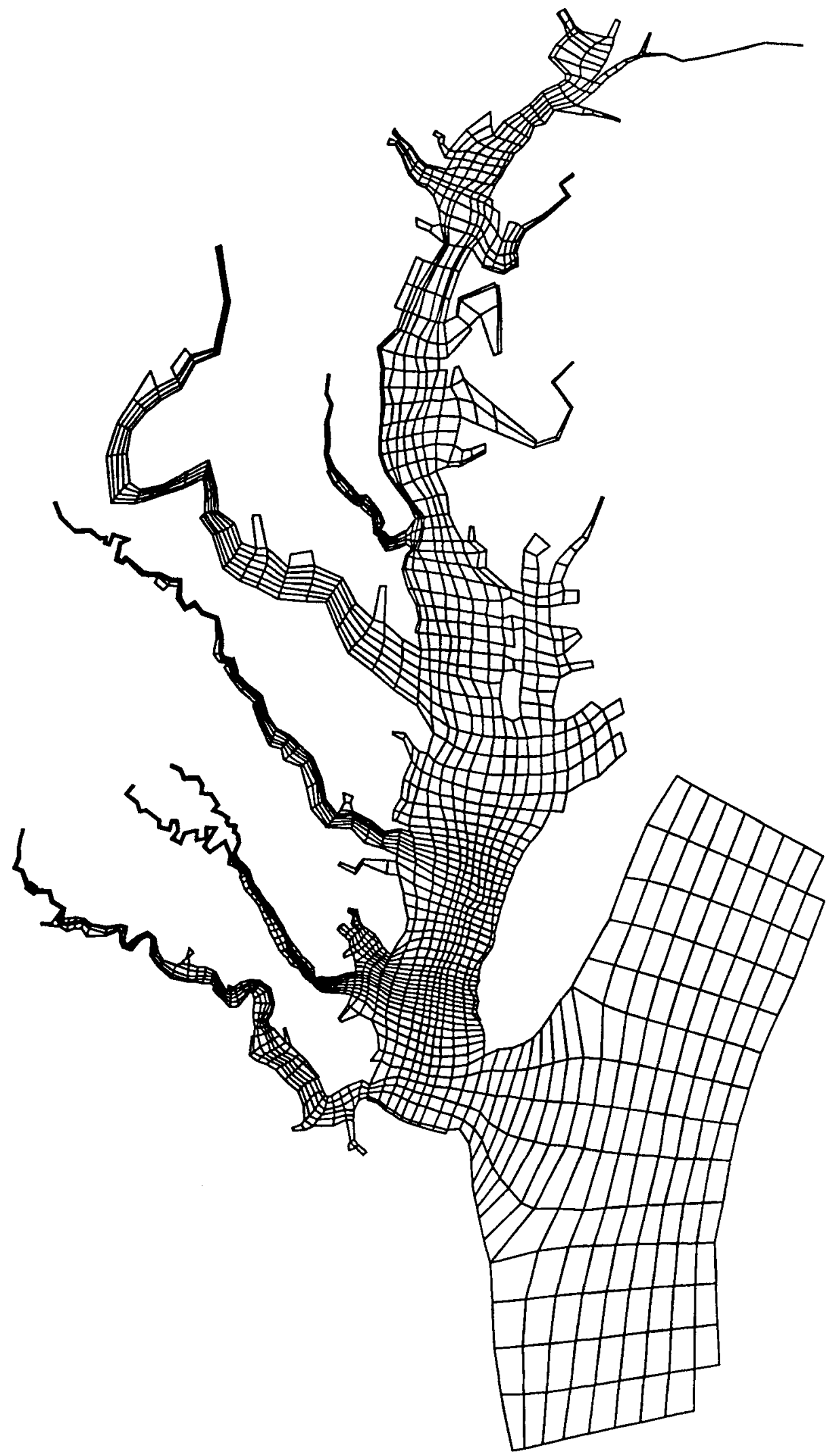

Figure 2. Planform numerical grid 


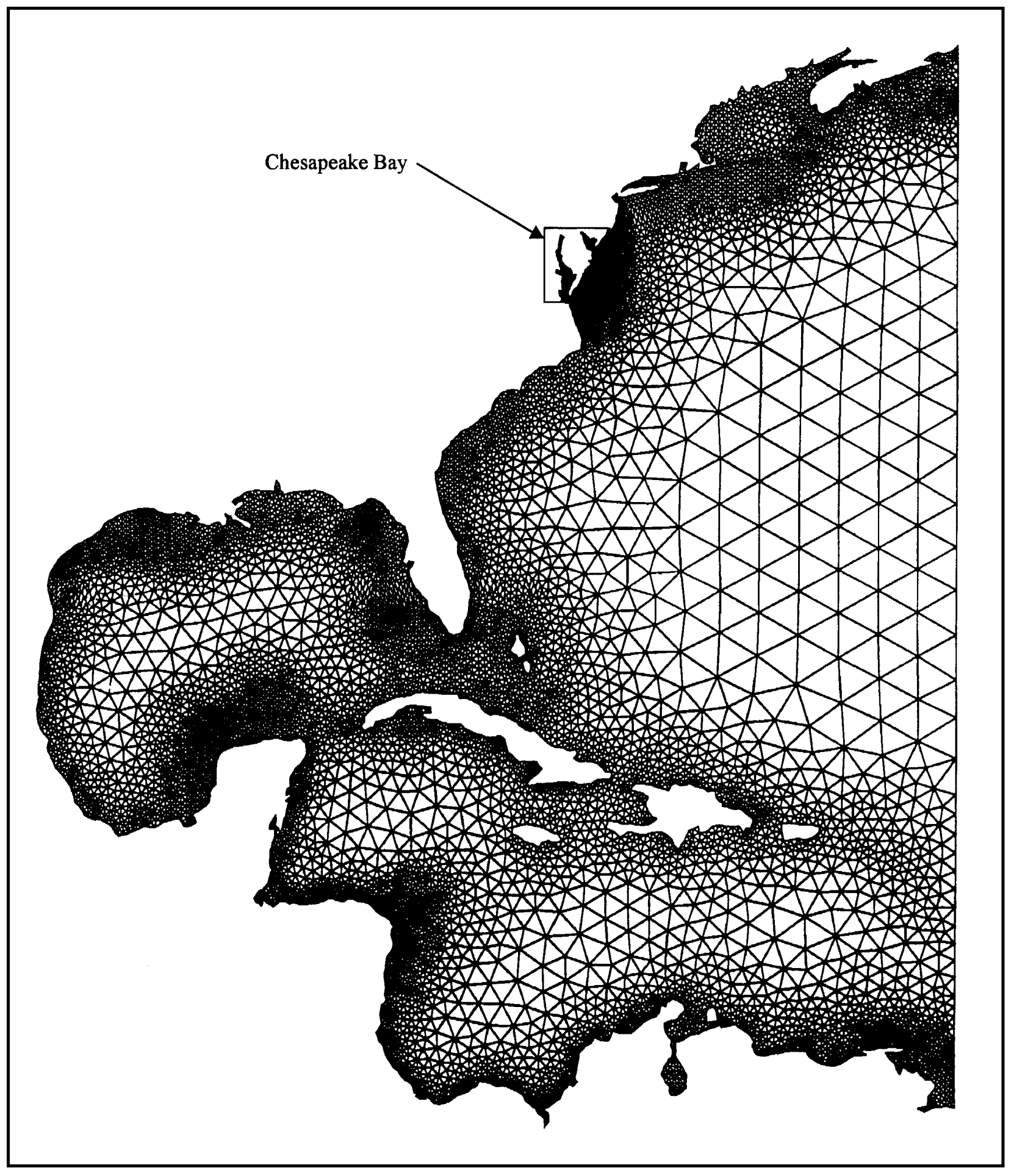

Figure 3. ADCIRC numerical model grid 


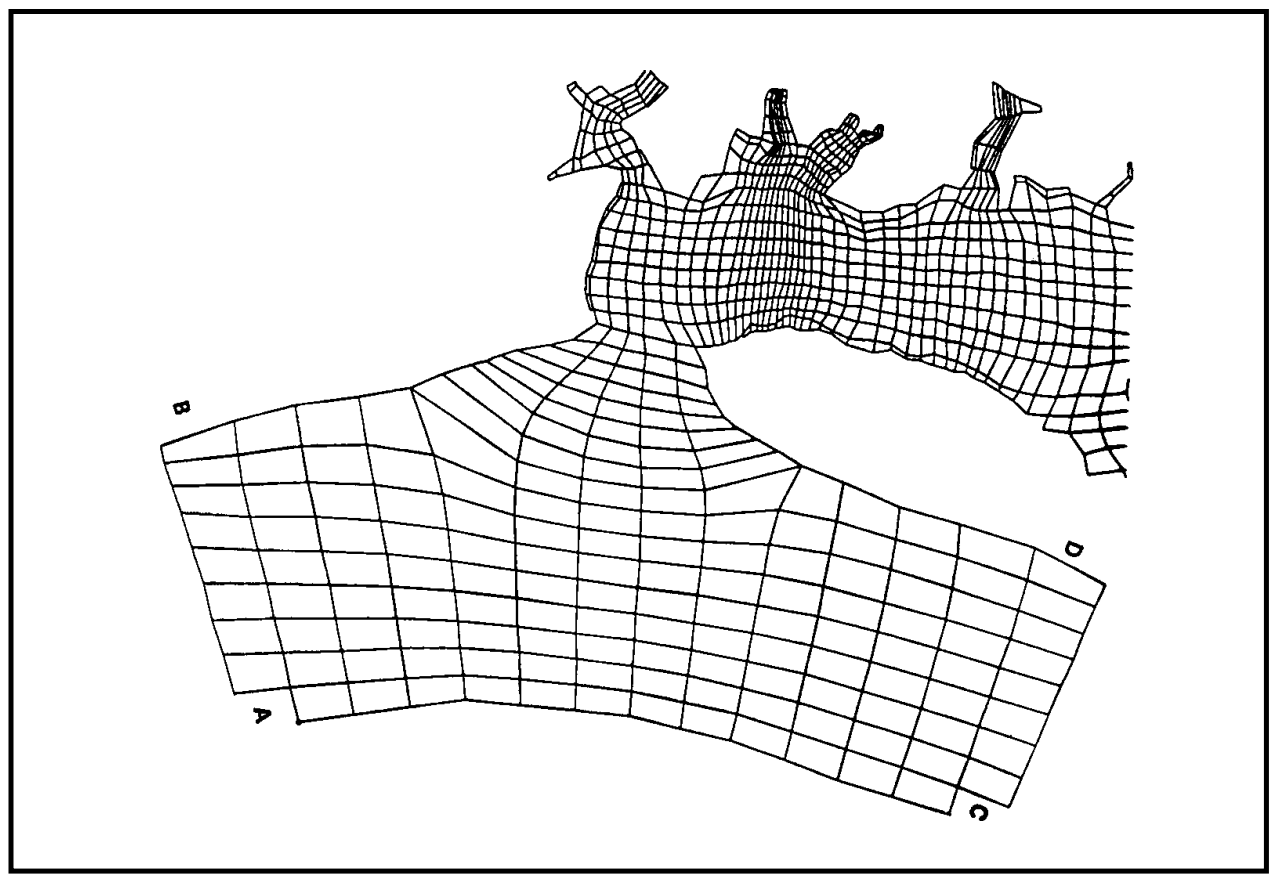

Figure 4. Location where open boundary salinity and temperature data are specified

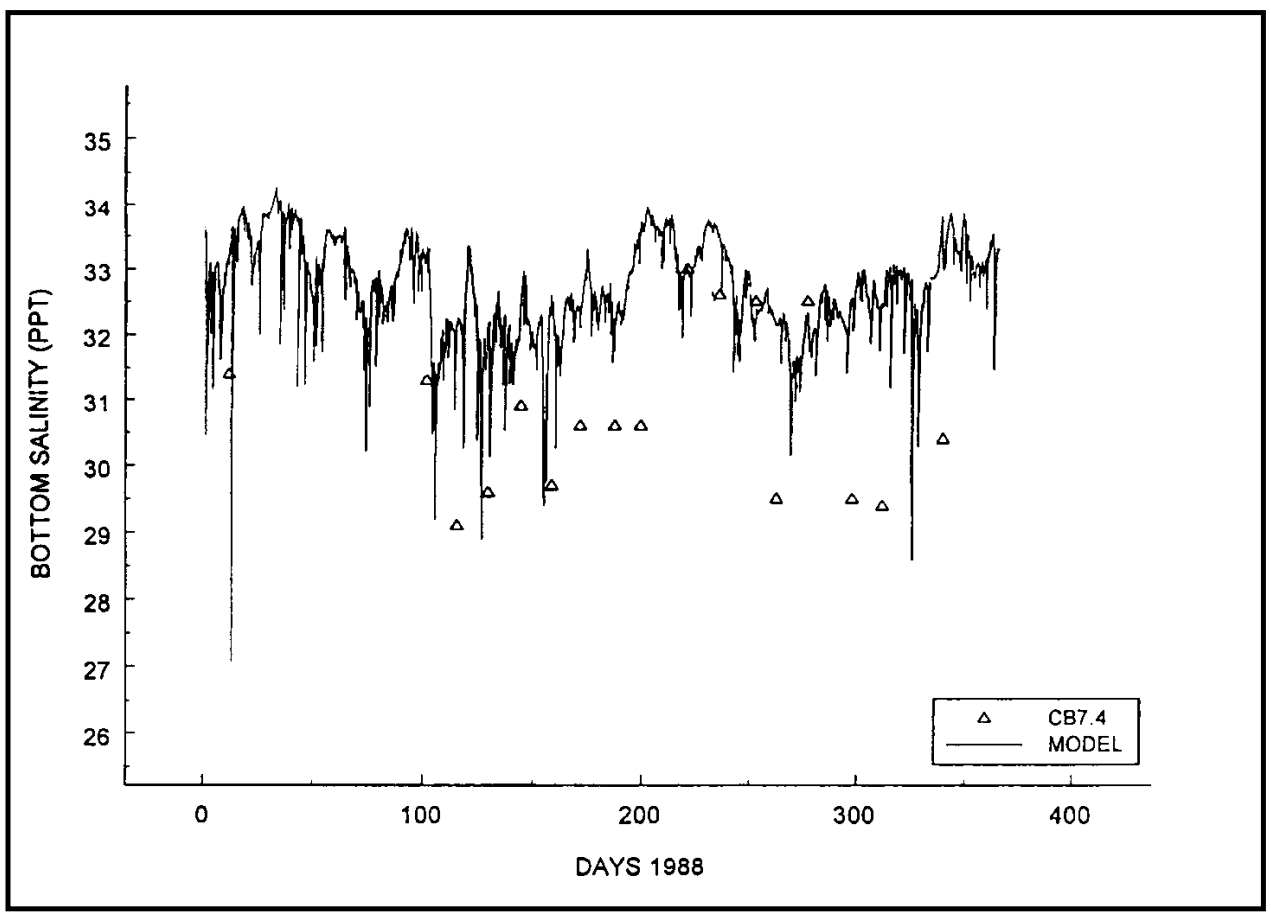

Figure 5. Near-bottom salinity at bay mouth with original salinity boundary condition 


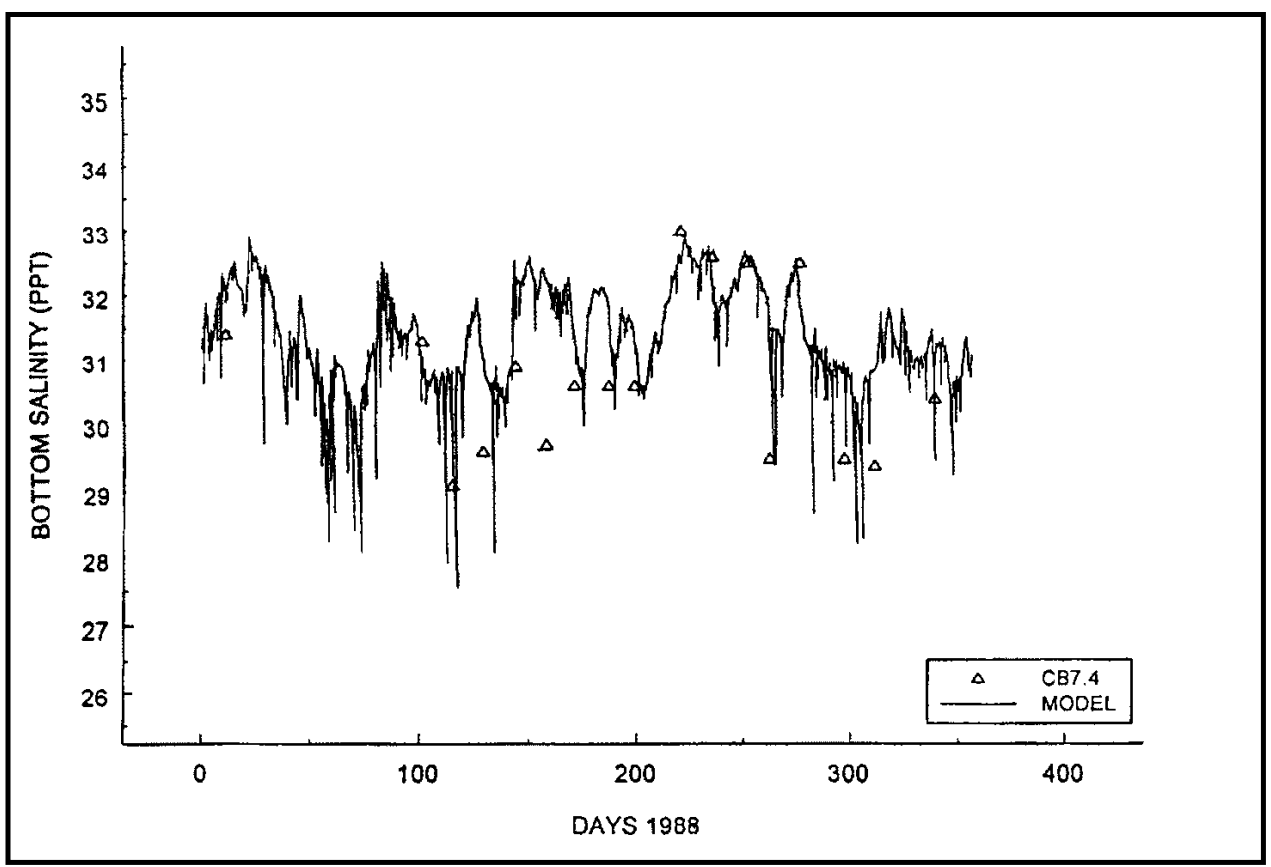

Figure 6. Near-bottom salinity at bay mouth with modified salinity boundary condition

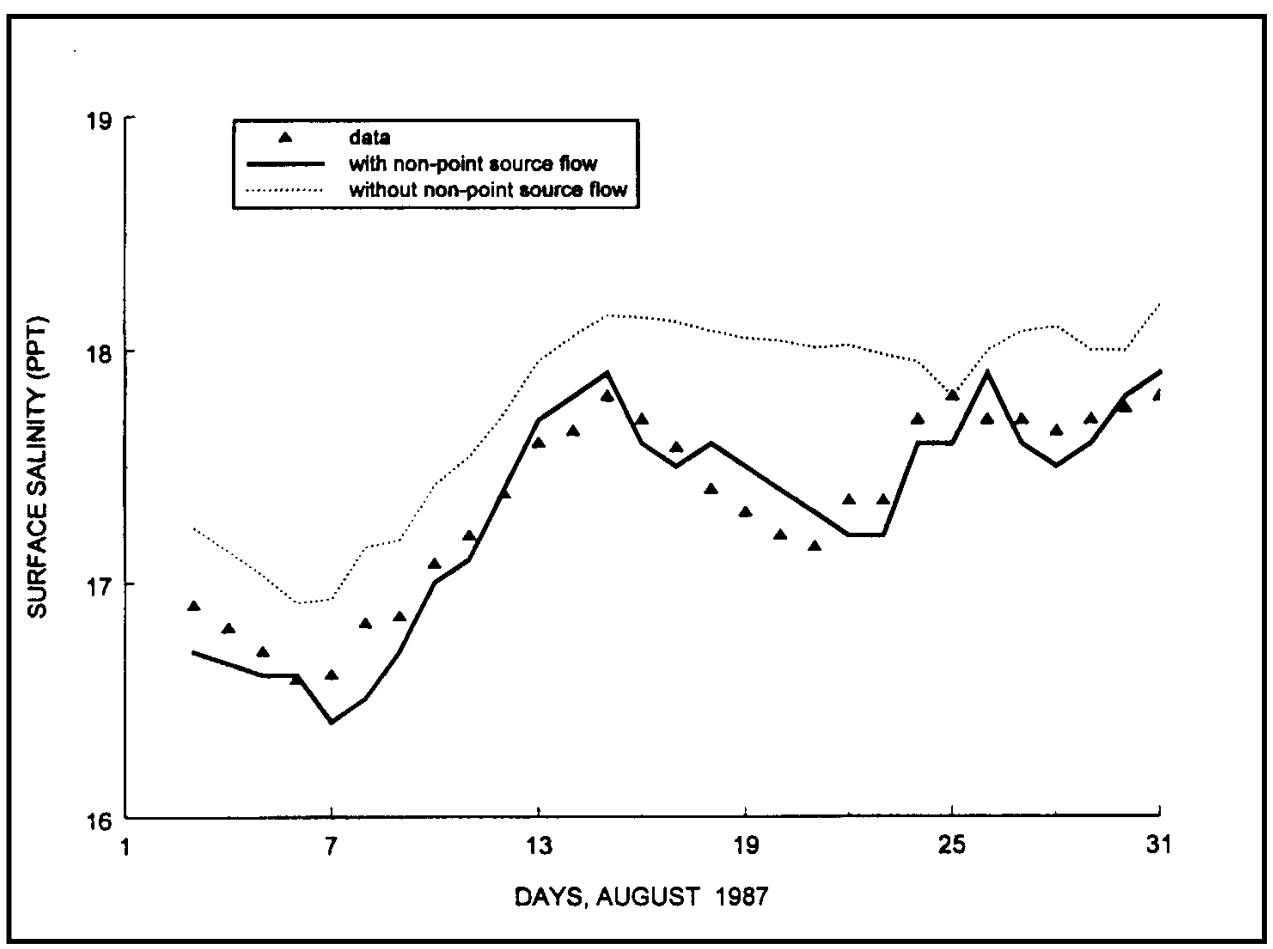

Figure 7. Impact of using watershed model flows on salinity on Rappahannock River 


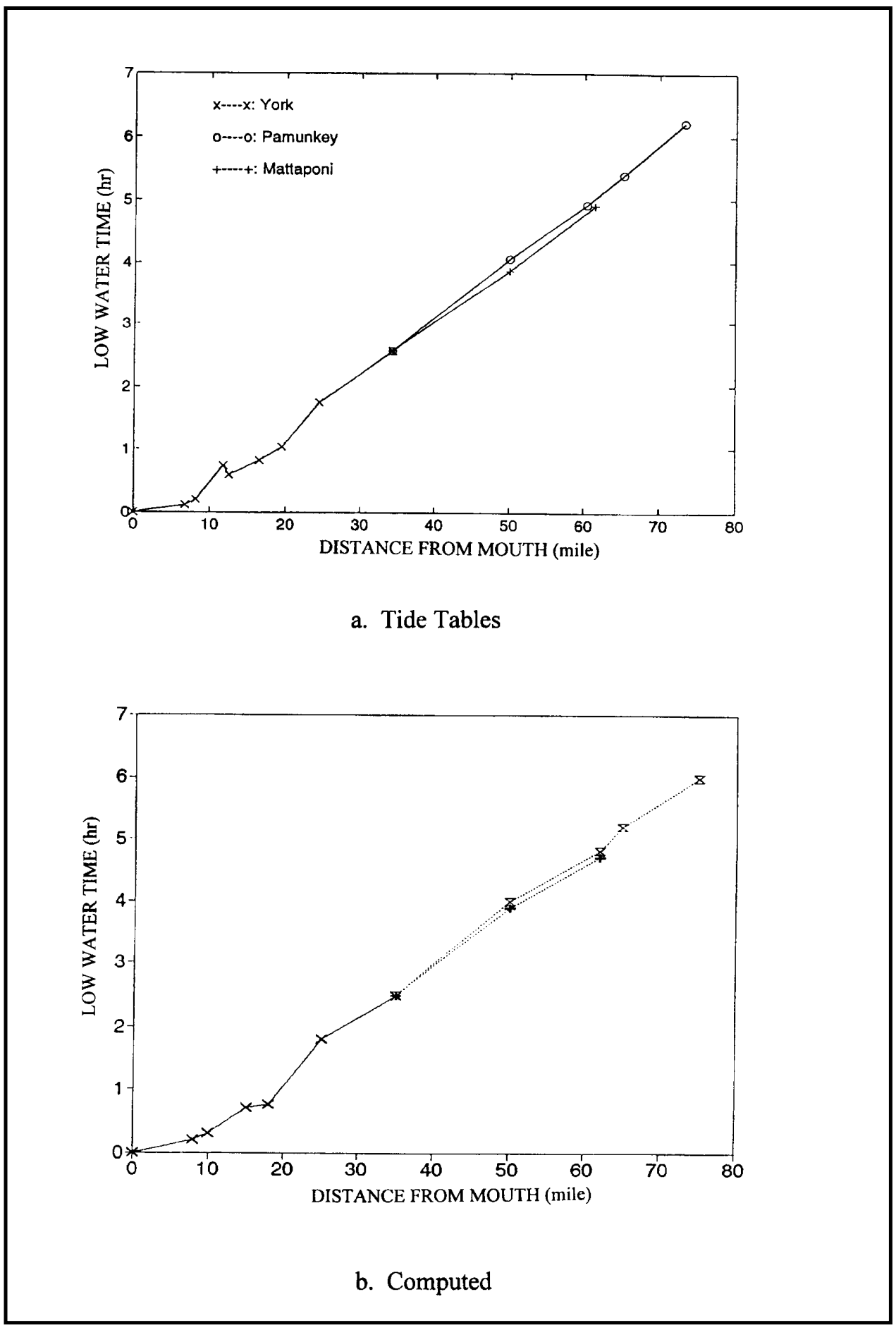

Figure 8. Comparison of computed and tabulated time to low water on York River 


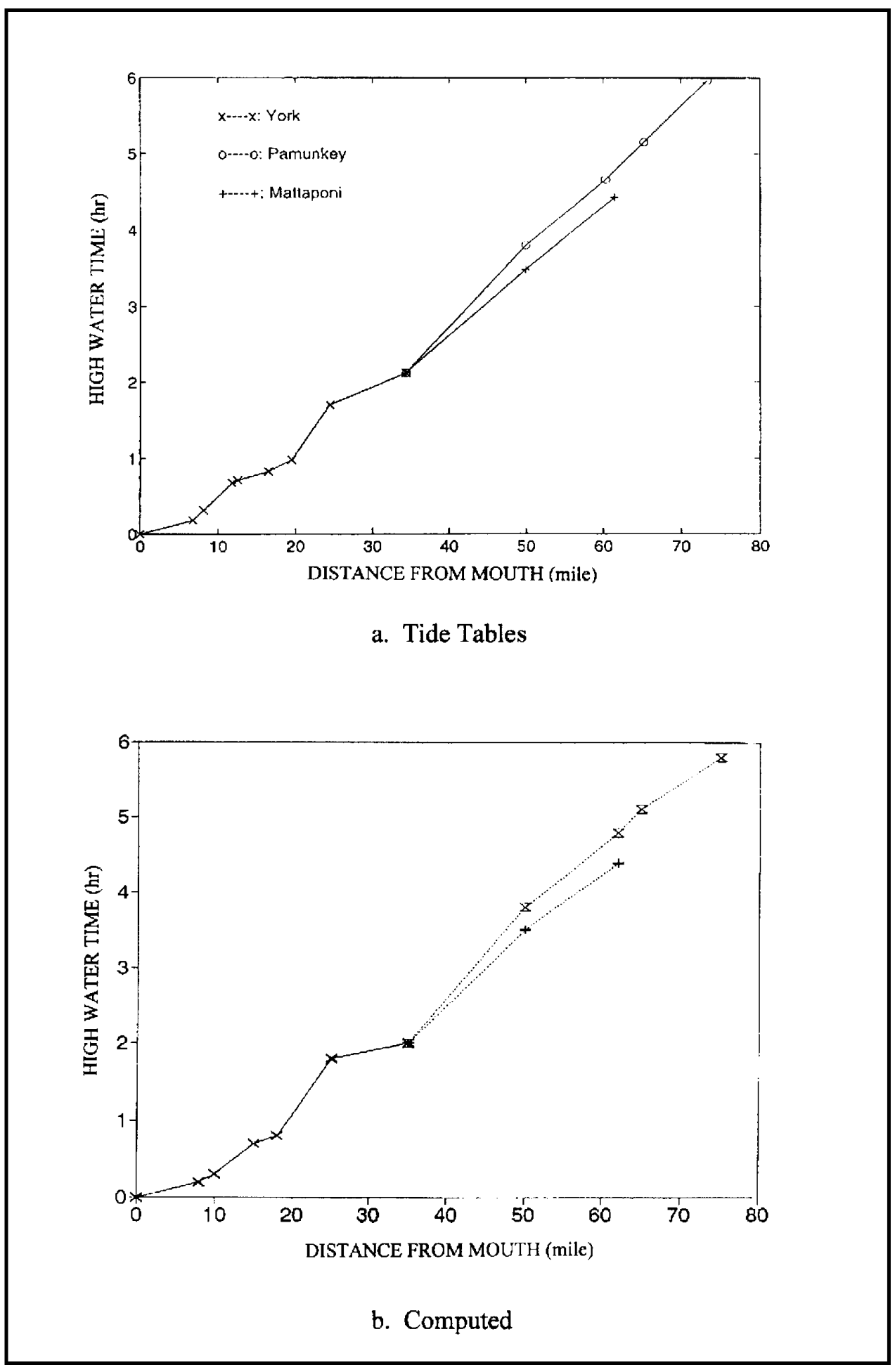

Figure 9. Comparison of computed and tabulated time to high water on York River 


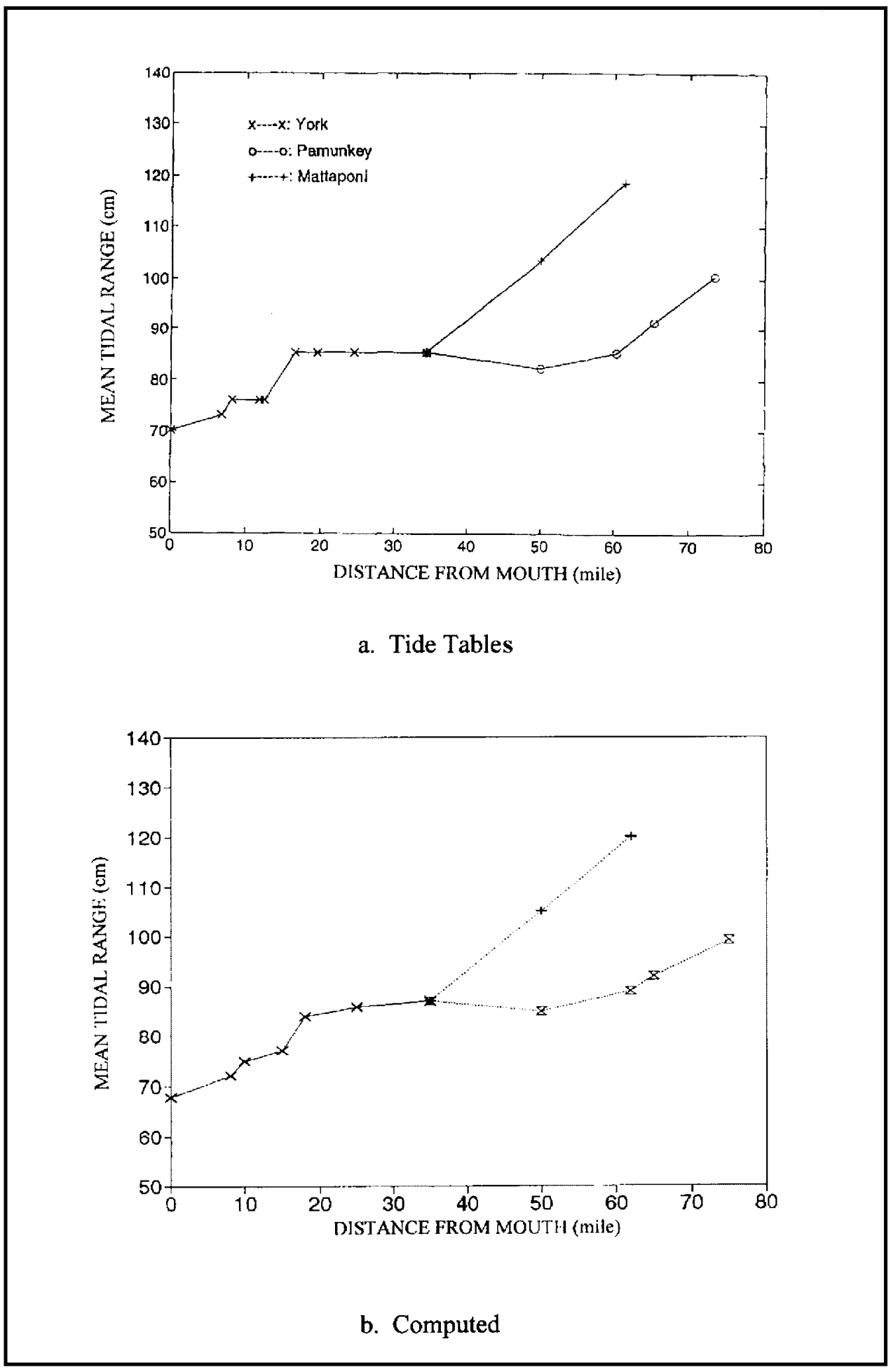

Figure 10. Comparison of computed and tabulated mean tide range on York River 


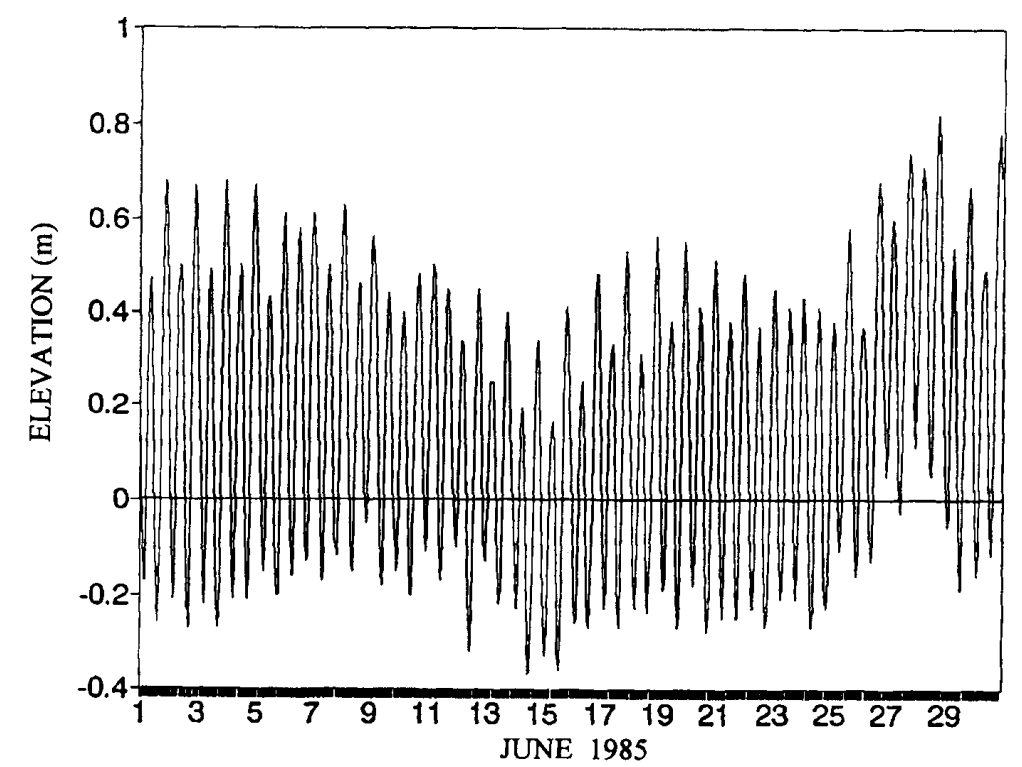

a. Observed

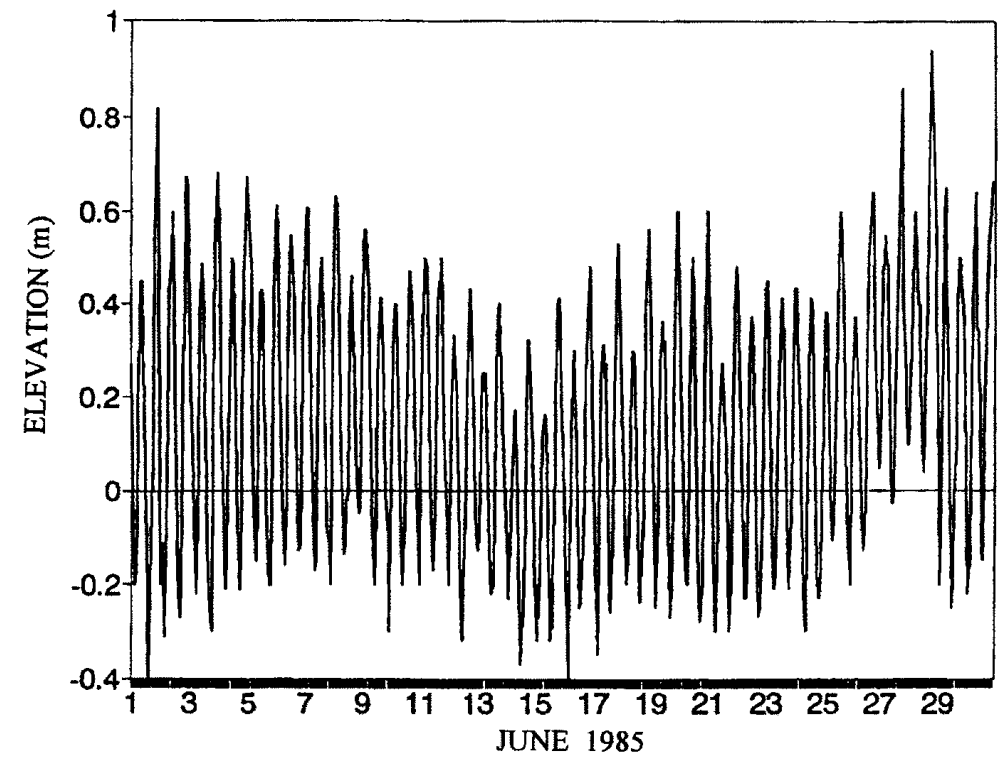

b. Computed

Figure 11. Comparison of observed and computed water surface at Fort Eustis 


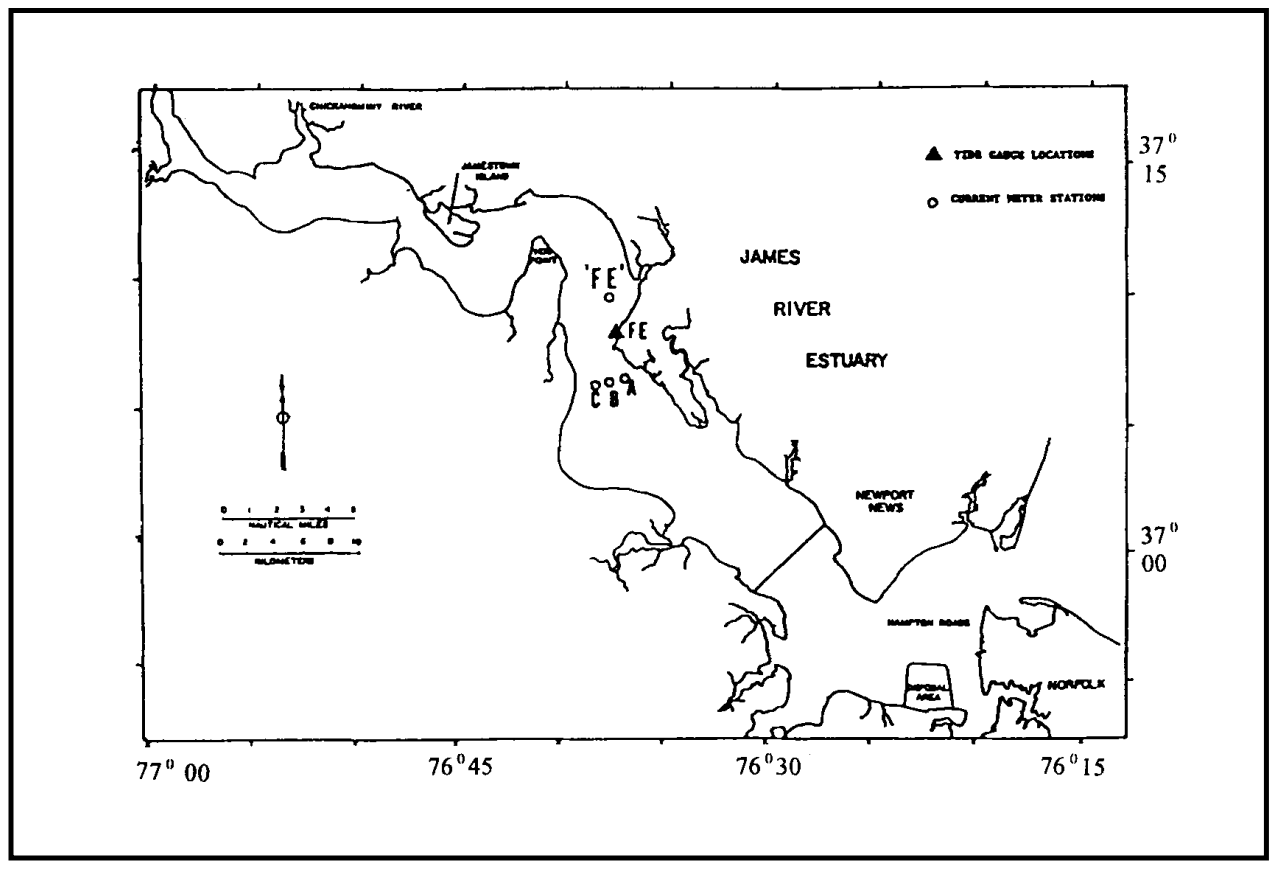

Figure 12. Location of sampling stations in the vicinity of Fort Eustis (FE)

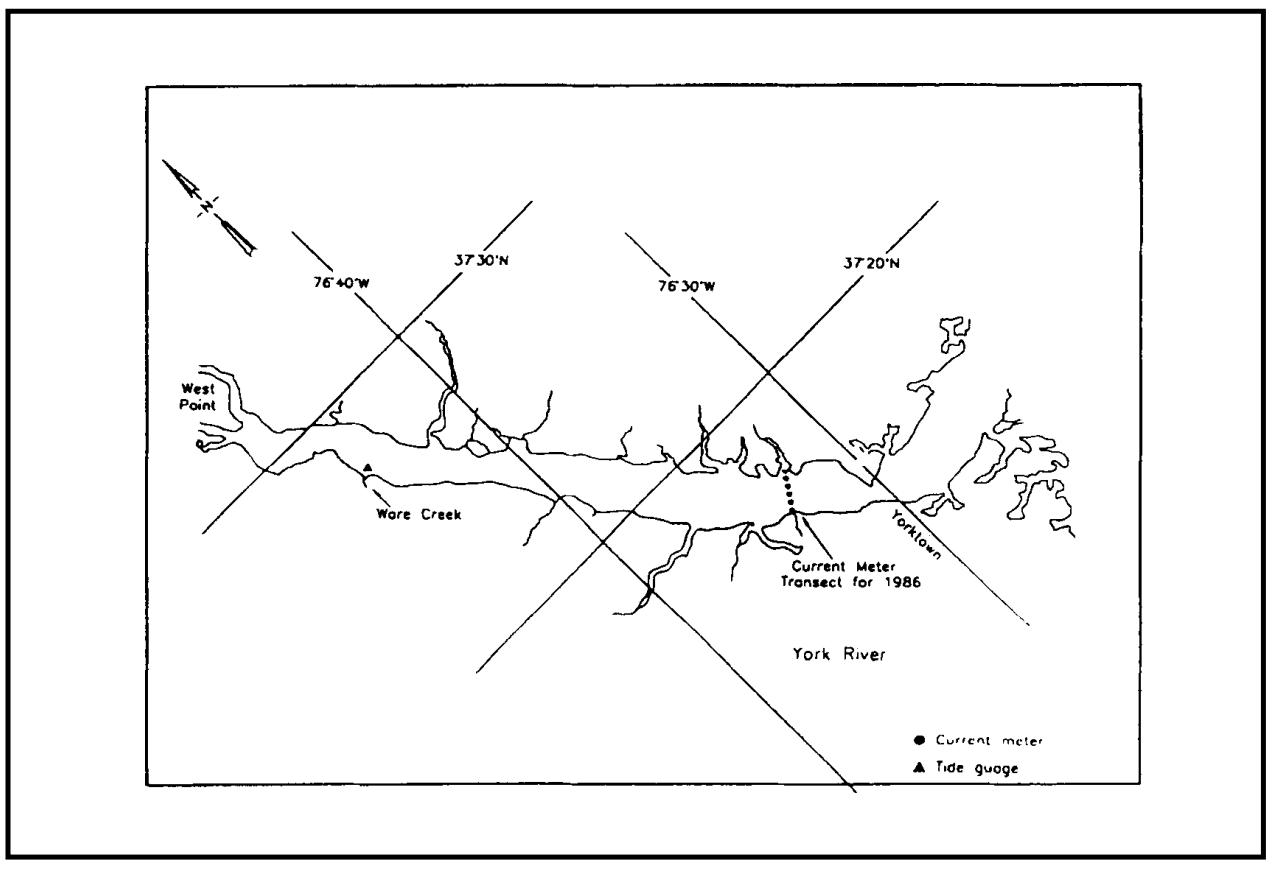

Figure 13. Location of sampling on York River 


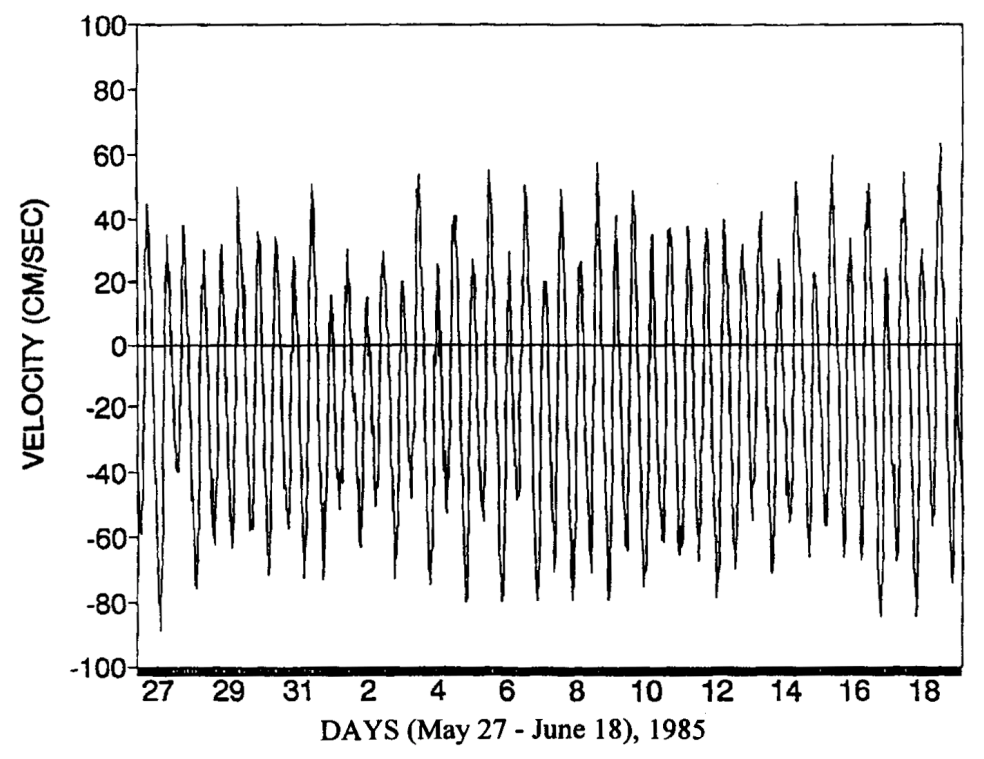

a. Observed

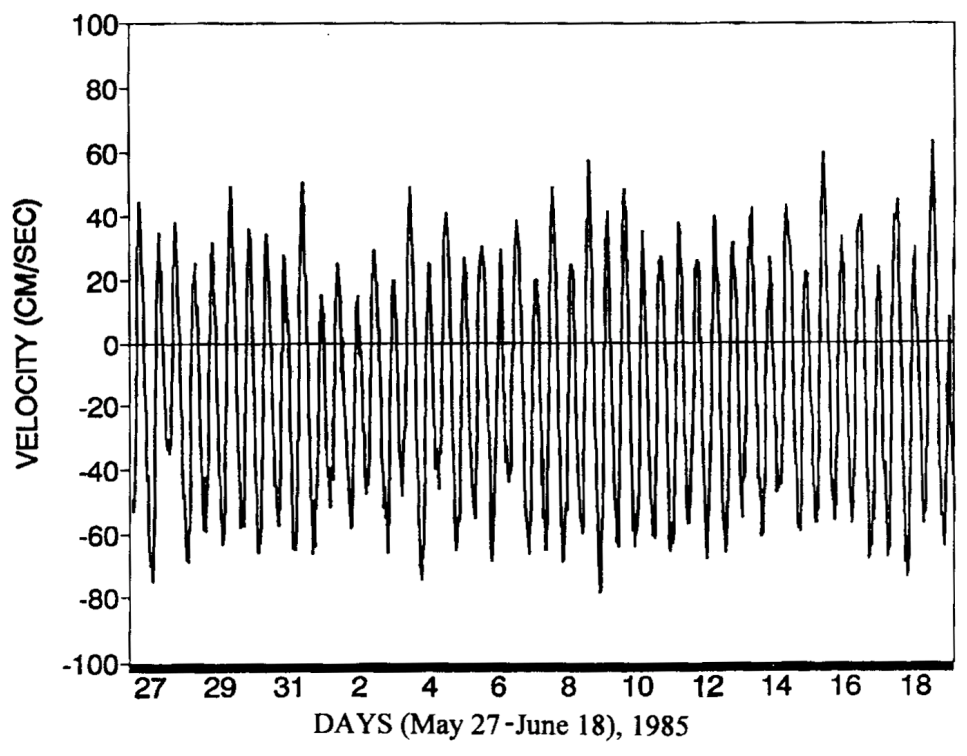

b. Computed

Figure 14. Comparison of observed and computed tidal velocity along the James River at Fort Eustis 


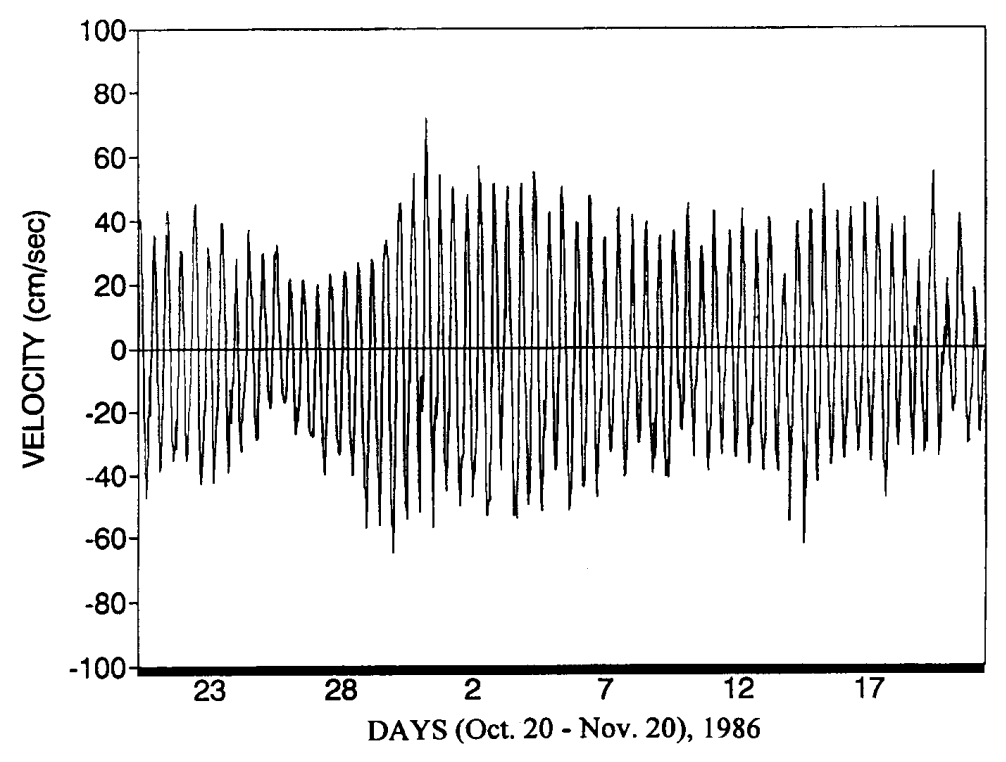

a. Observed

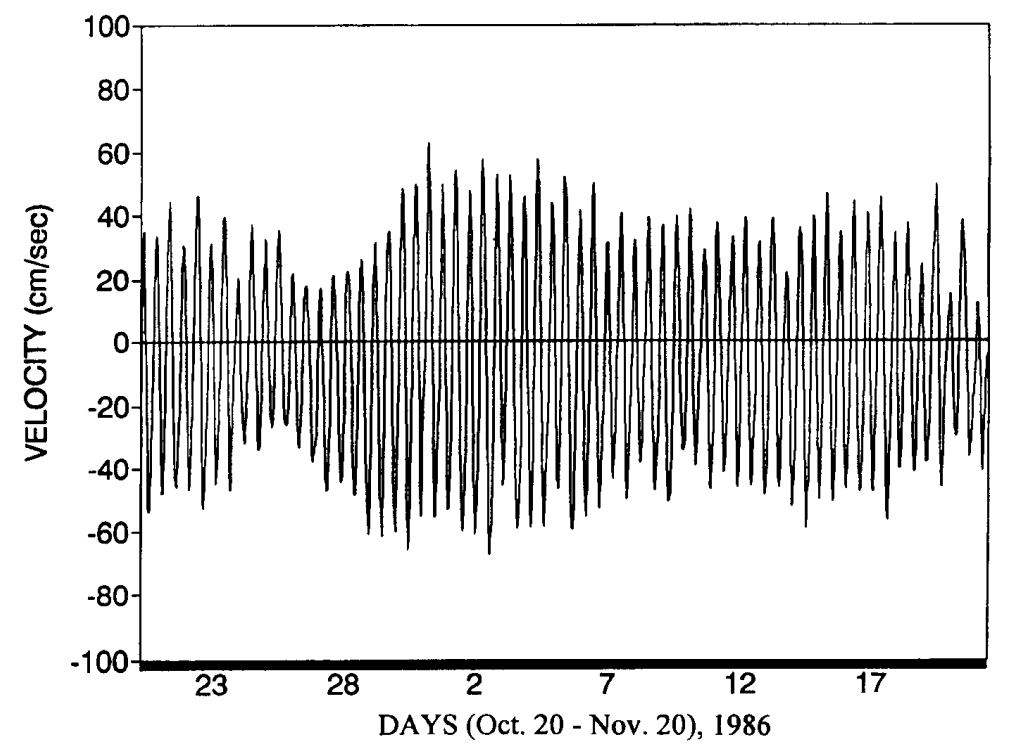

b. Computed

Figure 15. Comparison of observed and computed components of tidal velocity along the York River 


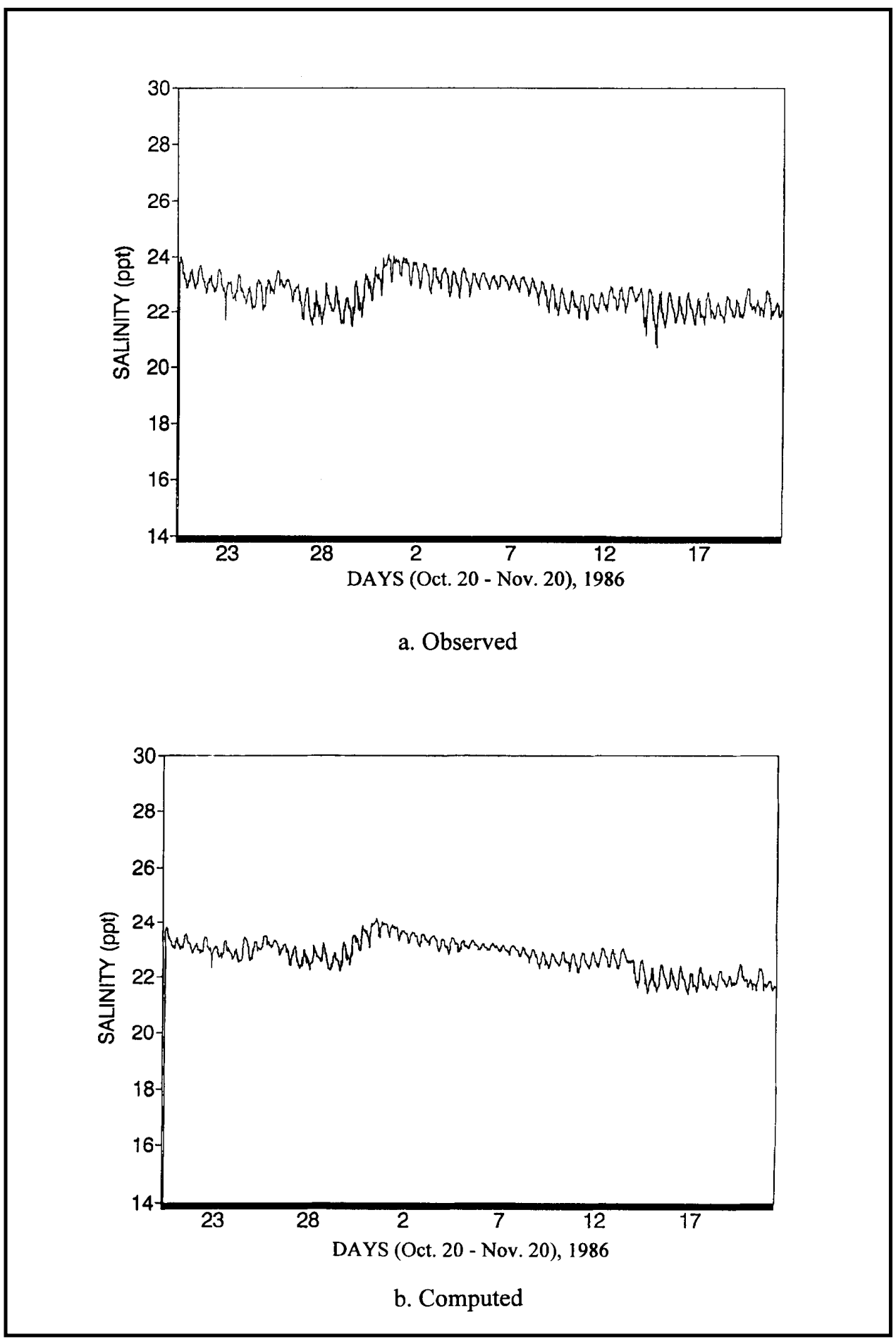

Figure 16. Comparison of observed and computed salinity on York River 


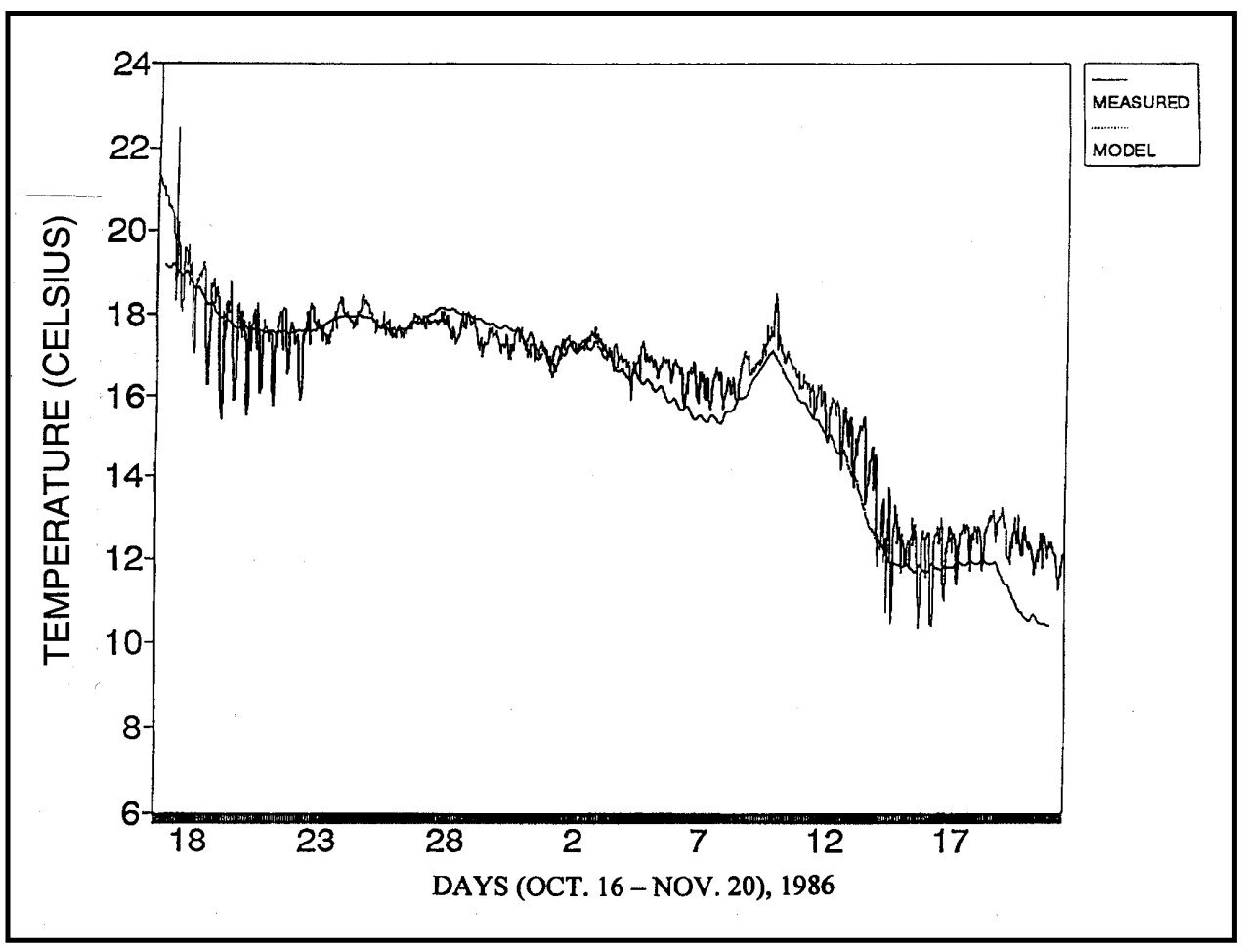

Figure 17. Comparison of observed and computed temperature on York River 


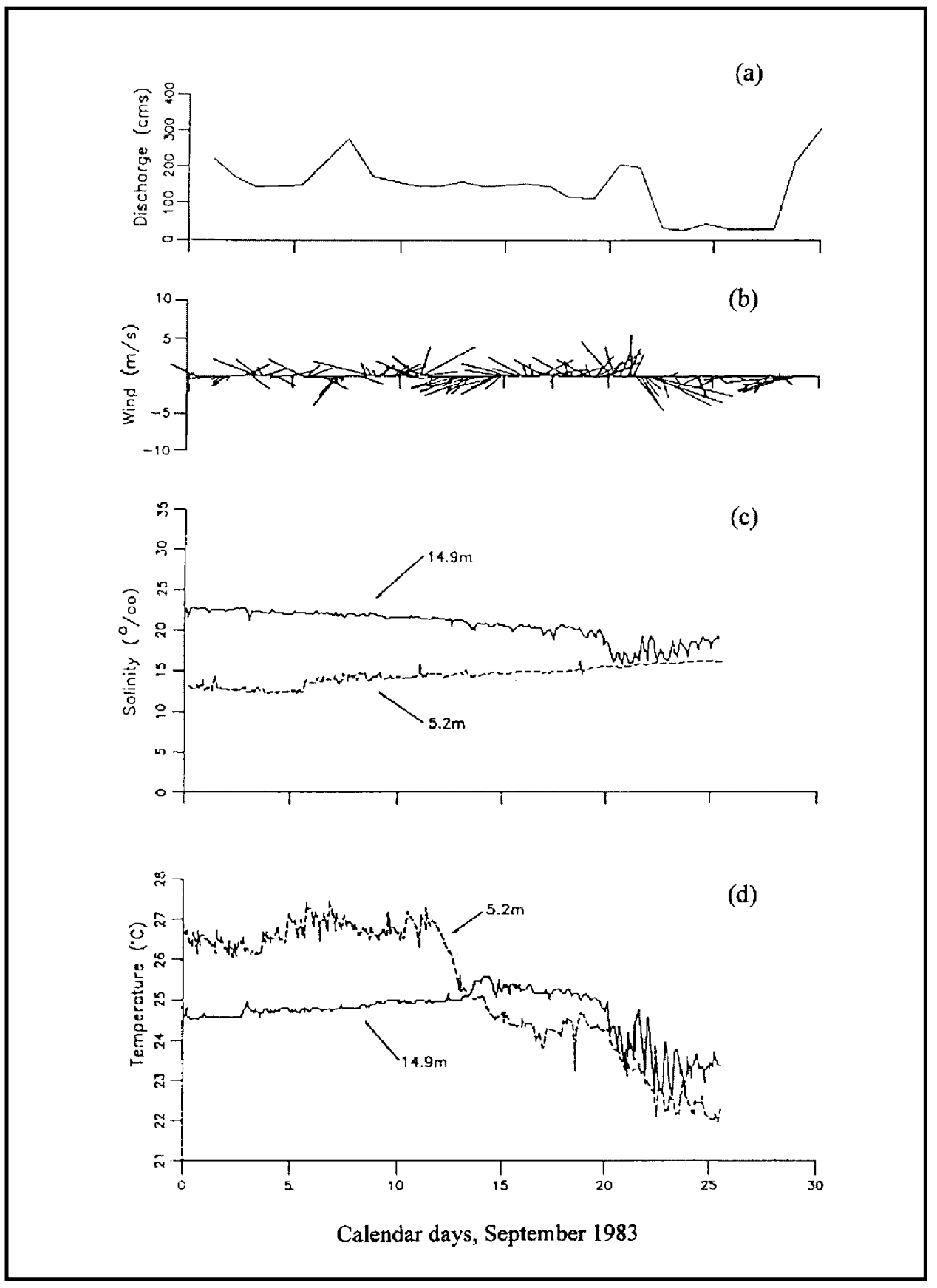

Figure 18. Observed data illustrating wind mixing: (a) Susquehanna River flow; (b) wind at Patuxent Naval Air Station; (c) salinity; (d) temperature at station CCA 


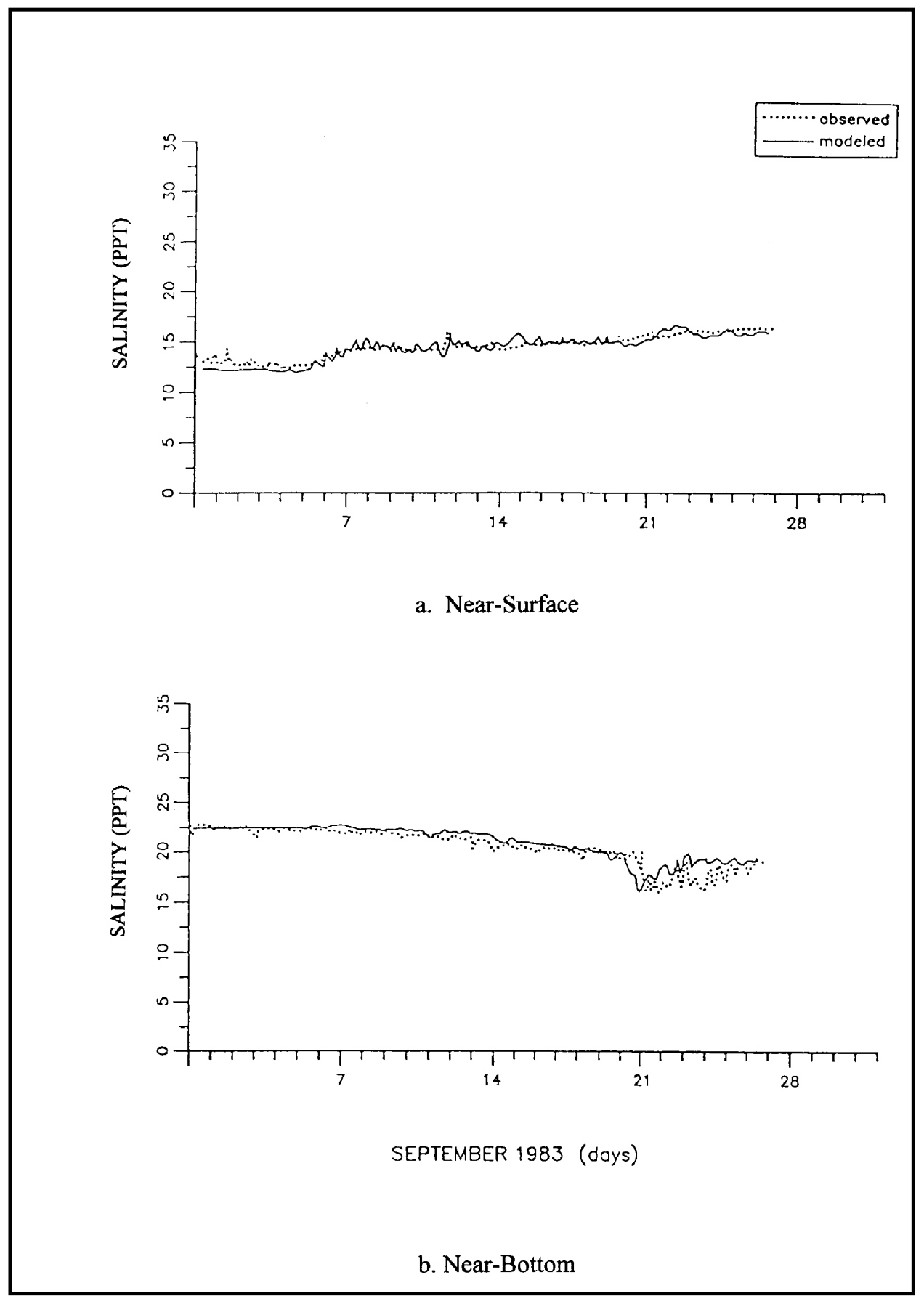

Figure 19. Computed salinity illustrating wind mixing 


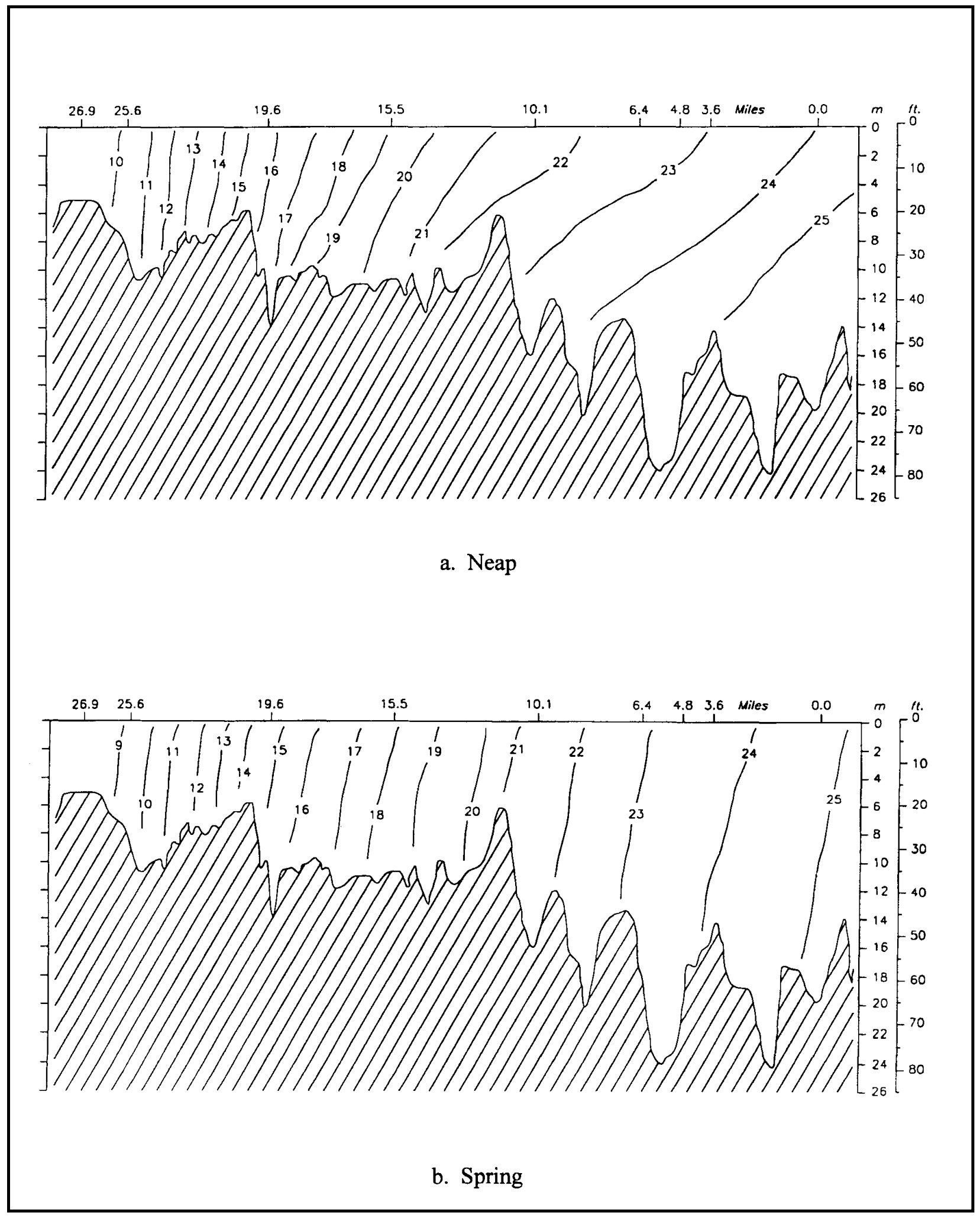

Figure 20. Illustration of computed neap-spring stratification in the York River 


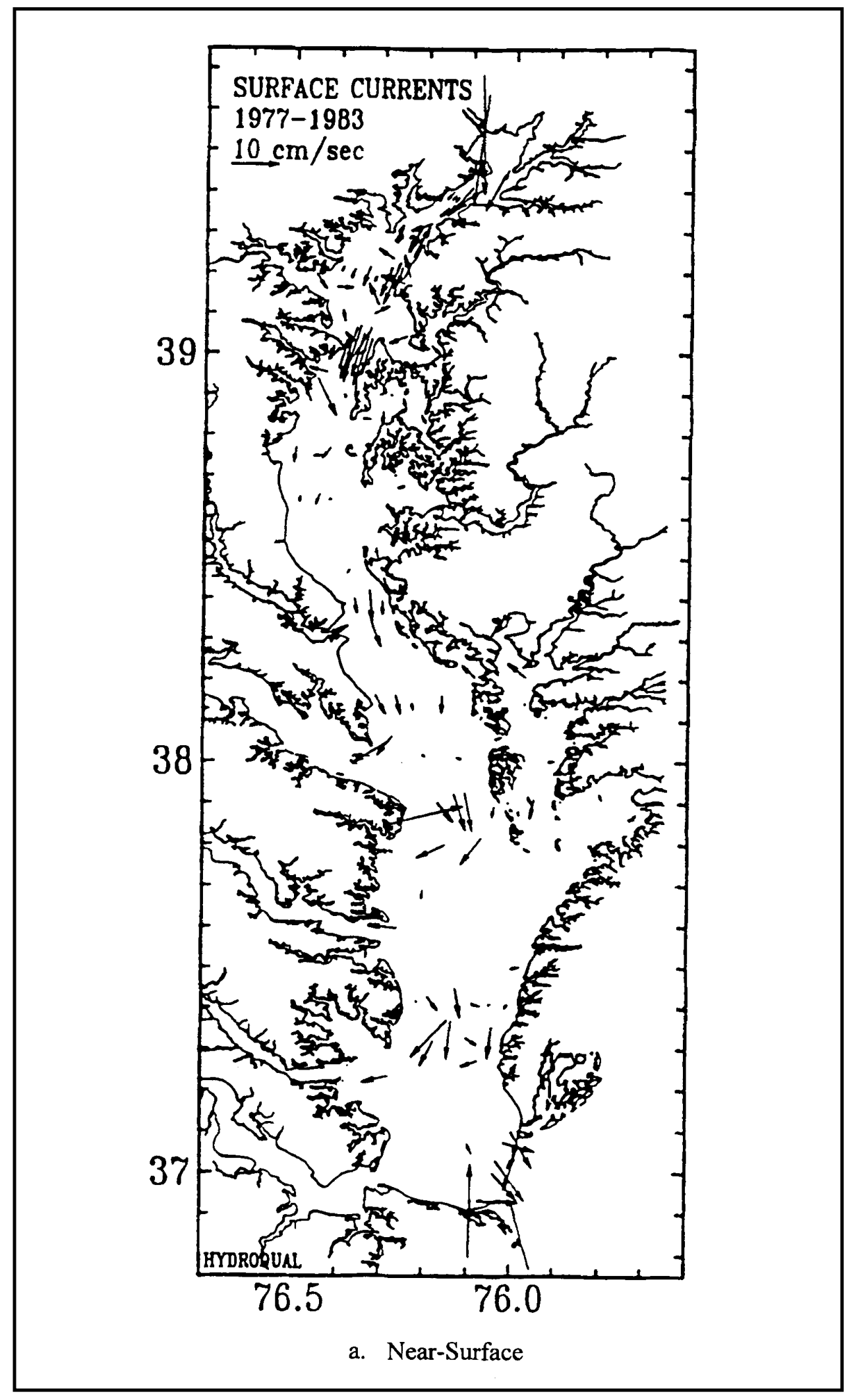

Figure 21. Residual currents computed from observed data (Continued) 


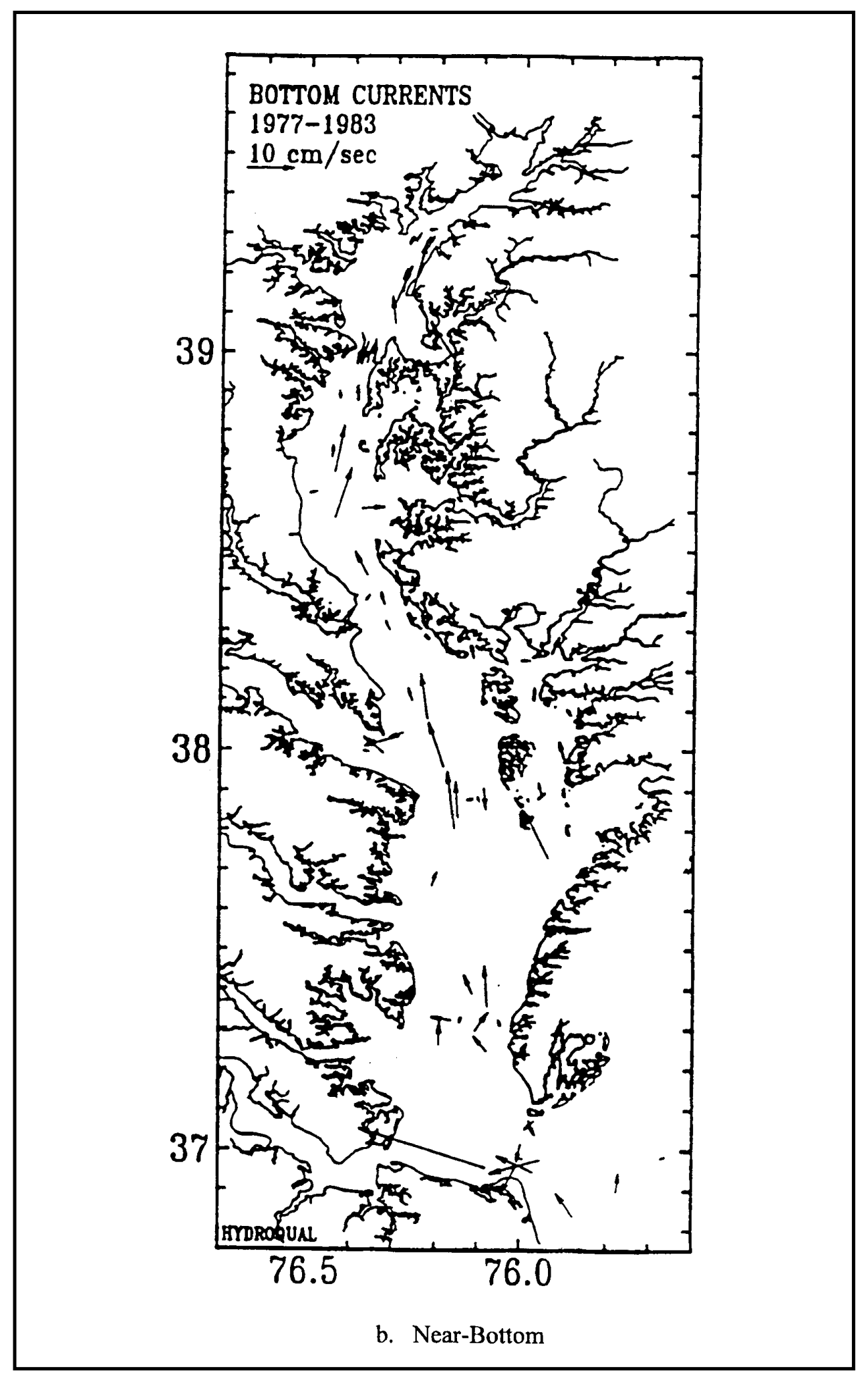

Figure 21. (Concluded) 


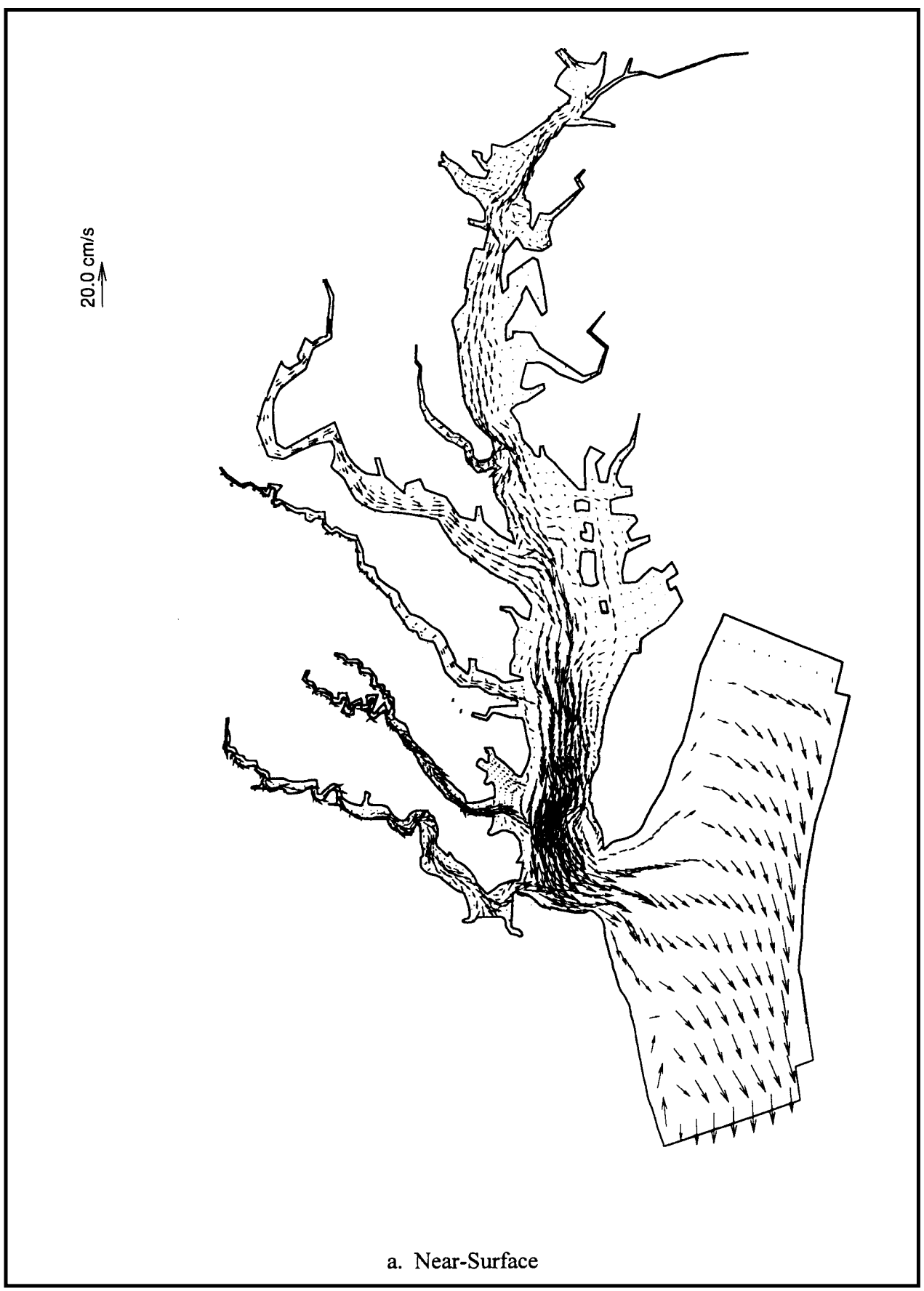

Figure 22. Residual currents computed by model (Continued) 


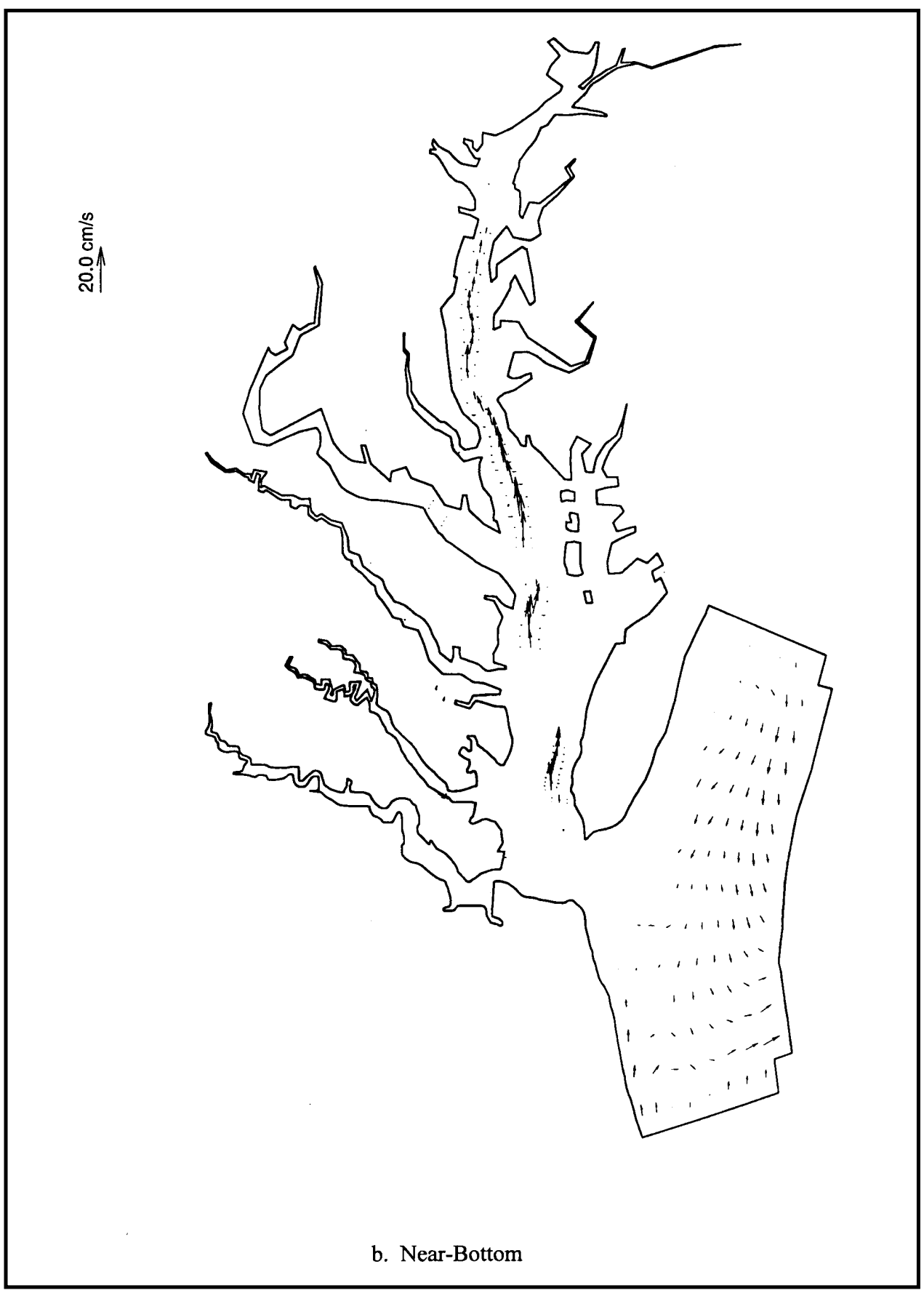

Figure 22. (Concluded) 


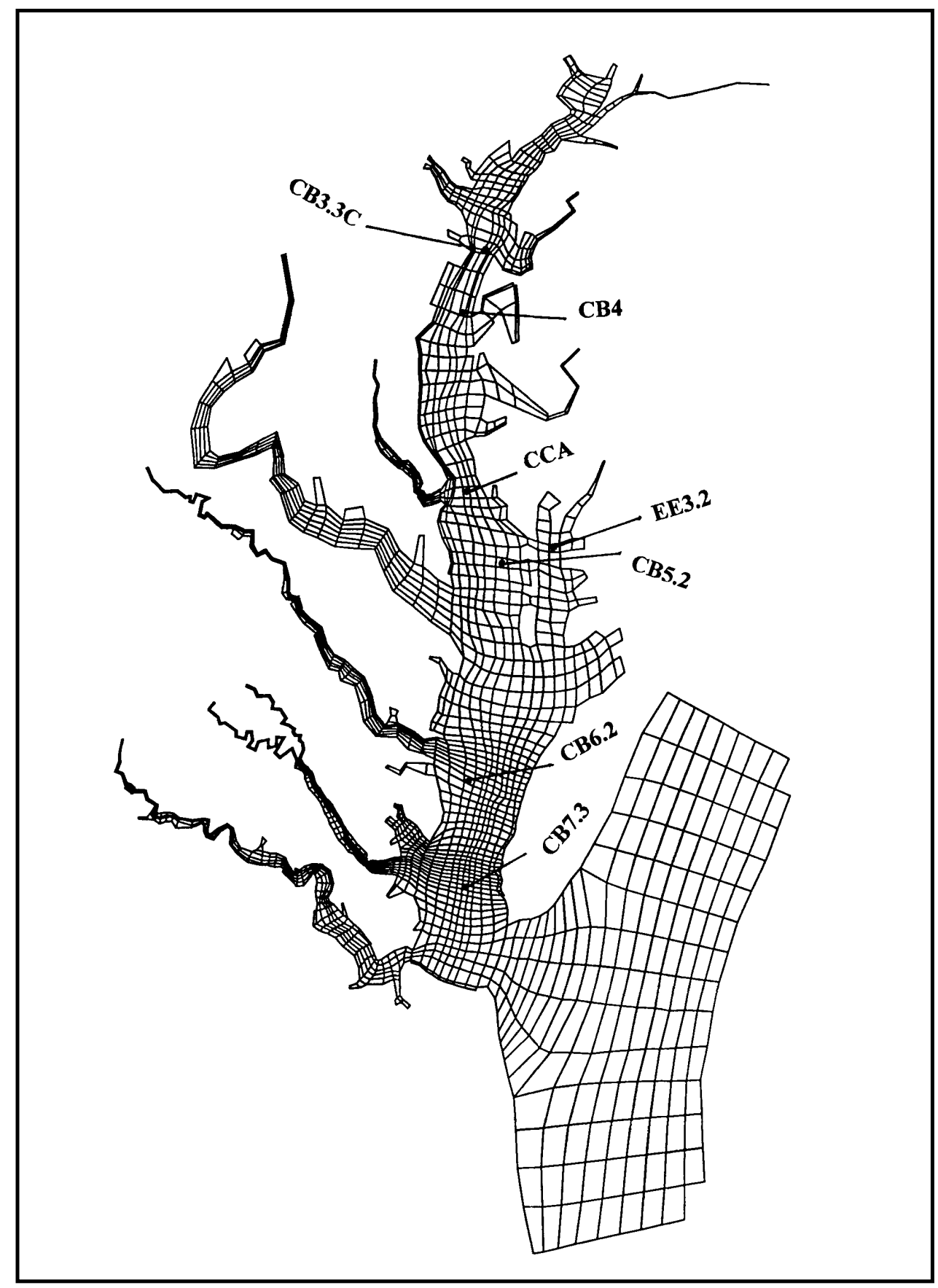

Figure 23. Location of data stations 


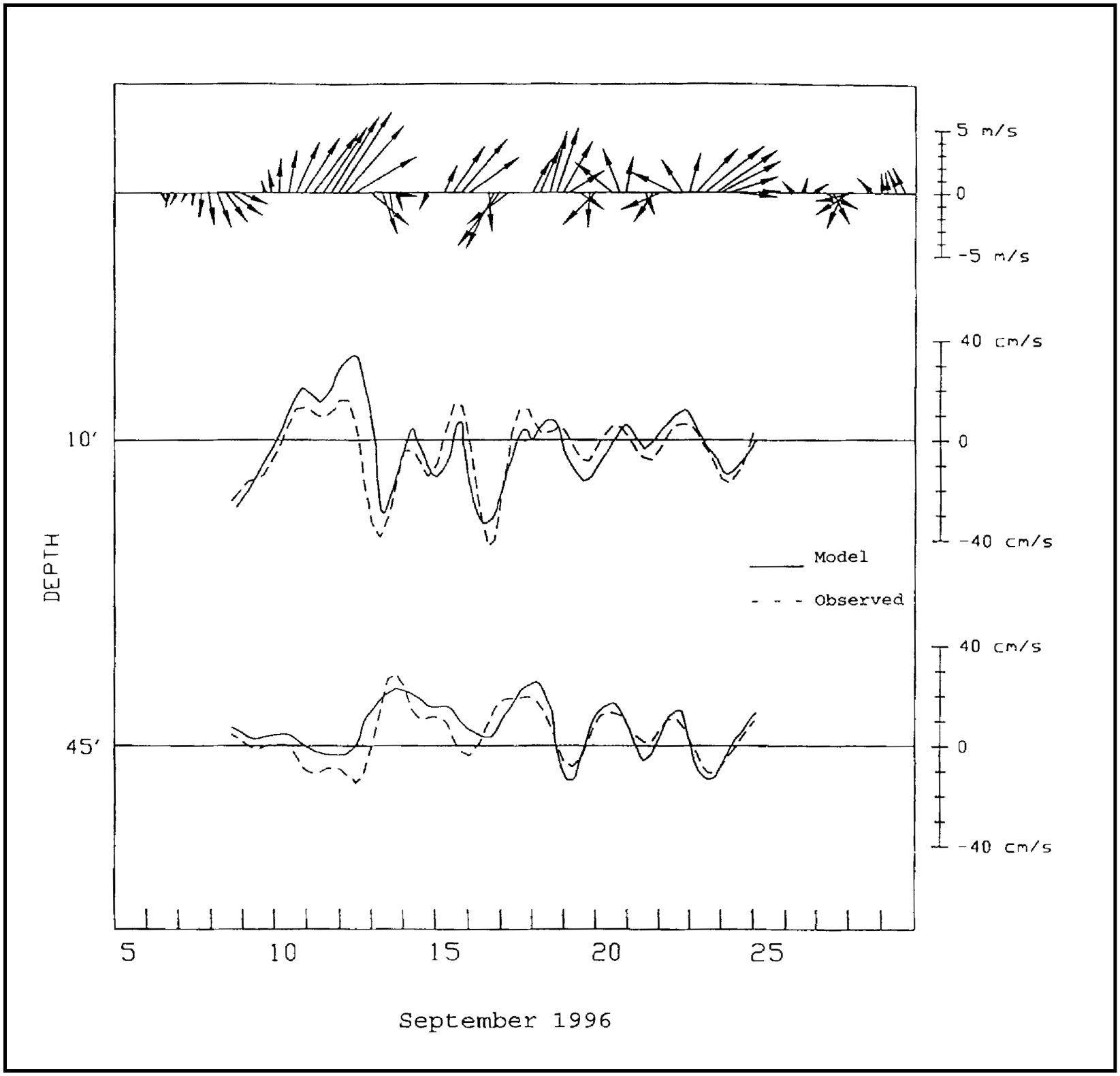

Figure 24. Comparison of low-pass observed and computed velocity at station CCA 


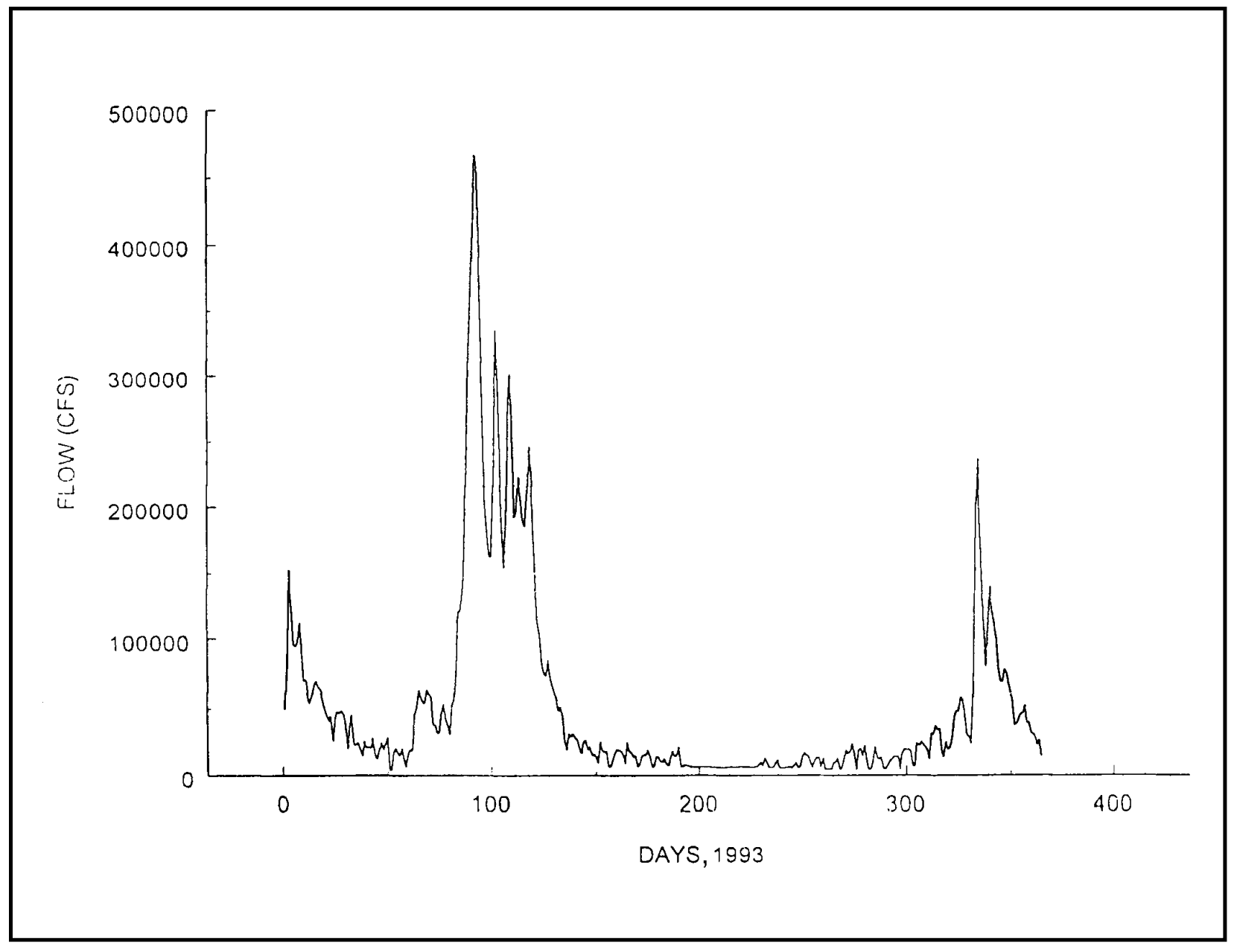

Figure 25. Susquehanna River discharge during spring of 1993 


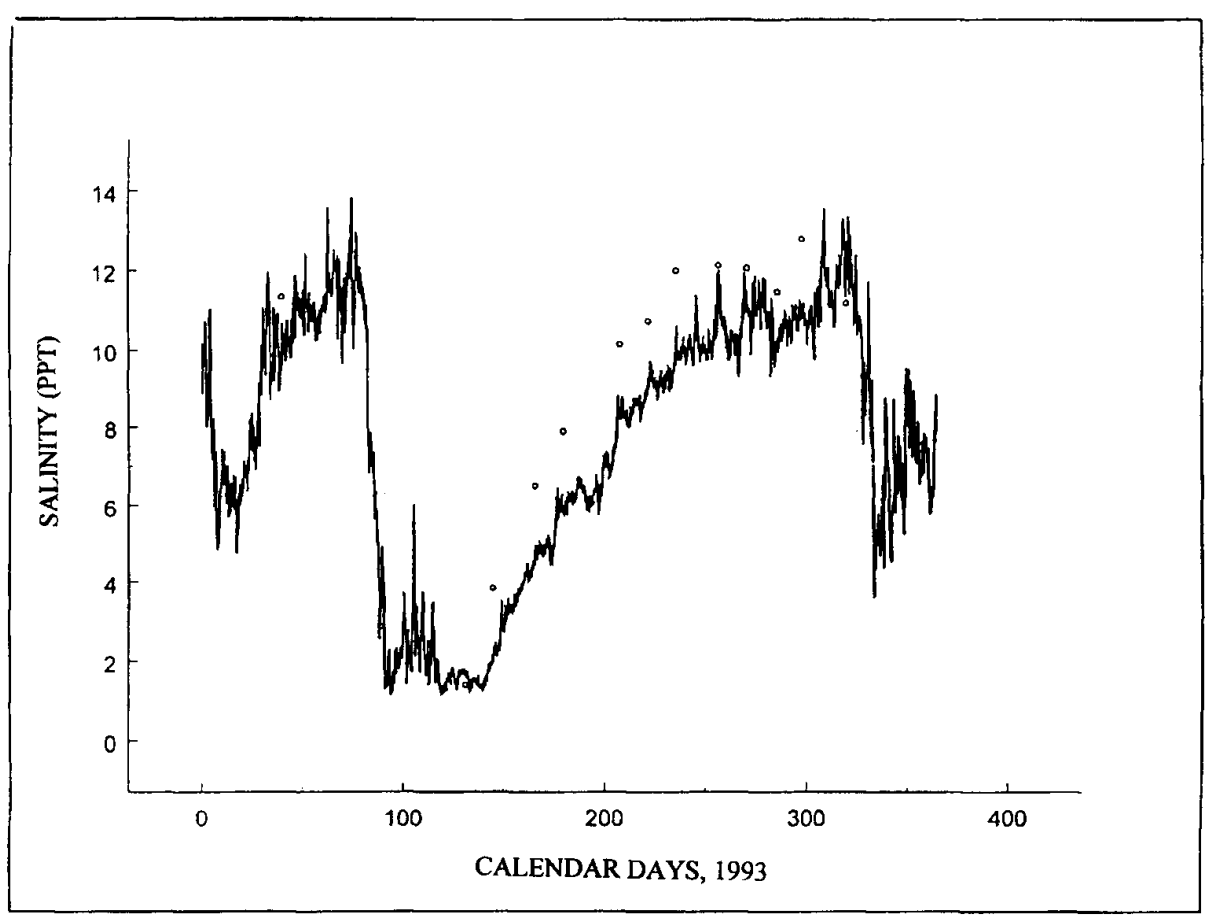

a. Near-surface

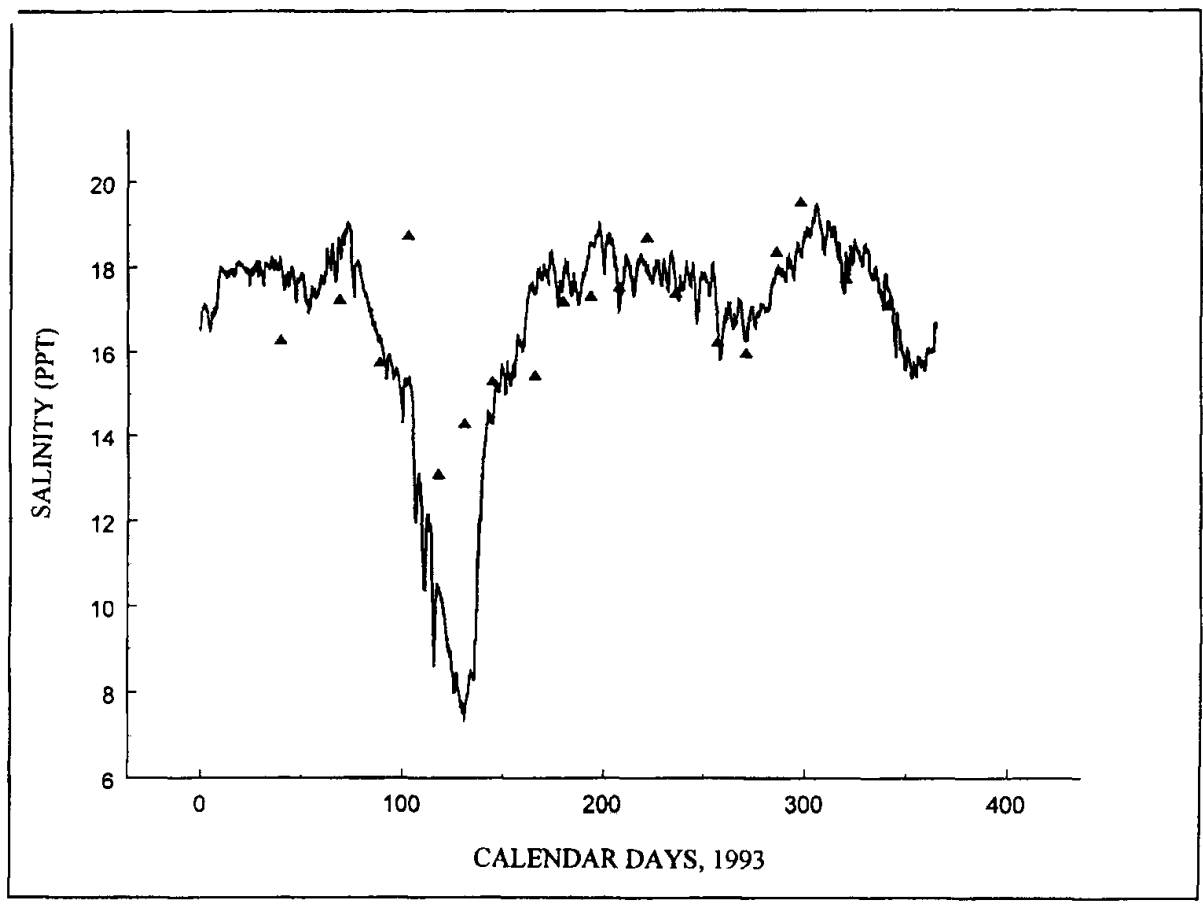

b. Near-bottom

Figure 26. Comparison of observed and computed salinity at CB3.3C during 1993 spring runoff 


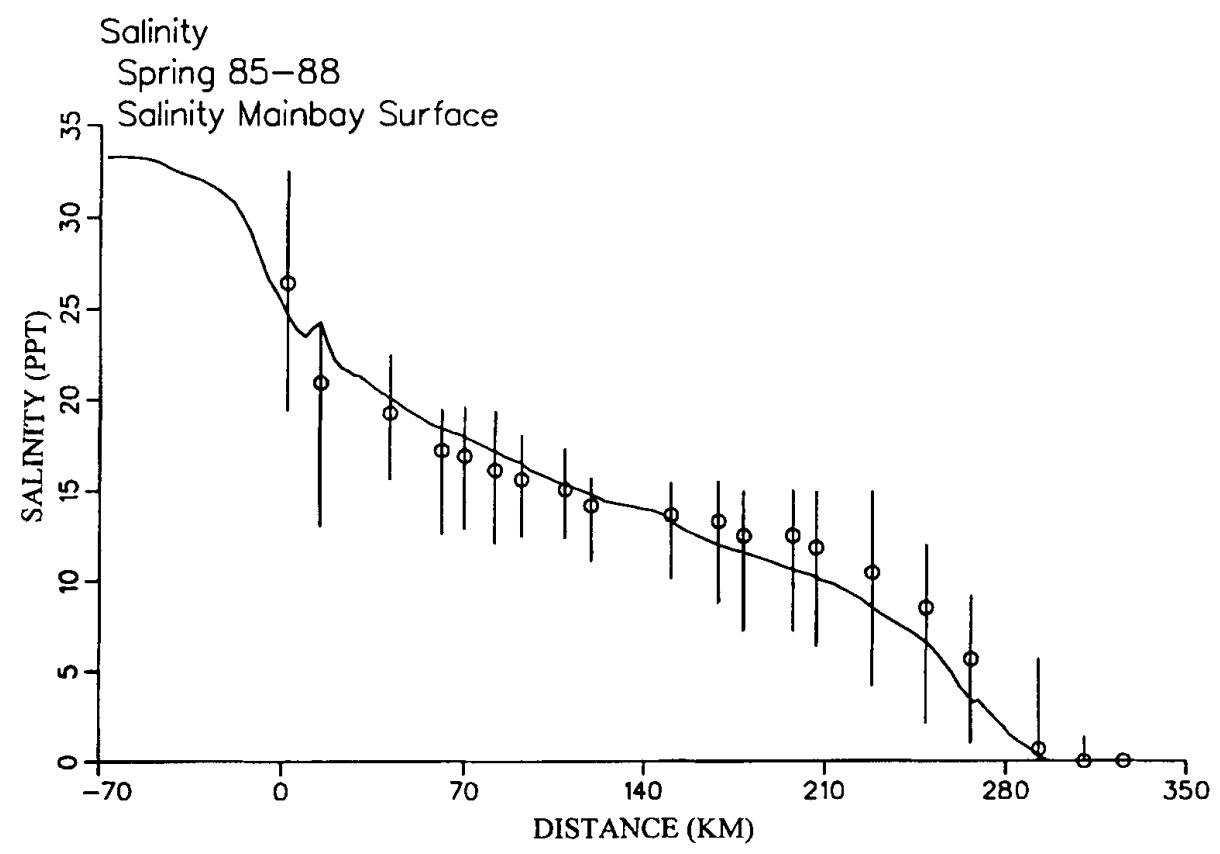

a. Near-Surface

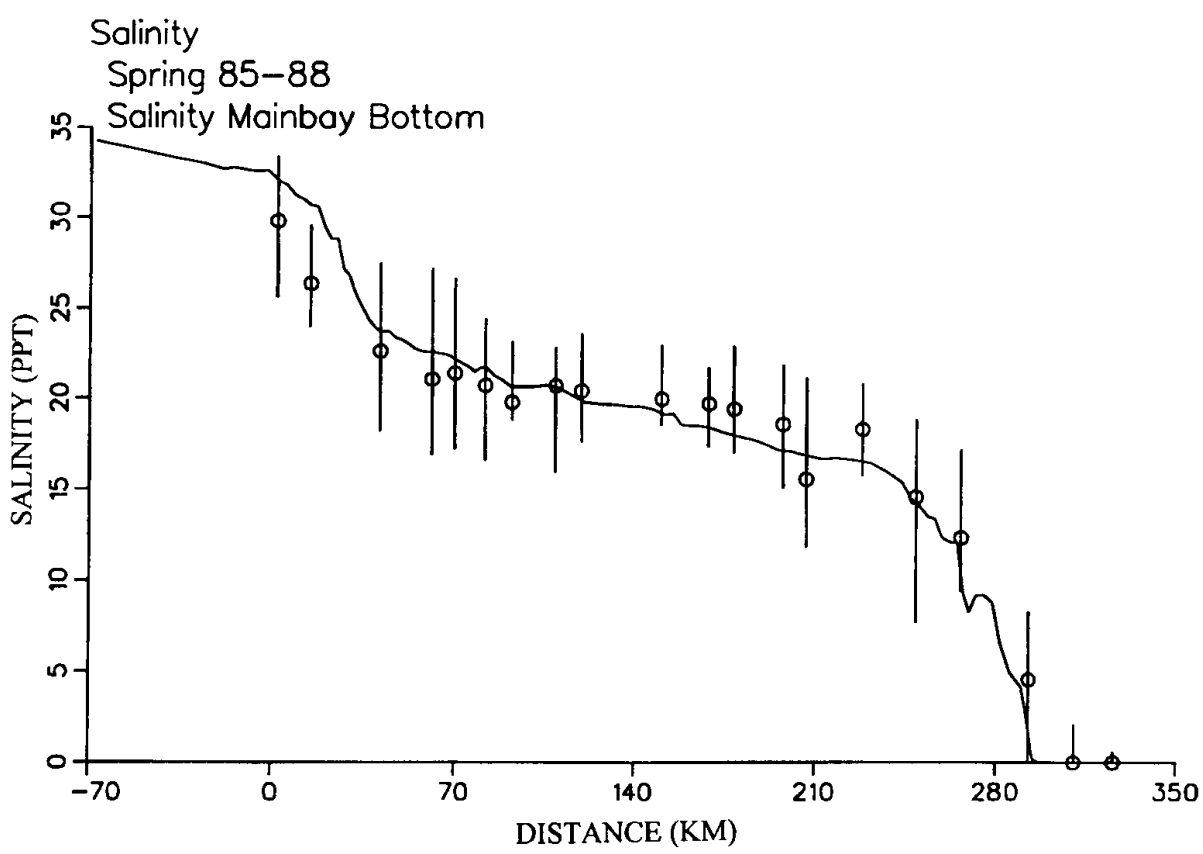

b. Near-Bottom

Figure 27 . Seasonally averaged salinity transect along main bay for springs of $1985-88$ 


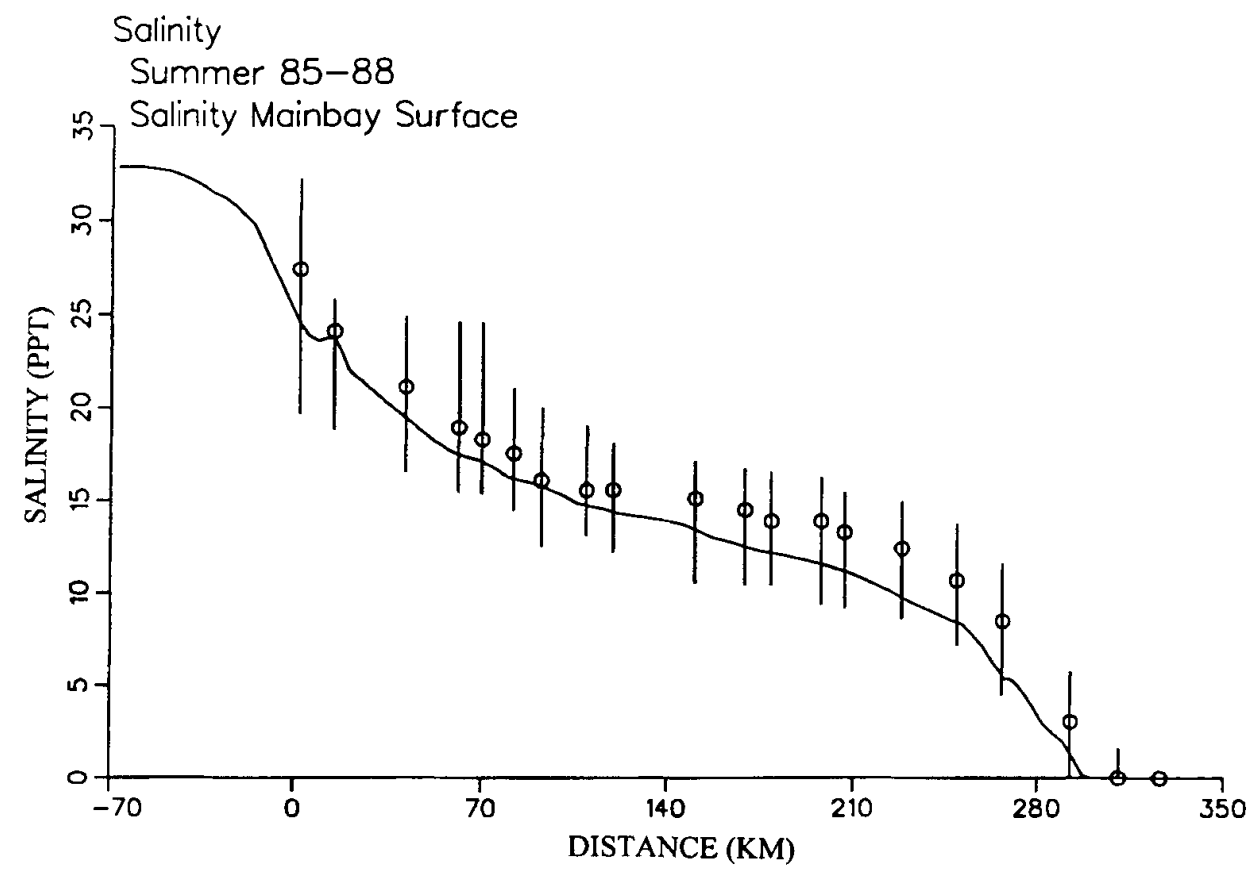

a. Near-Surface

Solinity

Summer 85-88

Salinity Mainbay Bottom

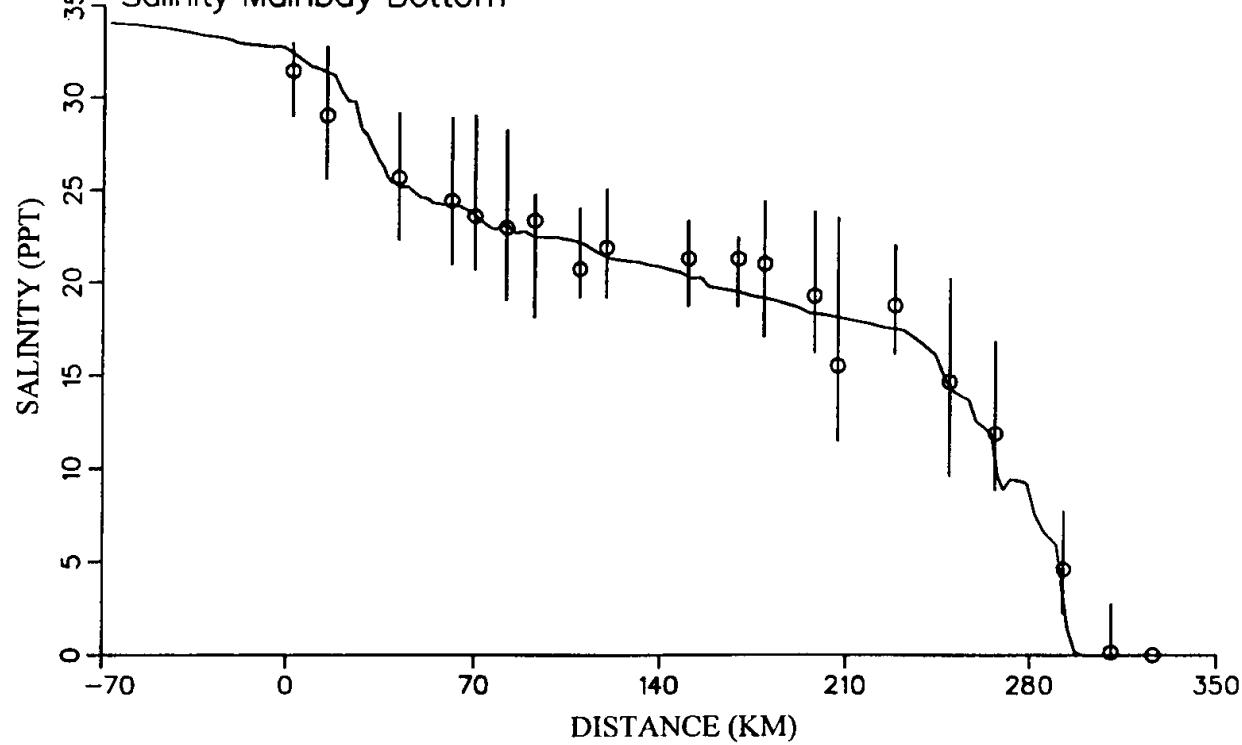

b. Near-Bottom

Figure 28. Seasonally averaged salinity transect along main bay for summers of 1985-88 


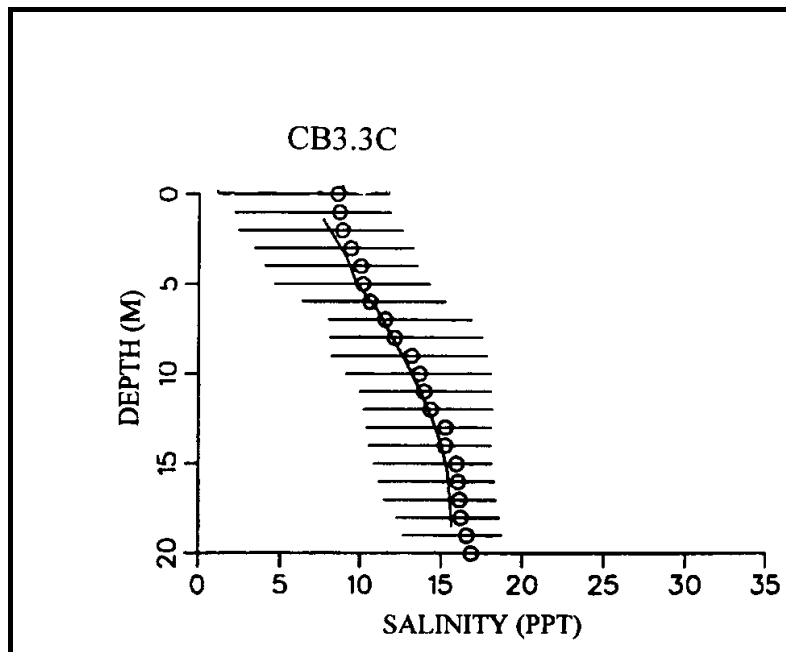

CB7.3

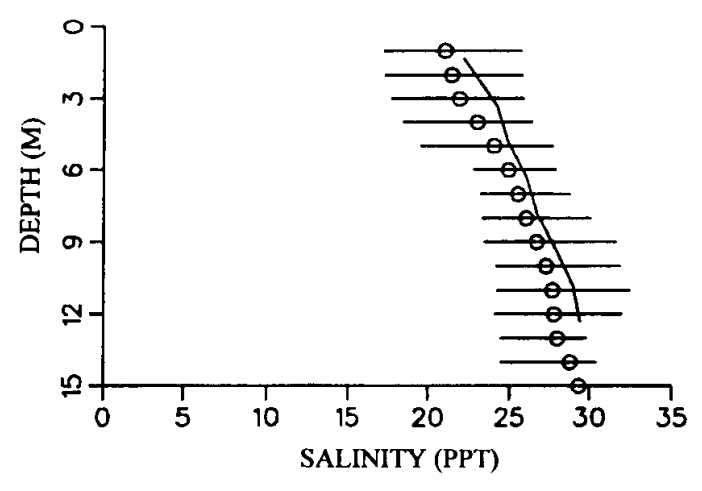

CB5.2

EE3.2
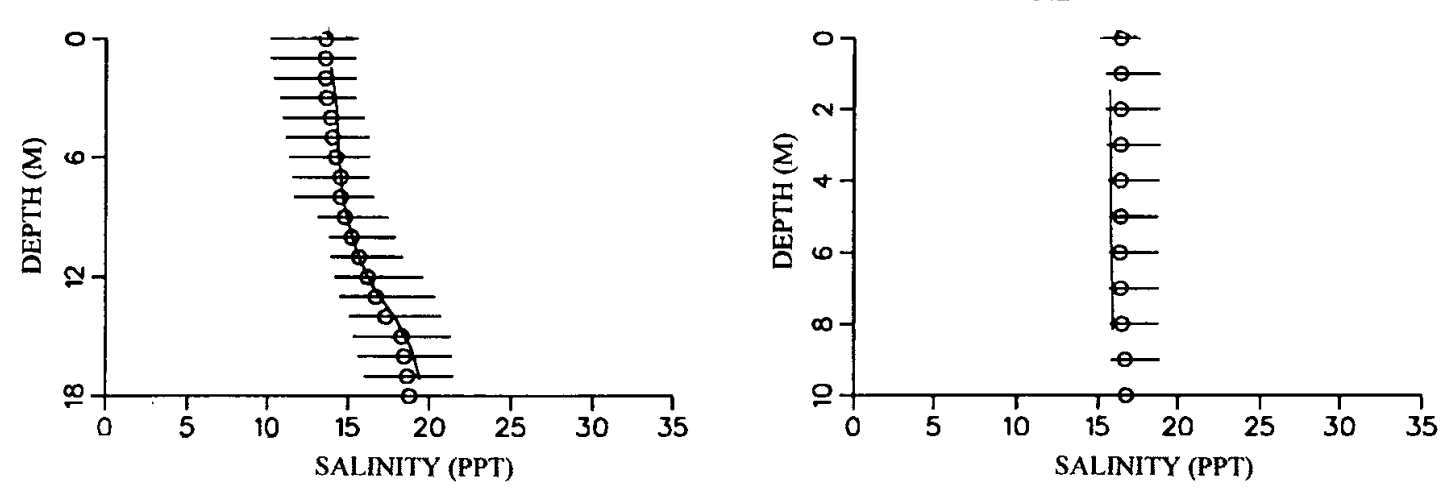

CB6.2

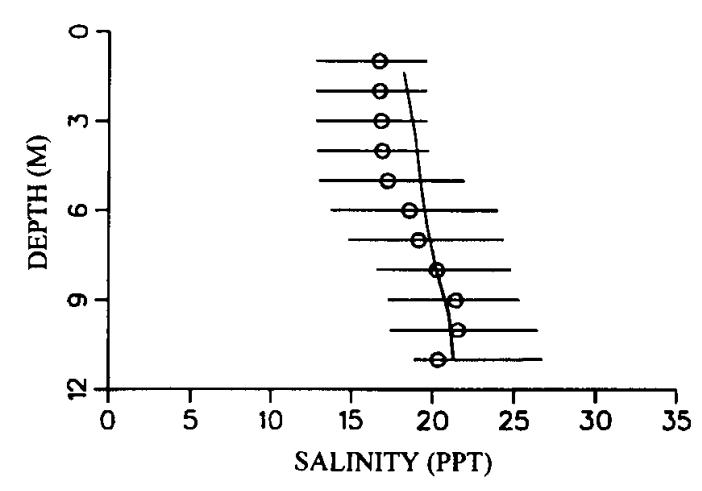

Figure 29. Seasonally averaged vertical profiles of salinity for springs of $1985-88$ 


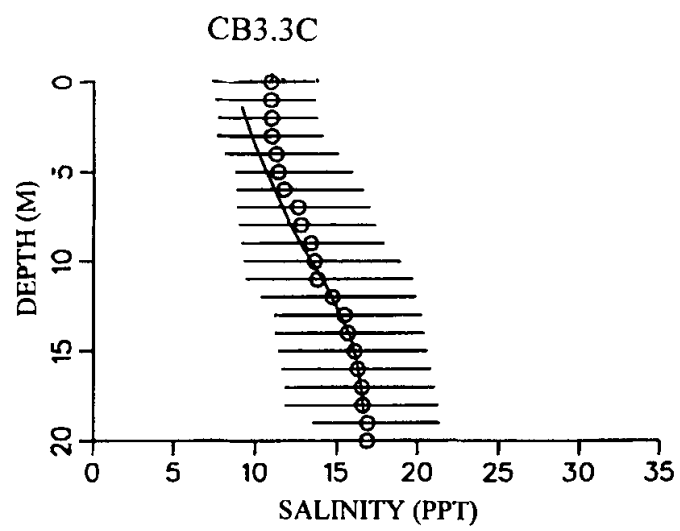

CB7.3

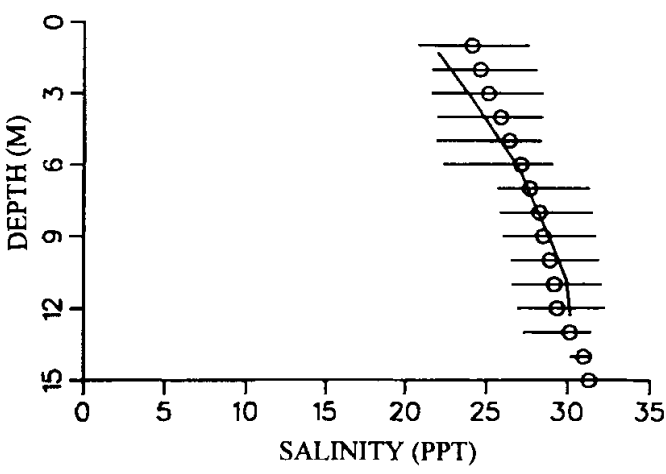

CB5.2
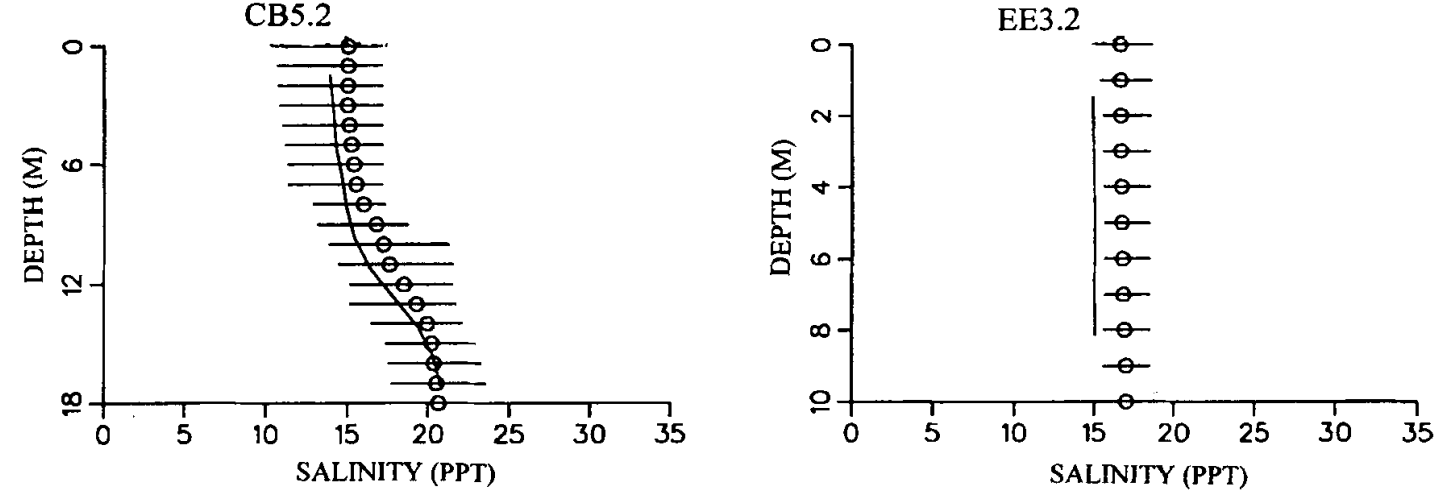

CB6.2

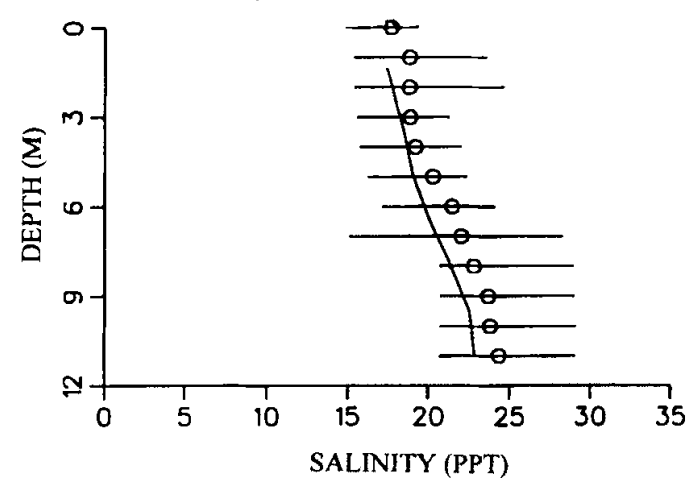

Figure 30. Seasonally averaged vertical profiles of salinity for summers of 1985-88 


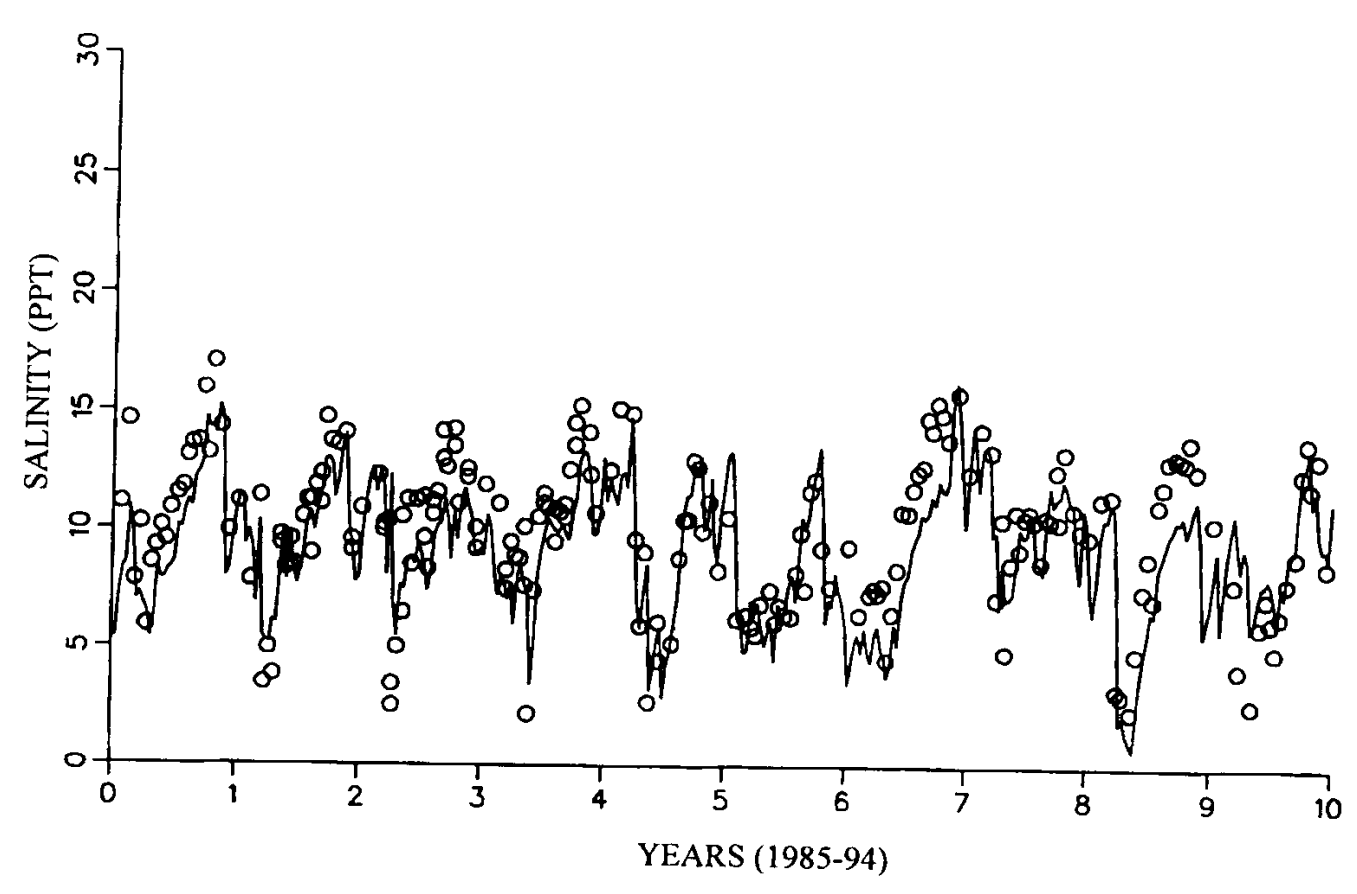

a. Near-Surface

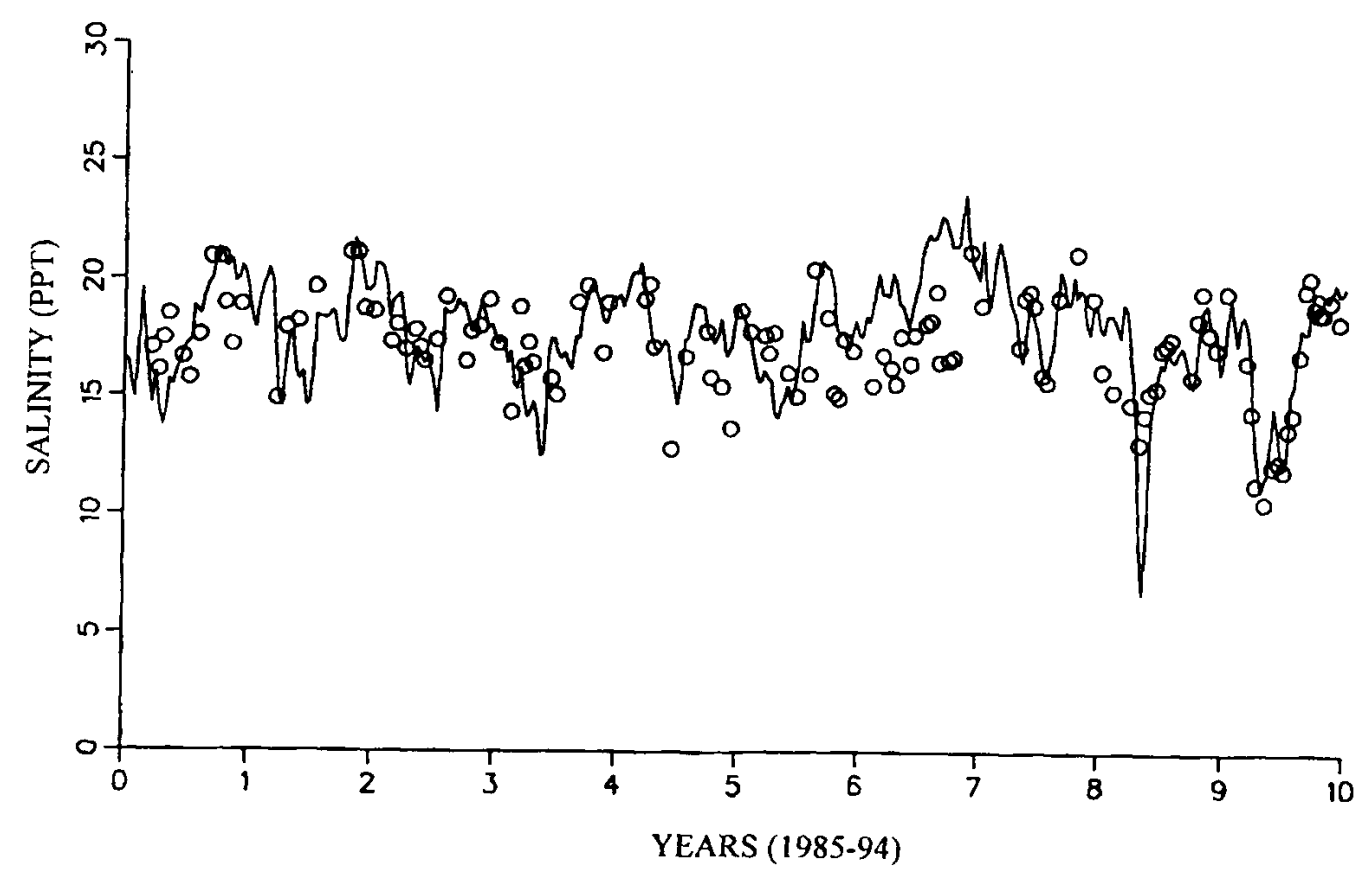

b. Near-Bottom

Figure 31. Ten years of observed (circle) and computed (solid line) salinity at CB3.3C 


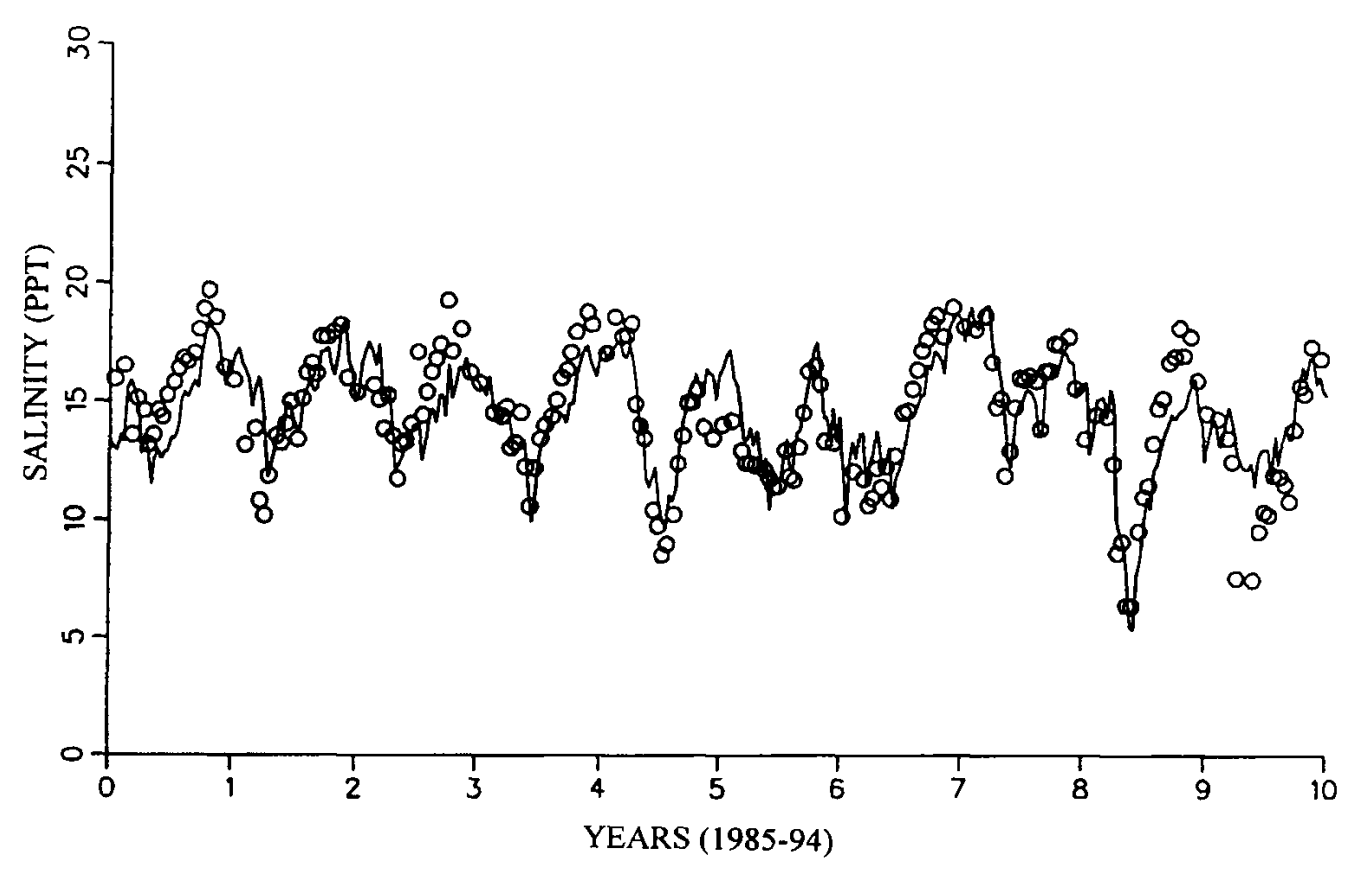

a. Near-Surface

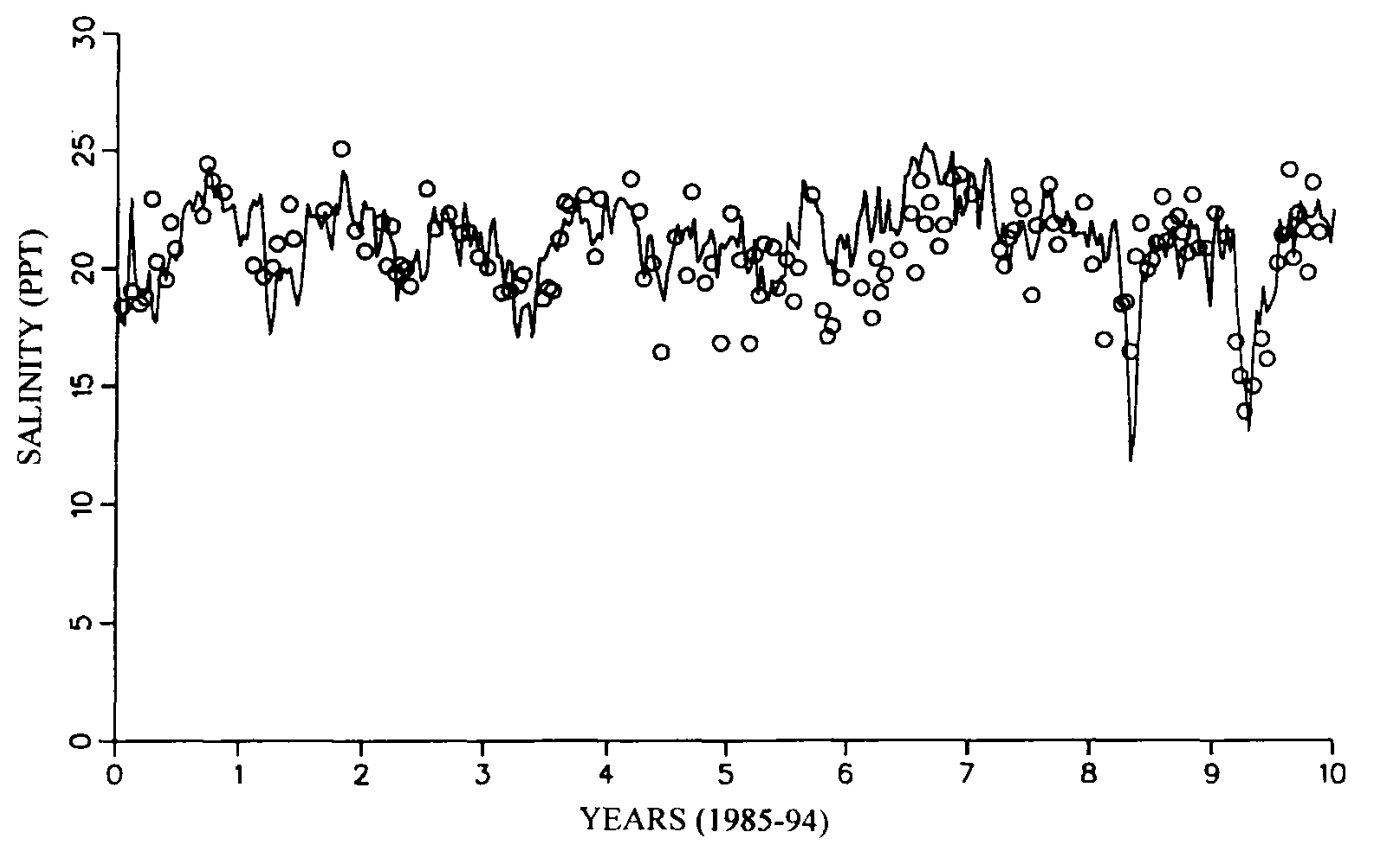

b. Near-Bottom

Figure 32. Ten years of observed (circle) and computed (solid line) salinity at CB5.2 


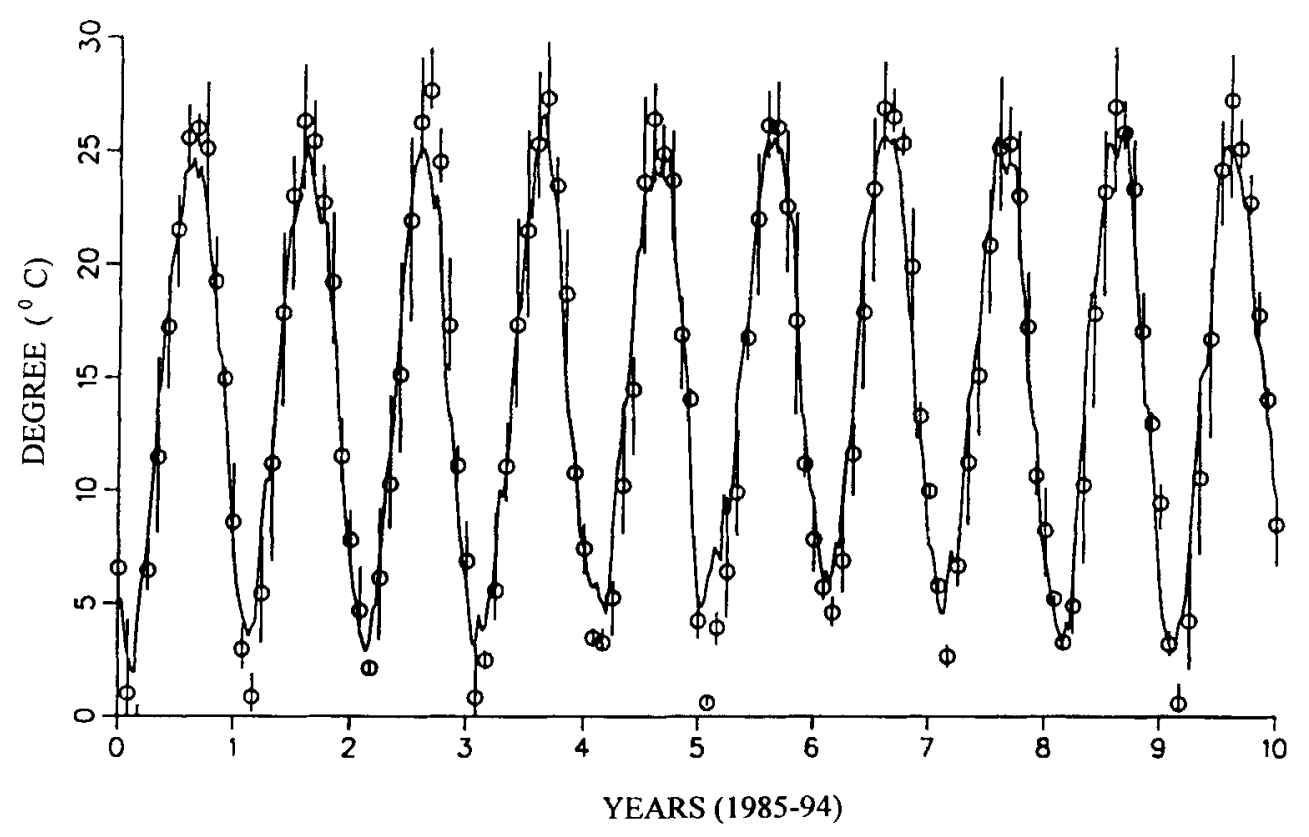

a. Near-Surface

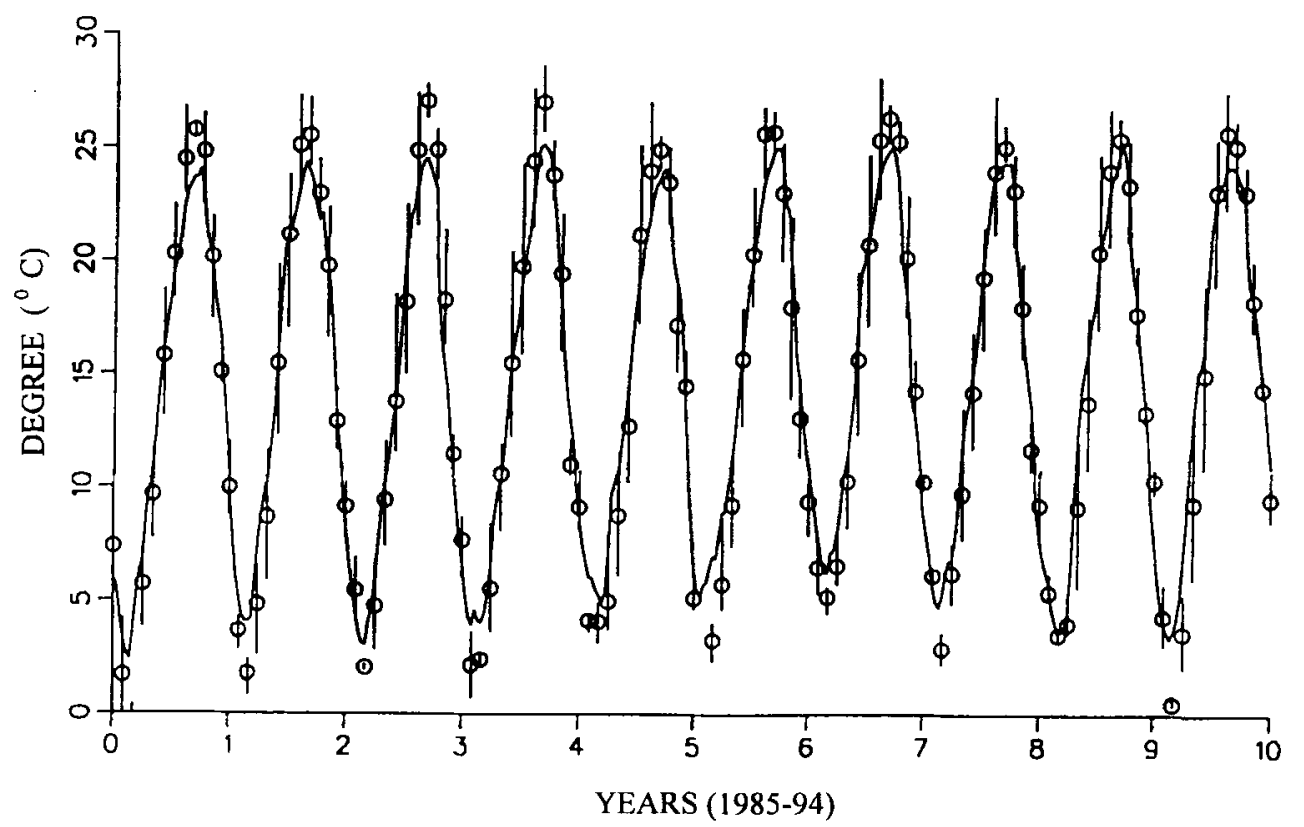

b. Near-Bottom

Figure 33. Ten years of observed (circle) and computed (solid line) temperature at CB4 


\section{Tributary Refinements to the Chesapeake Bay Model}

\section{Introduction}

The requirement to manage eutrophication within Chesapeake Bay led to the development and application of the CE-QUAL-ICM model (Cerco and Cole 1993). CE-QUAL-ICM was a three-dimensional, time-variable model of eutrophication processes in the water column and benthic sediments. As applied to Chesapeake Bay, the model was part of a package that included a threedimensional hydrodynamic model and a watershed model. Subsequent to validation, CE-QUAL-ICM was employed in scenario analysis (Cerco 1995a) and in examination of long-term trends in eutrophication (Cerco 1995b).

CE-QUAL-ICM was especially suited for examination of eutrophication processes within the main stem of the bay. The model was less successful in modeling the major western-shore tributaries, largely because of the coarse scale of the grid in these areas. In addition, distributed loads to these tributaries lacked spatial resolution, and point-source loads were frequently set to default values. In preparation for a periodic re-evaluation of management efforts in the bay, a course of tributary refinements was specified for CE-QUAL-ICM. Among these refinements were the following:

- Increased grid resolution within the major western-shore tributaries.

- Extension of the grid beyond the mouth of the bay onto the continental shelf.

- Direct simulation of living resources including zooplankton, submerged aquatic vegetation (SAV), and benthos.

- Extension of the validation period to include contemporary data.

Concurrent with refinements to CE-QUAL-ICM, the spatial resolution of loads from the watershed model was improved and a sampling program was conducted to define the point-source loads.

This chapter describes the refinements to CE-QUAL-ICM and provides examples of its improved capabilities. A subsequent paper is planned that examines incremental improvements gained in the course of refinements. 


\section{The Computational Grid}

Resolution of the grid (Figure 1) was improved through two procedures. First, the number of cells was increased with emphasis on the Virginia tributaries

(Table 1). Second, the grid was extended into shallow, littoral zones of depth from zero to $2 \mathrm{~m}$. Previously, the minimum depth represented was $3.7 \mathrm{~m}$. The grid was also extended $30 \mathrm{~km}$ out onto the continental shelf and $75 \mathrm{~km}$ north and south of the bay mouth. This extent was specified to capture large-scale circulation features outside the bay mouth.

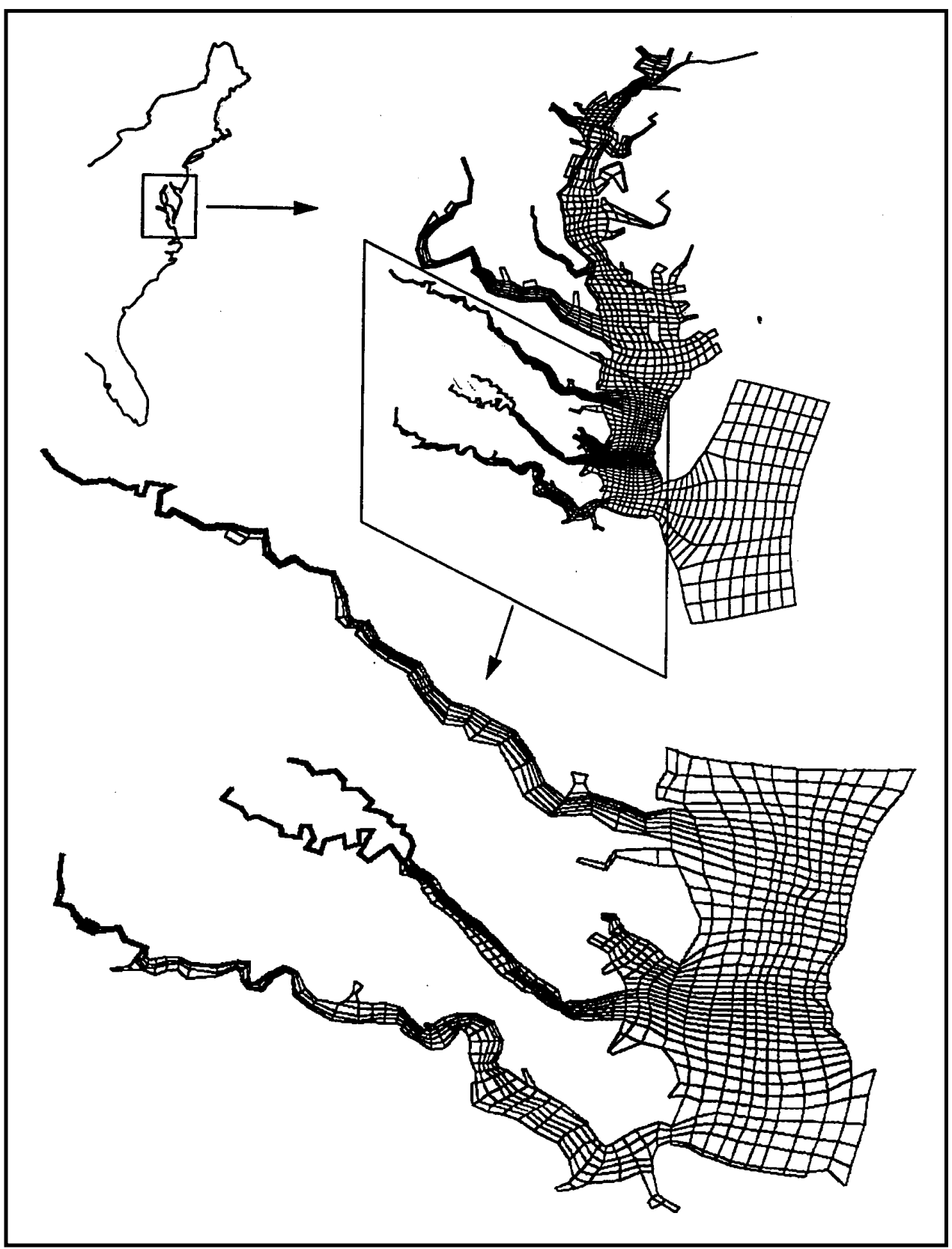

Figure 1. Location map, plan view of grid, and detail of Virginia portion of grid 


\begin{tabular}{|c|c|c|c|c|c|c|c|c|c|}
\hline Depth & Grid & James & York & Rappahannock & Potomac & Patuxent & $\begin{array}{l}\text { Bay and } \\
\text { Lesser } \\
\text { Tributaries }\end{array}$ & Shelf & Total \\
\hline \multirow[t]{2}{*}{ Surface } & Old Grid & 42 & 28 & 35 & 66 & 24 & 534 & 0 & 729 \\
\hline & New Grid & 258 & 235 & 162 & 131 & 72 & 1106 & 136 & 2100 \\
\hline \multirow[t]{2}{*}{ Total } & Old Grid & 139 & 92 & 120 & 348 & 100 & 3274 & 0 & 4073 \\
\hline & New Grid & 678 & 753 & 478 & 521 & 258 & 5811 & 1697 & 10196 \\
\hline
\end{tabular}

\section{Living Resources}

The ultimate aim of eutrophication modeling is to preserve precious living resources. Usually, the modeling process involves the simulation of livingresource parameters such as dissolved oxygen (DO). Computed parameters are compared to living-resource (e.g., DO) standards, and a projection is made whether computed conditions will be beneficial to the resources of interest (e.g., fish). The parameter approach does not provide computations of the resources themselves nor does it allow feedback between organisms and their environment. For example, the potential reduction of algal concentrations by enhanced populations of planktivorous fish cannot be examined. Models that simulate both eutrophication processes and living resources are largely beyond the state of the art. Within the tributary refinements, a decision was made to advance the state of the art by initiating direct interactive simulation of three living resource groups: zooplankton, benthos, and SAV.

\section{Zooplankton}

Zooplankton were selected for simulation because they are a valuable food source for finfish. A secondary objective was to improve computation of phytoplankton by providing dynamic closure to the predation term in the phytoplankton production equation. The zooplankton that inhabit the bay are a heterogeneous population of various species, size classes, and trophic levels. A decision was made to simulate two groups: microzooplankton $(44-201 \mu \mathrm{m})$ and mesozooplankton $(>201 \mu \mathrm{m})$. The decision was based largely on the availability of data; zooplankton monitoring within the bay is based primarily on size classes. Review of publications on Chesapeake Bay zooplankton (e.g., White and Roman 1992; Miller, Penry, and Glibert 1995) indicated the model should simulate a food web in which zooplankton feed on detritus, phytoplankton, and each other (Figure 2). One problem was presented by omission from the model of bacteria, which form an important food source for the microzooplankton. Since bacteria are not living resources of interest, the additional complication of incorporating bacteria into the model was unwarranted. Instead, microzooplankton were allowed to feed, at a very low efficiency, on dissolved organic carbon. The low-efficiency feeding represented the feeding of bacteria on dissolved organic carbon, metabolic losses by bacteria, and subsequent feeding of microzooplankton on bacteria. 


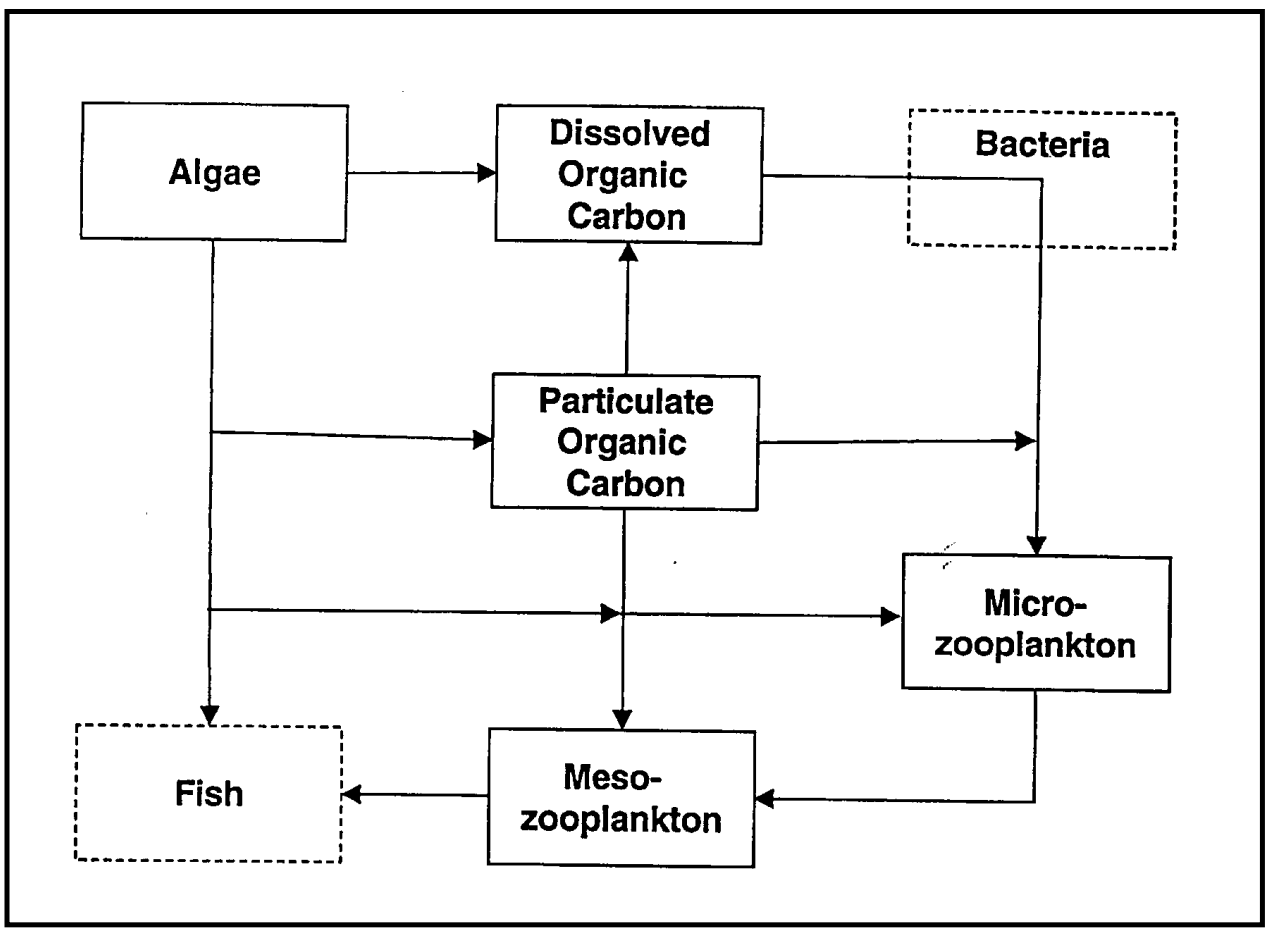

Figure 2. The model carbon cycle. Quantities enclosed by solid lines are model state variables

The three-dimensional mass-conservation equation applied to all CE-QUALICM state variables was presented by Cerco and Cole (1993). Omitting the transport terms, sources and sinks for each zooplankton group are as follows:

$$
\frac{d Z}{d t}=(G-B M) \cdot Z-P R
$$

where

$$
\begin{aligned}
Z & =\text { zooplankton biomass } \\
t & =\text { time } \\
G & =\text { growth rate } \\
B M & =\text { basal metabolic rate } \\
P R & =\text { predation rate }
\end{aligned}
$$

For microzooplankton, the predation rate is proportional to microzooplankton and mesozooplankton biomass. For mesozooplankton, a quadratic term based on biomass provides closure. The magnitude of the term is specified to agree with estimated predation by carnivorous fish.

The growth rate for each group is represented by Equation 2: 


$$
G=E \cdot(1-R F) \cdot R \max \cdot \frac{B}{K h+B}
$$

where

$$
\begin{aligned}
E & =\text { assimilation efficiency } \\
R F & =\text { respiratory cost of grazing } \\
R \max & =\text { maximum specific ration } \\
B & =\text { available prey } \\
K h & =\text { half-saturation concentration for grazing }
\end{aligned}
$$

Available prey concentration is determined by a linear weighting of all food sources. Key parameter values are reported in Table 2.

\section{Benthos}

Benthos were included in the model because they are an important food source for crabs, finfish, and other economically and ecologically significant biota. In addition, benthos can exert a substantial influence on water quality through their filtering of overlying water (Cohen et al. 1984; Newell 1988). Benthos within the model were divided into two groups: deposit feeders and filter feeders (Figure 3). The deposit-feeding group represents benthos that live within bottom sediments and feed on deposited material. The filter-feeding group represents benthos that live at the sediment surface and feed by filtering overlying water.

Deposit feeders. Algorithms to represent deposit feeders were incorporated into the existing sediment diagenesis submodel (DiToro and Fitzpatrick 1993). Within each cell of the model, deposit feeders were determined by the following relationship:

$$
\frac{d D F}{d t}=\alpha \cdot \frac{I d}{m} \cdot D F \cdot C-r \cdot D F-\beta \cdot D F^{2}
$$

where

$$
\begin{aligned}
D F & =\text { biomass } \\
\alpha & =\text { assimilation efficiency } \\
I d & =\text { ingestion rate } \\
m & =\text { sediment solids concentration } \\
C & =\text { sediment carbon concentration } \\
r & =\text { respiration rate } \\
\beta & =\text { nonrespiratory mortality rate }
\end{aligned}
$$




\begin{tabular}{|c|c|c|c|}
\hline \multicolumn{4}{|c|}{$\begin{array}{l}\text { Table } 2 \\
\text { Parameter Values } \\
\end{array}$} \\
\hline Equation & Parameter & Value & Units \\
\hline 1 & $B M$ & $\begin{array}{l}0.186 \text { (microzoopl), } \\
0.254 \text { (mesozoopl) }\end{array}$ & day $^{-1}$ \\
\hline 2 & $R \max$ & $\begin{array}{l}2.25 \text { (microzoopl), } \\
1.75 \text { (mesozoopl) }\end{array}$ & day $^{-1}$ \\
\hline 2 & $R F$ & $\begin{array}{l}0.5 \text { (microzoopl), } \\
0.07 \text { (mesozoopl) }\end{array}$ & \\
\hline 2 & $E$ & 0.3 & \\
\hline 2 & $K h$ & $\begin{array}{l}0.05 \text { (microzoopl), } \\
0.175 \text { (mesozoopl) }\end{array}$ & $\mathrm{gm} \mathrm{C} \mathrm{m}^{-3}$ \\
\hline 3 & Id & 175 & gm solids gm $^{-1} \mathrm{C}$ day ${ }^{-1}$ \\
\hline 3 & $\alpha$ & 0.25 to 0.8 & \\
\hline 3 & $r$ & 0.015 & day $^{-1}$ \\
\hline 3 & $\beta$ & $1 \times 10^{-4}$ & $\mathrm{~m}^{2} \mathrm{mg}^{-1} \mathrm{C}$ day $^{-1}$ \\
\hline 4 & If & 0.109 to 0.216 & $\mathrm{~m}^{3} \mathrm{gm}^{-1} \mathrm{C}$ day $^{-1}$ \\
\hline 4 & $\alpha$ & 0 to 0.8 & \\
\hline 4 & $r$ & 0.026 & day $^{-1}$ \\
\hline 4 & $\beta$ & 0.2 to $1 \times 10^{-6}$ & $\mathrm{~m}^{2} \mathrm{mg}^{-1} \mathrm{C}$ day $\mathrm{y}^{-1}$ \\
\hline 5 & $P$ & 0.16 to 0.27 & day $^{-1}$ \\
\hline 5 & $R$ & 0.013 to 0.02 & day $^{-1}$ \\
\hline 5 & $S L$ & 0.01 to 0.1 & day $^{-1}$ \\
\hline 5 & Fpsr & 0.1 to 0.85 & \\
\hline 5 & Krps & 0 to 0.05 & day $^{-1}$ \\
\hline 6 & $K e b$ & 0.05 to 0.7 & $\mathrm{~m}^{-1}$ \\
\hline 6 & $a$ & 0.083 to 0.117 & $\mathrm{~m}^{2} \mathrm{gm}^{-1}$ \\
\hline 6 & $b$ & 0.083 to 0.117 & $\mathrm{~m}^{2} \mathrm{gm}^{-1}$ \\
\hline 7 & $w$ & $\begin{array}{l}5 \text { (stormflows), } \\
0.5 \text { (otherwise) }\end{array}$ & $\mathrm{m} \mathrm{day}^{-1}$ \\
\hline 7 & $W r$ & $\begin{array}{l}0 \text { (stormflows), } \\
0.45 \text { (otherwise) }\end{array}$ & $m$ day $^{-1}$ \\
\hline
\end{tabular}

Ingestion, respiration, and mortality are computed as functions of temperature and DO concentration. Key parameter values are presented in Table 2.

Filter feeders. Filter feeders were incorporated into the model through creation of a new submodel that interacted with the main model of the water column and the sediment diagenesis submodel. Benthos monitoring data were examined, and a dominant species was identified for 25 regions of the bay. Three dominant species were sufficient to characterize the system: Rangia cuneata, Macoma balthica, and Corbicula flumenea. Each was modeled with the same equation: 


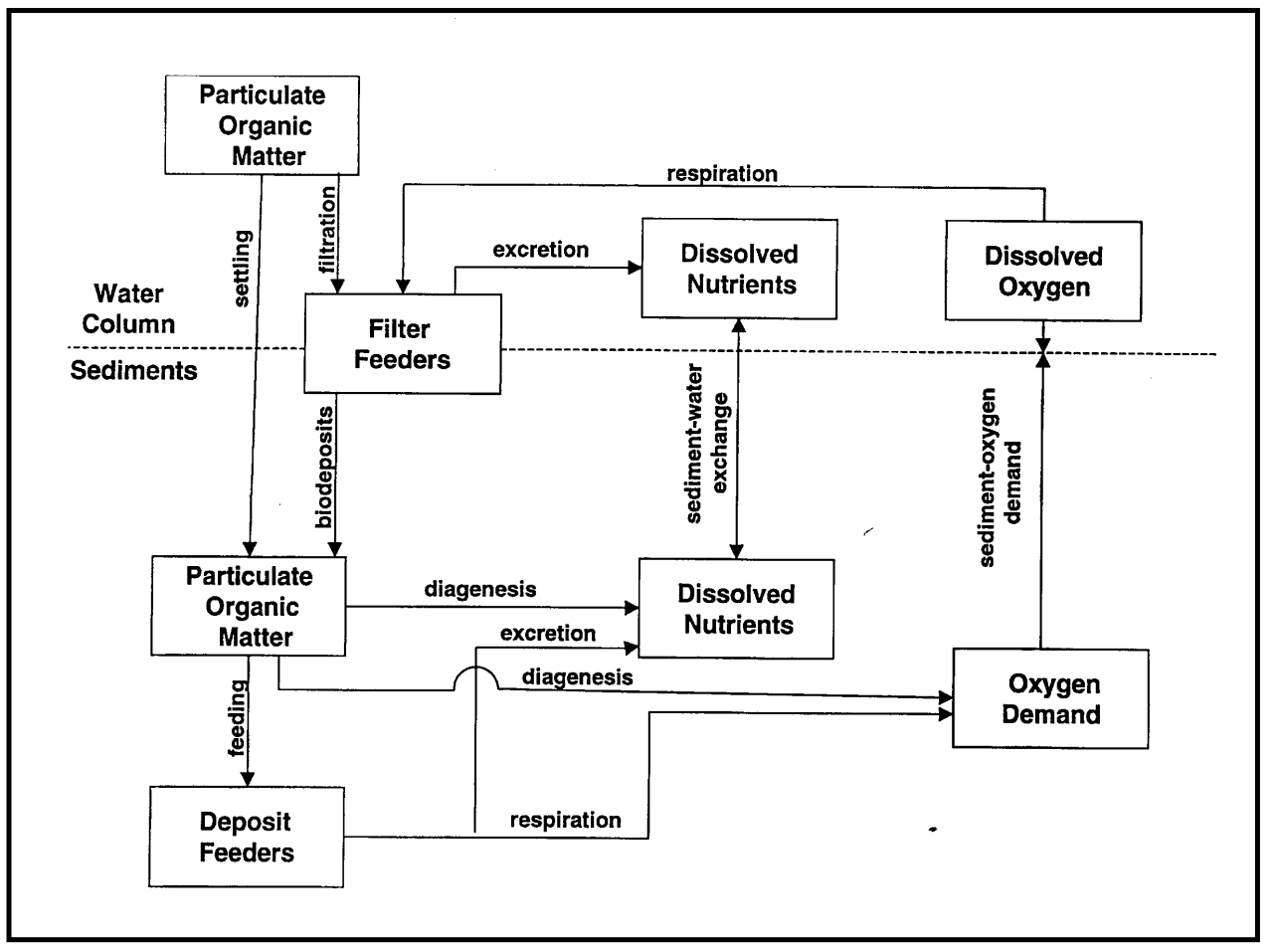

Figure 3. Benthos model schematic

$$
\frac{d F F}{d t}=I f \cdot \alpha \cdot P C \cdot F F-r \cdot F F-\beta \cdot F F^{2}
$$

where

$$
\begin{aligned}
F F & =\text { biomass } \\
I f & =\text { ingestion rate } \\
\alpha & =\text { assimilation efficiency } \\
P C & =\text { particulate carbon in water column } \\
r & =\text { respiration } \\
\beta & =\text { nonrespiratory mortality }
\end{aligned}
$$

Dominant species were differentiated through assignment of parameter values. In addition to temperature and DO, effects of suspended solids were considered in calculating ingestion, respiration, and mortality. Assimilation efficiencies were assigned to each form of particulate organic carbon in the water column. Key parameter values are presented in Table 2 .

\section{Submerged aquatic vegetation}

SAV provides habitat for numerous living resources of economic importance and supports, in part, the estuarine food chain as well. Major portions of the SAV 
beds in Chesapeake Bay disappeared between 1970 and 1975 (Orth and Moore 1984). Restoration of the beds is a priority goal in management of the system.

An SAV submodel, which interacted with the main model of the water column and the sediment diagenesis submodel, was created for the study (Figure 4). The model built upon concepts established by Wetzel and Neckles (1986) and Madden and Kemp (1996). Three state variables were modeled: shoots (aboveground biomass), roots (belowground biomass), and epiphytes (attached growth). For shoots, the governing equation was

$$
\frac{d S H}{d t}=[(1-F p s r) \cdot P-R-S L] \cdot S H+K r p s \cdot R T
$$

where

$$
\begin{aligned}
S H & =\text { shoot biomass } \\
F p s r & =\text { fraction of gross production routed from shoots to roots } \\
P & =\text { gross production } \\
R & =\text { respiration } \\
S L & =\text { sloughing } \\
K r p s & =\text { rate at which root biomass produces shoots } \\
R T & =\text { root biomass }
\end{aligned}
$$

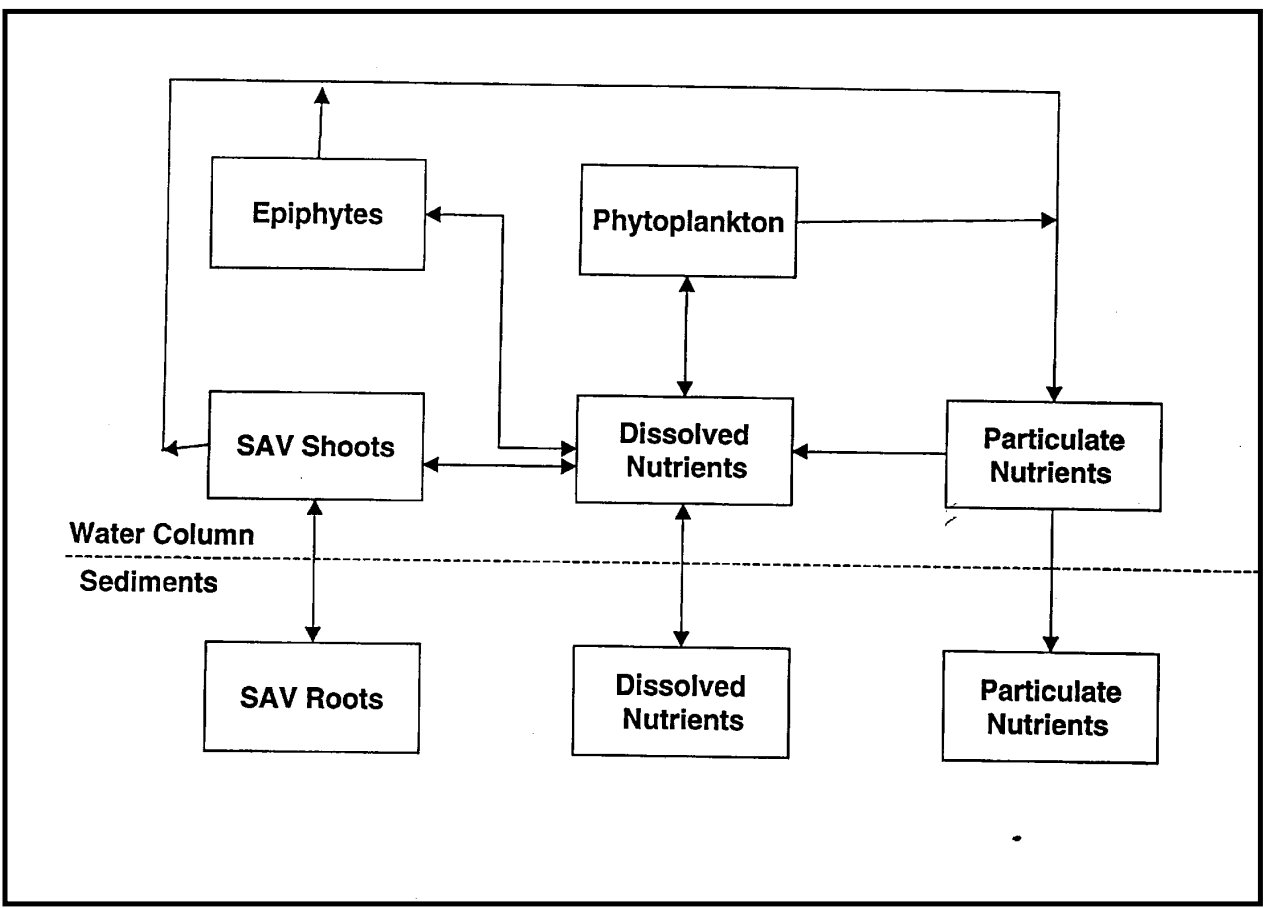

Figure 4. SAV model schematic 
Gross production was computed as a function of light and nutrient availability. The governing equation for roots was similar to the equation for shoots while the epiphyte kinetics were patterned after the phytoplankton relationships.

Three dominant SAV communities were identified in the bay based largely on salinity regimes (Moore, Wilcox, and Orth 2000). Within each community, a target species was selected: Vallisneria americana, Ruppia maritima, or Zostera marina. Each community was modeled using the same equations but with parameter values selected for the target species. Key parameter values are presented in Table 2 .

\section{Suspended Solids and Light Attenuation}

Since SAV production in the bay and tributaries is largely determined by light availability (Orth and Moore 1984; Kemp et al. 1983), a predictive representation of light attenuation was required. Light attenuation was computed:

$$
K e=K e b+a \cdot I S S+b \cdot V S S
$$

where

$$
\begin{aligned}
K e & =\text { light attenuation coefficient } \\
K e b & =\text { background value of light attenuation } \\
a & =\text { effect of fixed solids on light attenuation } \\
I S S & =\text { inorganic (fixed) solids concentration } \\
b & =\text { effect of volatile solids on light attenuation } \\
V S S & =\text { volatile solids concentration }
\end{aligned}
$$

Background light attenuation (color) and coefficients $a$ and $b$ were permitted to vary spatially. Initial parameter values were assigned through linear regression of attenuation versus solids concentrations. Initial values were refined through comparison of computed and observed attenuation. Typical parameter values are presented in Table 2 .

Computation of light attenuation required addition of fixed solids to the list of model state variables. (Volatile solids were obtained as a function of the algae and particulate organic carbon state variables.) Code for computation of fixed solids was incorporated in the original application of CE-QUAL-ICM, but no attempt was made to simulate solids at that time. The sources and sinks in the conservation equation for fixed solids were

$$
\frac{d I S S}{d t}=(W-W r) \cdot \frac{d I S S}{d z}
$$


where

$$
\begin{aligned}
W & =\text { settling velocity } \\
W r & =\text { resuspension velocity } \\
z & =\text { vertical coordinate }
\end{aligned}
$$

Resuspension velocity was assigned a value in cells interfacing with the benthic surface only. A limit was set $W r \leq W$ such that net deposition could be zero but no erosion occurred. Settling and resuspension velocities were assigned to match the observed solids distributions. Typical values are presented in Table 2.

\section{Model Results}

\section{Nutrients at the bay mouth}

In the 1993 study, the model grid was cut off at the bay mouth. The appearance of trends in nutrient observations at the mouth of the bay led to speculation that these trends were the result of load reductions within the bay watershed. If the trends were the result of load reductions, then boundary conditions at the bay mouth could not be held constant during the scenario process. In response to this issue, a mass-balance algorithm was employed that allowed boundary conditions to vary in response to conditions within the bay. In the second phase of the study, the decision was made to extend the grid to a location where boundary conditions were not influenced by conditions within the bay. The grid was extended beyond the region where the plume that extends from the bay mouth can normally be distinguished.

One barrier to extension of the grid was lack of data for specification of boundary conditions. Although monitoring data for dissolved inorganic nutrients were available (Frazier 1992), these components form only a small fraction of the total nutrient pools (Table 3). A full suite of nutrient samples were collected from May 1995 to August 1996 (Figure 5) to supplement the available data. Examination of all available data revealed substantial variability in several substances. Little or no periodicity or spatial trends were discernable, however. Consequently, boundary conditions were held constant over the simulation period with minor variation in the vertical dimension only.

Over 40 percent of the variability in observed total phosphorus at the bay mouth (Figure 6) can be explained by a simple relationship consisting of a longterm trend $\left(-0.00165 \mathrm{gm} \mathrm{P} \mathrm{m}^{-3}\right.$ year $\left.^{-1}, \mathrm{r}^{2}=0.21\right)$ and an annual harmonic (amplitude $=0.0074 \mathrm{gm} \mathrm{P} \mathrm{m}^{-3}, \mathrm{r}^{2}=0.21$ ). The model also illustrates a strong annual cycle (amplitude $=0.0072 \mathrm{gm} \mathrm{P} \mathrm{m}^{-3}, \mathrm{r}^{2}=0.69$ ) but no trend. The trend is largely attributable to the step-function decline that occurred in 1986. Temptation to ascribe the trend to load reduction is nearly irresistible, but major load reductions to nearby waters did not occur until post-1986 (e.g., Figure 9). Since detailed specification of loads is part of the model package, load influences on conditions at the bay mouth should show up in model results, but are lacking. Detailed examination of the observations indicates the trend is primarily in the dissolved 


\begin{tabular}{|c|c|c|c|c|c|}
\hline \multicolumn{6}{|c|}{$\begin{array}{l}\text { Table } 3 \\
\text { Observed Nutrient Concentrations, } \mathrm{gm} \mathrm{m}^{-3} \text { at Outer Edges of Model Grid }\end{array}$} \\
\hline Location & $\begin{array}{l}\text { Mean or } \\
\text { Range }\end{array}$ & Ammonium & Nitrate & $\begin{array}{l}\text { Dissolved Organic } \\
\text { Nitrogen }\end{array}$ & $\begin{array}{l}\text { Particulate } \\
\text { Organic Nitrogen }\end{array}$ \\
\hline \multirow{2}{*}{$\begin{array}{l}\text { Surface Mixed } \\
\text { Layer }\end{array}$} & Mean & 0.021 & 0.010 & 0.241 & 0.070 \\
\hline & Range & 0.001 to 0.134 & 0.001 to 0.123 & 0.041 to 1.04 & 0.021 to 0.182 \\
\hline \multirow[t]{2}{*}{ Subsurface } & Mean & 0.031 & 0.010 & 0.214 & 0.064 \\
\hline & Range & 0.002 to 0.16 & 0.002 to 0.070 & 0.005 to 1.28 & 0.020 to 0.223 \\
\hline Location & $\begin{array}{l}\text { Mean or } \\
\text { Range }\end{array}$ & $\begin{array}{l}\text { Dissolved } \\
\text { Phosphate }\end{array}$ & $\begin{array}{l}\text { Particulate } \\
\text { Inorganic } \\
\text { Phosphorus }\end{array}$ & $\begin{array}{l}\text { Dissolved Organic } \\
\text { Phosphorus }\end{array}$ & $\begin{array}{l}\text { Particulate } \\
\text { Organic } \\
\text { Phosphorus }\end{array}$ \\
\hline \multirow{2}{*}{$\begin{array}{l}\text { Surface Mixed } \\
\text { Layer }\end{array}$} & Mean & 0.011 & 0.005 & 0.015 & 0.004 \\
\hline & Range & 0 to 0.092 & 0.001 to 0.013 & 0.008 to 0.045 & 0 to 0.016 \\
\hline \multirow[t]{2}{*}{ Subsurface } & Mean & 0.014 & 0.005 & 0.011 & 0.004 \\
\hline & Range & 0.001 to 0.038 & 0.001 to 0.013 & 0.004 to 0.032 & 0 to 0.021 \\
\hline
\end{tabular}

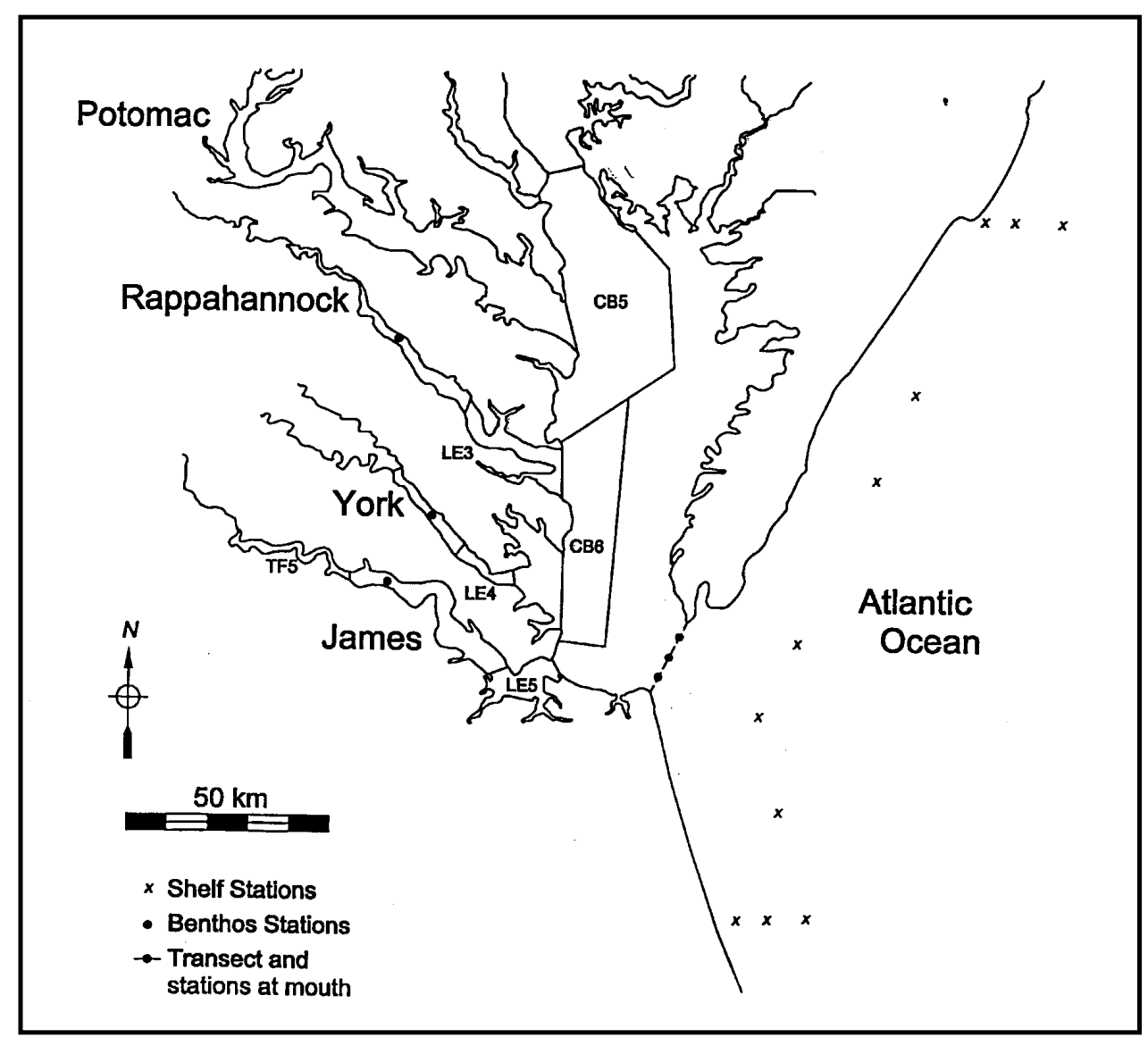

Figure 5. The lower bay and adjacent waters showing location of shelf sampling stations, sampling stations at mouth of bay, benthos stations in central estuaries, and segments for presentations of model and data 


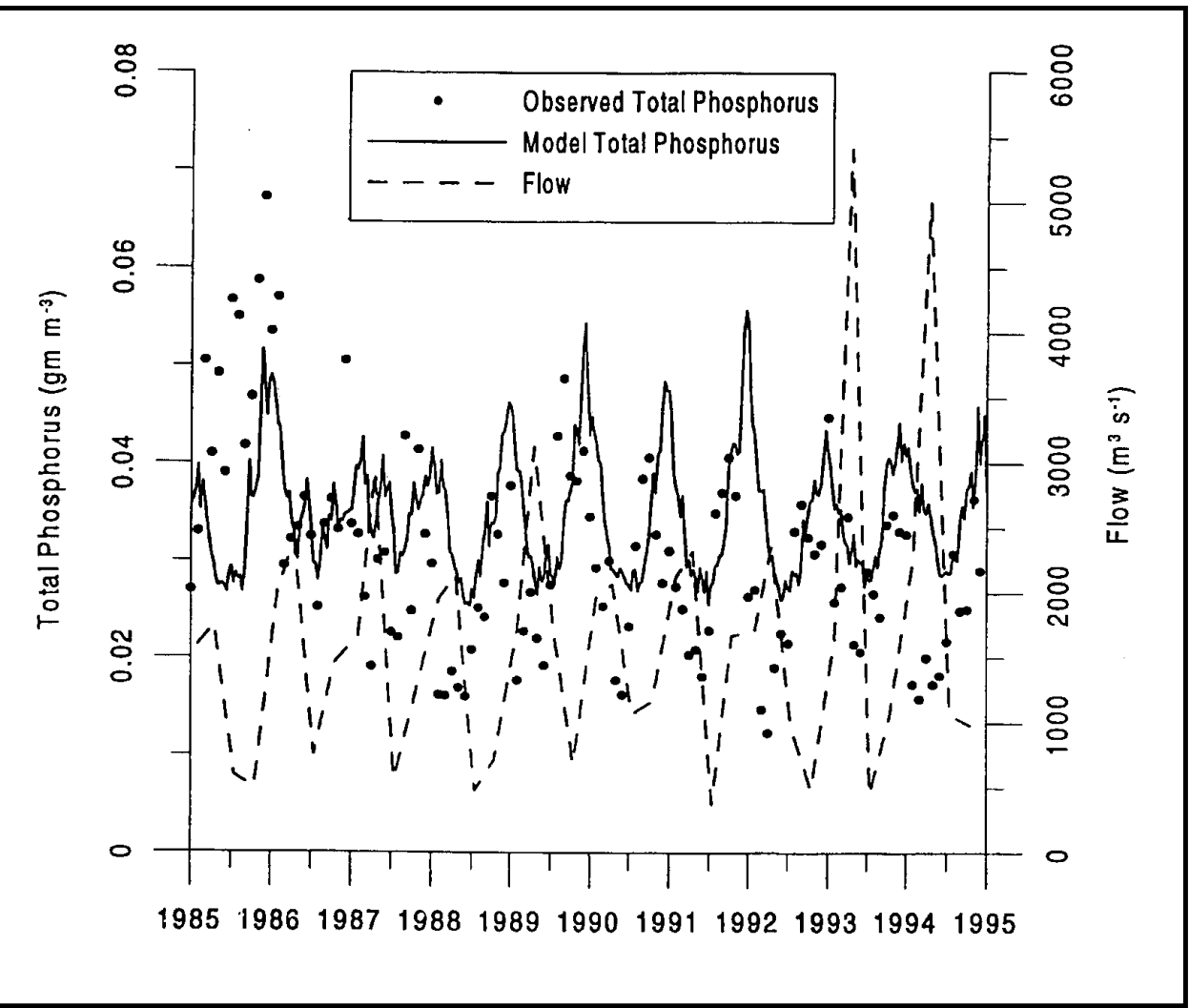

Figure 6. Time series of predicted and observed total phosphorus at bay mouth, and total runoff in Susquehanna, Potomac, and James Rivers. Observations are monthly means of all data collected in the surface mixed layer. Model results are 10-day averages of computations in the surface mixed layer

organic fraction, which is obtained by difference from several directly analyzed fractions. A change in analytical methods is strongly suggested, but examination of records by the bay program indicated no change occurred. Consequently, the trend remains unexplained.

Harmonic analysis of observed and modeled phosphorus and flow in the major tributaries indicates peak phosphorus at the bay mouth precedes peak flows by 2 to 3 months. During high-flow intervals, total phosphorus at the bay mouth is less than at intervals of lower flows. The total phosphorus profile along the main stem bay during winter and spring indicates a phosphorus sag with concentrations in the central bay less than peaks at the mouth and in the turbidity maximum. A conceptual model can be formed in which high flows push the sag downstream leading to lower concentrations at the bay mouth.

Observed total nitrogen at the bay mouth exhibits no significant trend or periodicity (Figure 7). Modeled total nitrogen illustrates a very weak annual harmonic (amplitude $=0.017 \mathrm{gm} \mathrm{N} \mathrm{m}^{-3}, \mathrm{r}^{2}=0.15$ ) and no trend. While mean observed $\left(0.318 \mathrm{gm} \mathrm{N} \mathrm{m}^{-3}\right)$ and modeled $\left(0.355 \mathrm{gm} \mathrm{N} \mathrm{m}^{-3}\right)$ total nitrogen are in reasonable agreement, one-to-one correspondence between observations and model is lacking. Since the model incorporates detailed information on loading 


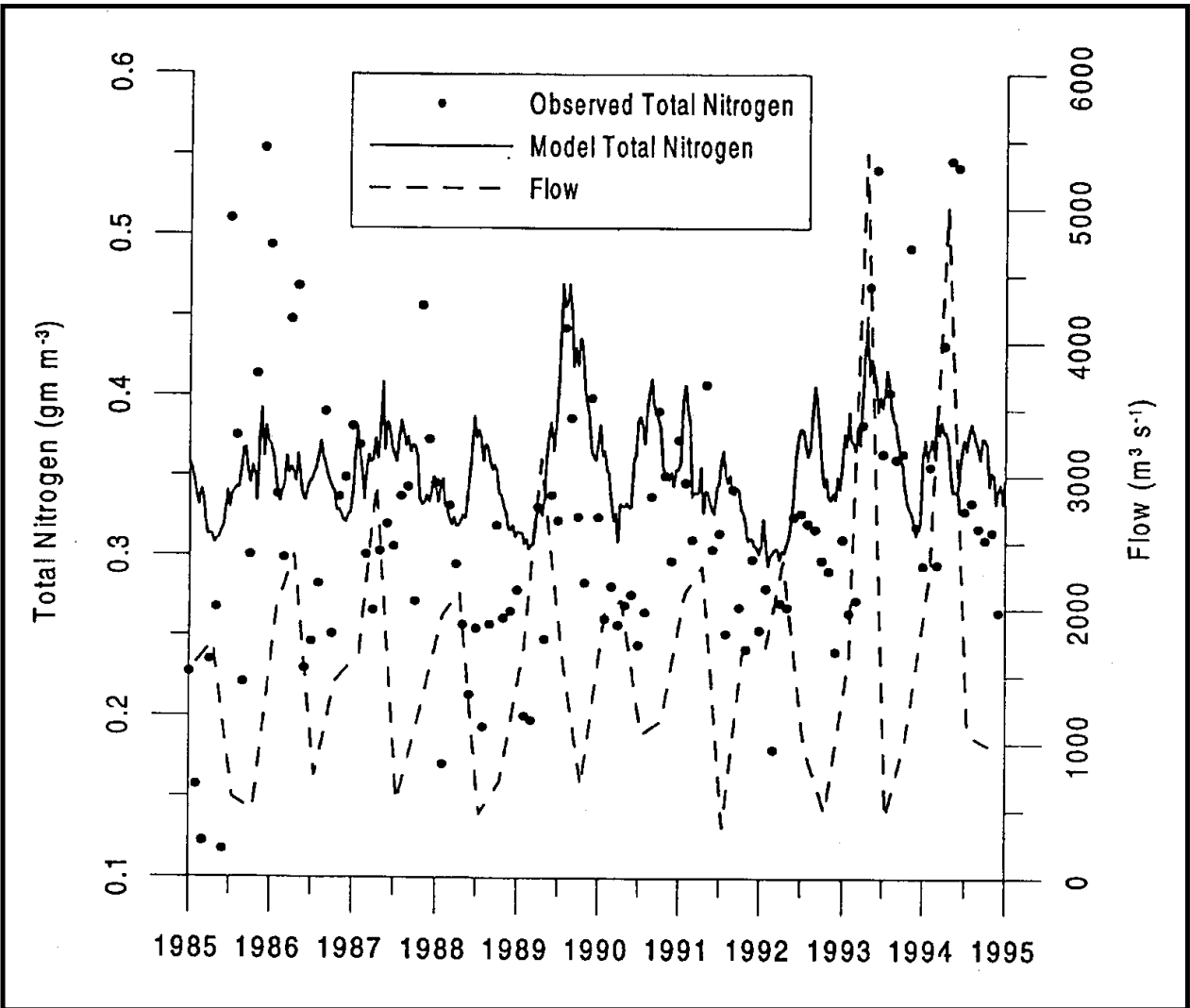

Figure 7. Time series of predicted and observed total nitrogen at bay mouth, total runoff in Susquehanna, Potomac, and James Rivers.

Observations are monthly means of all data collected in the surface mixed layer. Model results are 10-day averages of computations in the surface mixed layer

and runoff, the large variability in the observations appears to be driven by phenomena outside the model domain.

The grid extension allowed computation of mean phosphorus concentration and the annual harmonic at the bay mouth. While mean nitrogen concentration was represented, the variability was not. In the earlier study, the quantity of new nitrogen introduced to the bay from oceanic sources was shown to exceed the potential amount of nitrogen reductions achieved by limit-of-technology controls (Cerco 1995a). Consequently, understanding of the sources and dynamics of shelf nitrogen is crucial to understanding the potential for nutrient reductions to improve the bay. Extension of the grid was a necessary first step. Further extension of the model domain to include coastal sources north of the bay is the logical next extension.

\section{Dissolved oxygen in the lower tributaries}

Minimum DO concentrations in the Virginia tributaries occur during summer in bottom waters near the mouths. In the James, minimum bottom DO is roughly $4 \mathrm{gm} \mathrm{m}^{-3}$ (Figure 8). In the York, minimum bottom DO is roughly $2 \mathrm{gm} \mathrm{m}^{-3}$, while 


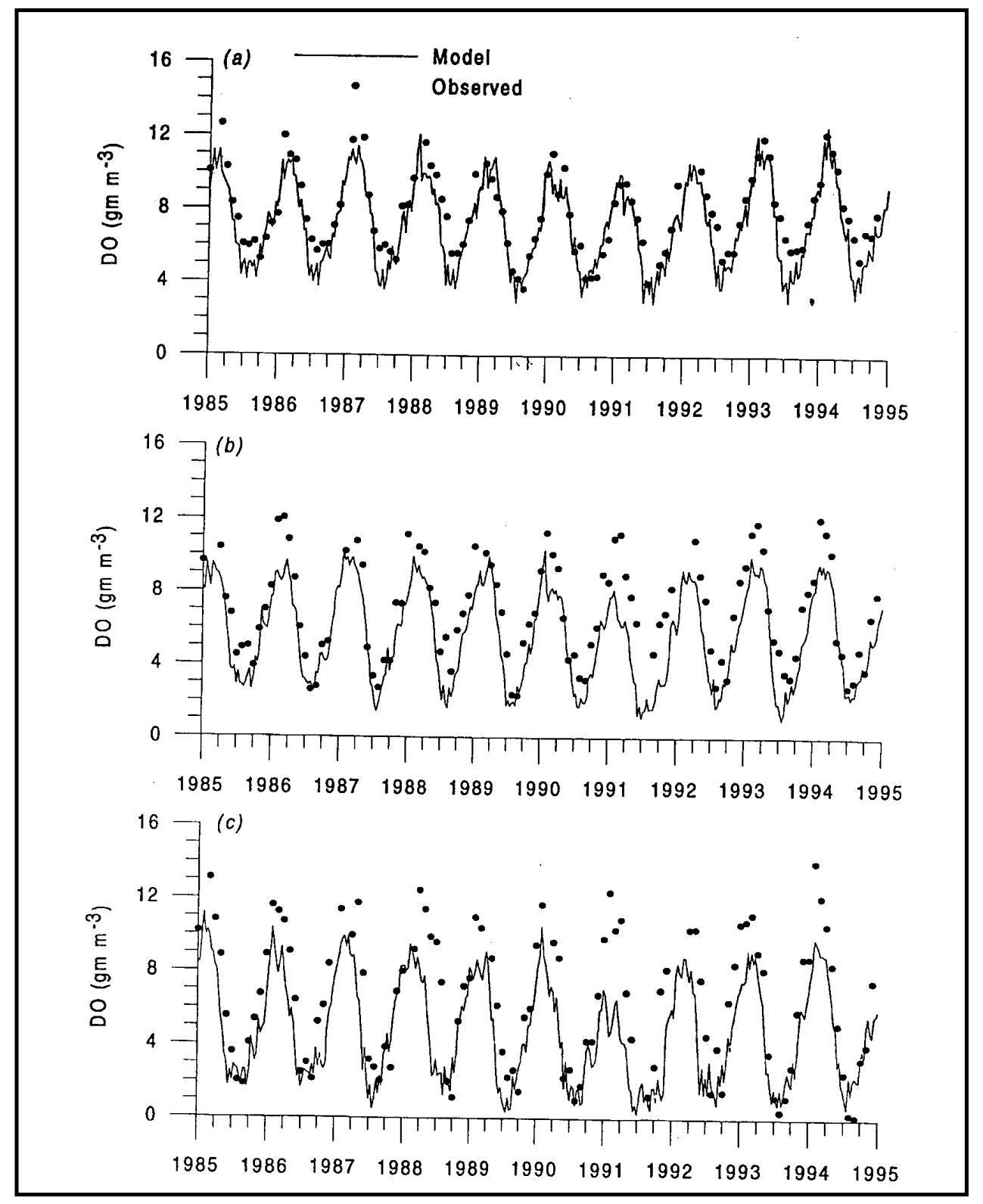

Figure 8. Time series of predicted and observed DO in the (a) lower James estuary; (b) lower York estuary; and (c) lower Rappahannock estuary. Observations are monthly means of all data collected below the pycnocline in segments LE5, LE4, and LE3, respectively. Model results are 10-day averages of computations in the same segments

in the Rappahannock near-zero concentrations occur. The gradient in bottom DO was noted by Kuo and Neilson (1987) and linked to residual circulation in the three tributaries. The river with the strongest residual circulation, the James, had the least anoxia while the river with the weakest circulation, the Rappahannock, had the most anoxia.

The model faithfully reproduces the gradient in bottom DO among the three tributaries (Figure 8). In keeping with Kuo and Neilson, the difference is related 
to residence time in the lower estuaries. Residence time does not directly correspond to circulation, however (Table 4). Although the James has the largest volumetric circulation on average, at times the circulation in the Rappahannock is greatest of all. The Rappahannock also has the greatest sub-pycnocline volume. Consequently, residence time in bottom waters (scaled as sub-pycnocline volume divided by net gravitational circulation) is larger in the Rappahannock than in the other two estuaries. Residence time in the York and James does not differ substantially. The difference in bottom oxygen between these two tributaries may be attributed, in part, to two other factors. The York is deeper than the James (Table 4 ), and exhibits summer surface DO concentration $\approx 1 \mathrm{gm} \mathrm{m}^{-3}$ lower than the James. Consequently, in the York, the vertical diffusion of DO occurs across a greater length scale than the James and the concentration of surface water that exchanges with the bottom is lower than in the James.

\begin{tabular}{|c|c|c|c|}
\hline \multicolumn{4}{|c|}{$\begin{array}{l}\text { Table } 4 \\
\text { Modeled Characteristics of Lower Estuaries }\end{array}$} \\
\hline Characteristic & James & York & Rappahannock \\
\hline Sub-pycnocline volume $\left(10^{6} \mathrm{~m}^{3}\right)$ & 284 & 218 & 528 \\
\hline Mean depth $(\mathrm{m})$ & 4.63 & 5.52 & 6.87 \\
\hline Net bottom velocity upstream $\left(\mathrm{cm} \mathrm{sec}^{-1}\right)$ & 2.4 to 4.9 & 2.8 to 5.2 & 1.7 to 5.2 \\
\hline Upstream circulation at mouth $\left(\mathrm{m}^{3} \mathrm{sec}^{-1}\right)$ & 500 to 521 & 363 to 453 & 387 to 595 \\
\hline Sub-pycnocline residence time scale (day) & 6.3 to 6.6 & 5.6 to 7.0 & 10.3 to 15.8 \\
\hline
\end{tabular}

\section{Phosphorus and chlorophyll in the tidal fresh James River}

The James River receives the largest phosphorus loading of the Virginia tributaries. The larger load is the result of distributed loads in the extensive upstream watershed, point sources within the watershed, and direct point-source loads to the estuary. Commencing in 1988, phosphorus loads to the Virginia tributaries were reduced, largely through a phosphate detergent ban and through point-source controls. In view of the major change in loading, the tidal fresh portion of the James estuary (Figure 5) provides a good example of the ability of the model to simulate long-term trends in water quality and to examine their origin.

Although the ban commenced in 1988, large runoff in 1989 postponed major reductions in phosphorus loads to the tidal fresh James until 1990 (Figure 9). On average, total phosphorus loads to the tidal river in 1990-1994 (3309 $\mathrm{kg} \mathrm{day}^{-1}$ ) were half the load in the years 1985-1989 $\left(6571 \mathrm{~kg} \mathrm{day}^{-1}\right)$. As a result of the load reductions, total phosphorus concentration from June to August, the period of maximum chlorophyll concentration, was reduced 24 percent (Table 5). Concurrent with the phosphorus reduction, summer chlorophyll concentration decreased 20 percent. The model faithfully reproduces the observed trend in phosphorus as well as the decline in chlorophyll (Figure 9). One of the most remarkable properties of the chlorophyll reduction is that it occurred despite the fact that dissolved inorganic phosphorus concentrations (Table 5) remained well above limiting values (model half saturation concentration $0.001 \mathrm{gm} \mathrm{m}^{-3}$ ). In fact, model computations indicate phosphorus was the least limiting of the three factors that 


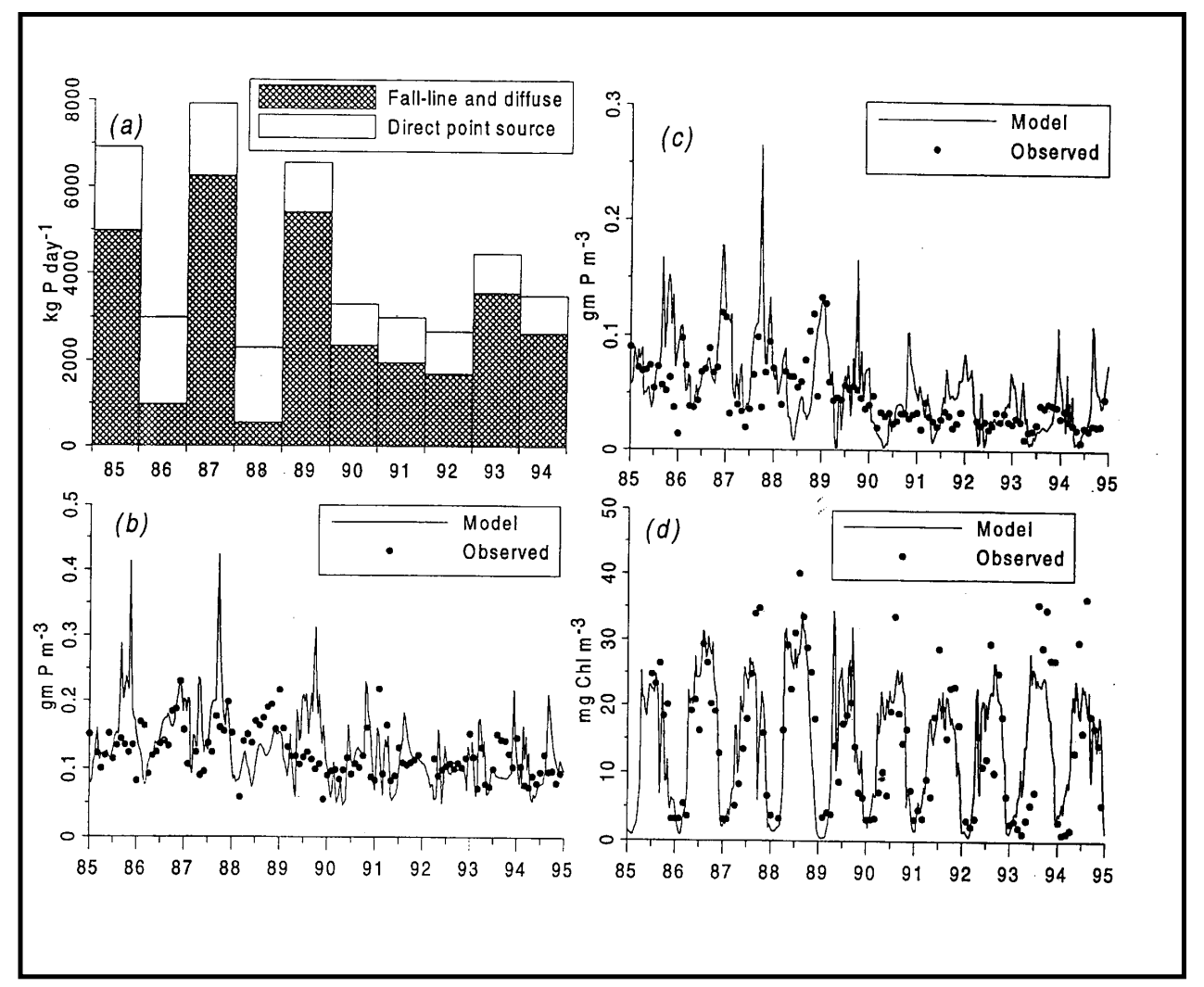

Figure 9. Time series of (a) total phosphorus load; (b) predicted and observed total phosphorus concentration; (c) predicted and observed dissolved inorganic phosphorus concentration; and (d) predicted and observed chlorophyll concentration in the tidal fresh James River. Observations are monthly means of all data collected in segment TF5. Model results are 10-day averages of computations in the same segment

\begin{tabular}{|c|c|c|c|c|}
\hline \multicolumn{5}{|c|}{$\begin{array}{l}\text { Table } 5 \\
\text { Observed and Modeled Characteristics of the Tidal Fresh James } \\
\text { River. All values represent the summer median } \\
\end{array}$} \\
\hline \multirow[b]{2}{*}{ Characteristic } & \multicolumn{2}{|c|}{$1985-1989$} & \multicolumn{2}{|c|}{$1990-1994$} \\
\hline & Observed & Model & Observed & Model \\
\hline Flow $\left(m^{3} \sec ^{-1}\right)$ & 69.7 & 69.7 & 122.2 & 122.2 \\
\hline Residence Time (days) & & 81 & & 46.5 \\
\hline Total Phosphorus $\left(\mathrm{gm} \mathrm{m}^{-3}\right)$ & 0.135 & 0.149 & 0.103 & 0.099 \\
\hline Dissolved Inorganic Phosphorus $\left(\mathrm{gm} \mathrm{m}^{-3}\right.$ ) & 0.059 & 0.056 & 0.024 & 0.022 \\
\hline Chlorophyll $\left(\mathrm{mg} \mathrm{m}^{-3}\right)$ & 23.2 & 24.9 & 18.6 & 21.1 \\
\hline Light Attenuation $\left(\mathrm{m}^{-1}\right)$ & 1.95 & 1.54 & 1.66 & 2.17 \\
\hline Nitrogen Limit $(0 \leq$ limit $\leq 1)$ & & 0.34 & & 0.37 \\
\hline Phosphorus Limit $(0 \leq$ limit $\leq 1)$ & & 0.97 & & 0.93 \\
\hline Light Limit $(0 \leq$ limit $\leq 1)$ & & 0.28 & & 0.25 \\
\hline
\end{tabular}


potentially limit algal growth. The dominant computed growth-limiting factor was light although at times nitrogen was most limiting.

If the computed impact of phosphorus controls is negligible, what is the origin of the chlorophyll reduction? Chlorophyll concentrations that seed the tidal fresh James from above the fall line are an order of magnitude lower than concentrations observed in the upper estuary. The concentrations that occur are the result of production within the estuary. Production requires favorable growth conditions and time for growth to occur. While computed growth limiting factors in the periods considered do not greatly differ, the residence time is much less in the later period, due to increased runoff (Table 5). While residence time in tidal waters is difficult to compute exactly, a simple scaling (volume/flow) indicates residence time in the tidal fresh James was diminished by 33 days ( 42 percent) in the 1990-1994 period compared with the 1985-1989 period. Diminished residence time and, consequently, diminished opportunity for growth are the dominant computed factors behind the modeled decline in chlorophyll.

\section{Zooplankton in the Central Bay}

Microzooplankton observations in the main stem bay (Figure 5) are "white noise" (Figure 10). Application of fundamental time-series analyses indicates no long-term trend or periodicity. Absence of regular patterns is not surprising since the microzooplankton community is a mixture of adult microzooplankton as well as juvenile forms of other invertebrates and vertebrates. For the model, growth, respiration, and other parameters (Table 2) were based on reported values and allometric relationships for adult rotifers. Computed microzooplankton (Figure 10) exhibit two annual "boom-bust" cycles. The first boom occurs near the beginning of every calendar year. The second occurs in late summer. The latesummer peak is the result of temperature-driven growth. The subsequent crash is caused by temperature-driven feeding of mesozooplankton on microzooplankton. As a result of mesozooplankton feeding, microzooplankton biomass is least at the time when specific growth rate is greatest.

Since the observations have no structure, visual comparison of the model and data provides limited insight. One alternative is a statistical comparison (Figure 10). Model and data were transformed and plotted against the standard normal deviate, Z (Thomann 1995). The resulting "probability plot" compares computations and observations with each other and with a standard normal distribution. The median of the plotted quantity occurs at $Z=0$, and 90 percent of the values occur in the interval $-1.65<\mathrm{Z}<1.65$. Quantities that are normally distributed plot as straight lines. The comparison indicates that the median computed biomass, $0.025 \mathrm{gm} \mathrm{C} \mathrm{m}^{-3}$, exceeds the median observed biomass, $0.15 \mathrm{gm} \mathrm{C} \mathrm{m}^{-3}$. The lower halves of the computed and observed distributions agree reasonably well, but in the upper half, computed values are well in excess of observations.

The mesozooplankton population in the main stem bay is characterized by a spring bloom and a secondary summer biomass maximum. The spring bloom is dominated by coldwater species Eurytemora affinis and Acartia hudsonica while the summer population is largely Acartia tonsa (Brownlee and Jacobs 1987). For 


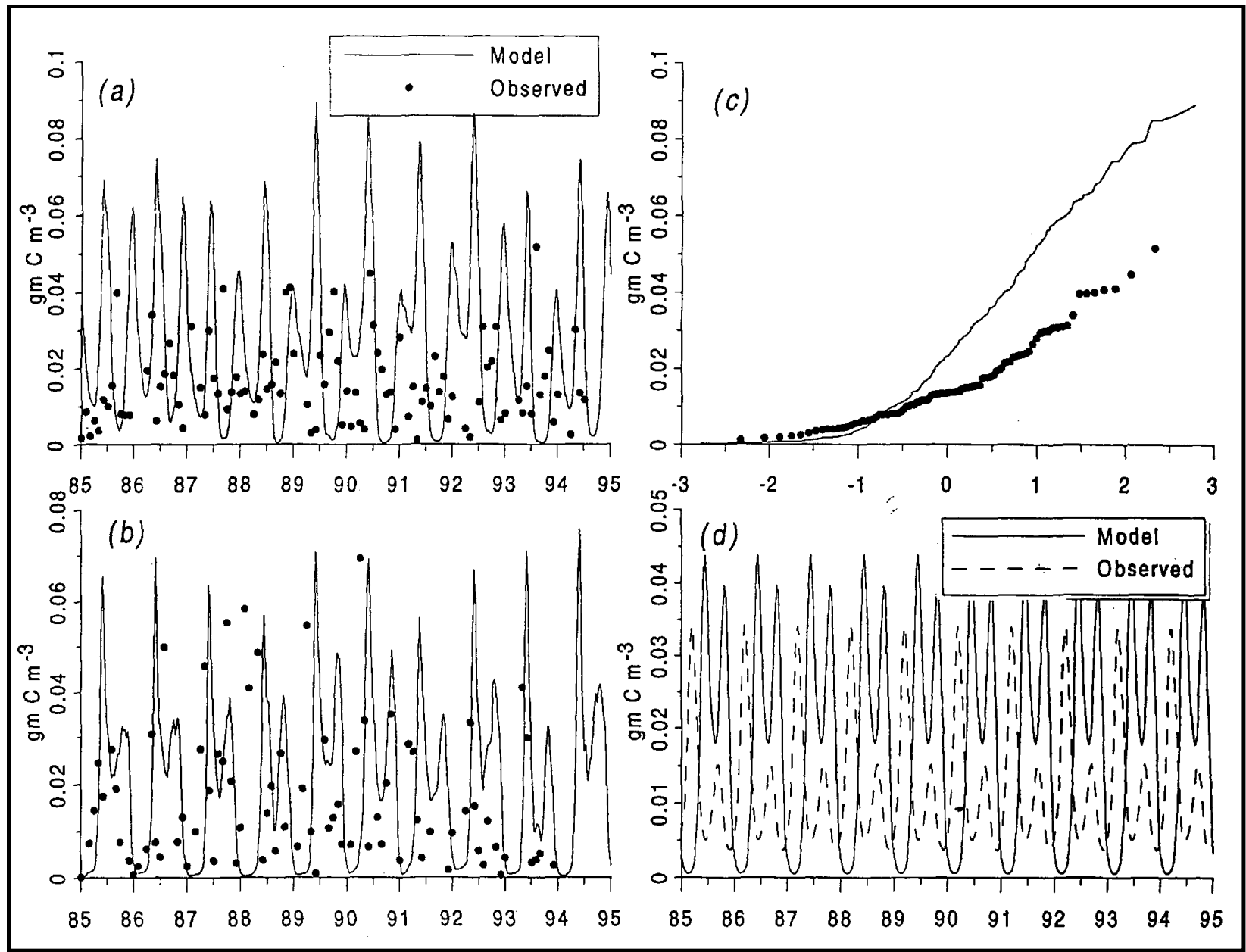

Figure 10. Time series of (a) predicted and observed microzooplankton biomass; (b) time series of predicted and observed mesozooplankton biomass; (c) probability distribution of microzooplankton biomass; and (d) harmonic analysis of mesozooplankton in segment CB5. Microzooplankton are from above the pycnocline; mesozooplankton are depth-averaged values

the model, growth, respiration, and other parameters (Table 2) were based on reported values and allometric relationships for $A$. tonsa. As with microzooplankton, visual evaluation of computed and observed time series is inconclusive. Also as with microzooplankton, statistical analysis is possible. Since the observations have a deterministic component, one approach is to compare the underlying time series behind the observations and computations. Linear regression was employed to evaluate the coefficients in the following relationship applied to model and data:

$$
\log (M Z)=A+B \cdot \sin (2 \pi \cdot t+\theta)+C \cdot \sin (4 \pi \cdot t+\phi)
$$

where

$$
M Z=\text { mesozooplankton }
$$




$$
\begin{aligned}
A & =\text { mean of log-transformed concentration } \\
B & =\text { amplitude of annual harmonic } \\
t & =\text { time in decimal years } \\
\theta \text { and } \phi & =\text { phase lags } \\
C & =\text { amplitude of semiannual harmonic }
\end{aligned}
$$

The relationship accounted for 37 percent of the variance in the transformed observations and 91 percent of the variance in the transformed computations, indicating the observations have a great deal of random variability while the model is largely deterministic. Log means of the modeled and observed populations are nearly identical: $0.010 \mathrm{gm} \mathrm{C} \mathrm{m}^{-3}$ (observed) versus $0.0095 \mathrm{gm} \mathrm{C} \mathrm{m}^{-3}$ (model). Examination of the time series clearly shows the spring bloom and the secondary summer population peak that underlie the observations (Figure 10). The model also shows two population peaks each year, the greatest of which lags the observed spring bloom. Examination of the processes which underlie the model indicates the annual harmonic is largely created by the temperature-driven growth function. The mid-year population dip is the result of mortality induced by hypoxia which prevails below the pycnocline in summer.

\section{Suspended solids distributions}

The Virginia tributaries receive the major portion of their solids loads at the fall line and lesser loads from bank erosion and runoff below the fall line. Despite the predominance of loading at the upstream end, peak solids concentrations, averaged over the long term, occur further downstream, at the head of the salinity intrusion. The midestuary peak is the classic turbidity maximum caused by the trapping of solids in the region where net upstream flow in the lower estuary meets net downstream flow in the tidal fresh river.

Simulation of the solids distribution is critical to the simulation of living resources, largely because solids attenuate light, thereby diminishing or eliminating SAV. At extremely high concentrations, solids also smother the filtration apparatus of filter-feeding zooplankton and benthos. For the SAV, the solids distributions in surface waters during spring and summer are most critical since these are the prime growing seasons. Model performance is excellent in capturing both the magnitude and location of the turbidity maximum in all three tributaries (Figure 11). The key to capturing the maximum lies in assignment of dual settling and resuspension velocities (Table 2). During storm events, velocities are specified so that large particles, advected over the fall line during flood flows, rapidly settle out. During dry conditions, velocity specification permits negligible net settling to the sediments, simulating the nearly conservative behavior of the fine particles that predominate in the water column during these periods. 


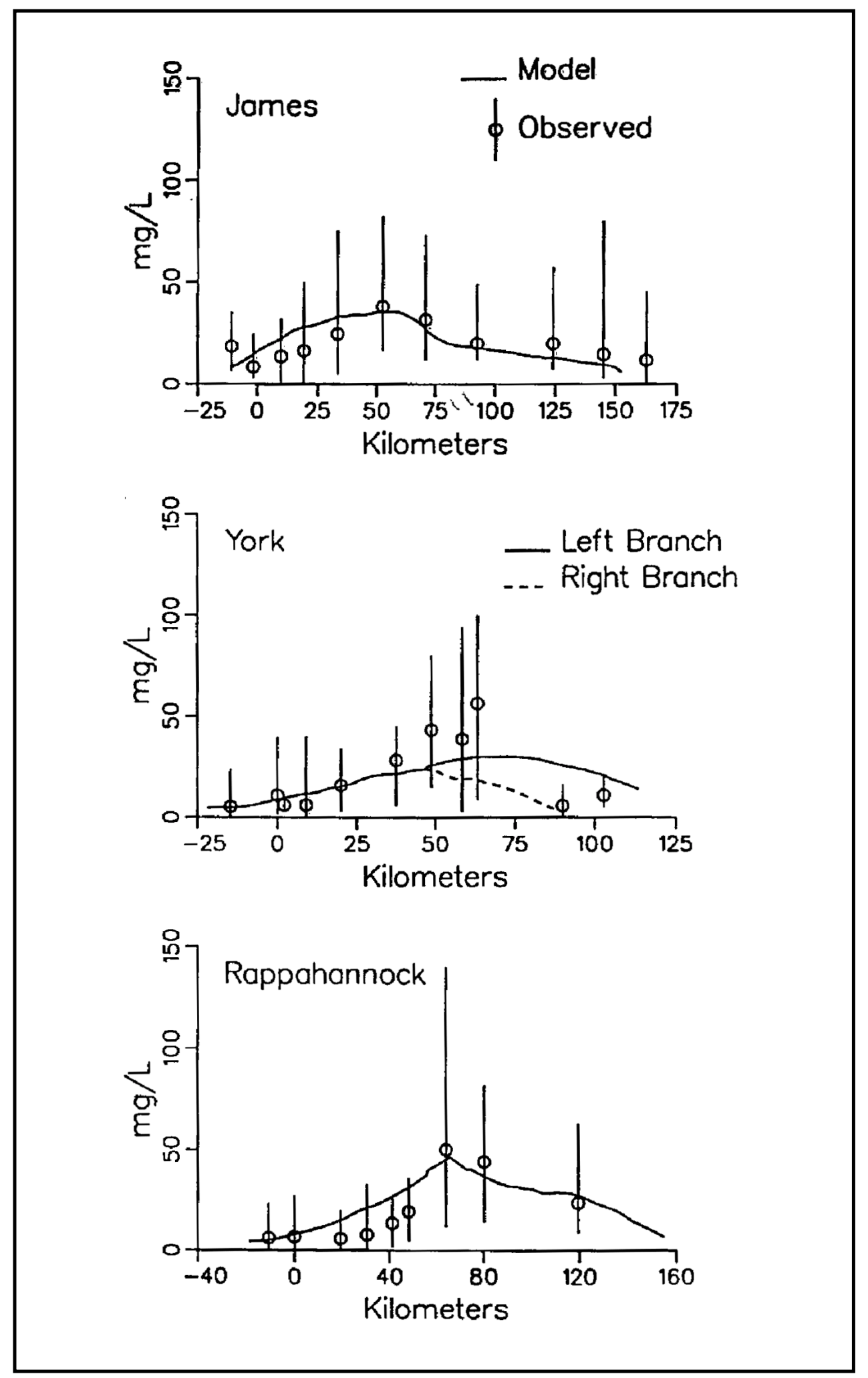

Figure 11. Long-term mean longitudinal distribution of suspended solids, March May 1985-1994, in the James, York, and Rappahannock estuaries.

Observed median and range are compared to model median 


\section{Submerged aquatic vegetation in the lower bay}

SAV in Chesapeake Bay declined precipitously in the 1970's (Orth and Moore 1984). An increase in light attenuation in the water column and by attached epiphytes is largely blamed for the decline (Orth and Moore 1984; Kemp et al. 1983). Present efforts to restore SAV hinge on reducing light attenuation through nutrient controls. Control of nutrients will reduce planktonic and attached algae, leading to diminished light attenuation and enhanced SAV density and distribution. Consequently, a successful SAV model requires successful computation of light attenuation. Computation of attenuation requires, in turn, successful computation of the quantities that compose attenuation (Equation 6) and correct evaluation of the parameters that relate the quantities to attenuation (Table 2).

The model well represents both the quantities that compose attenuation (e.g., Figure 11) and attenuation itself (Figure 12). In the region illustrated (Figure 5), computed attenuation is related to runoff. Spring runoff was low in the years 1985, 1990, and 1991 (Figure 6, right axis) resulting in lower attenuation during the SAV growing season (April-September). The years 1993 and 1994 had the greatest spring runoff and the highest attenuation. The relationship of attenuation to runoff is due to both direct loading of solids and stimulation of plankton due to runoff-associated nutrient loads.

Both observed and computed SAV are related to computed attenuation although the observations, especially, exhibit "inertia" in response. Both model and observations exhibit an arc in SAV biomass from 1989 to 1994. The increasing portion of the arc corresponds to diminished light attenuation from 1989 to 1991. Despite an increase in attenuation from 1991 to 1992, both model and observations demonstrate a slight increase in SAV biomass. Continued increase in attenuation through 1993 and 1994 produces a precipitous decline in computed SAV and a more gradual decline in observed biomass.

Epiphytes are not regularly monitored in the bay system. Comparison of the assembled data with model results confirms, however, that the model produces computations within the range of observed densities. Computed epiphyte density exhibits an annual cycle. Maximum densities typically occur in spring, concurrent with runoff-induced nutrient loads. Density diminishes in summer, as nutrients become scarce, and reaches an annual minimum concurrent with winter temperature minima. Year-to-year variation is linked to hydrology with lower densities occurring in dry years (e.g., 1991, 1992) with low runoff-borne nutrient loads.

\section{Benthos in the river-estuarine transition regions}

Monitoring of benthos in the Virginia portion of the system takes place at 26 fixed stations on a quarterly basis. Triplicate $0.18-\mathrm{m}^{2}$ box-core samples are collected and analyzed for species composition and abundance, size, and biomass. The sampling strategy and the nature of benthos distribution have a profound effect on the ability to quantify biomass and on model-data comparisons. The benthos distribution is patchy and the biomass captured in the grab is not necessarily representative of the biomass averaged over a larger portion of the bottom. 


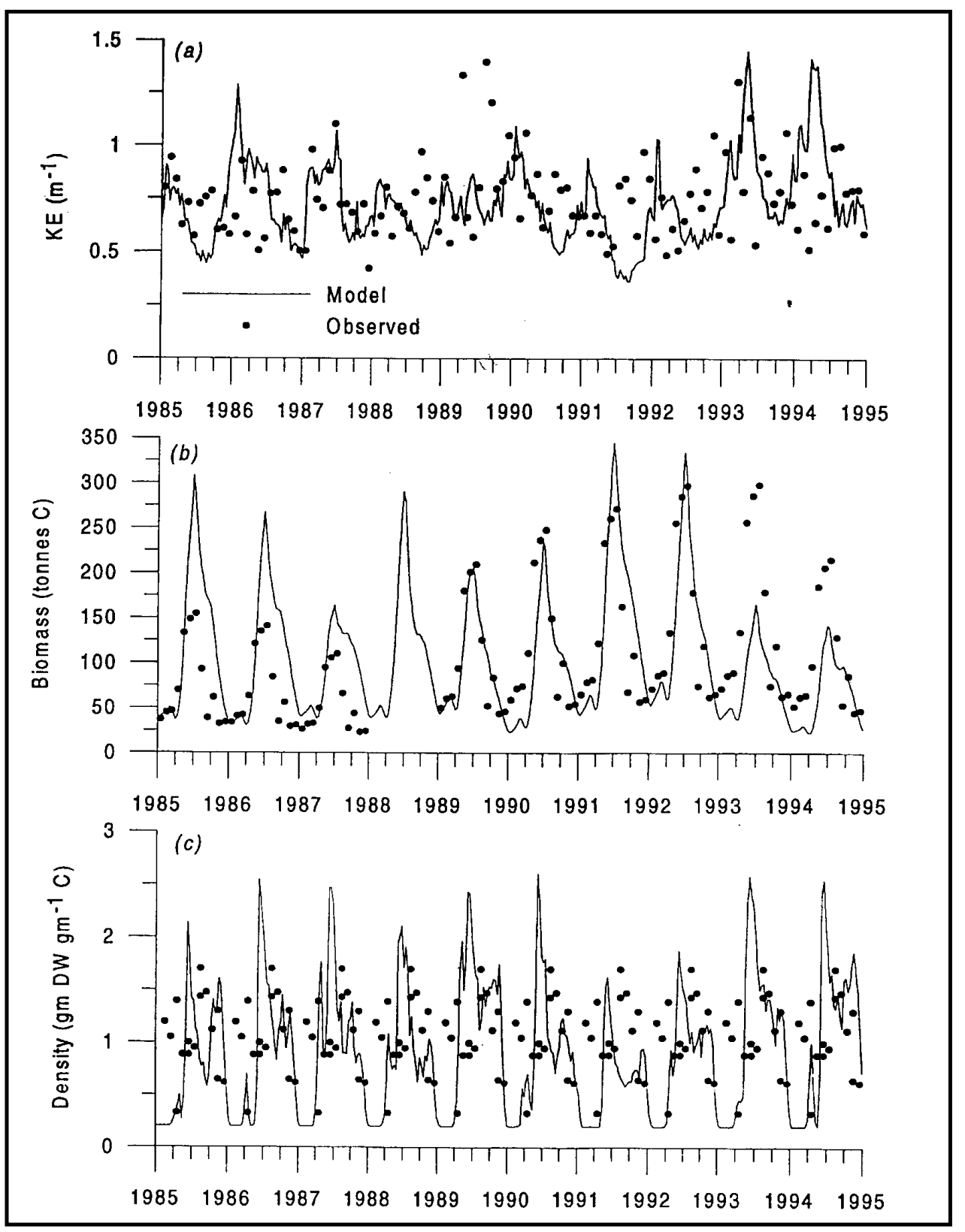

Figure 12. Time series of predicted and observed (a) light attenuation; (b) SAV biomass; and (c) epiphyte density in segment CB6. Observed light attenuation is monthly mean of all data collected in segment CB6. Observed SAV biomass is monthly sum of all SAV in segment CB6. Observed epiphyte density is an assembly of data from CB6 and adjacent waters. Model results are 10-day averages or sums of computations in the same segment

Consequently, biomass observations typically range over two orders of magnitude (Figure 13). In some instances, the grab captures no benthos at all. Interpretation of the observations for trends and annual cycles is almost impossible. At present, the best that can be expected of the model is order-of-magnitude agreement with the data since the data indicate only order of magnitude of the existing benthos. 


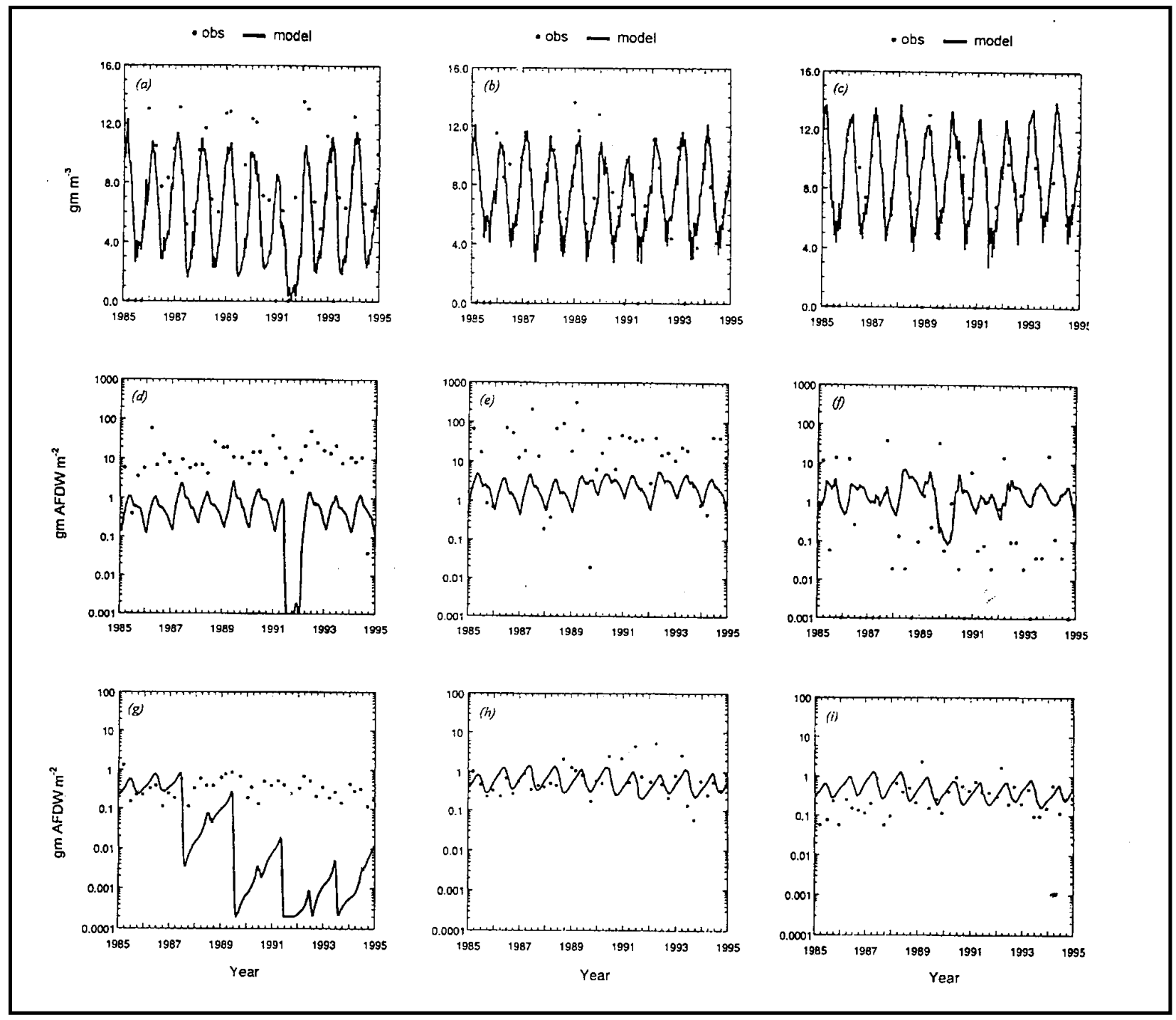

Figure 13. Time series of predicted and observed bottom DO in the central (a) Rappahannock, (b) York, and (c) James estuaries; predicted and observed filter-feeding biomass, ashfree dry weight (AFDW) in the central (d) Rappahannock, (e) York, and (f) James estuaries; and predicted and observed deposit-feeding biomass, AFDW, in the central (g) Rappahannock, (h) York, and (i) James estuaries. All observations are grab samples from a single location. Model results are 10 -day averages from the model cell containing the sample site

Within the constraints of the data, the model successfully represents benthic biomass in many portions of the system. In the central York and James Rivers (Figure 5), for example, both deposit feeders and filter feeders are within the range of the observations (Figure 13). In a similar stretch of the Rappahannock, however, deposit feeders are one to two orders of magnitude low while filter feeders, initialized at an appropriate value, decline precipitously through most of the simulation (Figure 13). The problems with benthos in this reach are caused by underprediction of dissolved oxygen in this model segment. Although anoxia occurs in this segment, the majority of DO observations are above $4 \mathrm{gm} \mathrm{m}^{-3}$. In contrast, computed DO commonly is $2 \mathrm{gm} \mathrm{m}^{-3}$ or less in summer. The low computed DO produces mortality in both the deposit- and filter-feeding 
organisms. The benthos computation can be no better than the DO computation in the identical model cell.

\section{Discussion}

\section{The eutrophication component}

The eutrophication component of the model is largely adapted from the previous application (Cerco and Cole 1993). The previous application was to a three year period: 1984-1986. Longer periods were simulated by substituting hydrodynamics from one of the three years for a year with similar hydrology in the longer period (Cerco 1995b). In the present study, an actual 10-year sequence of hydrodynamics was employed. Over the decade, the model was able to simulate observed trends (e.g., Figure 9) and provided information required to diagnose the trends. The model was able to reproduce observed properties of the bay (e.g., the differing DO concentration in the Virginia tributaries) and to relate these to underlying physics. Although improvements are always possible, a fair conclusion is that the present kinetics provide an accurate and comprehensive representation of eutrophication processes in the bay and major tributaries.

\section{The ocean boundary}

Nitrogen fluxes at the bay mouth are enormous relative to loading to the bay and especially compared to the controllable fraction of the loads (Cerco 1995a). As more and more of the local loads to the bay are reduced, increased attention is being focused on distant sources such as atmospheric loads and loads to the shelf from other estuaries including the Delaware and Hudson. The present model provided an initial attempt to move the model out to the continental shelf and to simulate interactions between the bay and the shelf. The study demonstrated that mean total nitrogen and phosphorus at the bay mouth can be computed when constant concentrations of these substances are specified 30 to $75 \mathrm{~km}$ away from the bay mouth. A large portion of the phosphorus dynamic at the bay mouth can also be captured, apparently because total phosphorus at the mouth is influenced to a large extent by runoff to the bay. Little of the nitrogen dynamic is captured, however, indicating nitrogen at the bay mouth is strongly influenced by the environment outside the bay. One solution to the problem of accurately specifying boundary conditions is to improve monitoring on the shelf. In view of the cost and logistics, extensive monitoring beyond that already conducted is unlikely. An alternative is a model of the shelf that incorporates loads from the land mass and deep ocean. A feasibility study of such a model is a planned extension of the bay model package.

\section{Living resources}

A major accomplishment of the present study is advancement of the computation from eutrophication to direct calculation of living resources. The study demonstrates that, with the environmental model and its associated watershed and 
hydrodynamic models, it is possible to route nutrients from their origin in the watershed down to the estuary, to transport nutrients throughout the estuary, to cycle nutrients within the water column and sediments, and to compute abundances of zooplankton, SAV, and benthos that agree with data aggregated over annual time scales and at spatial scales on the order of $100 \mathrm{~km}^{2}$.

At smaller spatial scales, correspondence between model and observations is difficult to observe. At smaller time scales the model is more or less successful. For SAV, the annual cycle is strongly related to temperature, and the intra-annual distribution of SAV is well represented. For zooplankton and benthos, the modeled concentrations are related to temperature, but corresponding relationships are not evident in the data.

The nature of the living-resource observations partly confounds detailed comparison of computations and observations. The observations are frequently sparse and highly variable. Spatial and temporal detail cannot be modeled if it cannot be detected. Novel ways of looking at living-resource data and of making comparisons with computations must be developed. For substances with a long modeling history, conventional means of presentation exist and practitioners can judge from experience the quality of the model calibration. Moreover, efforts at quantification of model performance have been presented (e.g., Thomann 1982). Conventional presentations are not always suited for living resource comparisons. Examples of two alternative presentations, probability plots and harmonic analysis, were presented here. Additional formats are possible. Through exploration of various formats, practitioners will gain experience in judging the quality of living resource model results. Quantitative measures of performance will eventually be developed also.

No matter how detailed the model grid, phenomena always exist at scales smaller than the model represents. Sub-grid scale distribution of living resources will have to be represented in future models of living resources. The behavior of a living resource distributed in patches is not necessarily the same as behavior of an equivalent biomass uniformly distributed over a model cell. With SAV, for example, the influence of self-shading within a dense patch is greater than in a uniformly distributed less dense assemblage. Initial steps to account for patchiness were completed for the SAV model. For the benthos model, representation of patchiness is a logical next step.

Successful modeling of living resources has two requirements. First, the model of the resource itself must be correctly formulated and parameterized. Second, the environmental factors affecting the living resources must be correctly represented. In this case, the requirement for correct representation of the environment means accurate predictions from the other models in the package. This requirement can be more challenging than creation of the living resource models themselves. With SAV, the loads of nutrients and solids must be correct. These loads must be transported to the vicinity of the SAV bed. The nutrients must be incorporated into organic matter, and the attenuation coefficients of both organic and inorganic solids must be correctly evaluated. The same requirements for nutrient loading, transport, and incorporation hold for benthos. In addition, the temporal and spatial distributions of DO and temperature above the bottom must 
be correctly represented. If the DO computations are faulty, benthos computations will be faulty as well, no matter how well the benthos component of the model itself operates. As a consequence of the demands made by living resource modeling, ever more accurate watershed, hydrodynamic, and eutrophication models must be developed concurrently with new living-resource models.

\section{References}

Brownlee, D., and Jacobs, F. (1987). "Mesozooplankton and microzooplankton in the Chesapeake Bay." Contaminant Problems and Management of Living Chesapeake Bay Resources, S. Majumdar, L. Hall, and H. Austin, ed., The Pennsylvania Academy of Science, Philadelphia, 218-269.

Cerco, C. (1995a). "Response of Chesapeake Bay to nutrient load reductions," Journal of Environmental Engineering 121, 549-557. . (1995b). "Simulation of long-term trends in Chesapeake Bay eutrophication," Journal of Environmental Engineering 121, 298-310.

Cerco, C., and Cole, T. (1993). "Three dimensional eutrophication model of Chesapeake Bay," Journal of Environmental Engineering 119, 1006-1025.

Cohen, R., Dresler, P., Phillips, E., and Cory, R. (1984). "The effect of the Asiatic clam, Corbicula Fluminea, on phytoplankton of the Potomac River, Maryland," Limnology and Oceanography 29, 170-180.

DiToro, D., and Fitzpatrick, J. (1993). "Chesapeake Bay sediment flux model," Contract Report EL-93-2, U.S. Army Engineer Waterways Experiment Station, Vicksburg, MS.

Frazier, T. (1992). "Mid-Atlantic near coastal eutrophication study: Nutrient and chlorophyll fluxes from the Delaware and Chesapeake Bays," U.S. Environmental Protection Agency, Environmental Services Division, Marine and Estuaries Section, Region III, Philadelphia, PA.

Kemp, W., Twilley, R., Stevenson, J., Boynton, W., and Means, J. (1983). “The decline of submerged vascular plants in upper Chesapeake Bay: Summary of results concerning possible causes," Marine Technology Society Journal 17(2), 78-89.

Kuo, A., and Neilson, B. (1987). "Hypoxia and salinity in Virginia estuaries," Estuaries 10(4), 277-283.

Madden, C., and Kemp, W. (1996). "Ecosystem model of an estuarine submersed plant community: Calibration and simulation of eutrophication responses," Estuaries 19(2B), 457-474.

Miller, C., Penry, D., and Glibert, P. (1995). "The impact of trophic interactions on rates of nitrogen regeneration and grazing in Chesapeake Bay," Limnology and Oceanography 40(5), 1005-1011.

Moore, K., Wilcox, D., Orth, R. (2000). "Analysis of the abundance of submerged aquatic vegetation communities in the Chesapeake Bay," Estuaries 23, 115127. 
Newell, R. (1988). "Ecological changes in Chesapeake Bay: Are they the results of overharvesting the American oyster (Crassostrea Virginica)?"

Understanding the estuary: Advances in Chesapeake Bay research. M. Lynch and E. Krome, ed., Chesapeake Bay Research Consortium Publication 129, Gloucester Point, VA, 536-546.

Orth, R., and Moore, K. (1984). "Distribution and abundance of submerged aquatic vegetation in Chesapeake Bay: An historical perspective," Estuaries (4B), 531-540.

Thomann, R. (1995). "Some considerations in the statistical analysis of chemicals in surface waters and aquatic ecosystems." Modeling of transport, fate, and bioaccumulation of toxic substances in surface waters, Manhattan College, Environmental Engineering Department, Riverdale, NY, 14-1-14-25.

. (1982). "Verification of water quality models," Journal of Environmental Engineering Division 108(EE5), 923-940.

Wetzel, R., and Neckles, H. (1986). "A model of zostera marina L. photosynthesis and growth: Simulated effects of selected physical-chemical variables and biological interactions," Aquatic Botany 26, 307-323.

White, J., and Roman, M. (1992). "Egg production by the calanoid copepod Acartia tonsa in the mesohaline Chesapeake Bay: The importance of food resources and temperature," Marine Ecology Progress Series 86, 239-249. 


\section{Phytoplankton Kinetics in the Chesapeake Bay Eutrophication Model}

\section{Introduction}

Modern eutrophication modeling of Chesapeake Bay commenced in 1987. In that year, an effort was completed that applied three-dimensional hydrodynamic and eutrophication models to data collected in 1965, 1984, and 1985 (HydroQual 1987). Summer-average, steady-state conditions were modeled independently in each year. The model provided credible representations of historic and contemporary conditions in the bay and tributaries. Despite the success of the modeling effort, limitations were apparent. The chief limitation was absence of a predictive model of sediment-water interactions. A second limitation was the steady-state nature of the analysis. The steady-state model allowed no influence of conditions in previous years or seasons on summer-average water quality.

A succeeding model effort combined an intertidal, three-dimensional hydrodynamic model (Johnson et al. 1993), a three-dimensional eutrophication model (Cerco and Cole 1993), and a predictive sediment diagenesis model (DiToro and Fitzpatrick 1993). The model package was applied in one continuous simulation to the period 1984-1986 and proved successful in simulating transport, eutrophication processes, and sediment-water interactions. Subsequently, the model package was employed in management scenarios (Cerco 1995a) and in analysis of long-term trends in eutrophication (Cerco 1995b).

Most recently, refinements were added to the 1993 model package including increased grid resolution within the major western-shore tributaries, extension of the grid beyond the mouth of the bay onto the continental shelf, direct simulation of living resources (zooplankton, submerged aquatic vegetation, and benthos), and extension of the validation period to include contemporary data (Cerco and Meyers 2000). The refinements also encompassed revisions to the eutrophication kinetics. The first objective of this chapter is to document the revised phytoplankton kinetics.

A review revealed the most recent model substantially underpredicted primary production in the bay. Lack of agreement was not surprising since computation of production was not a goal of the model effort. The production shortfall had severe 
implications, however, for planned expansion of the model into prediction of

higher trophic levels. Examination of similar models indicated underprediction of primary production was a common characteristic. A second objective of this chapter is to examine the current state of the model with regard to primary production and provide a basis for improving calculation of this process.

\section{Chesapeake Bay}

\section{Physical description}

The Chesapeake Bay system (Figure 1) consists of the main stem bay, five major western-shore tributaries, and a host of lesser tributaries and embayments. The main stem is roughly $300 \mathrm{~km}$ long, 8 to $48 \mathrm{~km}$ wide, and $8 \mathrm{~m}$ average depth. A deep trench with depths to $50 \mathrm{~m}$ runs up the center of the main stem.

Total drainage area of the bay is $166,000 \mathrm{~km}^{2}$. The primary source of fresh water to the system is the Susquehanna River ( $\approx 64$ percent of total gauged freshwater flow), which empties into the northernmost extent of the bay. Other major freshwater sources are the Potomac $(\approx 19$ percent $)$ and James Rivers $(\approx 12$ percent). The remaining western-shore tributaries, the York $(\approx 3$ percent $)$, the Rappahannock ( $\approx 3$ percent), and the Patuxent ( $<1$ percent) contribute only small fractions of the total freshwater flow to the bay.

The main stem bay and major tributaries are classic examples of partially mixed estuaries (Pritchard 1967). When flows in these estuaries are averaged over lengthy time periods, generally more than 15 days, a net longitudinal circulation is evident. Longitudinal density gradients push bottom water upstream and enhance flow of surface water downstream. The volume of the density-induced flow vastly exceeds the volume of freshwater runoff.

\section{Bottom-water hypoxia}

During the summer months, bottom waters of the main stem bay are characterized by hypoxic (low dissolved oxygen) or anoxic (no dissolved oxygen) conditions. Longitudinal and lateral extent of hypoxia is determined by the geometry of the trench that runs up the center of the bay. On occasion, hypoxic water extends from the bottom to within a few meters of the surface, but summeraverage oxygen concentration within the surface mixed layer is usually $6 \mathrm{~g} \mathrm{~m}^{-3}$ or greater.

Bottom-water hypoxia occurs at recurrent, predictable time intervals. The onset is in late May when spring warming enhances respiration in benthic sediments. Decay of material deposited in spring and in previous years removes oxygen from bottom water. Density stratification prevents mixing of oxygenated surface water downwards. Low-oxygen conditions continue through the summer, maintained by respiration in bottom water. In mid-September, autumn winds end the hypoxic period by mixing surface water down to the bottom. Respiration in 


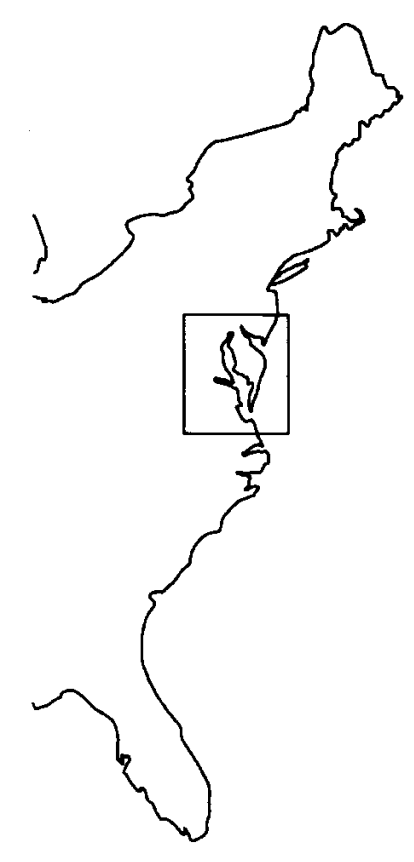

Susquehanna

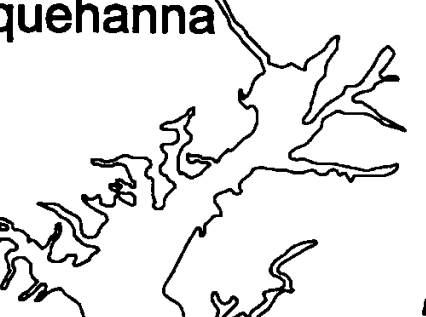

(1)

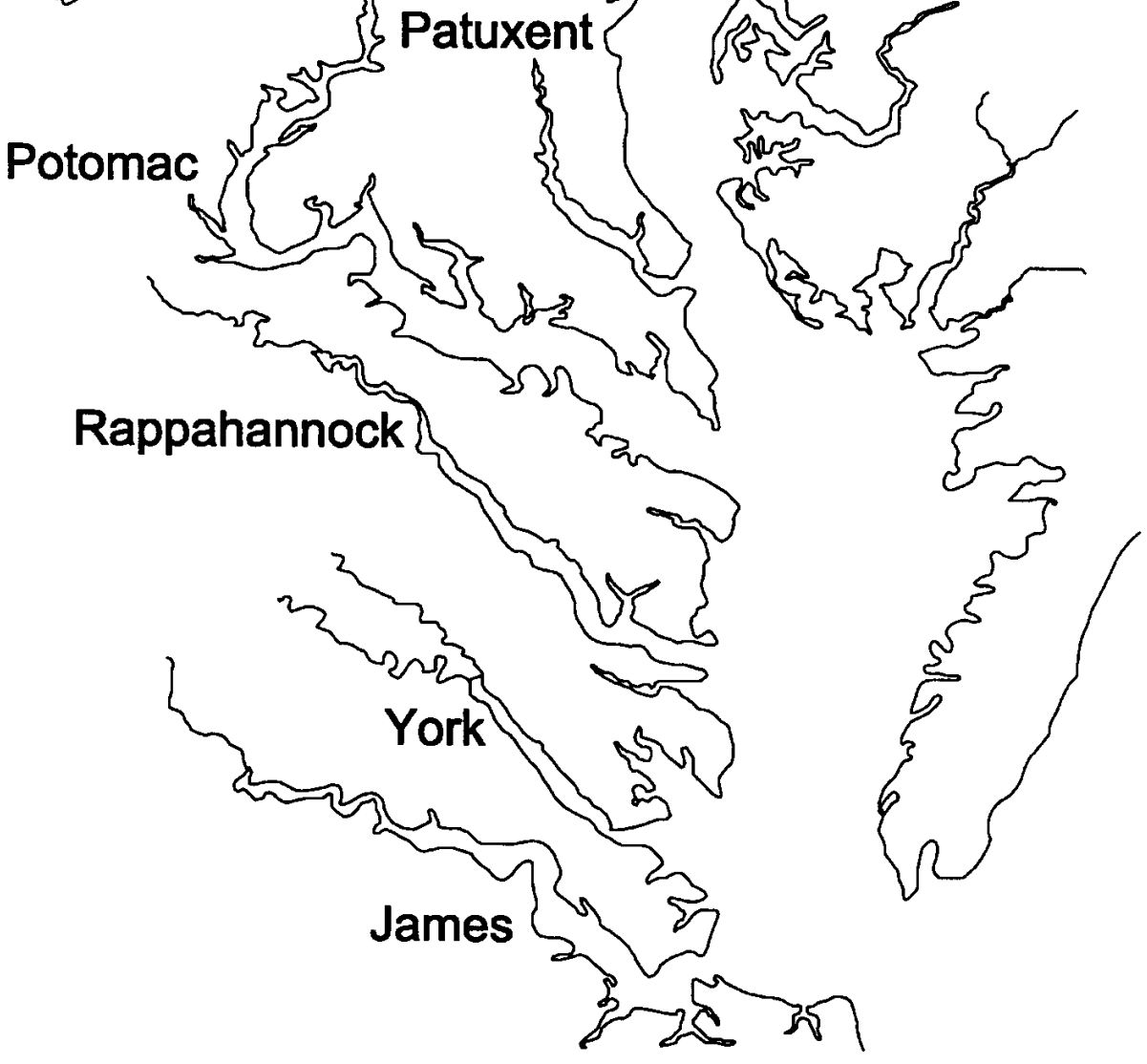

Atlantic

Ocean

Figure 1. Chesapeake Bay 
bottom water, diminished by cool temperature, is insufficient to reestablish hypoxia following the mixing event.

\section{Spring phytoplankton bloom}

A second recurring phenomenon in the bay is the spring phytoplankton bloom. The spring bloom consists primarily of diatoms including Skeletonema, Leptocylindrus, and Cyclotella (Marshall and Lacouture 1986). It usually commences in February and ends precipitously in late May. The bloom is characterized by high chlorophyll concentrations throughout the water column. At times, a subsurface chlorophyll maximum occurs. During summer, chlorophyll concentrations and algal biomass are generally less than in spring and restricted to surface waters. Despite the disparity in biomass, primary production in summer exceeds production in spring (Malone et al. 1988).

Although the bloom occurs regularly, the magnitude and spatial extent of the bloom vary from year to year. Factors affecting this variability are not well known. The occurrence and apparent survival of viable algae at great depth, in the absence of light, also remain unexplained.

The occurrence and magnitude of the spring bloom are linked to subsequent bottom-water anoxia. A spring peak in carbon deposition to sediments results from the algal bloom (Boynton and Kemp 1985), and the decay of this fresh organic matter contributes to oxygen demand. A subtle and potentially more important link is through a nutrient trapping mechanism (Malone et al. 1988). Nutrients in spring runoff are taken up by algae during the bloom. Predation and algal mortality result in the transfer of nutrients, in particulate organic form, to benthic sediments. In summer, the nutrients are mineralized in the sediments and released to the water column. Nutrients released from the sediments support summer algal production. Carbon produced by algae settles to bottom waters, decays, and consumes oxygen. Diminished oxygen in bottom water enhances sediment nutrient release, especially of ammonium. The nutrient release continues the cycle of benthic release, algal production, and oxygen consumption.

\section{Chesapeake Bay Model Package}

\section{Conservation of mass equation}

The hydrodynamic and eutrophication models operate by dividing the spatial continuum of the bay into a grid of discrete cells (Figure 2). The grid for the present study contained 2100 cells (roughly $1.5 \times 3 \mathrm{~km}$ ) in the surface plane and 1 to 19 cells ( 1.5 to $2 \mathrm{~m}$ thick) in the vertical. Total number of cells in the grid was 10196. CE-QUAL-ICM treats each cell as a control volume that exchanges material with its adjacent cells. CE-QUAL-ICM solves, for each volume and for each state variable, the three-dimensional conservation of mass equation: 


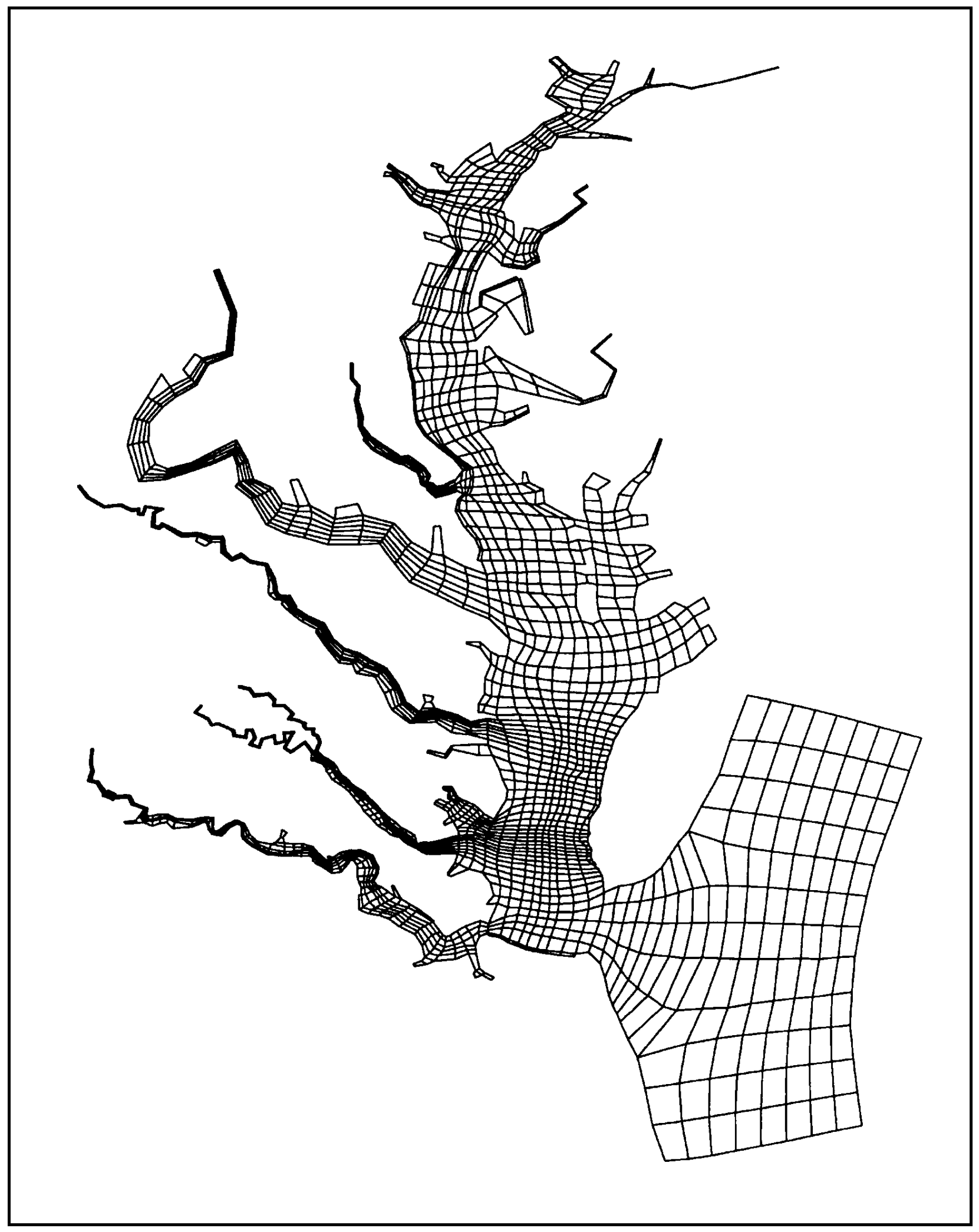

Figure 2. Plan view of model grid 


$$
\frac{\delta V_{i} C_{i}}{\delta t}=\sum_{j=1}^{n} Q_{j} C_{j}^{*}+\sum_{j=1}^{n} A_{j} \frac{\delta C_{i}}{\delta x_{j}} D_{j}+\sum S_{i}
$$

where

$$
\begin{aligned}
V_{i} & =\text { volume of } i^{\text {th }} \text { control volume }\left(\mathrm{m}^{3}\right) \\
C_{i} & =\text { concentration in } i^{\text {th }} \text { control volume }\left(\mathrm{g} \mathrm{m}^{-3}\right) \\
t, x & =\text { temporal and spatial coordinates } \\
n & =\text { number of flow faces attached to } i^{\text {th }} \text { control volume } \\
Q_{j} & =\text { volumetric flow across flow face } \mathrm{j} \text { of } i^{\text {th }} \text { control volume }\left(\mathrm{m}^{3} \mathrm{sec}^{-1}\right) \\
C_{j}^{*} & =\text { concentration in flow across flow face } j\left(\mathrm{~g} \mathrm{~m}^{-3}\right) \\
A_{j} & =\text { area of flow face } j\left(\mathrm{~m}^{2}\right) \\
x_{j} & =\text { horizontal or vertical coordinate } \\
D_{j} & =\text { diffusion coefficient at flow face } j\left(\mathrm{~m}^{2} \sec ^{-1}\right) \\
S_{i} & =\text { external loads and kinetic sources and sinks in } i^{\text {th }} \text { control volume }\left(\mathrm{g} \mathrm{sec}^{-1}\right)
\end{aligned}
$$

Solution to the mass-conservation equation is via the finite-difference method using the QUICKEST algorithm (Leonard 1979) in the horizontal directions and a Crank-Nicholson scheme in the vertical direction.

\section{Eutrophication model}

The central issues in the water quality model are computation of algal biomass and dissolved oxygen. Through primary production of carbon, algae provide the energy required by the ecosystem to function. Excessive primary production is detrimental, however, since its decomposition, in the water and sediments, consumes oxygen. Dissolved oxygen is necessary to support the life functions of higher organisms and is considered an indicator of the "health" of estuarine systems. In order to compute algae and dissolved oxygen, a large suite of model state variables is necessary (Table 1). The phytoplankton kinetics are detailed here. Formulation of the remaining eutrophication processes is largely as previously described (Cerco and Cole 1994).

\section{Phytoplankton kinetics}

The model simulates three algal groups. The spring algal group comprises the diatoms that dominate saline waters from January to May. The summer algal group represents the assemblage of flagellates, diatoms, and other phytoplankton that dominate the system from May to December. The blue-green algal group represents the Microcystis that are found only in the tidal freshwater portion of the Potomac River. Each algal group is represented by identical formulations. Differences between groups are determined by parameter specifications. 


\begin{tabular}{||l|l||}
\hline \hline $\begin{array}{l}\text { Table } 1 \\
\text { Water Quality Model State Variables }\end{array}$ \\
\hline \hline Temperature & Salinity \\
\hline Inorganic Suspended Solids & Freshwater Cyanobacteria \\
\hline Spring Algal Group (Diatoms) & Summer Algal Group \\
\hline Microzooplankton & Mesozooplankton \\
\hline Dissolved Organic Carbon & Labile Particulate Organic Carbon \\
\hline Refractory Particulate Organic Carbon & Ammonium \\
\hline Nitrate & Dissolved Organic Nitrogen \\
\hline Labile Particulate Organic Nitrogen & Refractory Particulate Organic Nitrogen \\
\hline Total Phosphate & Dissolved Organic Phosphorus \\
\hline Labile Particulate Organic Phosphorus & $\begin{array}{l}\text { Refractory Particulate Organic } \\
\text { Phosphorus }\end{array}$ \\
\hline Chemical Oxygen Demand & Dissolved Oxygen \\
\hline Particulate Biogenic Silica & Dissolved Silica \\
\hline \hline
\end{tabular}

For phytoplankton, the sources and sinks in the conservation equation include production, metabolism, predation, and settling. These are expressed in Equation 2:

$$
\frac{\Sigma S}{V}=\left(G-B M-W \frac{\delta}{\delta z}\right) B-P R
$$

where

$$
\begin{aligned}
S & =\text { kinetic sources } \\
V & =\text { cell volume }\left(\mathrm{m}^{3}\right) \\
G & =\text { growth }\left(\mathrm{d}^{-1}\right) \\
B M & =\text { basal metabolism }\left(\mathrm{d}^{-1}\right) \\
W & =\text { settling velocity }\left(\mathrm{m} \mathrm{d}^{-1}\right) \\
z & =\text { vertical coordinate }(\mathrm{m}) \\
B & =\text { algal biomass, expressed as carbon }\left(\mathrm{g} \mathrm{C} \mathrm{m}^{-3}\right) \\
P R & =\text { predation }\left(\mathrm{g} \mathrm{C} \mathrm{m}^{-3} \mathrm{~d}^{-1}\right)
\end{aligned}
$$

\section{Production}

Production by phytoplankton is determined by the availability of nutrients, by the intensity of light, and by the ambient temperature. 


\section{Light}

The influence of light on phytoplankton production is represented by a chlorophyll-specific production equation (Jassby and Platt 1976):

$$
P=P \max \frac{I}{\sqrt{I^{2}+I k^{2}}}
$$

where

$$
\begin{aligned}
P & =\text { production }\left(\mathrm{g} \mathrm{C} \mathrm{g}^{-1} \mathrm{Chl} \mathrm{day}^{-1}\right) \\
\text { Pmax } & =\text { production rate under optimal conditions }\left(\mathrm{g} \mathrm{C} \mathrm{g}^{-1} \mathrm{Chl} \mathrm{day}^{-1}\right) \\
I & =\text { irradiance }\left(\mathrm{E} \mathrm{m}^{-2} \text { day }^{-1}\right)
\end{aligned}
$$

Parameter $I k$ is defined as the irradiance at which the initial slope of the production versus irradiance relationship (Figure 3) intersects the value of Pmax:

$$
I k=\frac{\operatorname{Pmax}}{\alpha}
$$

where $\alpha$ is the initial slope of production versus irradiance relationship ( $\mathrm{g} \mathrm{C} \mathrm{g}^{-1}$ Chl $\mathrm{E}^{-1} \mathrm{~m}^{-2}$ ).

The formulation of production differs from the relations commonly employed in engineering models (e.g., DiToro, O'Connor, and Thomann 1971; Cole and Buchak 1995; Cerco and Cole 1994). Formulations similar to Equation 3 are widely employed in oceanographic models and elsewhere, however. The primary advantage in their use is that Pmax, $I k$, and $\alpha$ are commonly measured and reported. Chlorophyll-specific production rate is readily converted to carbonspecific growth rate for use in Equation 2 through division by the carbon-tochlorophyll ratio:

$$
G=\frac{P \max }{C C h l}
$$

where $C C h l$ is the carbon-to-chlorophyll ratio ( $\mathrm{g} \mathrm{C} \mathrm{g}^{-1}$ chlorophyll a).

\section{Nutrients}

Carbon, nitrogen, and phosphorus are the primary nutrients required for algal growth. Diatoms require silica, as well. Inorganic carbon is usually available in excess and is not considered in the model. The effects of the remaining nutrients on growth are described by the formulation commonly referred to as "Monod kinetics" (Monod 1949): 


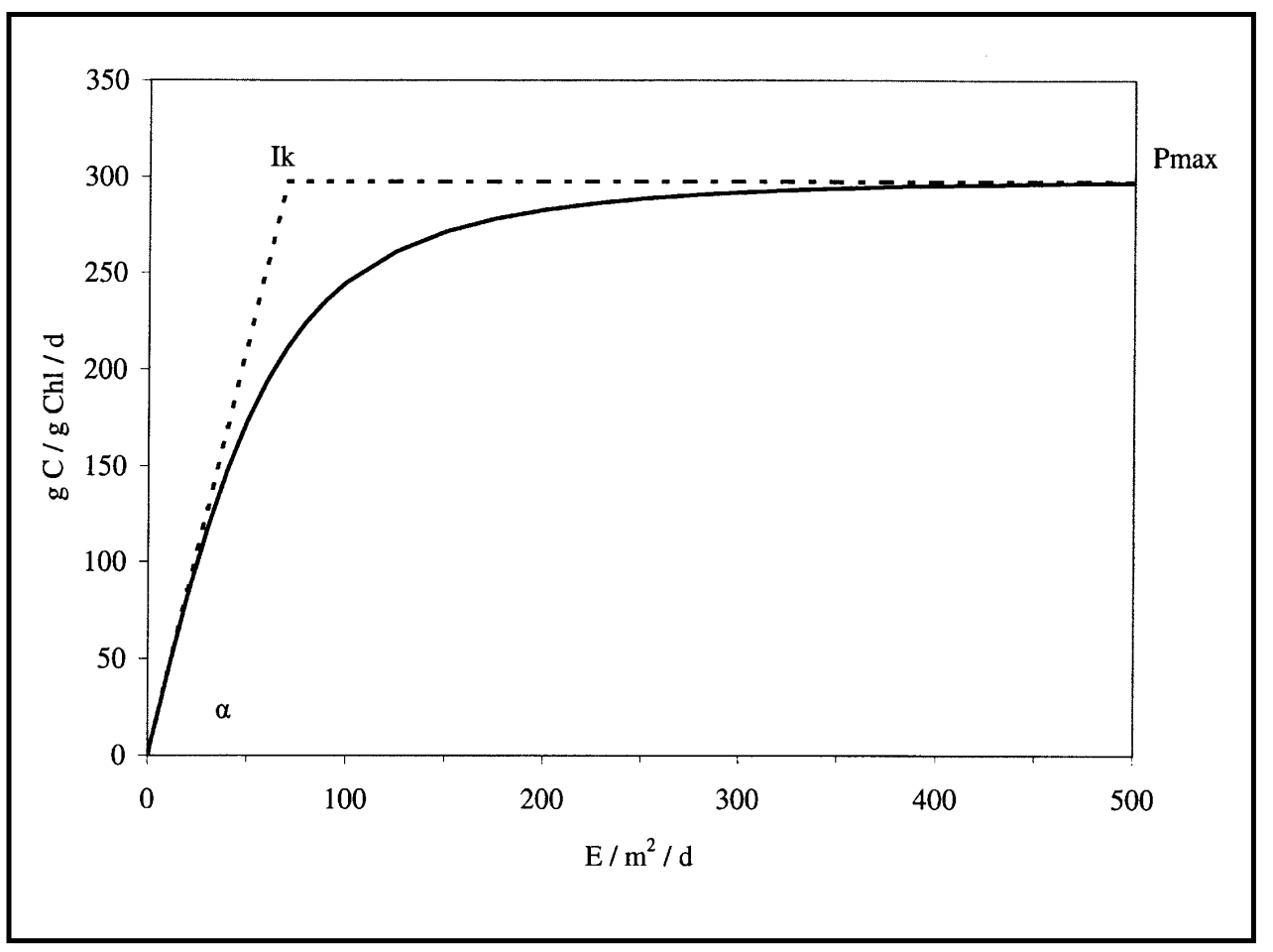

Figure 3. Photosynthesis versus irradiance curve

$$
f(N)=\frac{D}{K H d+D}
$$

where

$$
\begin{aligned}
f(N) & =\text { nutrient limitation on algal production }(0 \leq f(N) \leq 1) \\
D & =\text { concentration of dissolved inorganic nutrient }\left(\mathrm{g} \mathrm{m}^{-3}\right) \\
K H d & =\text { half-saturation constant for nutrient uptake }\left(\mathrm{g} \mathrm{m}^{-3}\right)
\end{aligned}
$$

\section{Temperature}

Algal production increases as a function of temperature until an optimum temperature or temperature range is reached. Above the optimum, production declines until a temperature lethal to the organisms is attained. Numerous functional representations of temperature effects are available. Inspection of growth versus temperature curves indicates a function similar to a Gaussian probability curve provides a good fit to observations:

$$
\begin{aligned}
f(T) & =e^{-K T g 1(T-T o p t)^{2}} \text { when } T \leq \text { Topt } \\
& =e^{-K T g 2(\text { Topt }-T)^{2}} \text { when } T>\text { Topt }
\end{aligned}
$$


where

$$
\begin{aligned}
T & =\text { temperature }\left({ }^{\circ} \mathrm{C}\right) \\
K T g 1 & =\text { effect of temperature below Topt on growth }\left({ }^{\circ} \mathrm{C}^{-2}\right) \\
T o p t & =\text { optimal temperature for algal growth }\left({ }^{\circ} \mathrm{C}\right) \\
K T g 2 & =\text { effect of temperature above Topt on growth }\left({ }^{\circ} \mathrm{C}^{-2}\right)
\end{aligned}
$$

\section{Combining effects of light, nutrients, and temperature}

Phytoplankton models that consider multiple nutrients commonly invoke Leibig's "law of the minimum" (Odum 1971) so that the nutrient limitation on growth is determined by the single most limiting nutrient (Ambrose et al. 1991; Cerco and Cole 1994; Cole and Buchak 1995). This logic is not always extended to incorporate the light limitation, however. Often, the nutrient limitation is multiplied by the light limit (DiToro, O'Connor, and Thomann 1971; Ambrose et al. 1991). As an alternative, Leibig's law can be extended to include light so that growth limitation is determined by the minimum of light or one of three nutrients. At present, models that functionally combine the effects of light and a single nutrient have been presented (Laws and Chalup 1990; Cloern, Grenz, and Vidergar-Lucas 1995), but no unifying theory for the effects of light and multiple nutrients exists. In the absence of this theory, extension of Leibig's law to include light seems most rational. That is, it takes a fixed ratio of nutrients and photons to produce a unit of carbon. Production will be limited by whichever one of these is most limiting. Thus, algal production is modeled:

$$
\begin{aligned}
P & =P \max \cdot f(T) \cdot \\
& \min \left(\frac{N H_{4}+N O_{3}}{K H n+N H_{4}+N O_{3}}, \frac{P O_{4} d}{K H p+P O_{4} d}, \frac{S i}{K H s i+S i}, \frac{I}{\sqrt{I^{2}+I k^{2}}}\right)
\end{aligned}
$$

where

$$
\begin{aligned}
\mathrm{NH}_{4} & =\text { ammonium concentration }\left(\mathrm{g} \mathrm{N} \mathrm{m}^{-3}\right) \\
\mathrm{NO}_{3} & =\text { nitrate concentration }\left(\mathrm{g} \mathrm{N} \mathrm{m}^{-3}\right) \\
K H n & =\text { half-saturation concentration for nitrogen uptake }\left(\mathrm{g} \mathrm{N} \mathrm{m}^{-3}\right) \\
\mathrm{PO}_{4} \mathrm{~d} & =\text { dissolved phosphate concentration }\left(\mathrm{g} \mathrm{P} \mathrm{m}^{-3}\right) \\
K H p & =\text { half-saturation concentration for phosphorus uptake }\left(\mathrm{g} \mathrm{P} \mathrm{m}^{-3}\right) \\
\mathrm{Si} & =\text { dissolved silica concentration }\left(\mathrm{g} \mathrm{Si} \mathrm{m}^{-3}\right) \\
K H s i & =\text { half-saturation concentration for silica uptake }\left(\mathrm{g} \mathrm{Si} \mathrm{m}^{-3}\right)
\end{aligned}
$$

\section{Basal metabolism}

Basal metabolism is considered to be an exponentially increasing function of temperature: 


$$
B M=B M r e^{K T b(T-T r)}
$$

where

$$
\begin{aligned}
B M r & =\text { metabolic rate at } \operatorname{Tr}\left(\mathrm{d}^{-1}\right) \\
K T b & =\text { effect of temperature on metabolism }\left({ }^{\circ} \mathrm{C}^{-1}\right) \\
\operatorname{Tr} & =\text { reference temperature for metabolism }\left({ }^{\circ} \mathrm{C}\right)
\end{aligned}
$$

\section{Predation}

The predation term includes the computed activity of zooplankton and a term that represents predation by planktivorous fish. Formulation and results of the zooplankton computation may be found in Cerco and Meyers (2000). Predation by fish is modeled by assuming fish clear a specific volume of water per unit biomass:

$$
P R=F \cdot B \cdot M
$$

where

$$
\begin{aligned}
& F=\text { filtration rate }\left(\mathrm{m}^{3} \mathrm{~g}^{-1} \text { fish } \mathrm{C}_{\text {day }}{ }^{-1}\right) \\
& M=\text { fish biomass }\left(\mathrm{g} \mathrm{C} \mathrm{m}^{-3}\right)
\end{aligned}
$$

Absent a fisheries model, specification of the spatial and temporal distribution of the predator population is impossible. One approach is to assume fish biomass is proportional to algal biomass, $M=\gamma \mathrm{B}$, in which case Equation 10 can be rewritten:

$$
P R=\gamma \cdot F \cdot B^{2}
$$

Since neither $\gamma$ nor $F$ is known precisely, the logical approach is to combine their product into a single unknown determined during the model calibration procedure. Effect of temperature on predation is represented with the same formulation as the effect of temperature on respiration. The final representation of predation, including zooplankton, is

$$
\begin{aligned}
P R= & \frac{B}{K H s z+B} \cdot R M s z \cdot S Z \\
& +\frac{B}{K H l z+B} \cdot R M l z \cdot L Z+P h t l \cdot B^{2}
\end{aligned}
$$


where

$$
\begin{aligned}
& K H s z=\text { half-saturation concentration for carbon uptake by microzooplankton } \\
& \left(\mathrm{g} \mathrm{C} \mathrm{m}^{-3}\right) \\
& R M s z=\text { microzooplankton maximum ration }\left(\mathrm{g} \text { algal } \mathrm{C} \mathrm{g}^{-1} \text { zoo } \mathrm{C} \mathrm{d}^{-1}\right) \\
& S Z=\text { microzooplankton biomass }\left(\mathrm{g} \mathrm{C} \mathrm{m}^{-3}\right) \\
& \mathrm{KHlz}=\text { half-saturation concentration for carbon uptake by mesozooplankton } \\
& \left(\mathrm{g} \mathrm{C} \mathrm{m}^{-3}\right) \\
& R M l z=\text { mesozooplankton maximum ration }\left(g \text { algal } \mathrm{C} \mathrm{g}^{-1} \text { zoo } \mathrm{C} \mathrm{d}^{-1}\right) \\
& L Z=\text { mesozooplankton biomass }\left(\mathrm{g} \mathrm{C} \mathrm{m}^{-3}\right) \\
& P h t l=\text { rate of predation by higher trophic levels }\left(\mathrm{m}^{3} \mathrm{~g}^{-1} \mathrm{C} \mathrm{d}^{-1}\right)
\end{aligned}
$$

\section{Effect of algae on phosphorus}

Model phosphorus state variables include total phosphate (dissolved, sorbed, and algal), dissolved organic phosphorus, labile particulate organic phosphorus, and refractory particulate organic phosphorus. The amount of phosphorus incorporated in algal biomass is quantified through a stoichiometric ratio. Thus, total phosphorus in the model is expressed:

$$
\begin{aligned}
\text { TotP }= & P_{4} d+P O_{4} p \\
& +A p c \cdot B+D O P+L P O P+R P O P
\end{aligned}
$$

where

$$
\begin{aligned}
\text { Tot } P & =\text { total phosphorus }\left(\mathrm{g} \mathrm{P} \mathrm{m}^{-3}\right) \\
P O_{4} d & =\text { dissolved phosphate }\left(\mathrm{g} \mathrm{P} \mathrm{m}^{-3}\right) \\
P O_{4} p & =\text { particulate inorganic phosphate }\left(\mathrm{g} \mathrm{P} \mathrm{m}^{-3}\right) \\
A p c & =\text { algal phosphorus-to-carbon ratio }\left(\mathrm{g} \mathrm{P} \mathrm{g}^{-1} \mathrm{C}\right) \\
D O P & =\text { dissolved organic phosphorus }\left(\mathrm{g} \mathrm{P} \mathrm{m}^{-3}\right) \\
L P O P & =\text { labile particulate organic phosphorus }\left(\mathrm{g} \mathrm{P} \mathrm{m}^{-3}\right) \\
R P O P & =\text { refractory particulate organic phosphorus }\left(\mathrm{g} \mathrm{P} \mathrm{m}^{-3}\right)
\end{aligned}
$$

Algae take up dissolved phosphate during production and release dissolved phosphate and organic phosphorus through respiration. The fate of phosphorus released by respiration is determined by empirical distribution coefficients. The fate of algal phosphorus incorporated by zooplankton and lost through zooplankton mortality is determined by a second set of distribution parameters. 


\section{Effect of algae on nitrogen}

Model nitrogen state variables include ammonium, nitrate, dissolved organic nitrogen, labile particulate organic nitrogen, and refractory particulate organic nitrogen. The amount of nitrogen incorporated in algal biomass is quantified through a stoichiometric ratio. Thus, total nitrogen in the model is expressed:

$$
\begin{aligned}
\operatorname{Tot} N= & \mathrm{NH}_{4}+\mathrm{NO}_{3} \\
& +A n c \cdot B+D O N+L P O N+R P O N
\end{aligned}
$$

where

$$
\begin{aligned}
\text { Tot } N & =\text { total nitrogen }\left(\mathrm{g} \mathrm{N} \mathrm{m}^{-3}\right) \\
\mathrm{NH}_{4} & =\text { ammonium }\left(\mathrm{g} \mathrm{N} \mathrm{m}^{-3}\right) \\
\mathrm{NO}_{3} & =\text { nitrate }\left(\mathrm{g} \mathrm{N} \mathrm{m}^{-3}\right) \\
A n c & =\text { algal nitrogen-to-carbon ratio }\left(\mathrm{g} \mathrm{N} \mathrm{g}^{-1} \mathrm{C}\right) \\
D O N & =\text { dissolved organic nitrogen }\left(\mathrm{g} \mathrm{N} \mathrm{m}^{-3}\right) \\
L P O N & =\text { labile particulate organic nitrogen }\left(\mathrm{g} \mathrm{N} \mathrm{m}^{-3}\right) \\
R P O N & =\text { refractory particulate organic nitrogen }\left(\mathrm{g} \mathrm{N} \mathrm{m}^{-3}\right)
\end{aligned}
$$

Algae take up ammonium and nitrate during production and release ammonium and organic nitrogen through respiration. Nitrate is internally reduced to ammonium before synthesis into biomass occurs (Parsons, Takahashi, and Hargrave 1984). Trace concentrations of ammonium inhibit nitrate reduction so that, in the presence of ammonium and nitrate, ammonium is utilized first. The "preference" of algae for ammonium is expressed by an empirical function (Thomann and Fitzpatrick 1982) with two limiting values (Figure 4). When nitrate is absent, the preference for ammonium is unity. When ammonium is absent, the preference is zero. In the presence of ammonium and nitrate, the preference depends on the abundance of both forms relative to the half-saturation constant for nitrogen uptake. When both ammonium and nitrate are abundant, the preference for ammonium approaches unity. When ammonium is scarce but nitrate is abundant, the preference decreases in magnitude and a significant fraction of algal nitrogen requirement comes from nitrate.

As with phosphorus, the fate of algal nitrogen released by metabolism and predation is represented by distribution coefficients.

\section{Effect of algae on silica}

The model incorporates two siliceous state variables: dissolved silica and particulate biogenic silica. The amount of silica incorporated in algal biomass is quantified through a stoichiometric ratio. Thus, total silica in the model is expressed: 


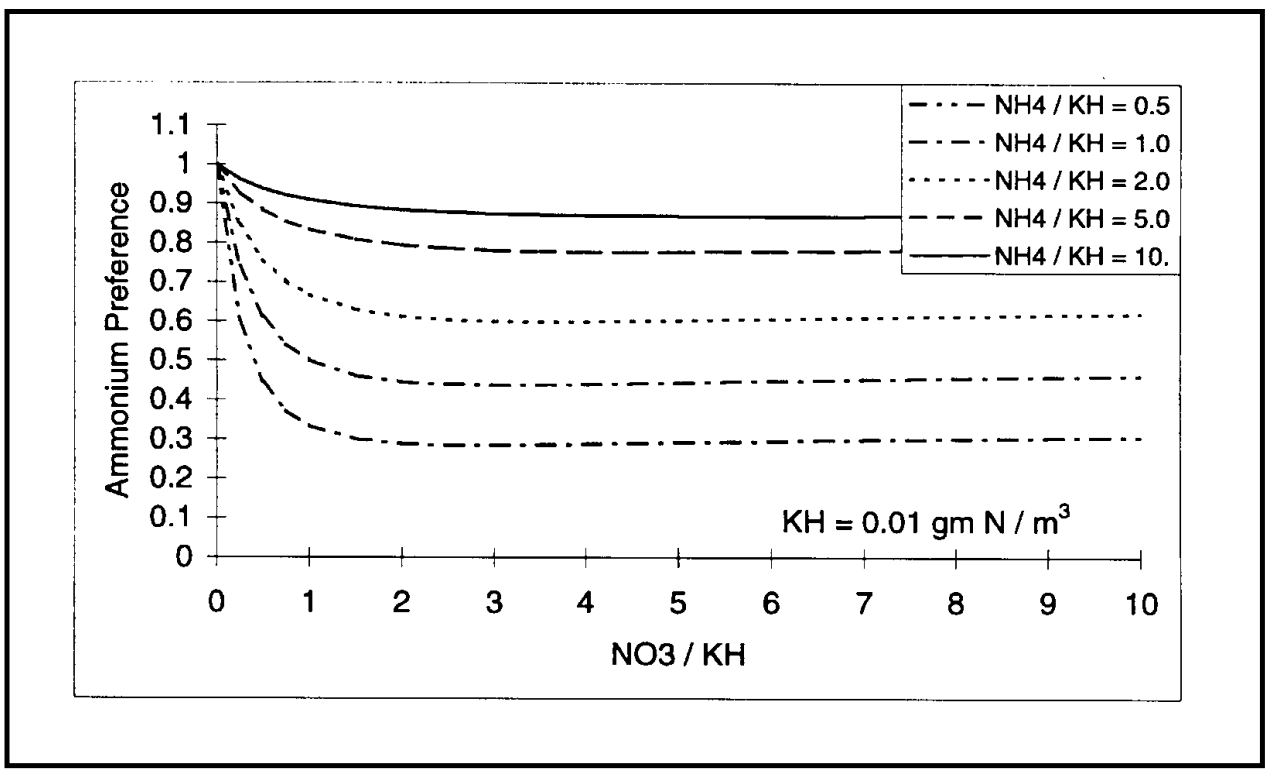

Figure 4. Algal nitrogen preference

$$
\text { TotSi }=\text { Dsil }+A s c \cdot B+P B S
$$

where

$$
\begin{aligned}
\text { TotSi } & =\text { total silica }\left(\mathrm{g} \mathrm{Si} \mathrm{m}^{-3}\right) \\
D s i l & =\text { dissolved silica }\left(\mathrm{g} \mathrm{Si} \mathrm{m}^{-3}\right) \\
A s c & =\text { algal silica-to-carbon ratio }\left(\mathrm{g} \mathrm{Si} \mathrm{g}^{-1} \mathrm{C}\right) \\
P B S & =\text { particulate biogenic silica }\left(\mathrm{g} \mathrm{Si} \mathrm{m}^{-3}\right)
\end{aligned}
$$

As with the other nutrients, the fate of algal silica released by metabolism and predation is represented by distribution coefficients.

\section{Parameter Evaluation}

In conventional eutrophication modeling, agreement between computed and observed concentrations (e.g., chlorophyll and nutrients) is visually optimized through parameter adjustment. The philosophy behind the model documented here is different. Parameter values were assigned, to the greatest extent possible, according to observed properties. When observations were not available, parameters were assigned in order to maximize primary production.

\section{Algal production parameters}

Maximum production rates and their temperature dependence were based on observations collected by Harding, Meeson, and Fisher (1986). The observed 
production rates were subject to in situ nutrient limitations. Since the maximum production rates employed by the model are for nutrient-unlimited situations, parameter values (Table 2) were selected to provide an envelope around reported rates (Figure 5) based on the assumption that reported rates represented nutrientlimited conditions.

\begin{tabular}{|c|c|c|c|}
\hline \multicolumn{4}{|c|}{$\begin{array}{l}\text { Table } 2 \\
\text { Algal Production Parameters }\end{array}$} \\
\hline Group & Parameter & Value & Units \\
\hline \multirow[t]{5}{*}{ Spring } & $P \max$ & 300 & $\mathrm{~g} \mathrm{C} \mathrm{g}^{-1} \mathrm{Chl} \mathrm{day}^{-1}$ \\
\hline & Topt & 20 & ${ }^{\circ} \mathrm{C}$ \\
\hline & KTg1 & 0.0025 & ${ }^{\circ} \mathrm{C}^{-2}$ \\
\hline & KTg2 & 0.012 & ${ }^{\circ} \mathrm{C}^{-2}$ \\
\hline & $\alpha$ & 4.25 & $\mathrm{~g} \mathrm{C} \mathrm{g}^{-1} \mathrm{Chl} \mathrm{E}^{-1} \mathrm{~m}^{-2}$ \\
\hline \multirow[t]{5}{*}{ Summer } & $P \max$ & 300 & $\mathrm{~g} \mathrm{C} \mathrm{g}^{-1} \mathrm{Chl} \mathrm{day}^{-1}$ \\
\hline & Topt & 25 & ${ }^{\circ} \mathrm{C}$ \\
\hline & $K T g 1$ & 0.0025 & ${ }^{\circ} \mathrm{C}^{-2}$ \\
\hline & KTg2 & 0.01 & ${ }^{\circ} \mathrm{C}^{-2}$ \\
\hline & $\alpha$ & 4.25 & $\mathrm{~g} \mathrm{C} \mathrm{g}^{-1} \mathrm{Chl} \mathrm{E}^{-1} \mathrm{~m}^{-2}$ \\
\hline
\end{tabular}

Initial model runs were conducted using values of $\alpha$ close to mean reported values (Harding, Meeson, and Fisher 1986), roughly $8 \mathrm{~g} \mathrm{C} \mathrm{g}^{-1} \mathrm{Chl} \mathrm{E}^{-1} \mathrm{~m}^{-2}$. While these values provided satisfactory computations of observed chlorophyll, computations did not agree with conventional wisdom regarding light limitations of algal production in the upper bay (Fisher et al. 1992; Glibert et al. 1995). Consequently, $\alpha$ was adjusted downward until light limitation was initiated in the turbidity maximum. As a result, $I k$ was substantially higher than reported values (Figure 6).

\section{Basal metabolism}

Tang and Peters (1995) summarized respiration rates measured for six algal divisions in 178 experiments. Respiration reported on a per-cell basis varied widely. When normalized by biomass, however, specific respiration demonstrated a relatively narrow range, 0.3 to $0.5 \mathrm{~d}^{-1}$. Respiration rates in this range were used as initial estimates in the model and refined in the calibration procedure. The final value for the summer group, $0.2 \mathrm{~d}^{-1}$, was close to the initial estimate. Final value for the spring group, $0.01 \mathrm{~d}^{-1}$, was much less than the initial estimate but was required to reproduce the elevated chlorophyll concentrations found at great depths during spring. When higher respiration rates were employed, algae expired rather than forming a subsurface chlorophyll maximum. The reference temperature $\left(\operatorname{Tr}=20{ }^{\circ} \mathrm{C}\right)$ and temperature effect $\left(K t b=0.0322^{\circ} \mathrm{C}^{-1}\right)$ were taken directly from Tang and Peters (1995). 


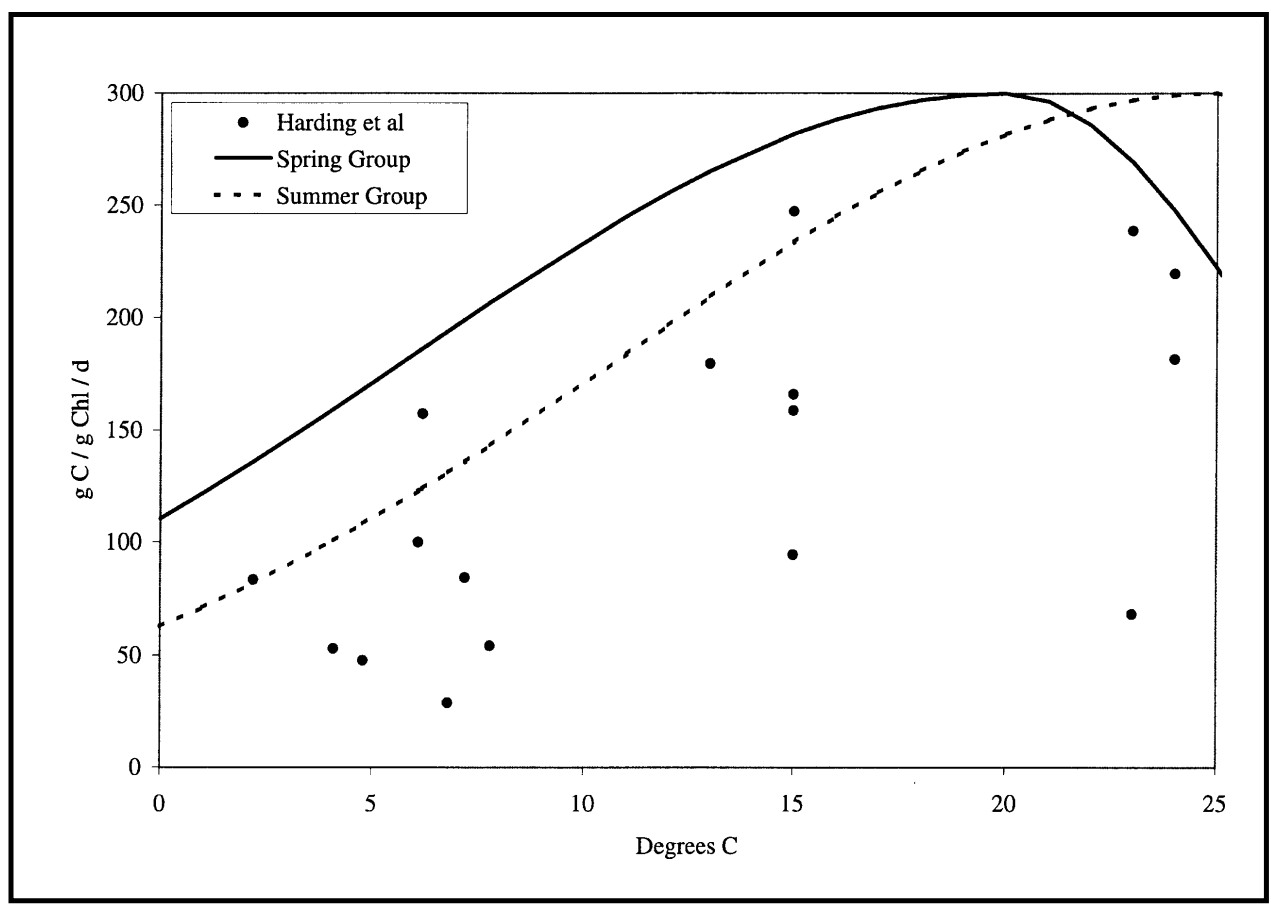

Figure 5. Modeled and observed algal production as a function of temperature

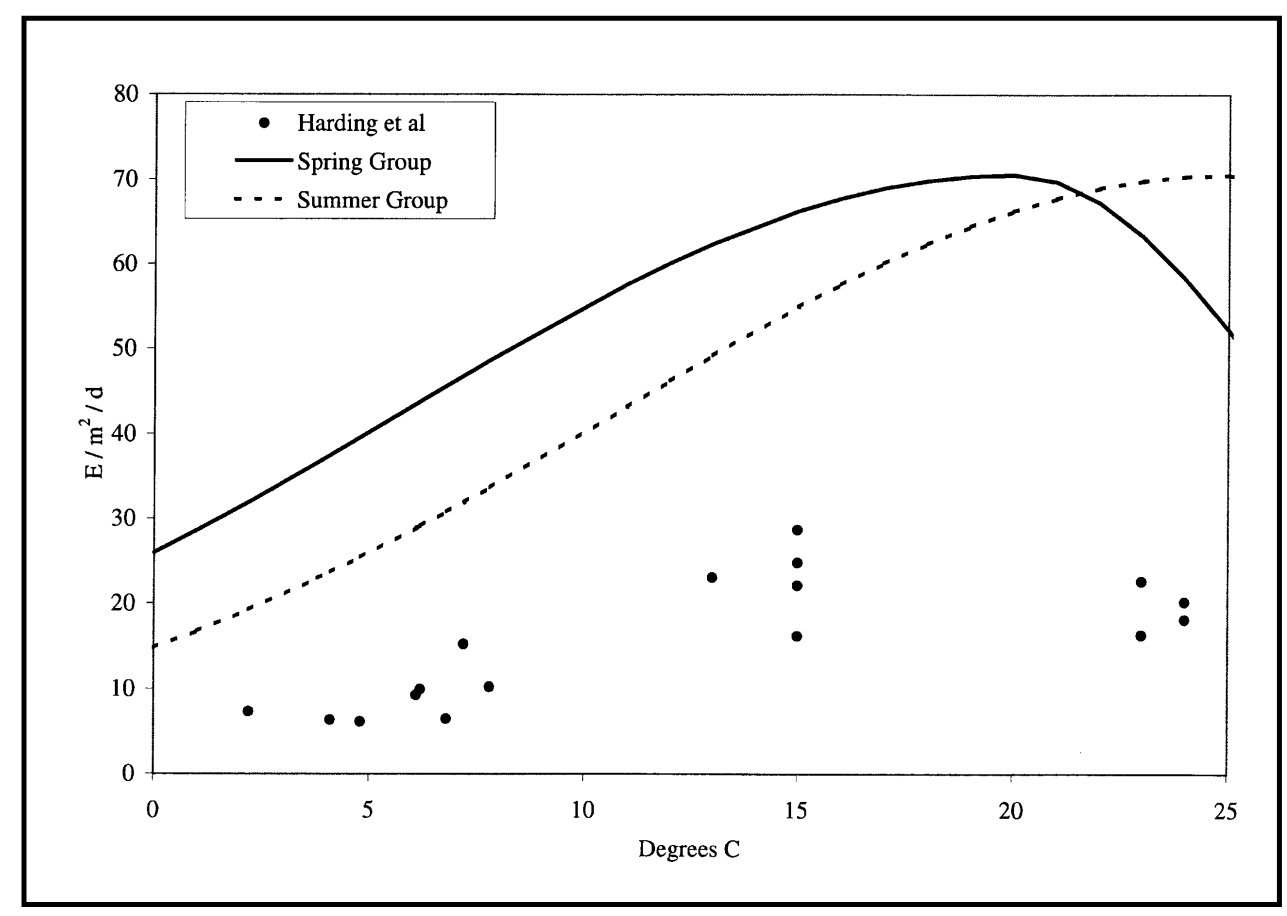

Figure 6. Modeled and observed $l k$ as a function of temperature

\section{Predation}

Parameters for the zooplankton model have been reported previously (Cerco and Meyers 2000). Parameters for predation by fish were based on information provided in a preliminary bioenergetics model of Atlantic menhaden (Bartleson 
et al. 1994). Menhaden enter the bay in spring as larvae and emigrate in fall as juveniles. The bioenergetics model indicated predation by menhaden consumes less than 5 percent of primary production in mid-Chesapeake Bay. Parameter Phtl was assigned a value, $0.01 \mathrm{~m}^{3} \mathrm{~g}^{-1} \mathrm{C} \mathrm{d}^{-1}$, such that computed predation was less than 5 percent of modeled primary production in the midbay (Figure 7). The predation term was specified at $20{ }^{\circ} \mathrm{C}$ and assumed to double for a $10{ }^{\circ} \mathrm{C}$ increase in temperature. The predation term was activated only from June to October when menhaden are present in the bay.

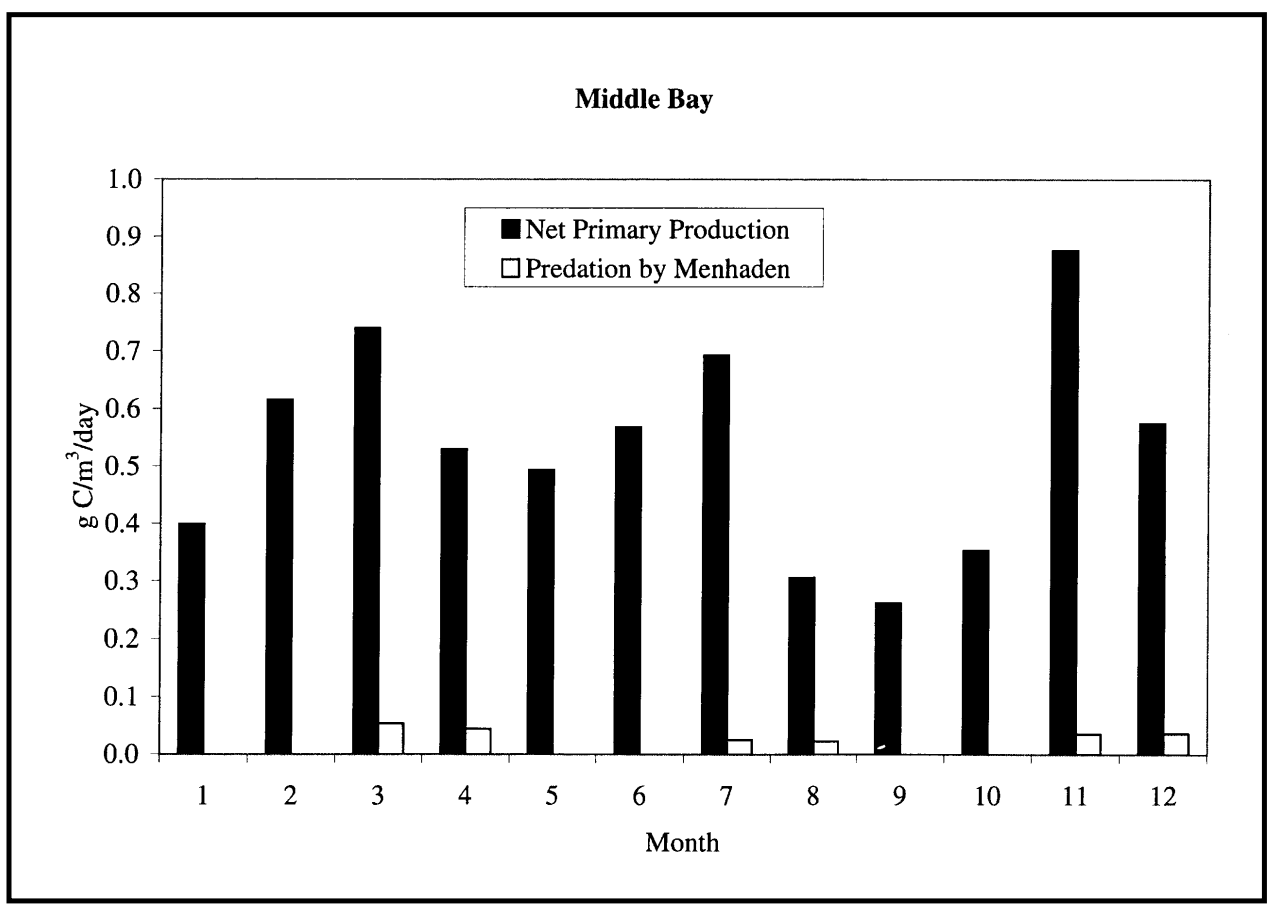

Figure 7. Seasonal menhaden predation pressure

\section{Composition}

Initial estimates of algal stoichiometry were obtained from monitoring data collected by the U.S. Environmental Protection Agency Chesapeake Bay Program Office. Estimates were based on the assumption that composition of organic particles near the surface of the bay (depth $\leq 2 \mathrm{~m}$ ) approximates the composition of viable algae. Observations collected in the main stem bay in 1994 (see Figure 12) were employed in the analysis. This year was selected since observations of particulate inorganic phosphorus and particulate biogenic silica were collected as part of a supplemental monitoring program.

Type II linear regression (Ricker 1973; Laws and Archie 1981), appropriate when the value of the independent variable is uncertain, was employed in the determination of all ratios. First, carbon-to-chlorophyll ratio was determined by finding the best fit to the relationship:

$$
P O C=P O C b+C C h l \cdot C H L
$$


where

$$
\begin{aligned}
P O C & =\text { observed particulate organic carbon }\left(\mathrm{g} \mathrm{C} \mathrm{m}^{-3}\right) \\
P O C b & =\text { mean value of non-algal POC }\left(\mathrm{g} \mathrm{C} \mathrm{m}^{-3}\right) \\
C H L & =\text { observed chlorophyll }\left(\mathrm{mg} C h l^{\wedge} \mathrm{a}^{\prime} \mathrm{m}^{-3}\right)
\end{aligned}
$$

The carbon-to-chlorophyll ratio (Table 3, Figure 8) was used in subsequent regressions to estimate, from the observed chlorophyll, the $P O C$ associated with viable algae. For nitrogen (Figure 9), the regression was

$$
P O N=P O N b+A n c \cdot(C C h l \cdot C h l)
$$

\begin{tabular}{|c|c|c|c|c|}
\hline \multicolumn{5}{|c|}{$\begin{array}{l}\text { Table } 3 \\
\text { Algal Composition }\end{array}$} \\
\hline Parameter & Regression & $\mathrm{R}^{2}$ & Model & Units \\
\hline $\mathrm{CChl}$ & 94 & 0.58 & $\begin{array}{l}90 \text { (spring) } \\
75 \text { (summer) }\end{array}$ & $\mathrm{gC} \mathrm{g}^{-1} \mathrm{Chl}$ \\
\hline Anc & 0.21 & 0.56 & 0.175 & $\mathrm{gN}^{-1} \mathrm{C}$ \\
\hline$A p c$ & 0.018 & 0.26 & 0.010 & $\mathrm{gP} \mathrm{g}^{-1} \mathrm{C}$ \\
\hline Asc & 0.87 & 0.43 & $\begin{array}{l}0.8 \text { (spring) } \\
0.3 \text { (summer) } \\
\end{array}$ & $\mathrm{gSig}^{-1} \mathrm{C}$ \\
\hline
\end{tabular}

where

$$
\begin{aligned}
P O N & =\text { observed particulate organic nitrogen }\left(\mathrm{g} \mathrm{N} \mathrm{m}^{-3}\right) \\
P O N b & =\text { mean value of non-algal } P O N\left(\mathrm{~g} \mathrm{~N} \mathrm{~m}^{-3}\right)
\end{aligned}
$$

A large fraction of the particulate phosphorus in Chesapeake Bay is in inorganic form (Keefe 1994). Consequently, regression against the particulate phosphorus commonly observed in the monitoring program can lead to spurious results. For phosphorus, observations of particulate inorganic phosphorus were subtracted from corresponding observations of particulate phosphorus to yield estimates of particulate organic phosphorus. Then a regression on a relationship similar to Equation 17 was employed to estimate algal composition (Table 3, Figure 10).

Determination of silica stoichiometry followed similar principles. An initial regression on all data yielded no significant relationship. When only data collected in March and May, during the spring bloom, were considered, a significant relationship was obtained (Table 3, Figure 11).

Final values of algal stoichiometry employed in the model (Table 3) were obtained by "tuning" the initial estimates to improve agreement between computed and observed organic carbon, chlorophyll, and nutrients. Model carbonto-chlorophyll ratios are close to initial estimates and compare well with the 


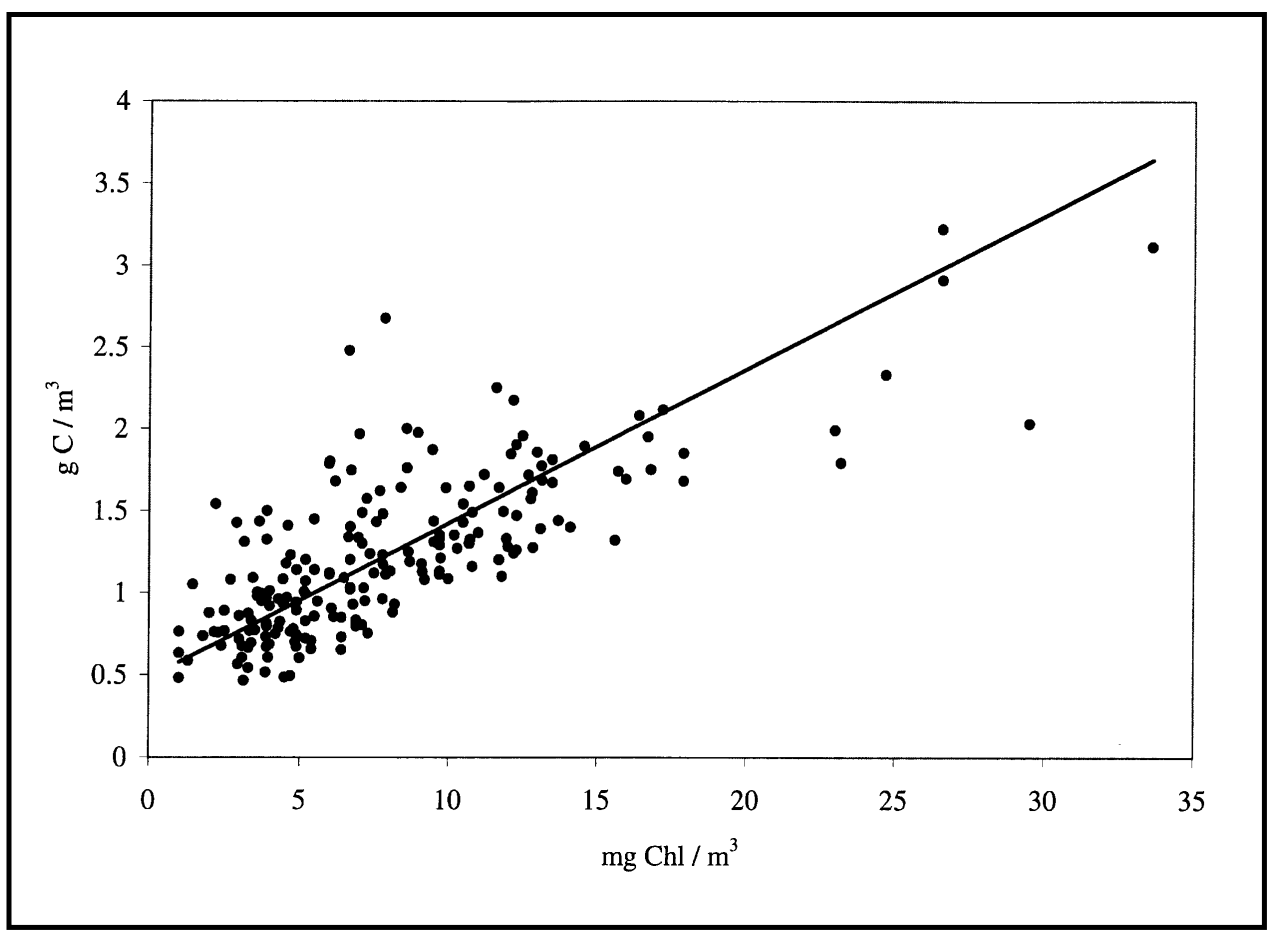

Figure 8. Carbon-to-chlorophyll ratio of algae in surface water

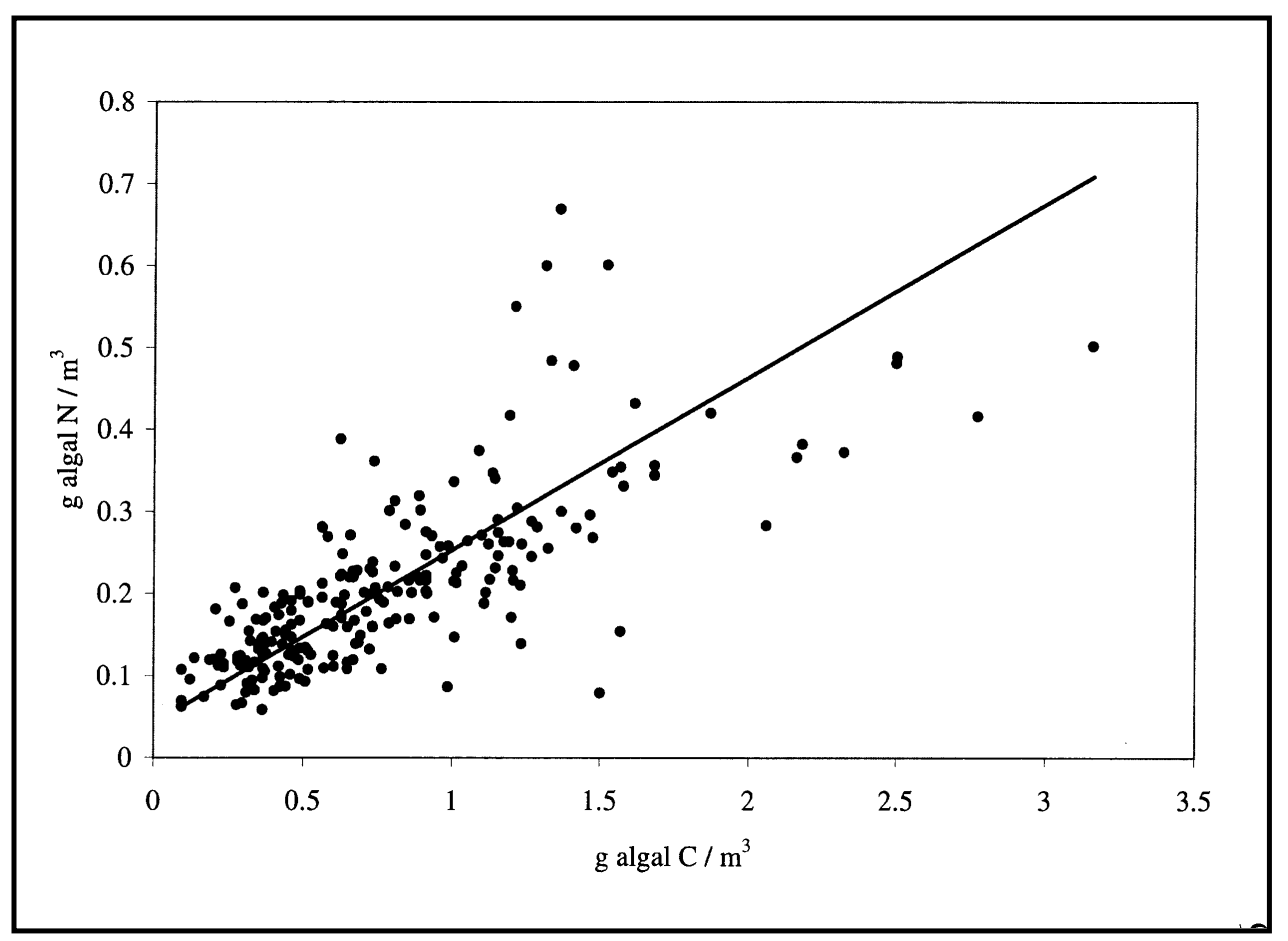

Figure 9. Nitrogen-to-carbon ratio of algae in surface water 


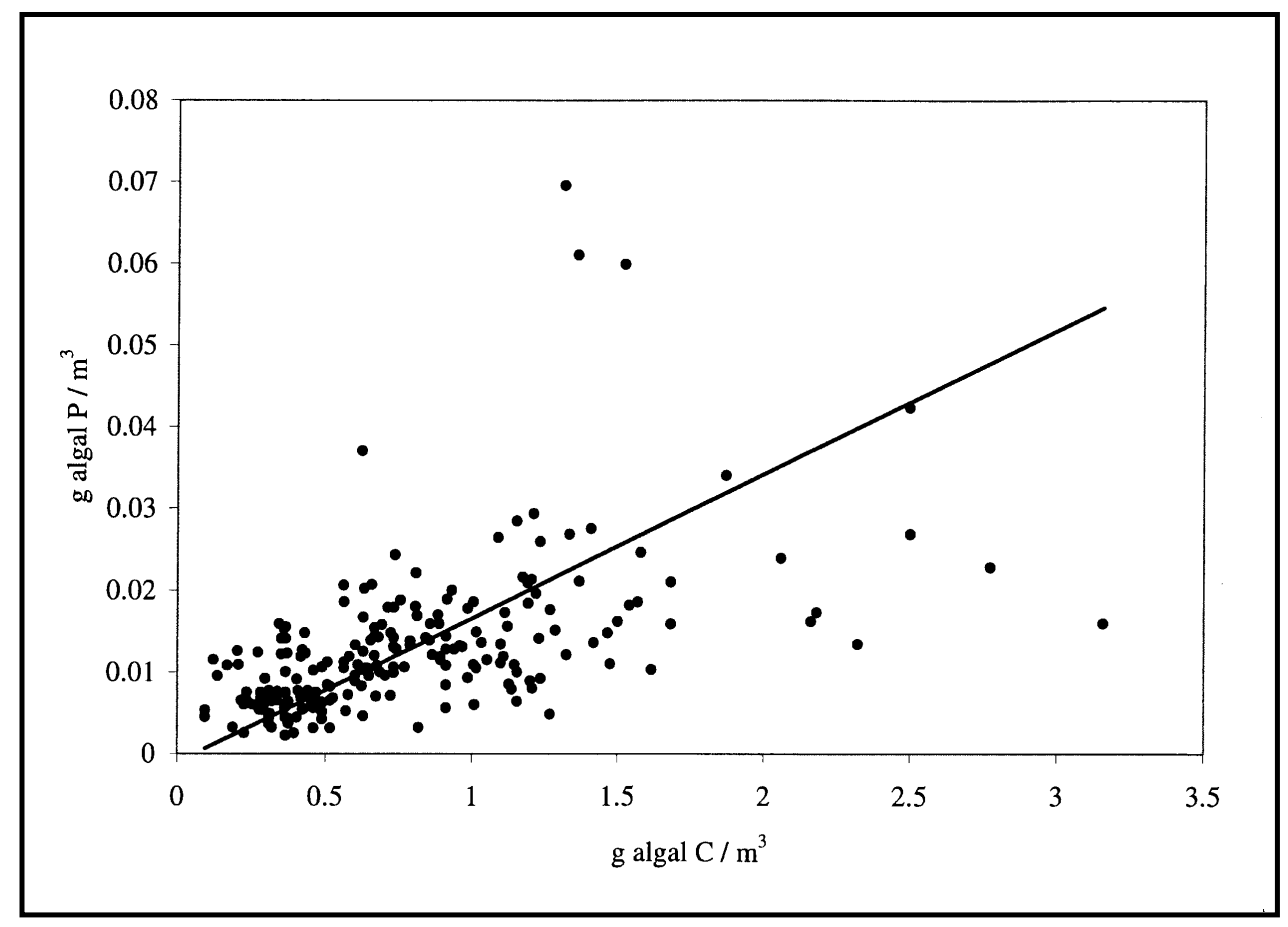

Figure 10. Phosphorus-to-carbon ratio of algae in surface water

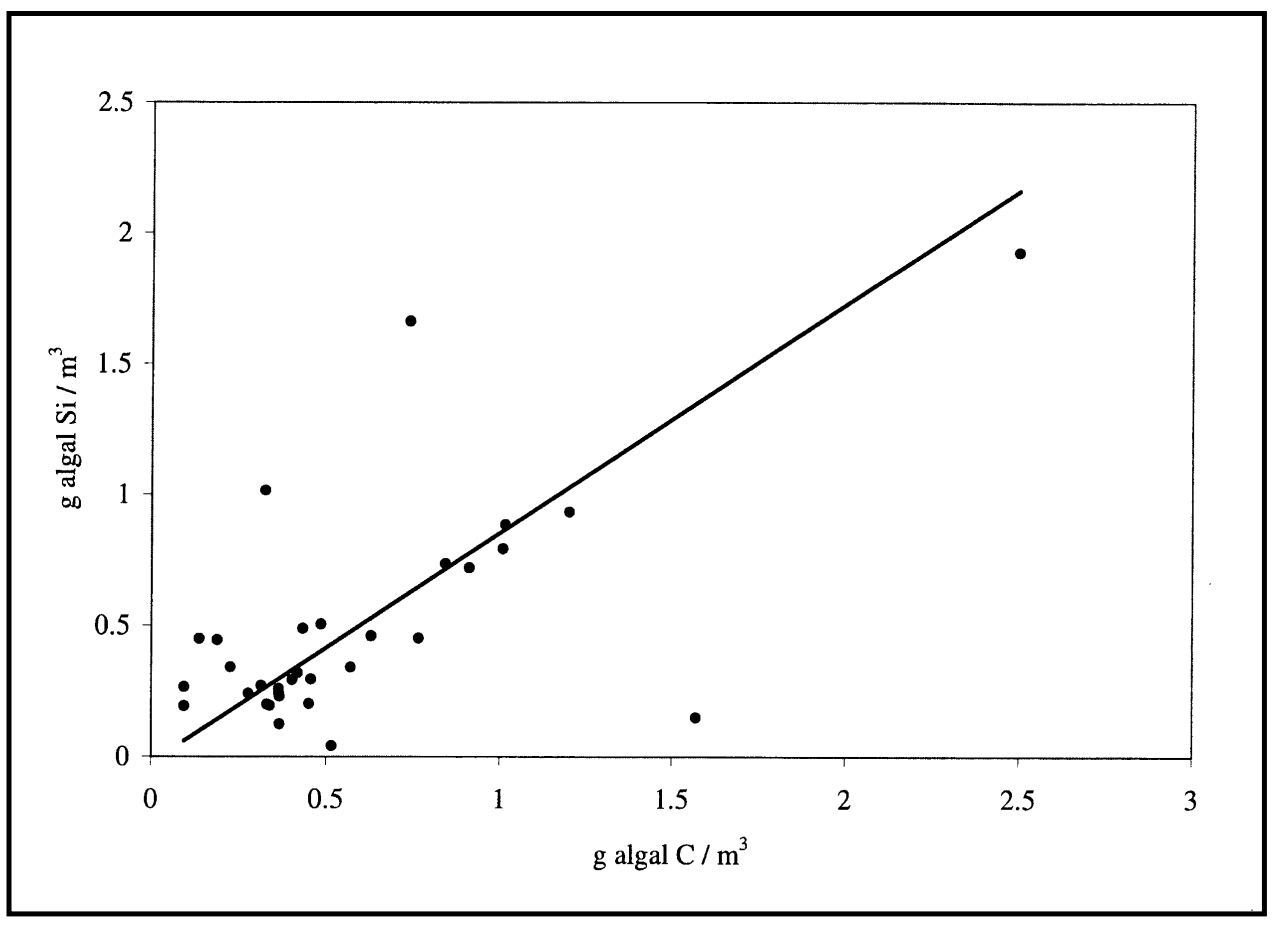

Figure 11. Silica-to-carbon ratio of spring algae in surface water 
ratio 90:1 proposed by Harding, Meeson, and Fisher (1986) and the mean value 63:1 derived from Malone et al. (1988). Model nitrogen-to-carbon ratios are closer to the classic Redfield ratio (Redfield, Ketchum, and Richards 1966), $0.176 \mathrm{~g} \mathrm{~N} \mathrm{~g}^{-1} \mathrm{C}$, than the regression value. Model phosphorus-to-carbon ratio is less than both the regression and Redfield stoichiometry $\left(0.019 \mathrm{~g} \mathrm{P} \mathrm{g}^{-1} \mathrm{C}\right)$. The model value was selected to optimize the fit of chlorophyll and phosphate during phosphorus-limited conditions such as the spring bloom. Model silica-to-carbon ratio for the spring algal group compares well with both the regression value and the range of values, 0.5 to $1.0 \mathrm{~g} \mathrm{Si} \mathrm{g}^{-1} \mathrm{C}$, summarized by Parsons, Takahashi, and Hargrave (1984). For the summer group, a much lower ratio was specified since diatoms compose only a fraction of the summer algal population.

\section{Nutrient uptake}

Reported half-saturation concentrations for algal nutrient uptake in Chesapeake Bay are 0.001 to $0.008 \mathrm{~g} \mathrm{~N} \mathrm{~m}^{-3}$ for ammonium (Wheeler, Gilbert, and McCarthy 1982) and 0.003 to $0.053 \mathrm{~g} \mathrm{P} \mathrm{m}^{-3}$ for phosphate (Taft, Taylor, and McCarthy 1975). Both studies comprised a limited number of observations conducted over a short term. The half-saturation concentrations reported by Wheeler, Gilbert, and McCarthy (1982) are much less than the range of values commonly reported for neritic phytoplankton. Means of values summarized by Eppley, Rogers, and McCarthy (1969) are in the range 0.028 to $0.052 \mathrm{~g} \mathrm{~N} \mathrm{~m}^{-3}$, depending on substrate composition and plankton division. Corresponding model values are $0.03 \mathrm{~g} \mathrm{~N} \mathrm{~m}^{-3}$ and $0.003 \mathrm{~g} \mathrm{P} \mathrm{m}^{-3}$ (spring group) and $0.025 \mathrm{~g} \mathrm{~N} \mathrm{~m}^{-3}$ and $0.001 \mathrm{~g} \mathrm{P} \mathrm{m}^{-3}$ (summer group). Summer values were specified smaller than spring values since the cell size of the pico-nanoplankton complex that dominates in summer (Marshall and Lacouture 1986) is smaller than that of the spring diatom group. Concentrations specified in the model closely reflect the reported summaries (Eppley, Rogers, and McCarthy 1969) for nitrogen and are at or below the lowest values for phosphorus reported by Taft, Taylor, and McCarthy (1975).

The model half-saturation concentration for silica uptake by spring diatoms, $0.05 \mathrm{~g} \mathrm{Si} \mathrm{m}^{-3}$, is well within reported values, 0.02 to $0.082 \mathrm{~g} \mathrm{Si} \mathrm{m}^{-3}$, for oceanic diatoms (Davis, Breitner, and Harrison 1978; Parsons, Takahashi, and Hargrave 1984). The half-saturation concentration for the summer group, $0.01 \mathrm{~g} \mathrm{Si} \mathrm{m}^{-3}$, was specified to prevent silica limitation from occurring during this season.

\section{Algal settling rates}

Reported algal settling rates typically range from 0.1 to $5 \mathrm{~m} \mathrm{~d}^{-1}$ (Bienfang, Harrison, and Quarmby 1982; Riebesell 1989; Waite, Thompson, and Harrison 1992). In part, this variation is a function of physical factors related to algal size, shape, and density (Hutchinson 1967). The variability also reflects regulation of algal buoyancy as a function of nutritional status (Bienfang, Harrison, and Quarmby 1982; Richardson and Cullen 1995) and light (Waite, Thompson, and Harrison 1992). Under appropriate conditions, diatoms exhibit ascent rather than settling (Moore and Villareal 1996) while dinoflagellates are capable of vertical migration both upwards and downwards (Eppley, Holm-Hansen, and Strickland 
1968; Heaney and Eppley 1981). The algal settling rate employed in the model represents the net effect of all physiological and behavioral processes that result in downward transport of phytoplankton. The settling rate employed, $0.1 \mathrm{~m} \mathrm{~d}^{-1}$, was derived through tuning of observed chlorophyll and nutrient concentrations.

\section{Distribution of algal carbon and nutrients}

Carbon, nitrogen, phosphorus, and silica released to the environment through algal metabolism and through predation on algae must be routed into appropriate model state variables. For carbon, these are dissolved, labile particulate, and refractory particulate organic forms. For nitrogen and phosphorus, a dissolved inorganic fraction must be specified as well as organic fractions. For silica, the splits are between dissolved silica and particulate biogenic silica.

A number of studies (Table 4) have incubated algae and algal detritus to examine the products and rate of decomposition. Direct relation of experimental observations to the model is difficult since the experiments were not designed to measure distribution as parameterized in the model. No universal distinction between labile and refractory exists. Definition in the present study was based on parameters employed in the sediment diagenesis model (DiToro and Fitzpatrick 1993). In the sediment model, the carbon fraction deemed labile (G1) had a decay rate of 0.035 day $^{-1}$ at $20{ }^{\circ} \mathrm{C}$. Ninety percent of G1 carbon was mineralized in 65 days. In interpretation of experiments, organic matter that mineralized in 60 days or less was considered labile.

Aspects of carbon and nutrient release from zooplankton have been studied (e.g., Morales 1987; Wen and Peters 1994; Miller, Penry, and Glibert 1995), but this material does not readily allow the apportionment of total consumption into releases in organic, inorganic, dissolved, and particulate form. Recycling of algal matter back to the water by fish must also be parameterized in some fashion. Ultimately, the splits of carbon and nutrients released by algal metabolism and by predation (Table 5) were determined by adjustment to agree with observed concentrations.

\section{Results}

Model simulations encompassed the period 1985-1994. The 10-year simulation was continuous, employing 15-minute time-steps. Intratidal hydrodynamics for each of the 10 years were provided by the CH3D-WES hydrodynamic model (Johnson et al. 1993) operating on the 10196-cell grid (Figure 2). Loads from the watershed were provided on a daily basis by a current version of the U.S. Environmental Protection Agency's Chesapeake Bay Watershed Model (Donigian et al. 1991). Point-source loads were specified monthly based on reports from state agencies. Atmospheric loads to the water surface were derived from observations and specified on a daily basis. 


\begin{tabular}{|c|c|c|}
\hline \multicolumn{3}{|c|}{$\begin{array}{l}\text { Table } 4 \\
\text { Reported Distributions of Carbon, Nitrogen, and Phosphorus }\end{array}$} \\
\hline & Distribution & Reference \\
\hline \multirow[t]{4}{*}{ Carbon } & $\begin{array}{l}\text { Refractory fraction of algae averages } 40 \% \\
\text { of ash-free dry weight }\end{array}$ & Foree and McCarty (1970) \\
\hline & $\begin{array}{l}22 \% \text { dissolved, } 73 \% \text { labile particulate, } 5 \% \\
\text { refractory particulate }\end{array}$ & Pett (1989) \\
\hline & $\begin{array}{l}33 \% \text { dissolved, } 33 \% \text { labile particulate, } 33 \% \\
\text { refractory particulate }\end{array}$ & Westrich and Berner (1984) \\
\hline & $\begin{array}{l}7 \% \text { dissolved, } 63 \% \text { labile particulate, } 30 \% \\
\text { refractory particulate }\end{array}$ & Otsuki and Hanya (1972) \\
\hline \multirow[t]{2}{*}{ Nitrogen } & $\begin{array}{l}5 \text { to } 7 \% \text { dissolved inorganic, } 30 \text { to } 50 \% \\
\text { dissolved organic, labile particulate }>22 \text { to } \\
44 \% \text {, refractory particulate }<21 \text { to } 23 \%\end{array}$ & Garber (1984) \\
\hline & $50 \%$ of particulate nitrogen is refractory & Grill and Richards (1964) \\
\hline \multirow[t]{3}{*}{ Phosphorus } & $\begin{array}{l}6 \% \text { dissolved organic, } 64 \% \text { labile } \\
\text { particulate, } 30 \% \text { refractory particulate }\end{array}$ & Otsuki and Hanya (1972) \\
\hline & $\begin{array}{l}24 \text { to } 27 \% \text { dissolved inorganic, } 42 \text { to } 56 \% \\
\text { dissolved organic, labile particulate }>4 \text { to } \\
16 \% \text {, refractory particulate }<7 \text { to } 27 \%\end{array}$ & Garber (1984) \\
\hline & $33 \%$ of particulate phosphorus is refractory & Grill and Richards (1964) \\
\hline
\end{tabular}

\begin{tabular}{||l|l|l|l|l|l||}
\hline \hline \multicolumn{6}{||l|}{$\begin{array}{l}\text { Table 5 } \\
\text { Modeled Distribution of Algal Carbon, Nitrogen, Phosphorus, Silica }\end{array}$} \\
\hline \hline \multirow{3}{*}{ Release } & Form & Carbon & Nitrogen & Phosphorus & Silica \\
\hline \hline \multirow{4}{*}{ Mortality } & Dissolved Inorganic & 1.0 & 0.5 & 0.5 & \\
\cline { 2 - 6 } & Dissolved Organic & & 0.3 & 0.5 & \\
\cline { 2 - 6 } & Labile Particulate & & 0.15 & & 1.0 \\
\cline { 2 - 6 } & Refractory Particulate & & 0.05 & & \\
\hline \multirow{4}{*}{ Predation } & Dissolved Inorganic & & 0.5 & 0.5 & 0.5 \\
\cline { 2 - 6 } & Dissolved Organic & 0.25 & 0.3 & 0.4 & \\
\cline { 2 - 6 } & Labile Particulate & 0.5 & 0.15 & 0.07 & 0.5 \\
\cline { 2 - 6 } & Refractory Particulate & 0.25 & 0.05 & 0.03 & \\
\hline
\end{tabular}

Chlorophyll, carbon, nutrients, and other substances are monitored at over fifty stations (Figure 12) in the main stem of Chesapeake Bay. Surveys are conducted at monthly or greater frequencies, and samples are collected at four or more depths in the water column. The enormous quantity of data provides both an opportunity and a challenge in model-data comparisons. Some degree of spatial and temporal aggregation is necessary to reduce the volume of information into a representative assembly.

\section{Spatial distribution of phytoplankton and nutrients}

One aggregation employed in the study compared model and data along a transect extending from the mouth of the bay to the head of tide at the Susquehanna River. The 10-year simulation period was divided into three 


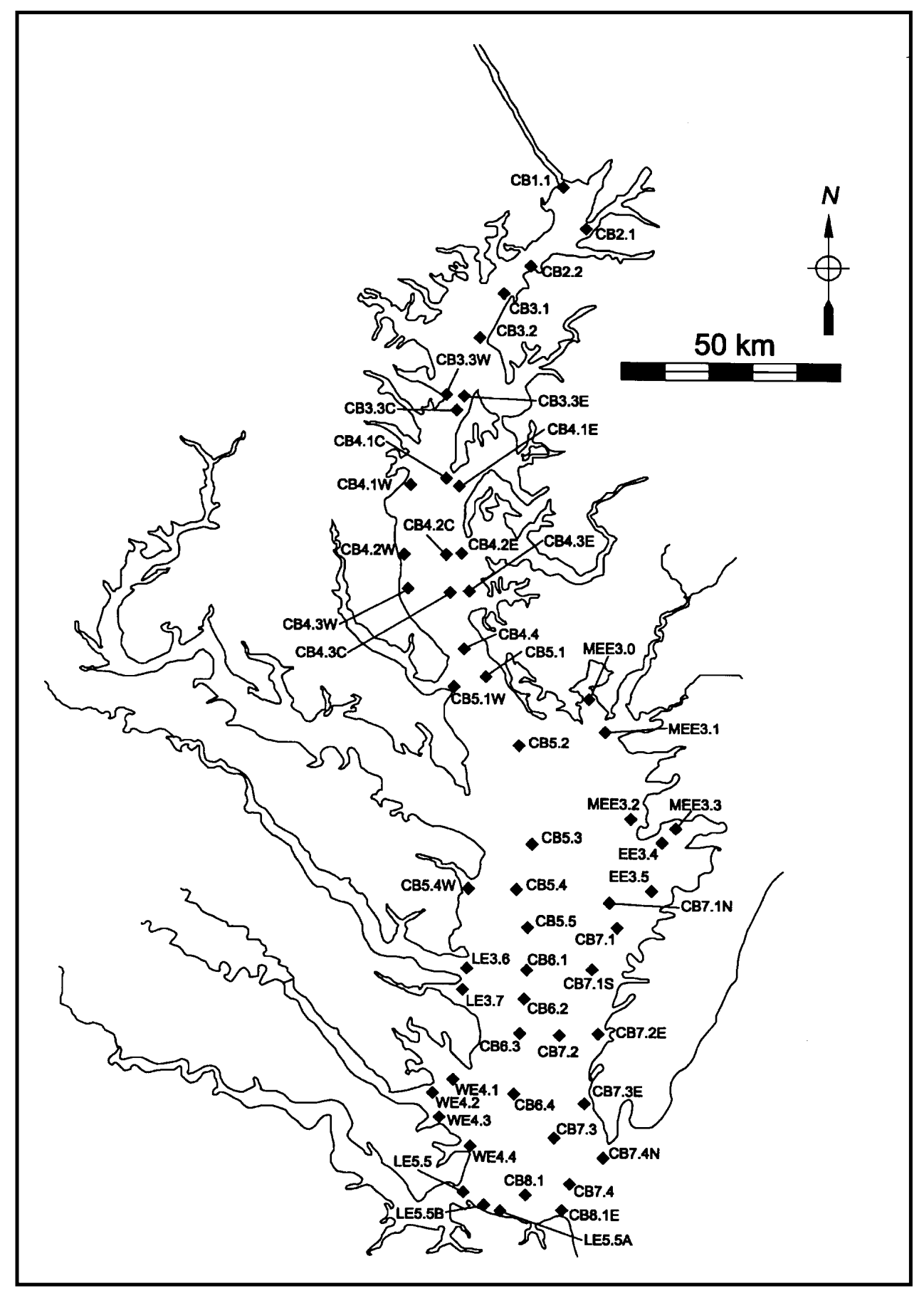

Figure 12. Monitoring stations in main stem Chesapeake Bay

intervals: 1985-1988, 1989-1992, 1993-1994. The first interval corresponded to the period prior to major phosphorus load controls. The second period encompassed phosphorus controls under years of average hydrology. The last 2 years represented unusually high runoff in the Susquehanna. Years were divided into seasons of 3 months each. Seasonal medians of observed and modeled concentrations were computed for four seasons in each of the three intervals. These comparisons provided a broad indication of the ability of the model to represent the 
spatial distribution of phytoplankton, nutrients, and other substances. Two seasons are discussed here: spring (March-May) and summer (June-August) 1989-1992. These seasons were selected to illustrate computations of the spring algal bloom and the summer period of maximum production. Results are shown for chlorophyll and the quantities that influence chlorophyll distribution: ammonium, nitrate, phosphate, silica, and light attenuation.

Spring. Median observed chlorophyll concentrations during spring (Figure 13) were 5 to $10 \mathrm{mg} \mathrm{m}^{-3}$ with a tendency for higher concentrations to occur in the upper half of the bay. The model provides good representation of the magnitude and distribution of surface chlorophyll. Observations indicate chlorophyll concentrations similar to surface values occur at the bottom of the water column. Modeled concentrations are roughly half of surface values throughout much of the bay.

Surface ammonium observations exhibit a peak in the upper part of the bay and are otherwise at trace concentrations. Surface nitrate observations demonstrate a substantial gradient from the $\mathrm{g} \mathrm{m}^{-3}$ range at the Susquehanna down to trace concentrations at the mouth of the bay. The magnitude of observed ammonium in the upper bay is well represented in the model although computed ammonium in the lower bay is roughly twice the observed values. Both the magnitude and spatial trends of the observed nitrate are reproduced in the model.

Dissolved inorganic phosphorus observations demonstrate little spatial variation. In much of the bay, they are at or below detection levels. Observations suggest higher values in the turbid waters at the head of the bay and perhaps at the mouth of the bay. Observations of higher values there are confused, however, by higher detection levels in samples from that region. The model clearly exhibits a trend to higher concentrations towards the bay mouth and little change in phosphate in the turbidity maximum.

As with nitrate, computed and observed dissolved silica levels exhibit orderof-magnitude variation from the Susquehanna River source to the mouth of the bay. Concentrations are in the $\mathrm{g} \mathrm{m}^{-3}$ range at the Susquehanna outfall yet depleted in the lower $150 \mathrm{~km}$ of the bay.

Observed light attenuation is highest in the turbidity maximum in the upper bay. Elsewhere, attenuation is roughly uniform. Light attenuation in the model is computed as a function of computed solids concentration and specified color (Cerco and Meyers 2000). The model reproduces both peak attenuation in the turbidity maximum and the lower, uniform values elsewhere.

Summer. Median observed surface chlorophyll concentrations during summer (Figure 14) were in the 5- to $10-\mathrm{mg} \mathrm{m}^{-3}$ range, similar to spring. The primary difference from spring is the absence of chlorophyll in bottom waters, except in the shallowest region near the head of tide. The magnitude of surface chlorophyll concentration and the absence of chlorophyll in bottom waters are well represented in the model. 


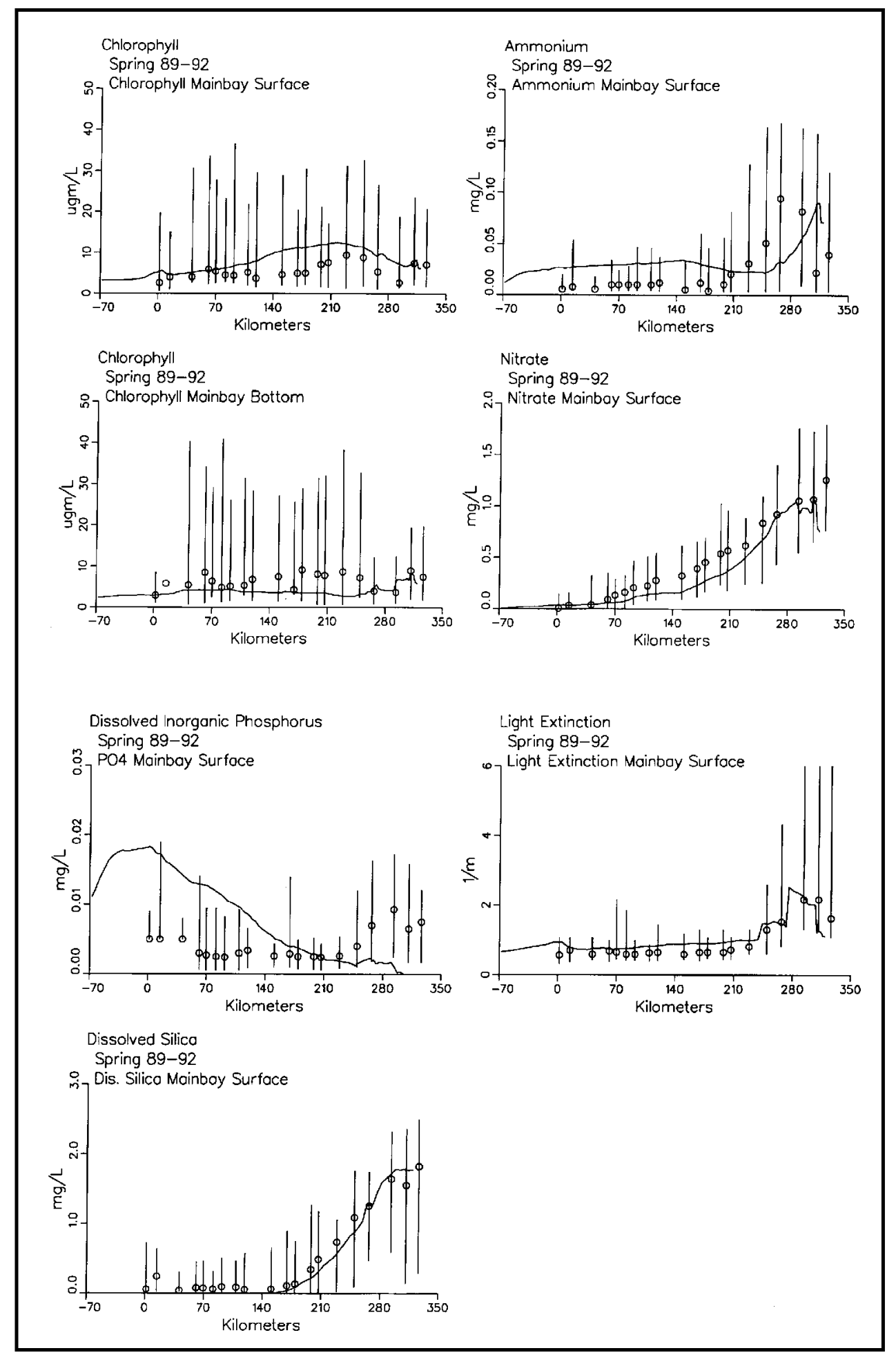

Figure 13. Longitudinal distribution of chlorophyll (surface and bottom), ammonium (surface), nitrate (surface), dissolved phosphate (surface), dissolved silica (surface) and light attenuation in spring, 1989-1992. Observed median and range are compared to model median 


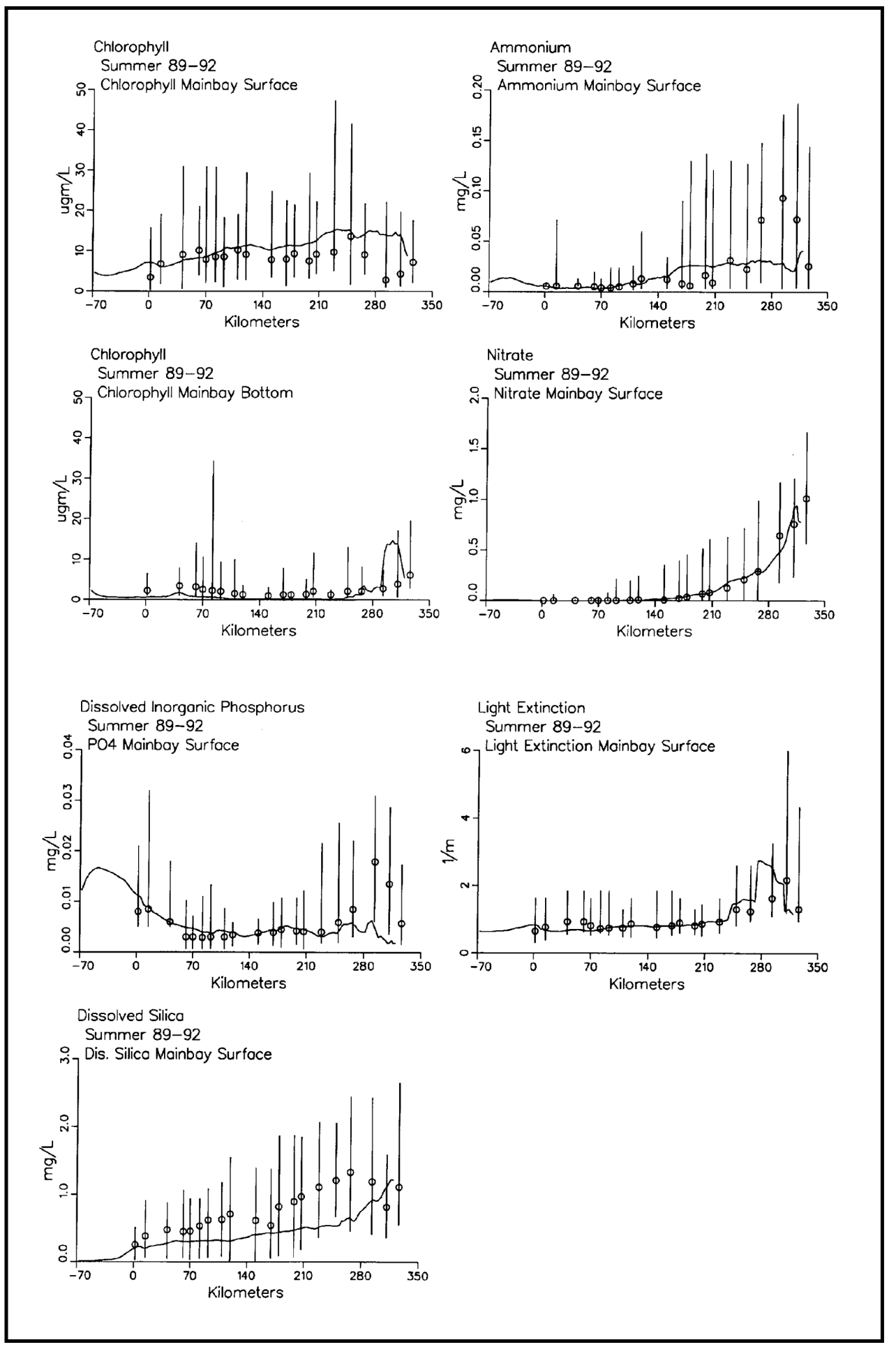

Figure 14. Longitudinal distribution of chlorophyll (surface and bottom), ammonium (surface), nitrate (surface), dissolved phosphate (surface), dissolved silica (surface), and light attenuation in summer, 1989-1992. Observed median and range are compared to model median 
As with spring, observed surface ammonium exhibits a peak in the turbid reaches of the upper bay and descends to trace concentrations elsewhere. Nitrate again shows enormous variation between the Susquehanna River and the mouth of the bay. In contrast to spring, however, the supply of nitrate from the Susquehanna is depleted in the lower two thirds of the bay. During spring, nitrate was detectable almost to the mouth of the bay. The magnitude and trends of both inorganic nitrogen forms are reproduced in the model.

During summer, observed phosphate exhibits peak values at the mouth of the bay and in turbid waters of the upper bay. In the central portion of the bay, phosphate is at or below detection levels. The model reproduces the higher concentrations near the bay mouth and the depletion in the central portion of the bay but shows no tendency to increase in the upper bay.

During summer, both computed and observed silica are plentiful in surface waters. As with spring, computed and observed light attenuation are highest in the turbidity maximum and nearly uniform elsewhere.

\section{Temporal distribution of phytoplankton and nutrients}

The temporal distributions of chlorophyll, nutrients, and light (Figure 15) are shown at station CB5.2, located nearly at the center of the bay. The primary feature of the observed chlorophyll time series is the occurrence of the spring bloom with concentrations over $25 \mathrm{mg} \mathrm{m}^{-3}$ in both surface and bottom waters. Compressed into a 10-year time series, the bloom can be difficult to discern in surface observations, but the subsurface chlorophyll maximum is easy to see in the bottom observations. Modeled surface chlorophyll exhibits both a spring bloom and a secondary summer peak associated with maximum productivity. Relative magnitudes of the two peaks and the duration of the interval between them depend on meteorology and hydrology of the simulated year. The difference between the bloom and subsequent summer period is clearly discerned in the modeled bottom chlorophyll concentration although the model substantially undercomputes the magnitude of the subsurface chlorophyll maximum.

Temporal structure in the observed surface ammonium is difficult to discern. The primary feature is the depletion that often occurs in the third quarter of the year. More temporal structure is evident in the nitrate observations, which show peaks associated with spring runoff events and nitrate depletion during summer intervals of low flow. Magnitudes of the observed concentrations are well reproduced, and the model also exhibits depletion of inorganic nitrogen forms in summer.

As with ammonium, observed dissolved phosphate shows little temporal structure in the surface waters of the central bay. Modeled phosphate is of the correct magnitude during spring when diatom uptake is substantial. Otherwise, modeled concentrations are substantially higher than observed. 


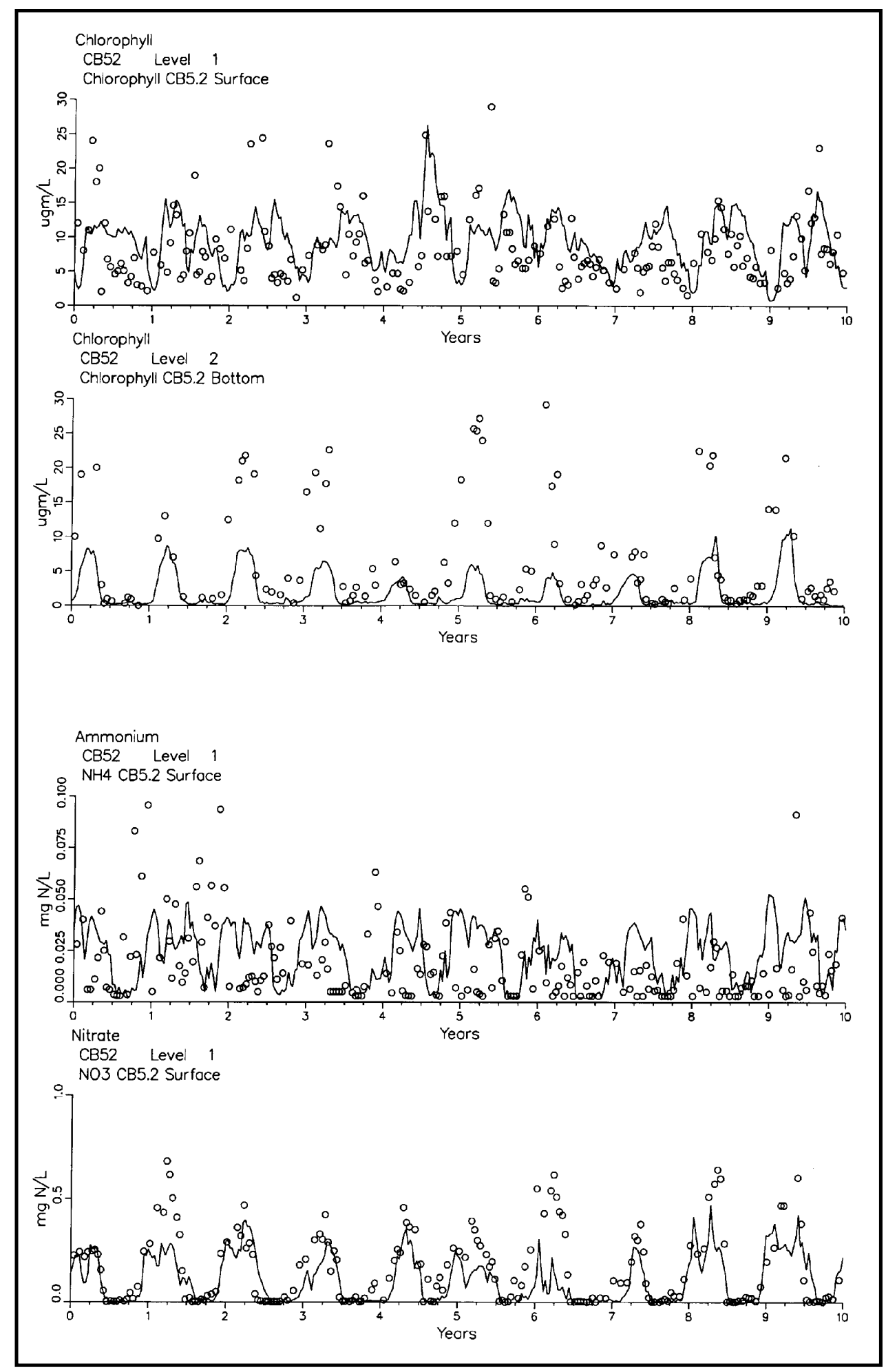

Figure 15. Chlorophyll (surface and bottom), ammonium (surface), nitrate (surface), dissolved phosphate (surface), dissolved silica (surface), and light attenuation at station CB5.2, 1985-1994. Individual observations are compared to model results produced at 10-day intervals (Continued) 


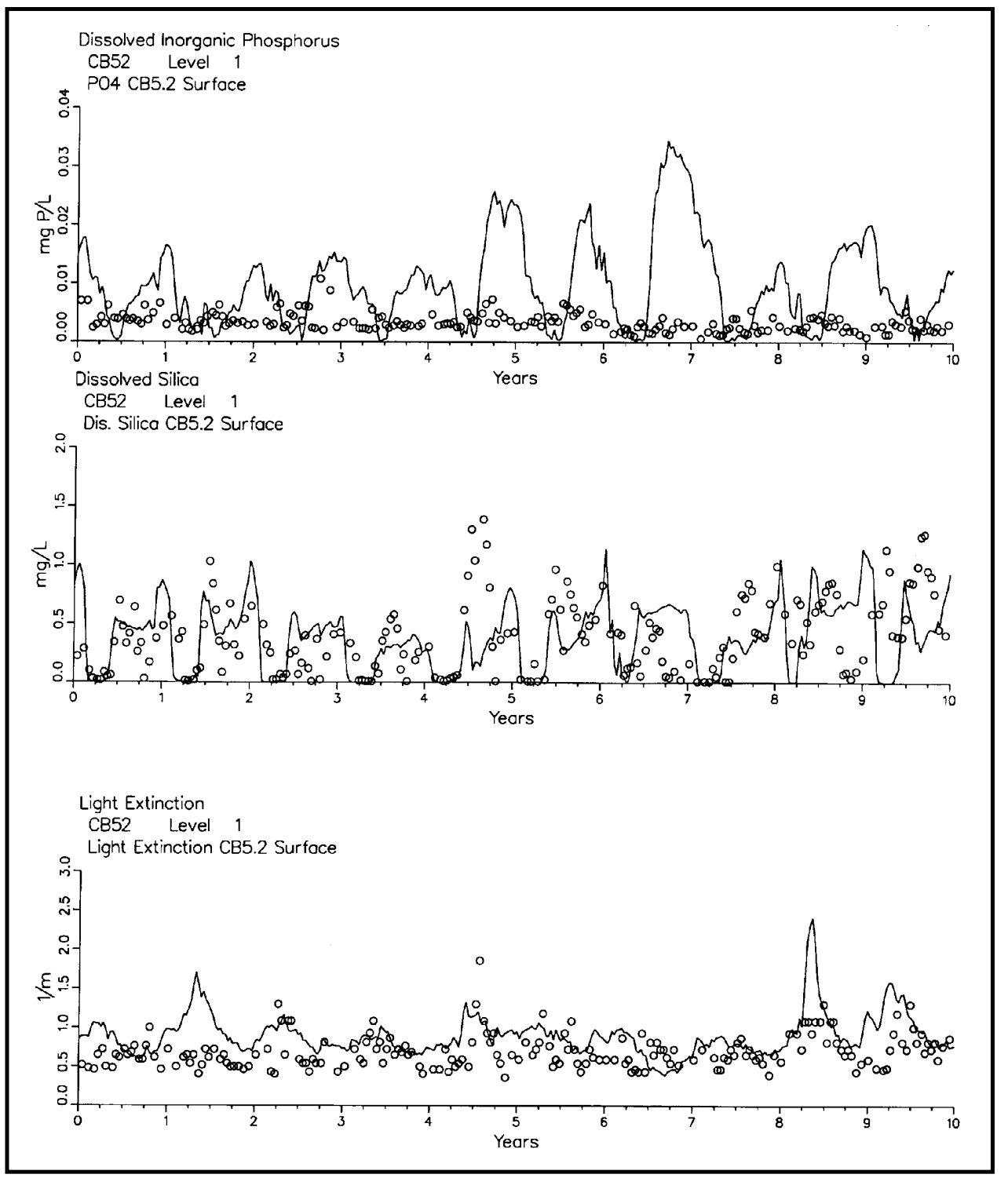

Figure 15. (Concluded)

Observed dissolved silica exhibits a strong seasonal pattern that is out of phase with runoff events. Observed silica is usually least during spring, when diatom uptake is large. Following the spring bloom, silica concentrations increase, despite the low volume of runoff. Concentrations fluctuate but remain at relatively high levels until the subsequent spring bloom period. Magnitude and temporal trends in dissolved silica are well reproduced in the model.

Temporal structure is also difficult to observe in the light attenuation observations. The primary phenomenon, observable in both observations and model, is the occurrence of runoff events that introduce large solids loads and carry these loads down the bay past the usual location of the turbidity maximum. These events are especially prominent in the high-flow years 1993 and 1994. 


\section{Light and nutrient limitations}

The nature and degree of nutrient limitations in the main stem bay vary with season and location. One prime determinant is runoff from the Susquehanna River. River runoff is highly enriched with nitrogen relative to algal requirements. Consequently, in spring, when runoff is high, phosphorus and silica tend to be more limiting than nitrogen (Fisher et al. 1992; Malone et al. 1996). During summer, when runoff is low and oceanic water intrudes up the bay, and when internal nutrient recycling provides a substantial portion of algal nutrient requirements, nitrogen is the most limiting nutrient (Fisher et al. 1992; Malone et al. 1996).

Since the estuary transitions from nearly oceanic conditions at the mouth to fresh water at its extreme upstream limit, nutrient limitations also show a spatial trend with phosphorus more limiting at the freshwater extreme and nitrogen and silica more limiting near the mouth (Glibert et al. 1995). Location is also the most important determinant of the relative importance of light relative to nutrient limitations. The bay exhibits a persistent turbidity maximum near the head of salt intrusion (Schubel 1968) and light can be more limiting than nutrients in this region (Fisher et al. 1992; Glibert et al. 1995).

Computed limitations to algal growth are shown at three locations in the bay: station CB2.2 located near the turbidity maximum, station 5.2 in the center of the bay, and station 7.3 located near the bay entrance (Figure 12). Limits are shown for the year 1990, which was a year of average runoff in the Susquehanna River. Although limiting factors respond to annual hydrology and loads, results shown here are largely generalizable across the simulation. Limiting factors are restricted in magnitude from zero to unity (Equation 8 ). The factor with the lowest value is most limiting.

At the upper bay station, light is the predominant limiting factor although, during the height of the spring bloom, phosphorus limitation occurs (Figure 16). Near the center of the bay, growth limits exhibit seasonal dependence (Figure 17). During the winter months (December-February) light is most limiting. As the days grow longer and the spring bloom commences, phosphate and silica become the most limiting factors. At the end of the spring bloom, the limiting nutrient transitions to nitrogen, which limits until the early winter light limit commences.

Limits at the lower bay station (Figure 18) resemble the middle bay although the winter light limitation is of shorter duration. During the spring bloom, silica predominates over phosphate as the limiting nutrient while nitrogen is most limiting from late spring through autumn.

Model computations agree well with conventional wisdom regarding spatial and temporal distribution of limiting factors. In the model, phosphate and silica are most limiting in spring while nitrogen is most limiting in summer. Computed light and phosphate limits are dominant in the upper bay while nitrogen and silica limits are dominant in the lower bay. 


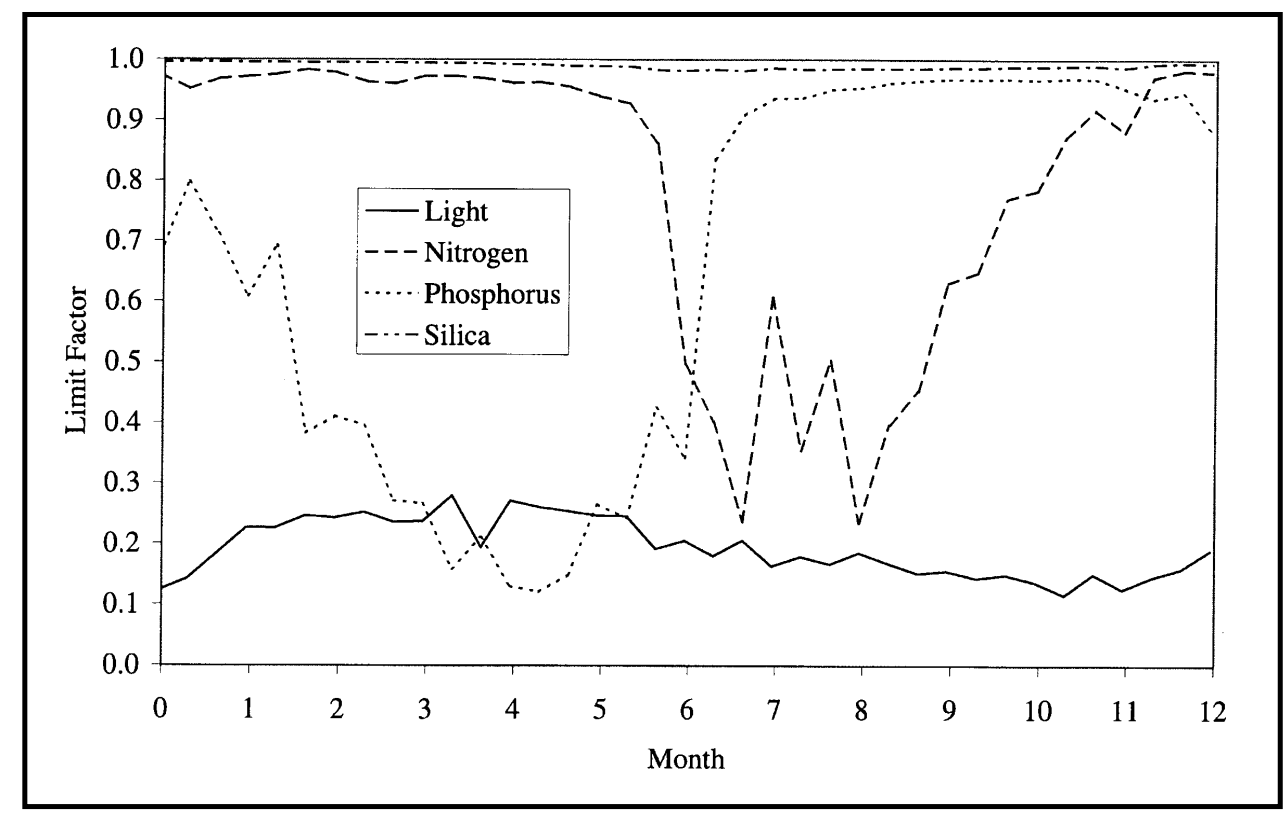

Figure 16. Growth-limiting factors at station CB2.2

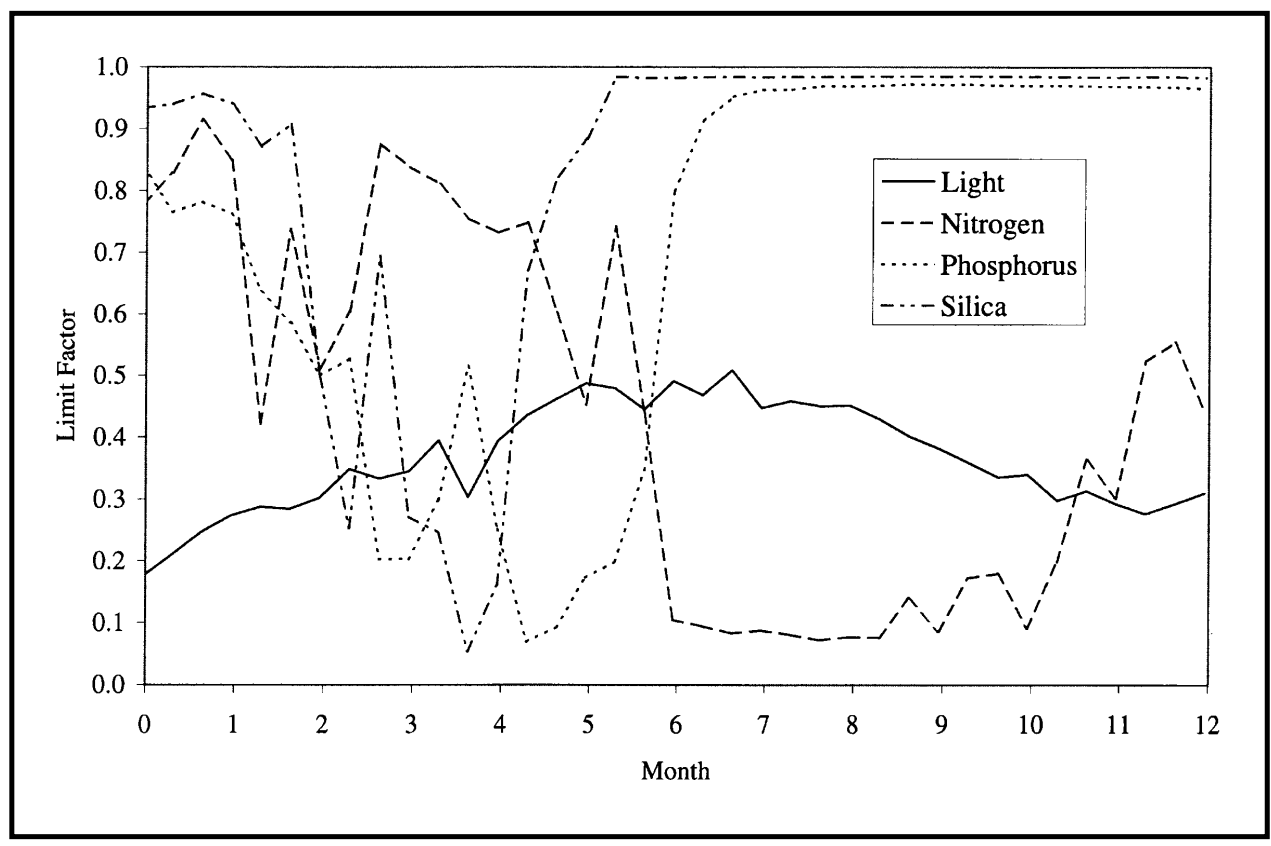

Figure 17. Growth-limiting factors at station CB5.2

\section{Primary production}

Primary production is the fixation of carbon dioxide by photosynthesis. Substantial variation exists in techniques to measure and report algal production. It can be measured in situ or in vivo, as carbon uptake or as oxygen evolution. Production is alternately reported on a volumetric or areal basis. Techniques and reporting influence the methods for comparison of computed and observed values. 


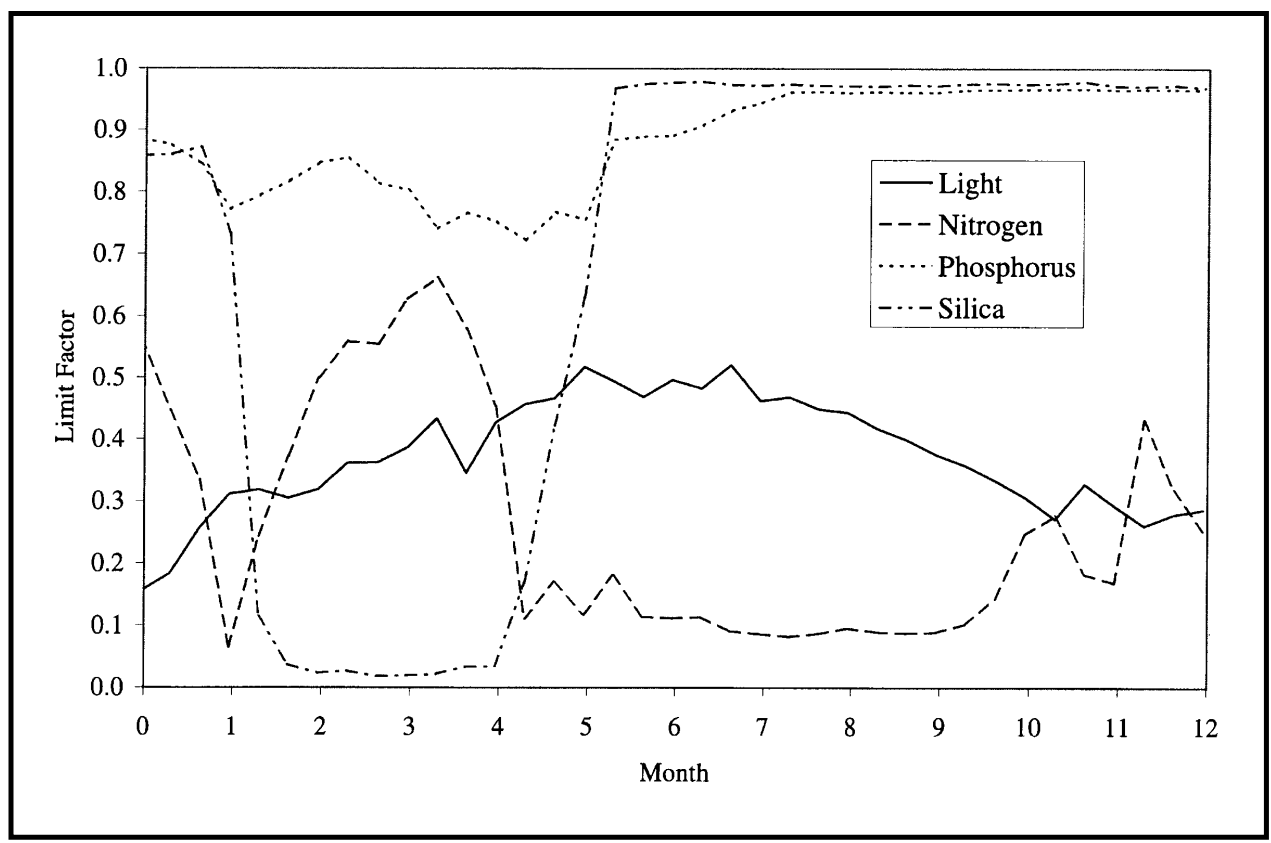

Figure 18. Growth-limiting factors at station CB7.3

For comparison with the model, one important factor is to differentiate between gross production and net production. Gross production is the rate of carbon fixation; net production is carbon fixation less algal respiration losses. On a volumetric basis, gross production in the present model is

$$
G P P=\frac{P \max }{C C h l} \cdot f(T) \cdot \operatorname{minimum}\left(\frac{D}{K H d+D}, \frac{I}{\sqrt{I^{2}+I k^{2}}}\right) \cdot B
$$

where GPP is gross primary production $\left(\mathrm{g} \mathrm{C} \mathrm{m}^{-3} \mathrm{~d}^{-1}\right)$.

Modeled net primary production, NPP, is the gross minus metabolism computed by Equation 9. Production on an areal basis is computed by integration of the volumetric rates over an appropriate depth.

\section{Primary production measures in Chesapeake Bay}

Measures of primary production were collected by Harding, Meeson, and Fisher (1986) as part of the same study that provided production parameters for this model. Between March 1982 and April 1983, measures were collected at stations (Figure 19) grouped below the Susquehanna River mouth, in the reach from the Chester to Choptank Rivers, and in the reach from the Potomac to Rappahannock River mouths. Simulated in situ incubations were conducted on deck, four times daily, using the ${ }^{14} \mathrm{C}$ method. Measures were integrated over the depth of the pycnocline or the depth of the photic zone, whichever was greater, and reported as net production. 


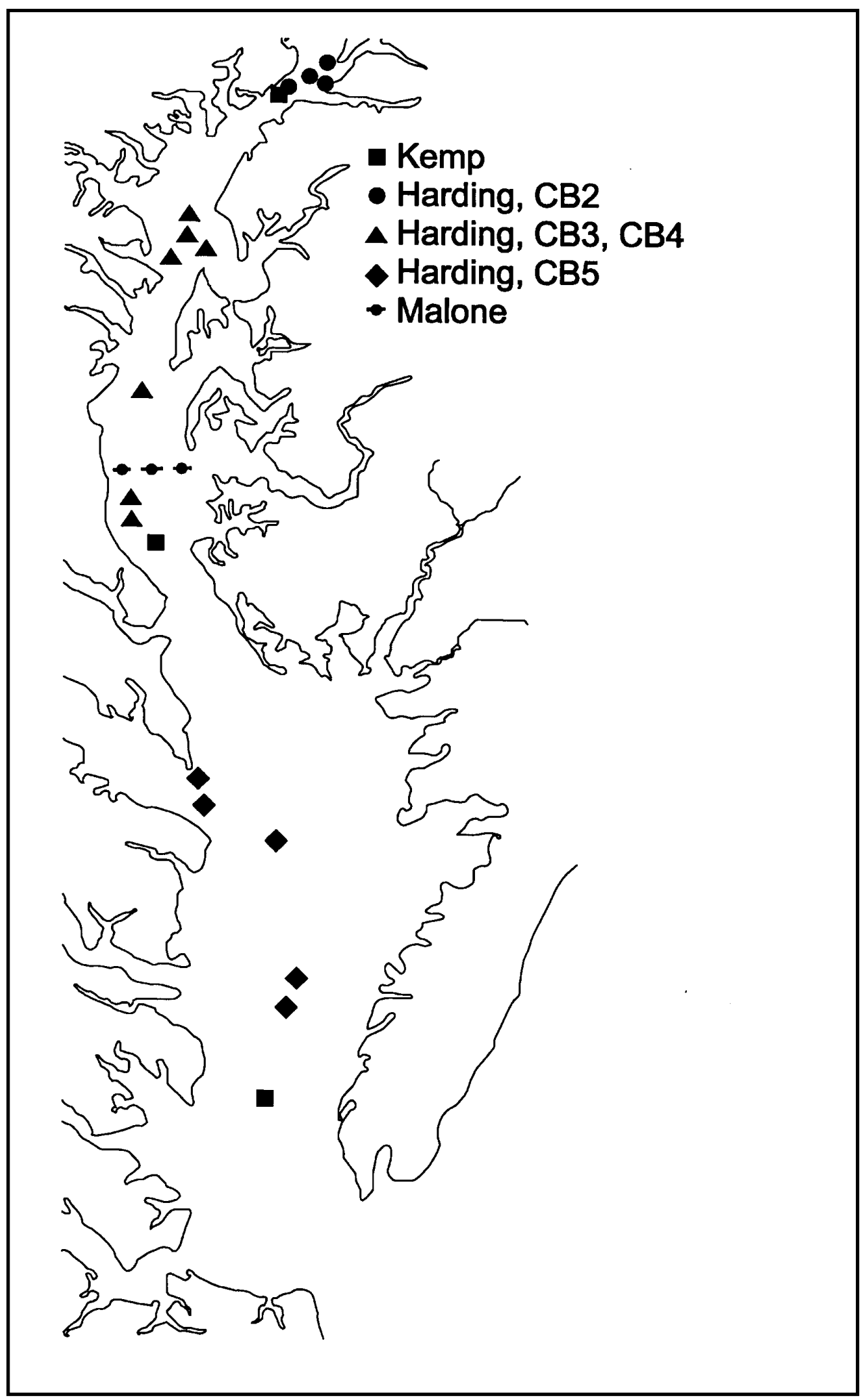

Figure 19. Location of primary production measures in Chesapeake Bay 
Malone et al. (1988) conducted primary production measures at a transect located opposite the mouth of the Choptank River (Figure 19). The ${ }^{14} \mathrm{C}$ method was employed in 24-hour on-deck incubations conducted over a 2-year period, 1985-1986. The 24-hour incubations provided estimates of net productivity in the photic zone.

Primary production measures collected from 1990 to 1992 at three locations in the bay (Figure 19) were reported by Kemp et al. (1997). Production was measured via oxygen evolution and consumption in light and dark bottles. Incubations were conducted on deck, at multiple light levels, for a period of 4 to 5 hours. Measures were corrected for respiration and reported as gross primary production.

\section{Comparison with observations}

For comparison with the Harding, Meeson, and Fisher (1986) observations, model net primary production was integrated over the depth of the photic zone. The photic zone was defined as the depth of 1 percent light penetration, based on light attenuation as computed within the model. Observations were compared to computations in the model years closest to the observations, 1985-1986. In the upper bay (Figure 20), observed and modeled primary production are in reasonable agreement. Maximum observed production, roughly $0.8 \mathrm{~g} \mathrm{C} \mathrm{m}^{-2} \mathrm{~d}^{-1}$, compared to a modeled maximum of $1.2 \mathrm{~g} \mathrm{C} \mathrm{m}^{-2} \mathrm{~d}^{-1}$. A deterministic relation of observations to temperature cannot be discerned although, clearly, primary production measured at temperatures exceeding $10{ }^{\circ} \mathrm{C}$ exceeds primary production measured at lower temperatures. The model exhibits a general exponential dependence of primary production on temperature with maxima occurring in a broad band between 15 and $25^{\circ} \mathrm{C}$.

Monotonic temperature dependence is absent from the observations collected near the Chester and Choptank Rivers (Figure 21). Primary production peaks were observed during the spring bloom period at $6{ }^{\circ} \mathrm{C}$ and during the summer period of maximum temperatures. Modeled production again showed a dependence on temperature. Maximum modeled production was substantially lower than observed.

Observed primary production in the midbay to lower bay (Figure 22) exhibited a U-shaped dependence on temperature. Maximum production occurred at the coldest temperature, during the spring bloom. Elevated production also was observed during summer at temperatures of 15 to $25^{\circ} \mathrm{C}$. The model clearly replicated the U-shaped temperature function and the magnitude of observed primary production although the modeled maximum occurred in summer, not spring.

The observations of Malone et al. (1988) demonstrated strong interannual variability in primary production. In 1985, maximum production occurred in August-October. Maximum production was lower in 1986 and occurred earlier in the summer. Maximum observations, roughly $4.5 \mathrm{~g} \mathrm{C} \mathrm{m}^{2} \mathrm{~d}^{-1}$, were substantially 


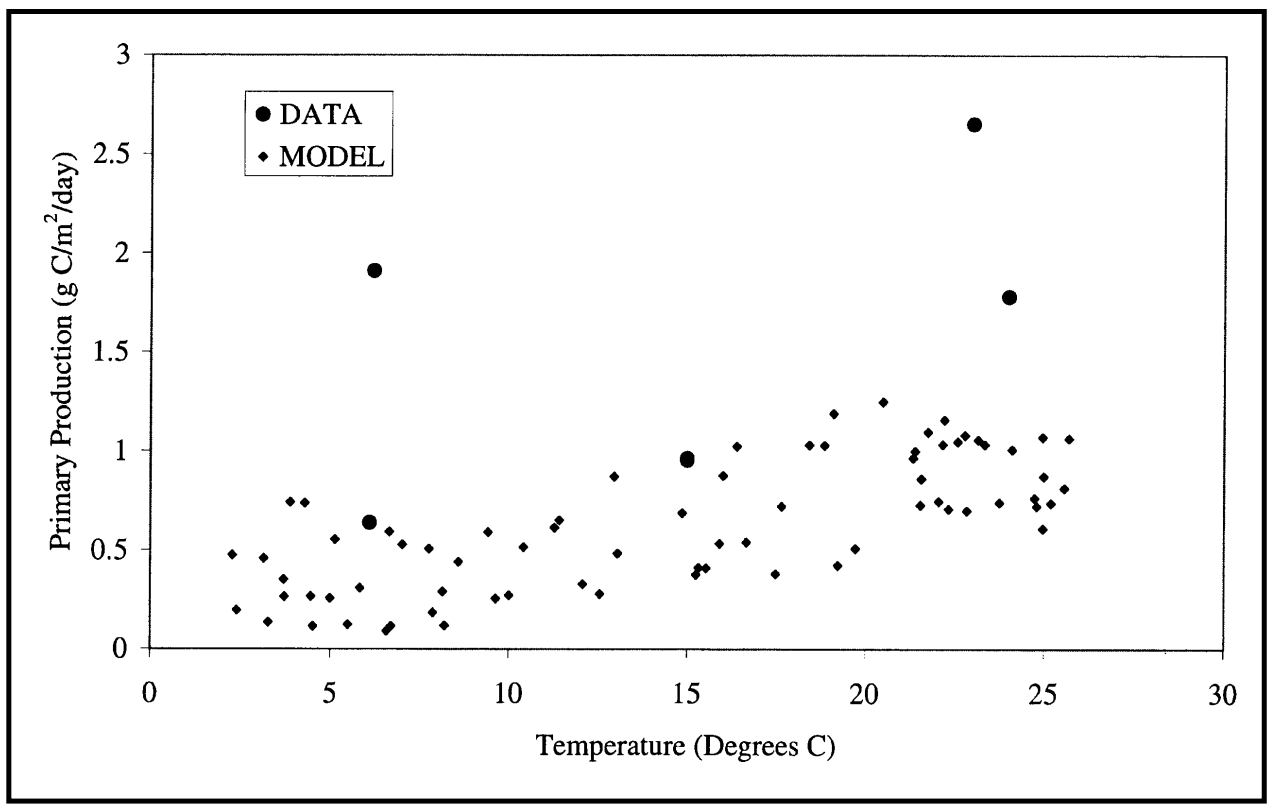

Figure 20. Computed and observed net primary production in segment CB2

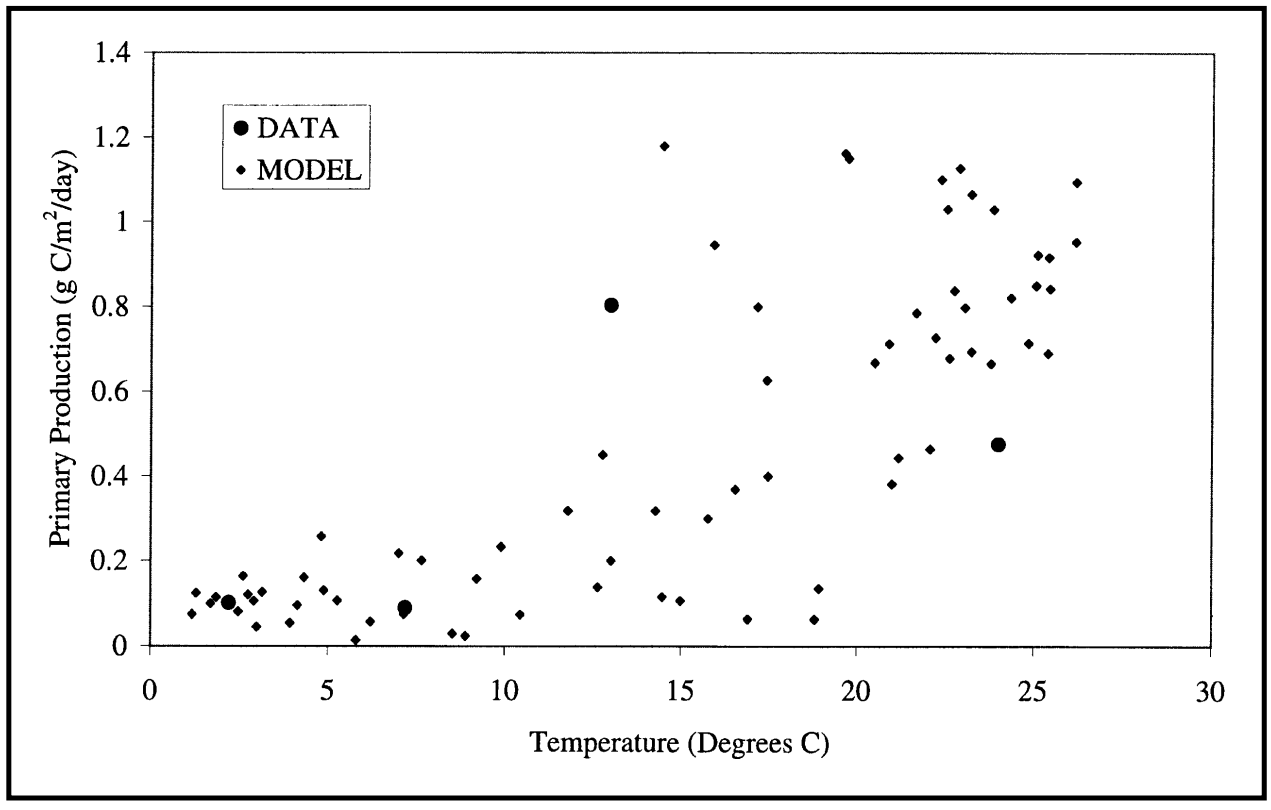

Figure 21. Computed and observed net primary production in segments CB3 and CB4

higher than maxima observed by Harding, Meeson, and Fisher (1986) in the same area. For comparison with this data set, model net primary production was again integrated over the depth of the photic zone. Model values agree with data in the winter-spring period, February-May but fall short of observations in JuneDecember (Figure 23). 


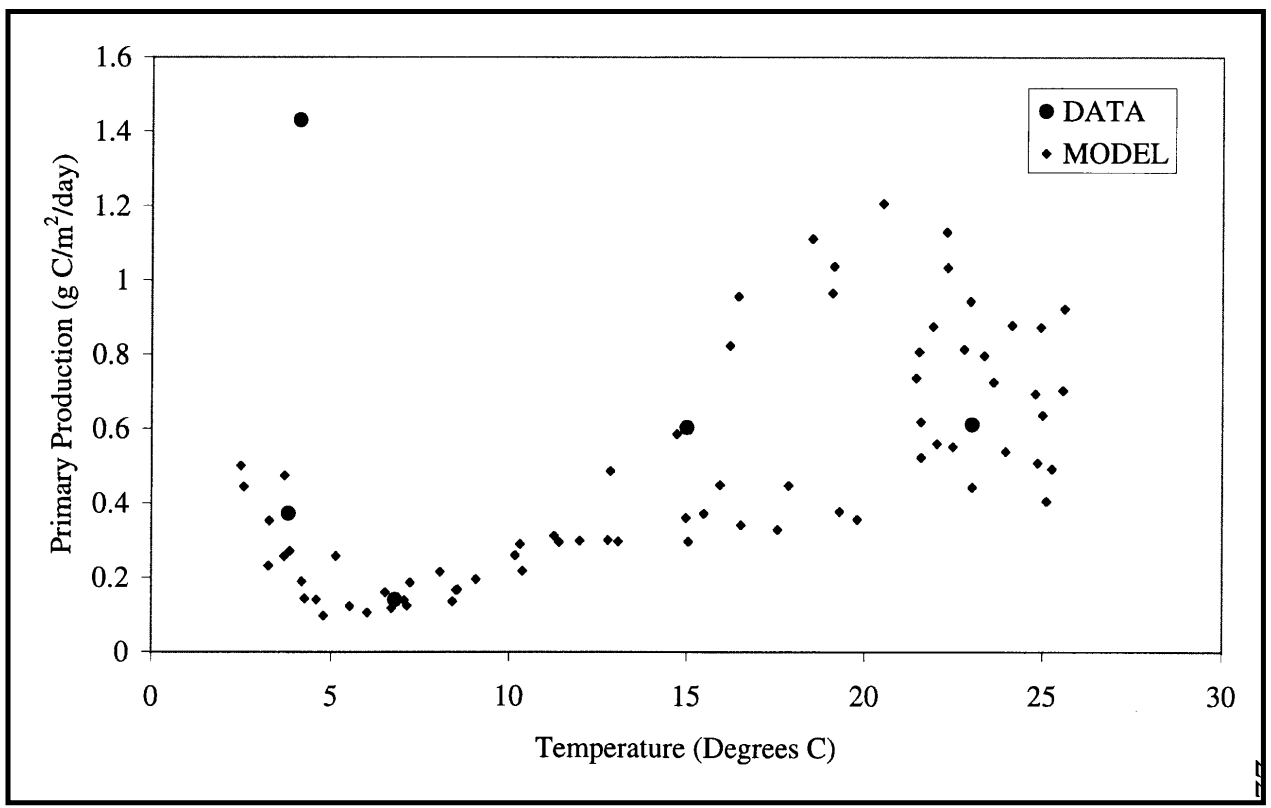

Figure 22. Computed and observed net primary production in segment CB5

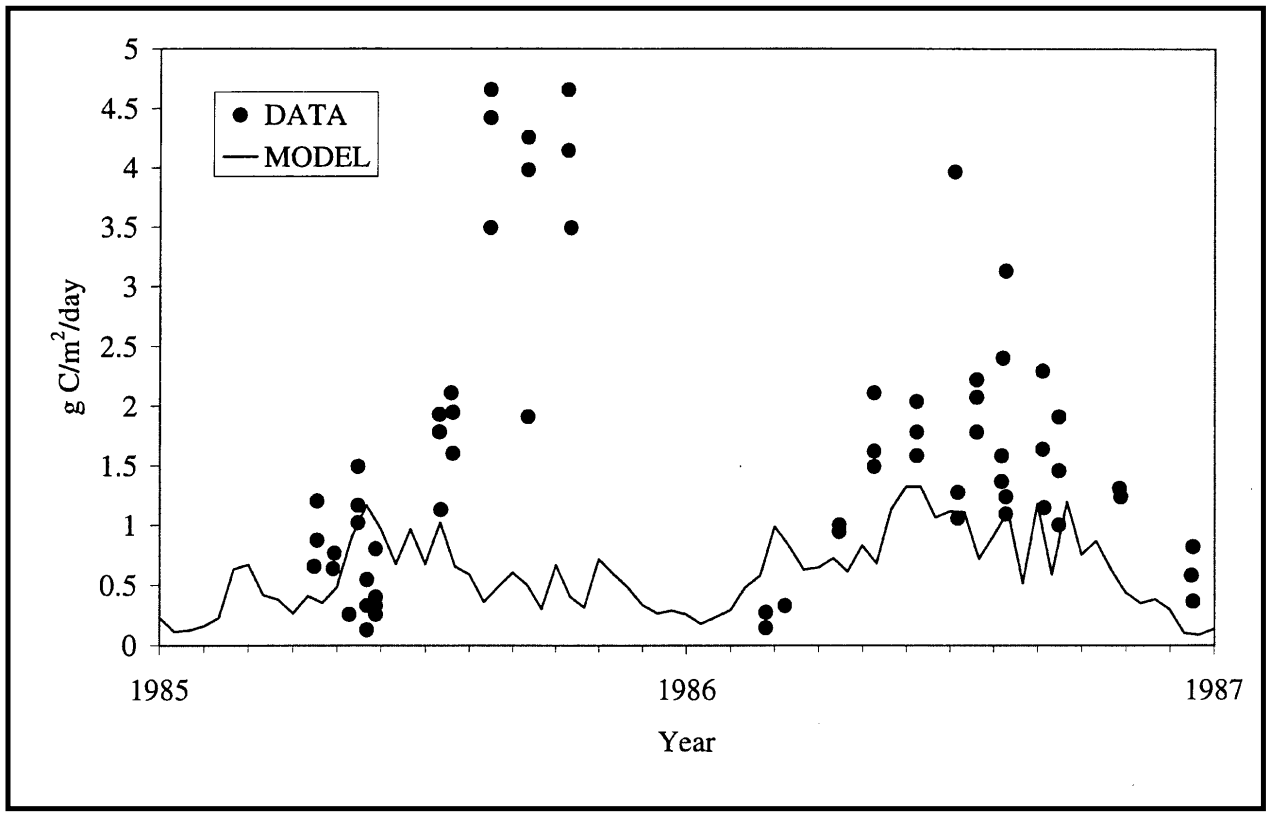

Figure 23. Computed and observed net primary production in Choptank-Patuxent transect

Kemp et al. (1997) combined their observations from 3 years into annual time series at three stations. For comparison, model gross production from 1990-1992 was averaged into annual time series at corresponding locations. At the upper bay station (Figure 24), modeled gross production exhibited the same temporal behavior as the observed but was twice as large. In the middle bay and lower bay, modeled production was in reasonable agreement with observations in the period October through March but was short of observed rates from April through August (Figures 25 and 26). 


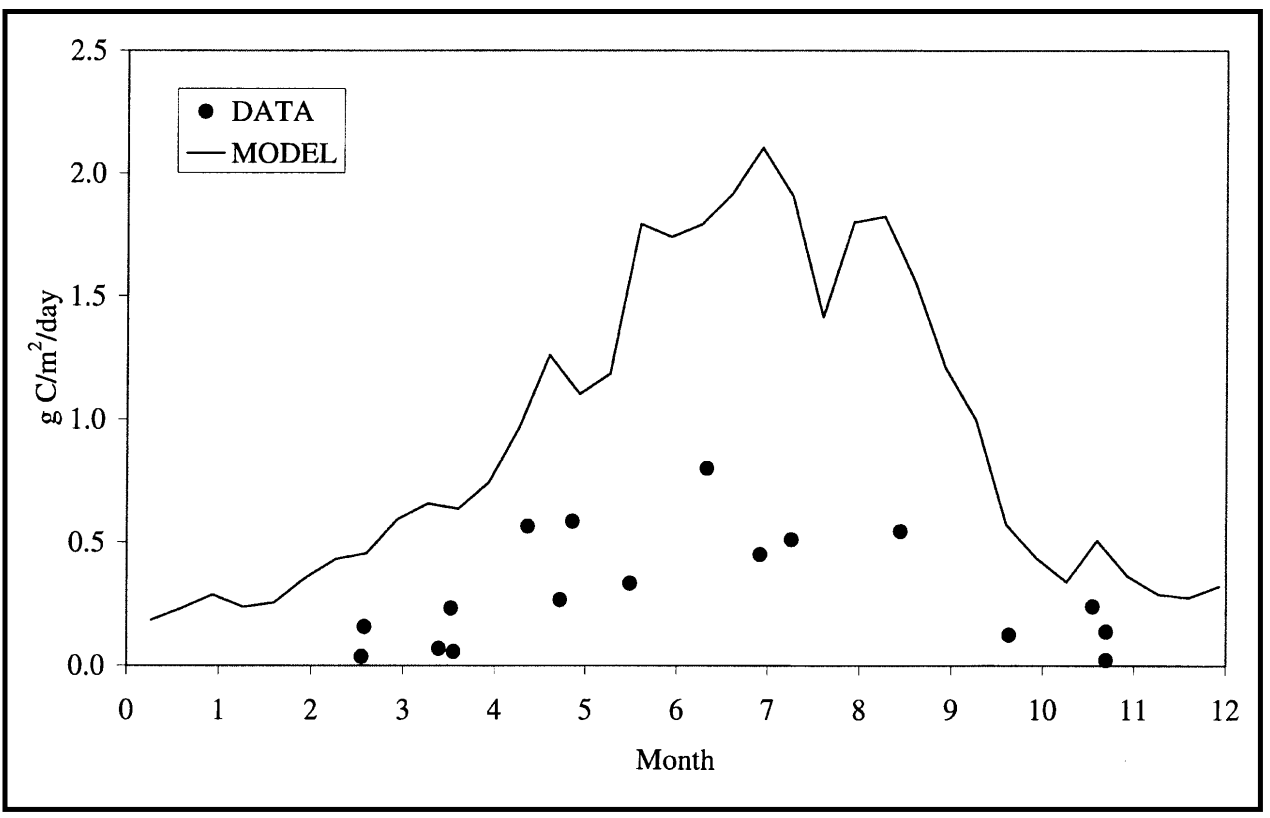

Figure 24. Computed and observed gross primary production at upper bay station

\section{Discussion}

The kinetics formulations documented here are nearly identical to those employed in the tributary refinements phase of the Chesapeake Bay model (Cerco and Meyers 2000). Parameter values were revised, however, to improve agreement with reported parameters. As a consequence, the present model results are not optimal in the sense that computed concentrations match observations. In some instances (e.g., dissolved inorganic phosphorus in summer) differences exist between computations and observations that would not be tolerated in a management application. The discrepancies that exist between computations and observations are indicative of areas in which improved formulations or measures of parameter values are required.

Observations (Figures 13 and 14) suggest that the light limitation in the turbidity maximum around $\mathrm{km} 280$ is more severe than computed in the model. The model parameter $\alpha$, which determines light sensitivity, can readily be adjusted to produce greater light limitation in the turbidity maximum. Under these circumstances, computed ammonium and phosphate increase providing improved agreement with observations. Elsewhere in the system, however, the light limit becomes exaggerated. Consequently, $\alpha$ was specified to provide a reasonable representation of light limitation systemwide.

The high computed phosphate concentrations (Figure 15) can be countered by increasing the phosphorus content of algal cells, APC. Increasing APC promotes too great a phosphorus limit at other times of the year, however. Consequently, APC was specified to correctly represent phosphate during spring, when reports indicate phosphorus limitation is most significant. 


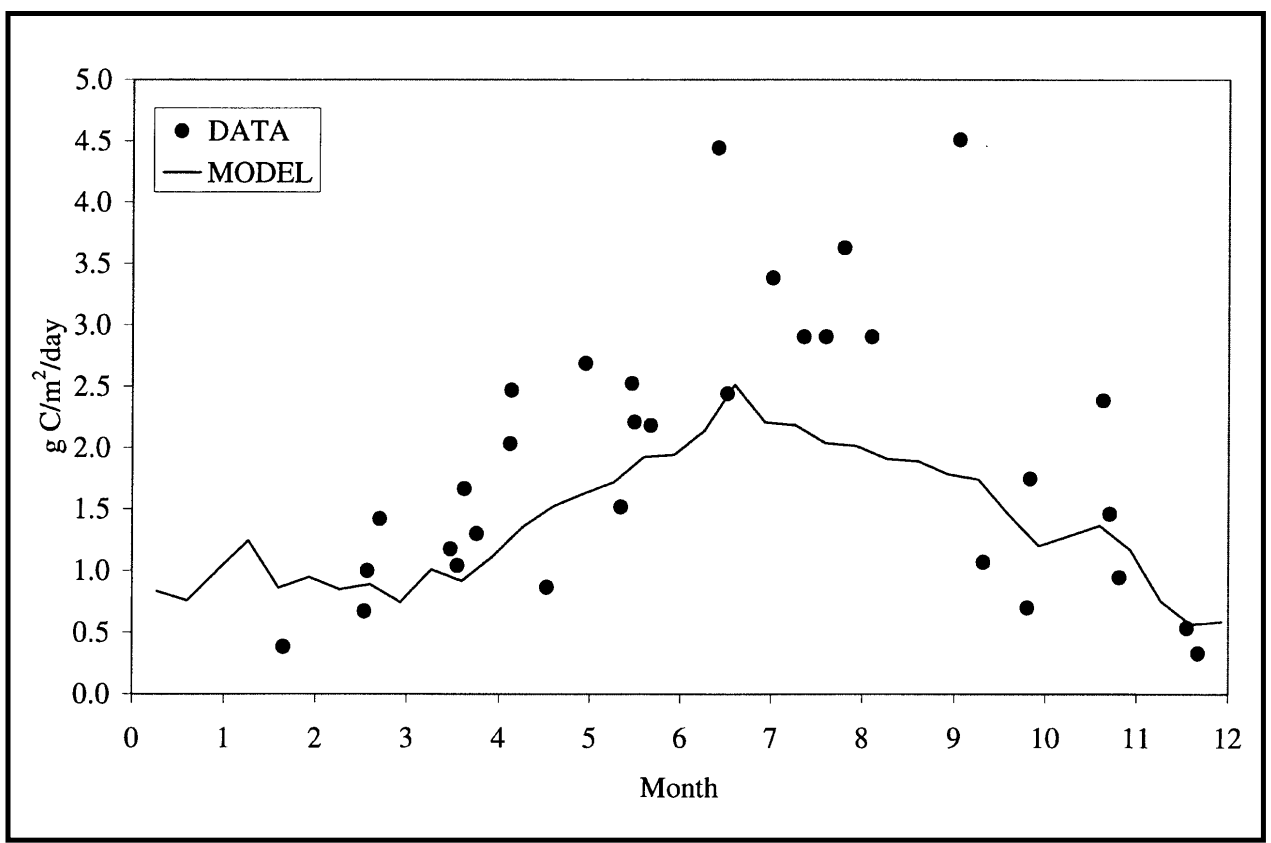

Figure 25. Computed and observed gross primary production at midbay station

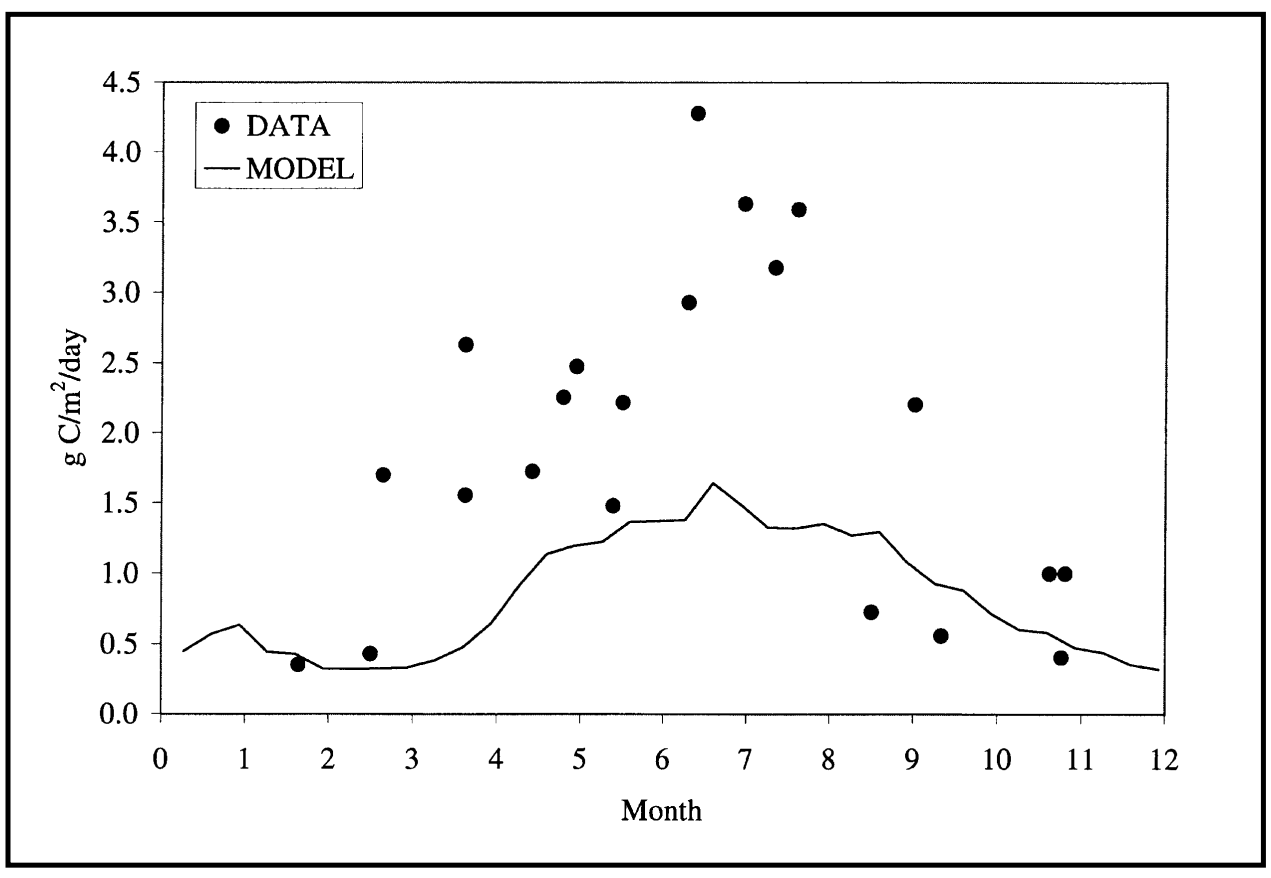

Figure 26. Computed and observed gross primary production at lower bay station

The accomplishments of the present study should not be underestimated. Decade-long, continuous, systemwide simulations were performed on a routine basis. The simulations of eutrophication processes were coupled to detailed, threedimensional hydrodynamics computed at 5-minute intervals. Loads from a $166,000-\mathrm{km}^{2}$ watershed were routed to the headwaters and shores of the bay. Over 
$10^{6}$ observations were processed for comparison with the model. The comparisons indicate largely excellent agreement between computed chlorophyll, nutrients, and other substances.

Although different results are possible, the chances of substantially improved results from the present formulation are slim. Consequently, it is worth examining where the model falls short and considering the possibility of improved formulations.

The magnitude of the spring subsurface chlorophyll maximum has been undercomputed since the earliest phases of this study. Although more-or-less successful computations have been obtained by varying settling velocities and respiration rates, clearly something is missing from the model. Most likely, the ability of diatoms to regulate their buoyancy (Bienfang, Harrison, and Quarmby 1982; Richardson and Cullen 1995; Waite, Thompson, and Harrison 1992). At present, algae are represented as passive particles that can only settle. Creation of localized aggregations is discouraged by vertical diffusion, which moves algae against the concentration gradient. Although the treatment of algae as Lagrangian particles with individual behaviors is a long way off, insertion of processes into the model that simulate phytoplankton behavior as a function of light and nutrients should be possible.

The earliest version of this model incorporated an empirical representation of variable algal phosphorus stoichiometry (Cerco and Cole 1994). The iterative algorithm was computationally burdensome and dropped from the formulation. Since then, advances have been made in the formulation of phytoplankton models that compute both variable carbon-to-chlorophyll and nitrogen-to-chlorophyll ratios (Laws and Chalup 1990; Cloern, Grenz, and Vidergar-Lucas 1995). Although a complete model of algal composition as a function of temperature, light, and nutrients is not available, introduction of available formulations will begin to address some of the problems encountered in this study. Computation of carbon-to-chlorophyll ratio as a function of light may balance the light limitation between the turbidity maximum and other regions of the bay. Reintroduction of variable stoichiometry, computed from sound principles, will help balance the computation of phosphate throughout the seasons.

The present model was calibrated to "states" of the system. That is, parameters were adjusted to optimize agreement between computed and observed concentrations. No attempt was made to examine computed rates of production or recycling. Subsequent comparisons of computed and observed primary production indicated the model was only partially successful in reproducing this key rate. Comparisons were most successful in the upper bay (Figures 20 and 24) and during winter and early spring (Figures 23, 25, and 26). Production in the turbidity maximum and in winter-spring is largely light limited. In regions and periods in which production is strongly nutrient limited, the model undercomputes primary production (Figures 21, 23, 25, and 26).

Computed and observed primary production compare well in turbid, nutrientrich portions of the bay and during winter when productivity is low. When observed production is maximal and strongly nutrient-limited, computations tend 
to be low. One question is whether this behavior is unique to the present model or characteristic of a range of similar models. While model studies that examine sensitivity of primary production to various factors are plentiful, models that explicitly compare computed and observed primary production are difficult to find. When the search is narrowed to models that compute both nutrient and light effects on primary production, the field gets narrower still.

Fasham, Ducklow, and McKelvie (1990) applied a model that included phytoplankton, zooplankton, bacteria and nutrients to ocean station S near Bermuda. They calibrated their model to match observed primary production. Their simulations "greatly overestimated the phytoplankton biomass in the summer and autumn." Their results are the inverse of the present model. In Chesapeake Bay, summer phytoplankton biomass is well represented, but primary production is underestimated. At station S summer primary production was matched, but phytoplankton biomass was overestimated.

Doney, Glover, and Najjar (1996) modeled phytoplankton, zooplankton, and nutrients near Bermuda also. The preponderance of primary production observations exceeded computed rates. They noted model performance was weakest "during late summer, when the model cannot supply enough nutrients to support the high production observed."

The results of McGillicuddy, McCarthy, and Robinson (1995) are especially interesting. They showed computed and observed vertical profiles of primary production in the North Atlantic. In 10 of 13 cases, primary production was undercomputed at the surface, where light is abundant and nutrients are scarce. In deeper waters, where light is attenuated and nutrients are more abundant, modeldata comparisons were much improved. Their results were analogous to the present model in which production is matched or exceeded in light-limited regions but not in nutrient-limited regions.

If the results obtained here are widely applicable, the first question is why? One response is the relation

$$
G P P=\frac{P \max }{C C h l} \cdot f(T) \cdot \frac{D}{K H d+D} \cdot B
$$

that applies under nutrient-limited conditions is not appropriate. Changes in algal carbon-to-chlorophyll ratio in response to nutrient-limited conditions are welldocumented (e.g., Laws and Bannister 1980; Riemann, Simonsen, and Stensgaard 1989). Cloern, Grenz, and Vidergar-Lucas (1995) compared algal growth rates computed with alternate model formulations. One model explicitly accounted for nutrient effects on carbon-to-chlorophyll ratio. The second model formulation was identical to the present one. Computed growth rate with the first model was often substantially higher than with the second model. The greatest differences, however, were under conditions of low light and high nutrients. Under strongly nutrient-limited conditions, differences in the two models were not substantial. 
A second possibility is that the formulation for production under nutrientlimited conditions is correct but the pool of available nutrients should be expanded to include some fraction of dissolved organic forms. Recently, Lomas and Glibert (1999) reported that up to 40 percent of nitrogen uptake by Chesapeake Bay phytoplankton is in the form of urea.

Still another possibility is that some behavioral process is missing from the model. Heaney and Eppley (1981) noted that vertical migrations of dinoflagellates were influenced by nutrient status and that nutrient-depleted cells appear to migrate towards the oceanic nitracline. Moore and Villareal (1996) observed vertical migration of oceanic diatoms and indicated this migration is a source of nitrogen to the euphotic zone. These results suggest that the model formulation in which algae are influenced solely by nutrient concentrations in their local cell requires revision. The spacing of cells in the vertical is a construct required to model vertical density structure. If algae are capable of migrating vertically, then perhaps algal concentrations and available nutrients should be averaged over a length scale that describes the extent of their migrations.

Another question is: "Does the underestimation of primary production matter?" The answer is: "It depends on the objective of the model." The present model construct provides excellent comparisons of computed and observed algal biomass and of the factors that limit biomass. If the objective of a model study is to compute algal biomass and to investigate the management of biomass through nutrient controls, the present construct is adequate. If the objective of a model is to reproduce the carbon cycle or to investigate the transfer of production from primary producers to high trophic levels, then the present construct requires revision.

\section{References}

Ambrose, R., Wool, T., Martin, J., Connolly, J., and Schanz, R. (1991). "WASP4, a hydrodynamic and water quality model - model theory, user's manual, and programmer's guide," Environmental Research Laboratory, Office of Research and Development, U.S. Environmental Protection Agency, Athens, GA.

Bartleson, R., Boynton, W., Brandt, S., Hagy, J., Hartman, K., Kemp, W., Luo, J., Madden, C., Meyers, M., Rippetoe, T., and Wetzel, R. (1994). "Chesapeake Bay ecosystem modeling program technical synthesis report 1993-1994," U.S. Environmental Protection Agency, Chesapeake Bay Program Office, Annapolis, MD.

Bienfang, P., Harrison, P., and Quarmby, L. (1982). "Sinking rate response to depletion of nitrate, phosphate, and silicate in four marine diatoms," Marine Biology 67, 295-302.

Boynton, W., and Kemp, W. (1985). "Nutrient regeneration and oxygen consumption along an estuarine salinity gradient," Marine Ecology Progress Series 23, 45-55. 
Cerco, C. (1995a). "Response of Chesapeake Bay to nutrient load reductions," Journal of Environmental Engineering 121(8), 549-557.

(1995b). "Simulation of long-term trends in Chesapeake Bay eutrophication," Journal of Environmental Engineering 121(4), 298-310.

Cerco, C., and Cole, T. (1993). "Three-dimensional eutrophication model of Chesapeake Bay," Journal of Environmental Engineering 119(6), 100610025.

. (1994). "Three-dimensional eutrophication model of Chesapeake Bay,” Technical Report EL-94-4, U.S. Army Engineer Waterways Experiment Station, Vicksburg, MS.

Cerco, C., and Meyers, M. (2000). "Tributary refinements to the Chesapeake Bay model," Journal of Environmental Engineering 126(2), 164-174.

Cloern, J., Grenz, C., and Vidergar-Lucas, L. (1995). "An empirical model of the phytoplankton chlorophyll:carbon ratio - The conversion factor between productivity and growth rate," Limnology and Oceanography 40(7), 13131321.

Cole, T., and Buchak, E. (1995). "CE-QUAL-W2: A two-dimensional, laterally averaged, hydrodynamic and water quality model, version 2.0," Instruction Report EL-95-1, U.S. Army Engineer Waterways Experiment Station, Vicksburg, MS.

Davis, C., Breitner, N., and Harrison, P. (1978). "Continuous culture of marine diatoms under silicon limitation. 3. A model of Si-limited diatom growth," Limnology and Oceanography 23, 41-52.

DiToro, D., O'Connor, S., and Thomann, R. (1971). "A dynamic model of the phytoplankton population in the Sacramento-San Joaquin Delta." Nonequilibrium systems in water chemistry. American Chemical Society, Washington, DC, 131-180.

DiToro, D., and Fitzpatrick, J. (1993). "Chesapeake Bay sediment flux model," Contract Report EL-93-2, U.S. Army Engineer Waterways Experiment Station, Vicksburg, MS.

Doney, S., Glover, D., and Najjar, R. (1996), “A new coupled, one-dimensional biological-physical model for the upper ocean: Applications to the JGOFS Bermuda Atlantic Time-series Study (BATS) site," Deep Sea Research II 43(2-3), 591-624.

Donigian, A., Bicknell, B., Patwardhan, A., Linker, L., Alegre, D., Chang, C., and Reynolds, R. (1991). "Watershed model application to calculate bay nutrient loadings," U.S. Environmental Protection Agency, Chesapeake Bay Program Office, Annapolis, MD.

Eppley, R., Holm-Hansen, O., and Strickland, J. (1968). "Some observations on the vertical migration of dinoflagellates," Journal of Phychology 4, 333-340.

Eppley, R., Rogers, J., and McCarthy, J. (1969). "Half-saturation constants for uptake of nitrate and ammonium by marine phytoplankton," Limnology and Oceanography 14(6), 912-920. 
Fasham, M., Ducklow, H., and McKelvie, S. (1990). "A nitrogen-based model of plankton dynamics in the oceanic mixed layer," Journal of Marine Research 48, 591-639.

Fisher, T., Peele, E., Ammerman, J., and Harding, L. (1992). "Nutrient limitation of phytoplankton in Chesapeake Bay," Marine Ecology Progress Series 82, 51-63.

Foree, E., and McCarty, P. (1970). "Anaerobic decomposition of algae," Environmental Science and Technology 4, 842-849.

Garber, J. (1984). "Laboratory study of nitrogen and phosphorus remineralization during the decomposition of coastal plankton and seston," Estuarine, Coastal and Shelf Science 18, 685-702.

Glibert, P., Conley, D., Fisher, T., Harding, L., and Malone, T. (1995). "Dynamics of the 1990 winter/spring bloom in Chesapeake Bay," Marine Ecology Progress Series 122, 27-43.

Grill, E., and Richards, F. (1964). "Nutrient regeneration from phytoplankton decomposing in seawater," Journal of Marine Research 22, 51-69.

Harding, L., Meeson, B., and Fisher, T. (1986). "Phytoplankton production in two east coast estuaries: Photosynthesis-light functions and patterns of carbon assimilation in Chesapeake and Delaware bays," Estuarine, Coastal and Shelf Science 23, 773-806.

Heaney, S., and Eppley, R. (1981). "Light, temperature and nitrogen as interacting factors affecting diel vertical migrations of dinoflagellates in culture," Journal of Plankton Research 3(2), 331-344.

Hutchinson, G. (1967). A treatise on limnology. Volume II, John Wiley, New York, 245-305.

HydroQual. (1987). "A steady-state coupled hydrodynamic/water quality model of the eutrophication and anoxia process in Chesapeake Bay," Final Report, HydroQual, Inc., Mahwah, NJ.

Jassby, A., and Platt, T. (1976). "Mathematical formulation of the relationship between photosynthesis and light for phytoplankton," Limnology and Oceanography 21, 540-547.

Johnson, B., Kim, K., Heath, R., Hsieh, B., and Butler, L. (1993). "Validation of a three-dimensional hydrodynamic model of Chesapeake Bay," Journal of Hydraulic Engineering 199(1), 2-20.

Keefe, C. (1994). "The contribution of inorganic compounds to the particulate carbon, nitrogen, and phosphorus in suspended matter and surface sediments of Chesapeake Bay," Estuaries 17(1B), 122-130.

Kemp, W., Smith, E., DiPasquale, M., and Boynton, W. (1997). "Organic carbon balance and net ecosystem metabolism in Chesapeake Bay," Marine Ecology Progress Series 150, 229-248.

Laws, E., and Archie, J. (1981). "Appropriate use of regression analysis in marine biology," Marine Biology 65, 13-16. 
Laws, E., and Bannister, T. (1980). "Nutrient- and light-limited growth of Thalassiosira fluviatis in continuous culture, with implications for phytoplankton growth in the ocean," Limnology and Oceanography 25(3), 457473.

Laws, E., and Chalup, M. (1990). "A microalgal growth model," Limnology and Oceanography 35(3), 597-608.

Leonard, B. (1979). "A stable and accurate convection modeling procedure based on quadratic upstream interpolation," Computer Methods in Applied Mechanics and Engineering 19, 59-98.

Lomas, M., and Glibert, P. (1999). "Temperature regulation of nitrate uptake: A novel hypothesis about nitrate uptake and reduction in cool-water diatoms," Limnology and Oceanography 44(3), 556-572.

Malone, T., Crocker, L., Pike, S., and Wendler, B. (1988). "Influences of river flow on the dynamics of phytoplankton production in a partially stratified estuary," Marine Ecology Progress Series 48, 235-249.

Malone, T., Conley, D., Fisher, T., Glibert, P., Harding, L., and Sellner, K. (1996). "Scales of nutrient-limited phytoplankton productivity in Chesapeake Bay," Estuaries 19(2B), 371-385.

Marshall, H., and Lacouture, R. (1986). "Seasonal patterns of growth and composition of phytoplankton in the lower Chesapeake Bay and vicinity," Estuarine, Coastal and Shelf Science 23, 115-130.

McGillicuddy, D., McCarthy, J., and Robinson, A. (1995). "Coupled physical and biological modeling of the spring bloom in the North Atlantic (I): Model formulation and one dimensional bloom processes," Deep Sea Research I 42(8), 1313-1357.

Miller, C., Penry, D., and Glibert, P. (1995). "The impact of trophic interactions on rates of nitrogen regeneration and grazing in Chesapeake Bay," Limnology and Oceanography 40(5), 1005-1011.

Monod, J. (1949). "The growth of bacterial cultures," Annual Review of Microbiology 3, 371-394.

Moore, J., and Villareal, T. (1996). "Size-ascent relationships in positively buoyant marine diatoms," Limnology and Oceanography 41(7), 1514-1520.

Morales, C. (1987). "Carbon and nitrogen content of copepod faecal pellets: effect of food concentration and feeding behavior," Marine Ecology Progress Series $36,107-114$.

Odum, E. (1971). Fundamentals of Ecology. 3rd ed., W. B. Saunders, Philadelphia, PA, 106-107.

Otsuki, A., and Hanya, T. (1972). "Production of dissolved organic matter from dead green algal cells. I. Aerobic microbial decomposition," Limnology and Oceanography 17, 248-257.

Parsons, T., Takahashi, M., and Hargrave, B. (1984). Biological oceanographic processes. 3rd ed., Pergamon Press, Oxford. 
Pett, R. (1989). "Kinetics of microbial mineralization of organic carbon from detrital Skeletonema Costatum cells," Marine Ecology Progress Series 52, 123-128.

Pritchard, D. (1967). "Observations of circulation in coastal plain estuaries." Estuaries. G. Lauff, ed., American Association for the Advancement of Science, Washington, 37-44.

Redfield, A., Ketchum, B., and Richards, F. (1966). "The influence of organisms on the composition of sea-water." The Sea. Volume II, Interscience Publishers, New York, 26-48.

Richardson, T., and Cullen, J. (1995). "Changes in buoyancy and chemical composition during growth of a coastal marine diatom: Ecological and biogeochemical consequences," Marine Ecology Progress Series 128, 77-90.

Ricker, W. (1973). "Linear regressions in fishery research," Journal of the Fisheries Research Board of Canada 30, 409-434.

Riebesell, U. (1989). "Comparison of sinking and sedimentation rate measurements in a diatom winter/spring bloom," Marine Ecology Progress Series 54, 109-119.

Riemann, B., Simonsen, P., and Stensgaard, L. (1989). "The carbon and chlorophyll content of phytoplankton from various nutrient regimes," Journal of Plankton Research 11(5), 1037-1045.

Schubel, J. (1968). "Turbidity maximum of the northern Chesapeake Bay," Science 161, 1013-1015.

Taft, J., Taylor, W., and McCarthy, J. (1975). "Uptake and release of phosphorus by phytoplankton in the Chesapeake Bay estuary, USA," Marine Biology 33, 21-32.

Tang, E., and Peters, R. (1995). "The allometry of algal respiration," Journal of Plankton Research 17(2), 303-315.

Thomann, R., and Fitzpatrick, J. (1982). "Calibration and verification of a mathematical model of the eutrophication of the Potomac Estuary," HydroQual, Inc., Mahwah, NJ.

Waite, A., Thompson, P., and Harrison, P. (1992). "Does energy control the sinking rates of marine diatoms?", Limnology and Oceanography 37(3), 468-477.

Wen, Y., and Peters, R. (1994). "Empirical models of phosphorus and nitrogen excretion by zooplankton," Limnology and Oceanography 39(7), 1669-1679.

Westrich, J., and Berner, R. (1984). "The role of sedimentary organic matter in bacterial sulfate reduction: The G model tested," Limnology and Oceanography 29, 236-249.

Wheeler, P., Gilbert, P., and McCarthy, J. (1982). "Ammonium uptake and incorporation by Chesapeake Bay phytoplankton: Short-term uptake kinetics," Limnology and Oceanography 27, 1113-1128. 


\section{Systemwide Submerged Aquatic Vegetation Model for Chesapeake Bay}

\section{Introduction}

Approximately 30 years ago, submerged aquatic vegetation (SAV) in Chesapeake Bay commenced an unprecedented decline. By the early 1980's, the distribution and abundance of SAV had reached a historic low point (Orth and Moore 1984). Consensus centered on increased light attenuation as the mechanism behind the decline (Kemp et al. 1983; Twilley et al. 1985). The increased attenuation was attributed directly to increased concentrations of fixed solids and indirectly to increased concentrations of nutrients in the water column. The nutrients stimulate the growth of planktonic and epiphytic algae, thereby diminishing light available to SAV leaves. Following the decline, restoration of the SAV community, largely through controls on nutrient loads, has been a cornerstone of bay management policy (Baliles et al. 1987).

Initial efforts to evaluate the benefit of nutrient controls on SAV relied on living-resources habitat criteria. A systemwide eutrophication model (Cerco and Cole 1993) was used to estimate chlorophyll concentration, nutrient concentrations, and light attenuation. These were compared to living-resources criteria (Dennison et al. 1993) and potential benefits to SAV were implied. The livingresources criteria approach had two shortcomings. First, only qualitative, not quantitative improvements were implied. Second, feedback effects between improved SAV abundance and the surrounding environment were omitted. For example, the damping effect of SAV on suspended solids (Ward, Kemp, and Boynton 1984) could not be computed. As a consequence of these shortcomings, the decision was made to incorporate an SAV submodel into the eutrophication model. This SAV submodel directly simulates SAV abundance, distribution, and interactions between SAV and the environment.

Three components are required to make up a systemwide SAV model. The first is a unit-level model of a plant. The second is an environmental model that provides light, temperature, nutrient concentrations, and other forcing functions to the plant component. The third is a coupling algorithm that links the systemwide environmental model to the local-scale plant model. The environmental model has been largely previously described (Cerco and Cole 1993). Significant 
improvements to the model since original publication include a refined, finer scale grid and simulation of suspended solids concentrations (Cerco and Meyers 2000). This chapter describes the unit model, the coupling between the unit model and the environmental model, and results of the application of the systemwide SAV model.

\section{Methods}

\section{Submerged aquatic vegetation unit model}

The SAV unit model (Figure 1) incorporates three state variables: shoots (aboveground biomass), roots (belowground biomass), and epiphytes (attached growth). Epiphytes and shoots exchange nutrients with the water-column component of the eutrophication model while roots exchange nutrients with the diagenetic sediment component (DiToro and Fitzpatrick 1993). Light available to the shoots and epiphytes is computed via a series of sequential attenuations by color, fixed and organic solids in the water column, and self-shading of shoots and epiphytes. The selection of state variables and basic principles of the model were based on principles established by Wetzel and Neckles (1986) and Madden and Kemp (1996).

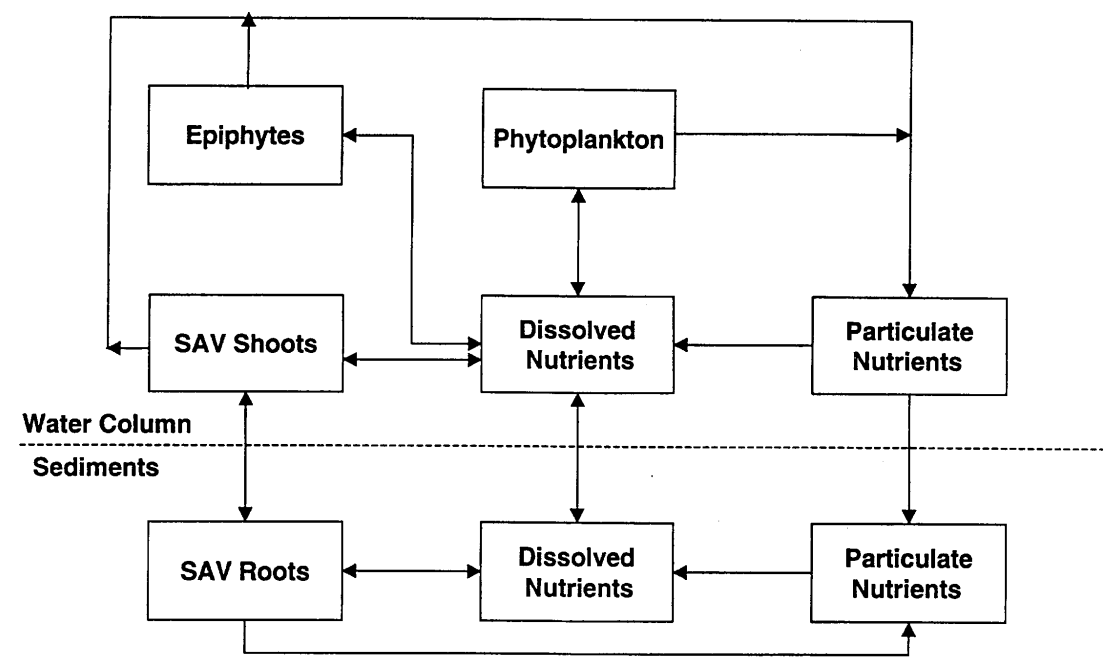

Figure 1. SAV model state variables (boxes) and mass flows (arrows)

\section{Shoots}

The governing equation for shoots establishes a balance between sources and sinks of aboveground biomass:

$$
\frac{d S H}{d t}=[P \cdot(1-F p s r)-R s h-S L] \cdot S H+\operatorname{Tr} s \cdot R T
$$


in which

$$
\begin{aligned}
S H & =\text { shoot biomass }\left(\mathrm{g} \mathrm{C} \mathrm{m}^{-2}\right) \\
t & =\text { time }(\mathrm{d}) \\
P & =\text { production }\left(\mathrm{d}^{-1}\right) \\
F p s r & =\text { fraction of production routed from shoot to root } \\
R s h & =\text { shoot respiration }\left(\mathrm{d}^{-1}\right) \\
S L & =\text { sloughing }\left(\mathrm{d}^{-1}\right) \\
T r s & =\text { rate at which carbon is transported from root to shoot }\left(\mathrm{d}^{-1}\right) \\
R T & =\text { root biomass }\left(\mathrm{g} \mathrm{C} \mathrm{m}^{-2}\right)
\end{aligned}
$$

Production is computed as the product of a specified maximum rate (a function of temperature) and a limiting factor. The limiting factor is the minimum of independently evaluated light, nitrogen, and phosphorus limitations. Light limitation is selected from one of several functions (Jassby and Platt 1976) that fit observed production versus irradiance curves:

$$
f(I)=\frac{I s h}{\sqrt{I s h^{2}+I k^{2}}}
$$

in which $f(I)$ is the light limitation, and $I s h$ is the irradiance at leaf surface $\left(\mathrm{E} \mathrm{m}^{-2}\right.$ day $\left.^{-1}\right)$. Parameter $I k$ is derived from two specified parameters:

$$
I k=\frac{\operatorname{Pmax}(T)}{\alpha}
$$

in which Pmax is the maximum production as a function of temperature $\left(\mathrm{g} \mathrm{C} \mathrm{g}^{-1} \mathrm{DW} \mathrm{d}^{-1}\right)$ and $\alpha$ is the initial slope of production versus irradiance curve $\left(\mathrm{g} \mathrm{C} \mathrm{g} \mathrm{g}^{-1} \mathrm{DW}\right)\left(\mathrm{E} \mathrm{m}^{-2}\right)^{-1}$.

Nutrient limitations for nitrogen and phosphorus are evaluated using a formula (Madden and Kemp 1996) that combines individual Monod-like functions for the roots and shoots:

$$
f(N)=\frac{N w+K^{*} \cdot N s}{K h w+N w+K^{*} \cdot N s}
$$

in which

$$
\begin{aligned}
f(N) & =\text { nutrient limitation } \\
N w & =\text { nutrient concentration }\left(\mathrm{g} \mathrm{m}^{-3}\right) \text { in water column } \\
N S & =\text { nutrient concentration }\left(\mathrm{g} \mathrm{m}^{-3}\right) \text { in sediment pore water }
\end{aligned}
$$




$$
\begin{aligned}
K h w & =\text { half-saturation concentration for nutrient uptake by shoots }\left(\mathrm{g} \mathrm{m}^{-3}\right) \\
K h s & =\text { half-saturation concentration for nutrient uptake by roots }\left(\mathrm{g} \mathrm{m}^{-3}\right) \\
K^{*} & =K h w / K h s
\end{aligned}
$$

\section{Roots}

The governing equation for roots establishes a balance between sources and sinks of belowground biomass:

$$
\frac{d R T}{d t}=F p s r \cdot P \cdot S H-R r t \cdot R T-T r s \cdot R T
$$

in which $R r t$ is root respiration $\left(\mathrm{d}^{-1}\right)$.

\section{Epiphytes}

Epiphytes are quantified as mass per unit of shoot mass:

$$
\frac{d E P \cdot S H}{d t}=(P e p \cdot D L-R e p-P R \cdot E P-S L) \cdot S H \cdot E P
$$

in which

$$
\begin{aligned}
E P & =\text { epiphyte abundance }\left(\mathrm{g} \text { epiphyte } \mathrm{C}^{-1} \text { shoot } \mathrm{C}\right) \\
P e p & =\text { epiphyte production }\left(\mathrm{d}^{-1}\right) \\
D L & =\text { density limitation function } \\
R e p & =\text { epiphyte respiration }\left(\mathrm{d}^{-1}\right) \\
P R & =\text { predation on epiphytes }\left(\mathrm{g}^{-1} \text { shoot } \mathrm{C}^{-1} \text { epiphyte } \mathrm{C} \mathrm{d}^{-1}\right)
\end{aligned}
$$

The formulation provides a change in epiphyte abundance as a function of epiphyte processes and shoot processes. Net production of epiphytes without corresponding production of shoots results in an increase in epiphyte abundance on the shoots. Net production of shoots without corresponding epiphyte production results in diminished epiphyte abundance. Sloughing results in loss of attached epiphytes and produces no net change in abundance. The density limitation function diminishes production as leaf substrate becomes filled with epiphytes.

Epiphyte production is modeled as a function of light, nutrients, and temperature. Light effects are computed using formulae similar to Equations 2 and 3 while nutrient effects are evaluated with conventional Monod functions. Neckles, Wetzel, and Orth (1993) showed that predation can be an important limitation on epiphyte abundance. Absence of data prevents inclusion of predators in the model, 
however. Instead, a linear proportionality between predators and prey is assumed. Parameter $P R$ incorporates both the proportionality and predation rate and is evaluated empirically.

\section{SAV composition and nutrient cycling}

A fundamental assumption of the model is that plants have uniform, constant composition. Nitrogen and phosphorus in plant biomass are quantified as fractions of the carbonaceous biomass. Nutrients are taken up in stoichiometric relation to net production. Proportions removed from the water column and sediments are determined by the relative nutrient limits in each pool. Respiration and sloughing return appropriate quantities of nutrients to the sediments and water column.

\section{The light field}

A conceptual model has been long established in which light reaching SAV shoots is first attenuated by dissolved and particulate matter in the water column and next by epiphytic material (e.g., Kemp et al. 1983). The representation of selfshading by shoots and by epiphytes and potential shading of epiphytes by SAV is murkier. One approach is to incorporate density-limiting functions into the model that simulate both self-shading and space limitations (Wetzel and Neckles 1986; Madden and Kemp 1996). The density-limit approach is adopted here for epiphytes since it appears reasonable that epiphyte abundance will ultimately be limited by leaf substrate available for attachment. The concept of a space limitation on SAV shoots is less appealing, however. Consequently, self-shading by SAV shoots is considered explicitly.

Light available to SAV shoots is computed through a series of sequential attenuations. First, light at the top of the canopy is computed:

$$
I c=I o \cdot e^{-(K w+K i \cdot I S S+K v \cdot V S S) \cdot Z t c}
$$

in which

$$
\begin{aligned}
I c & =\text { light at the canopy top }\left(\mathrm{E} \mathrm{m}^{-2} \mathrm{day}^{-1}\right) \\
I o & =\text { light at water surface }\left(\mathrm{E} \mathrm{m}^{-2} \mathrm{day}^{-1}\right) \\
K w & =\text { attenuation due to color }\left(\mathrm{m}^{-1}\right) \\
K i & =\text { attenuation coefficient for fixed solids }\left(\mathrm{m}^{2} \mathrm{~g}^{-1}\right) \\
I S S & =\text { fixed solids concentration }\left(\mathrm{g} \mathrm{m}^{-3}\right) \\
K v & =\text { attenuation coefficient for volatile solids }\left(\mathrm{m}^{2} \mathrm{~g}^{-1}\right) \\
V S S & =\text { volatile solids concentration }\left(\mathrm{g} \mathrm{m}^{-3}\right) \\
Z t c & =\text { depth to canopy }(\mathrm{m})
\end{aligned}
$$


Next, mean light within the canopy is evaluated. Assuming that attenuation by shoots follows an exponential relationship analogous to Equation 7 (Titus and Adams 1979), the mean light field within the canopy is

$$
I w c=\frac{I c}{K s h \cdot S H} \cdot\left(1-e^{-K s h \cdot S H}\right)
$$

in which $I w c$ is the mean light within the canopy $\left(\mathrm{E} \mathrm{m}^{-2} \mathrm{day}^{-1}\right)$, and $K s h$ is attenuation by SAV shoots $\left(\mathrm{m}^{2} \mathrm{~g}^{-1} \mathrm{C}\right)$. Iwc is the light available to epiphytes.

Although epiphyte accumulation in Chesapeake Bay and elsewhere can be related to nutrient concentrations (Kemp et al. 1983; Twilley et al. 1985; Borum 1985), not all epiphytic material is viable algae. Total accumulation of epiphytic material is an order of magnitude greater than viable algae (Figure 2). A rough proportionality between total accumulation and biomass is maintained over several orders of magnitude of biomass. The proportionality is represented in the model by the quantity Adwcep, the ratio of total epiphyte dry weight to viable epiphyte carbon. Employing this parameter, light reaching the shoots through the epiphyte layer is computed:

$$
I S h=I w c \cdot e^{-K e p \cdot A c l a \cdot A d w c e p \cdot E P}
$$

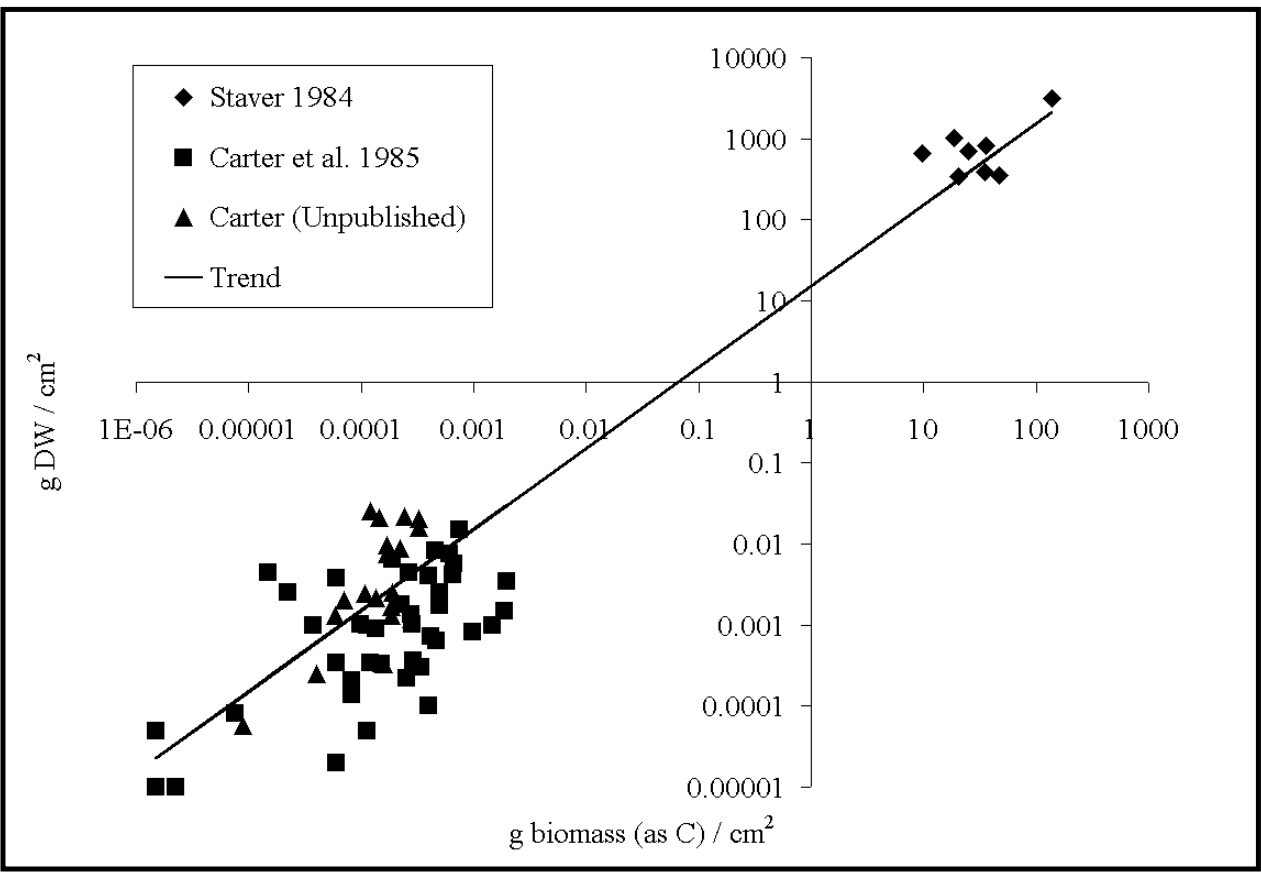

Figure 2. Epiphytic dry weight versus viable carbon. Staver's data from "control" and "low" ponds. Carbon obtained from chlorophyll measures using carbon-to-chlorophyll ratio of 75 . Trend indicates a 15:1 ratio (Unpublished Carter data are from U.S. Geological Survey, Reston, $\mathrm{VA})$ 
in which

$$
\begin{aligned}
I s h & =\text { light available to shoots }\left(\mathrm{E} \mathrm{m}^{-2} \text { day }^{-1}\right) \\
K e p & =\text { attenuation by epiphytes }\left(\mathrm{m}^{2} \text { leaf surface } \mathrm{g}^{-1} \mathrm{DW}\right) \\
\text { Acla } & =\mathrm{g} \text { shoot } \mathrm{C} \mathrm{m}^{-2} \text { leaf area }
\end{aligned}
$$

\section{SAV effect on suspended solids}

The damping of wind-generated waves in SAV beds (Ward, Kemp, and Boynton 1984) results in diminished suspended sediment concentrations relative to concentrations outside the bed (Figure 3 ). The effect of SAV on suspended solids is represented by addition of an SAV-dependent net settling velocity to the mass balance equation for suspended solids:

$$
\frac{\delta I S S}{\delta t}=\text { net transport }-\frac{1}{H} \cdot(\text { Wiss }+ \text { Wsav } \cdot S H) \cdot I S S
$$

in which

$$
H=\text { local depth (m) }
$$

Wiss $=$ net settling velocity of suspended solids in open water $\left(\mathrm{m} \mathrm{d}^{-1}\right)$

$W s a v=$ enhanced net settling due to SAV $\left(\mathrm{m}^{3} \mathrm{~g}^{-1} \mathrm{C} \mathrm{d}^{-1}\right)$

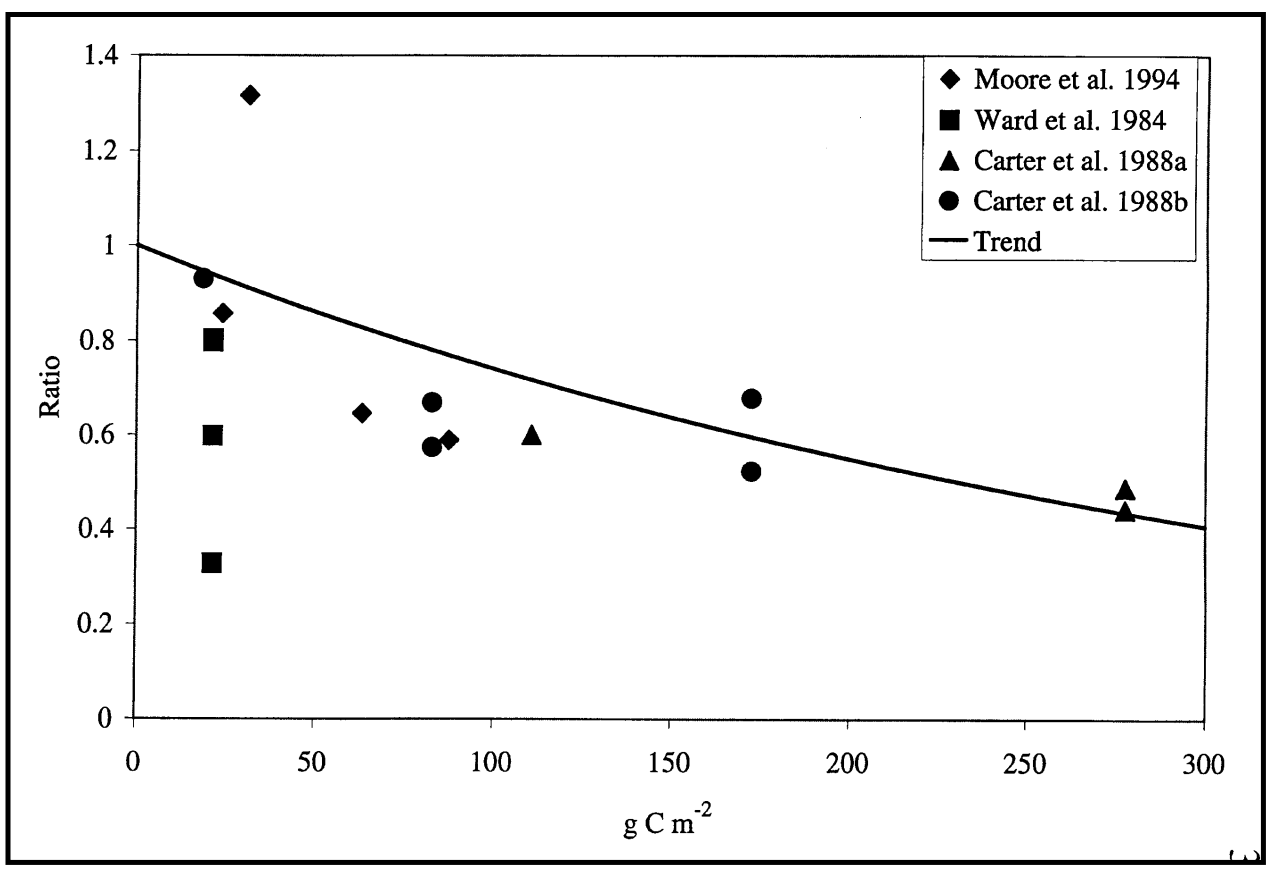

Figure 3. Ratio of suspended solids in vegetated areas to suspended solids in adjacent nonvegetated areas. Trend determined by visual comparison with observations 
Parameter Wiss varies spatially and temporally but has a characteristic value of $0.05 \mathrm{~m} \mathrm{~d}^{-1}$. The value of Wsav, $0.05 \mathrm{~m}^{3} \mathrm{~g}^{-1} \mathrm{C} \mathrm{d}^{-1}$, is assigned to reproduce in the model the observed trend.

\section{From the unit to the system}

The Chesapeake Bay Environmental Model Package (CBEMP) operates by dividing the continuum of the bay into a grid of discrete cells. In the present grid, the surface plane of the bay and its major tributaries is sectioned into 2100 cells with a length scale of $2 \mathrm{~km}$. Width of each cell varies depending on the local geometry. For the SAV model, a ribbon of littoral cells was created along the land-water margin of the system. Width of each littoral cell corresponded to the distance from the 2-m depth contour to the shore. The 2-m depth was selected since restoration of SAV to the 2-m contour is a major goal of the bay management effort (Batiuk et al. 1992). SAV was modeled in these littoral cells and in a few additional cells in regions that historically supported SAV. Littoral cells were represented as having a mean depth of $1 \mathrm{~m}$. Depth of the additional cells was determined by local bathymetry and was usually $2 \mathrm{~m}$.

The major problem in coupling the systemwide model with the unit model is the difference in scales represented by the two models. The minimum scale represented by the CBEMP is on the order of $\mathrm{km}$ while the scale on which SAV is distributed is orders of magnitude smaller. Three scaling factors were employed to relate biomass on the unit level to abundance on the grid scale: truncation error, coverage, and patchiness (Figure 4). Truncation error is the ratio of actual area within the 2-m contour to the area of the quadrilateral model cell. Coverage is the fraction of a cell occupied by SAV beds, and patchiness represents the fraction of bottom area covered by plants within an SAV bed. Abundance within each cell is then

$$
M=S H \cdot A \cdot T E \cdot C \cdot P t c h
$$

in which

$$
\begin{aligned}
M & =\text { aboveground abundance }(\mathrm{g} \mathrm{C}) \\
A & =\text { cell surface area }\left(\mathrm{m}^{2}\right) \\
T E & =\text { truncation error } \\
C & =\text { coverage } \\
P t c h & =\text { patchiness }
\end{aligned}
$$

Truncation error was determined by comparison of model surface area with actual area determined by a Geographic Information System. The error ranged from 0.2 to 1.55 with a mean value of 0.75 . Coverage was assumed to be 50 percent. Patchiness was determined by comparison of computed and observed abundance and was determined to be 0.3 for the FRESHWATER and ZOSTERA community types and 0.8 for the RUPPIA community. 


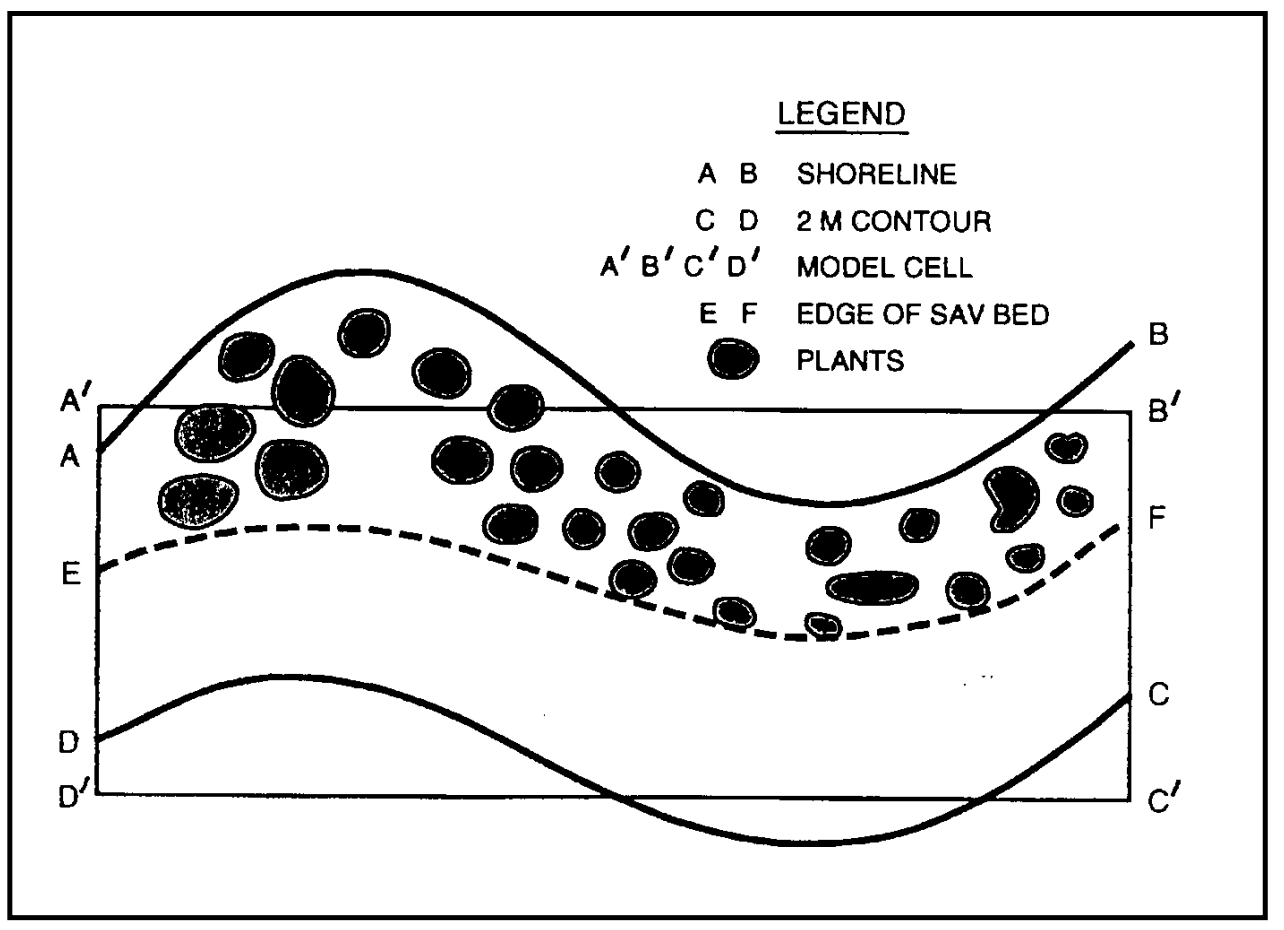

Figure 4. Truncation error, coverage, and patchiness. Truncation error $=$ Area $(A B C D) /$ Area $\left(A^{\prime} B^{\prime} C^{\prime} D^{\prime}\right)$. Coverage = Area $(A B E F) /$ Area $(A B C D)$. Patchiness $=$ Area $($ plants $) /$ Area $(A B E F)$

The relationship of shoot (and root) biomass to abundance allowed uptake and release of materials by plants on a unit area basis to be converted to a mass basis for employment in the mass-balance equation applied to each cell (Cerco and Cole 1993).

\section{The databases}

The primary database for comparison of computed and observed SAV was a monthly time series of aboveground abundance estimates (Moore, Wilcox, and Orth 2000) for the period 1985-1996. Estimates were provided for four mutually exclusive SAV community types and were available on an aggregate basis and for each of 44 Chesapeake Bay Program Segments (CBPS). Program segments are subdivisions of the bay determined by mean salinity, natural boundaries, and other features. Thirty-five segments (Figure 5), having a median area of $150 \mathrm{~km}^{2}$, are included in the model grid.

Suspended solids and light attenuation observations were drawn from monitoring data provided by the Chesapeake Bay Program Office (CBPO), Annapolis, $\mathrm{MD}$. The CBPO conducts a program in which observations are collected at over 100 stations in 20 surveys per year. For comparison with the model, observations were averaged by month and over CBPS. Light attenuation measures were largely in the form of disk visibility and were converted to attenuation through the relationship: 


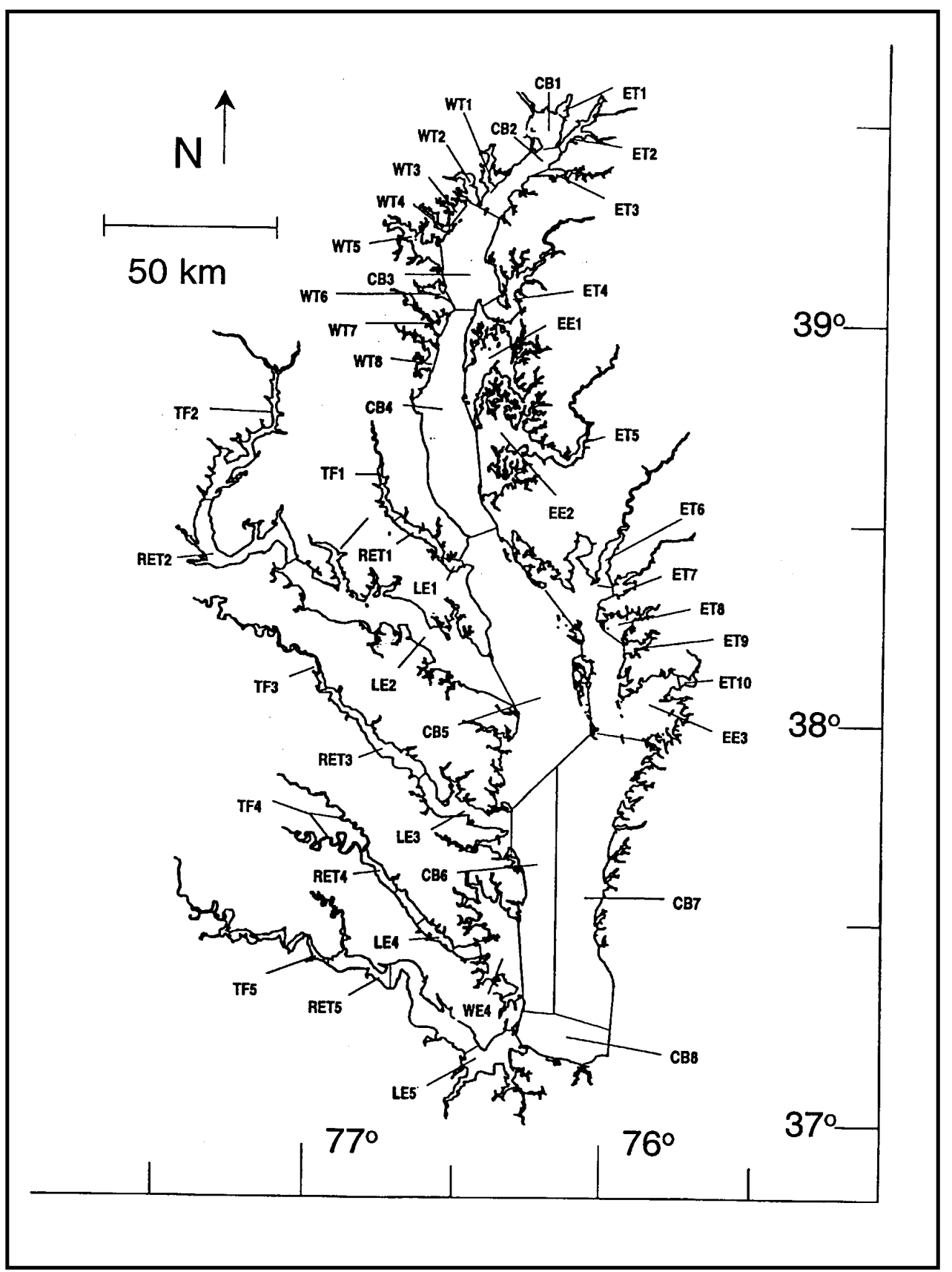

Figure 5. Chesapeake Bay Program Segments

$$
K E=\frac{1.33}{D V}
$$

in which $K E=$ diffuse light attenuation $\left(\mathrm{m}^{-1}\right)$, and $D V$ is disk visibility $(\mathrm{m})$. The factor 1.33 was validated through comparison with measures of light penetration conducted in the upper bay (Personal Communication, R. Lacouture, Smithsonian Environmental Research Center, Edgewater, MD) and is typical for turbid estuarine waters (Holmes 1970; Keefe, Flemer, and Hamilton 1976). 


\section{Modeled communities}

Three major, mutually exclusive SAV community types were modeled: ZOSTERA, RUPPIA, and FRESHWATER. Moore, Wilcox, and Orth (2000) identified a fourth type, POTAMOGETON, but the abundance in this type was negligible compared with the others. Since the distributions of POTAMOGETON and RUPPIA often overlap, the POTAMOGETON community was combined with the RUPPIA community for model purposes. Model cells were assigned a community type (Figure 6) based on observed distribution and environmental factors (Moore, Wilcox, and Orth 2000).

\section{Parameter Evaluation}

\section{The SAV component}

Parameter evaluation for the SAV component of the model is both an art and a chore. Although substantial observations exist, especially for the ZOSTERA community, variations in methodology and reporting preclude determination of a definitive set of model parameters. The evaluation procedure consisted of selection of an initial parameter set from the literature, followed by revisions to improve agreement between modeled and observed biomass in CBPS that support substantial SAV communities.

For ZOSTERA, primary data sources included Wetzel and Penhale (1983), Evans, Webb, and Penhale (1986), and Marsh, Dennison, and Alberte (1986). Parameters (Table 1) were selected to optimize agreement between computed and observed shoot and root biomass (Figure 7). For RUPPIA, primary data sources were Wetzel and Penhale (1983) and Evans, Webb, and Penhale (1986). Final parameters (Table 1) were selected to optimize agreement between computed and observed shoot (Figure 8) and root biomass. Insufficient data were found to assemble monthly means and ranges of root biomass. Observations collected by Moore et al. (1994) over a year indicate a range in root biomass of 0.8 to $13 \mathrm{~g}$ $\mathrm{C} \mathrm{m}^{-2}$ with a mean of $6.1 \mathrm{~g} \mathrm{C} \mathrm{m}^{-2}$. These compare to a model range of 1.7 to $11.3 \mathrm{~g} \mathrm{C} \mathrm{m}^{-2}$ and mean of $6.1 \mathrm{~g} \mathrm{C} \mathrm{m}^{-2}$ in segment EE1. For the FRESHWATER community, primary data sources included Van, Haller, and Bowes (1976), Bowes et al. (1977), Bowes, Holaday, and Haller (1979), and Barko and Smart (1981). Final parameters (Table 1) were selected to optimize agreement between computed and observed shoot (Figure 9) and root biomass. As with RUPPIA, insufficient data were found to assemble meaningful monthly means and ranges of root biomass. Available information indicates the roots of freshwater SAV compose from 4 percent to 41 percent of total plant biomass (Haller and Sutton 1975; Barko and Smart 1981). In the model, roots composed 23 percent of total plant biomass during the growing season (April-October) in segment CB1.

\section{Epiphytes}

Epiphyte accumulation on natural and artificial substrates has been measured at various locations in situ (Carter, Paschal, and Bartow 1985) and in artificial 


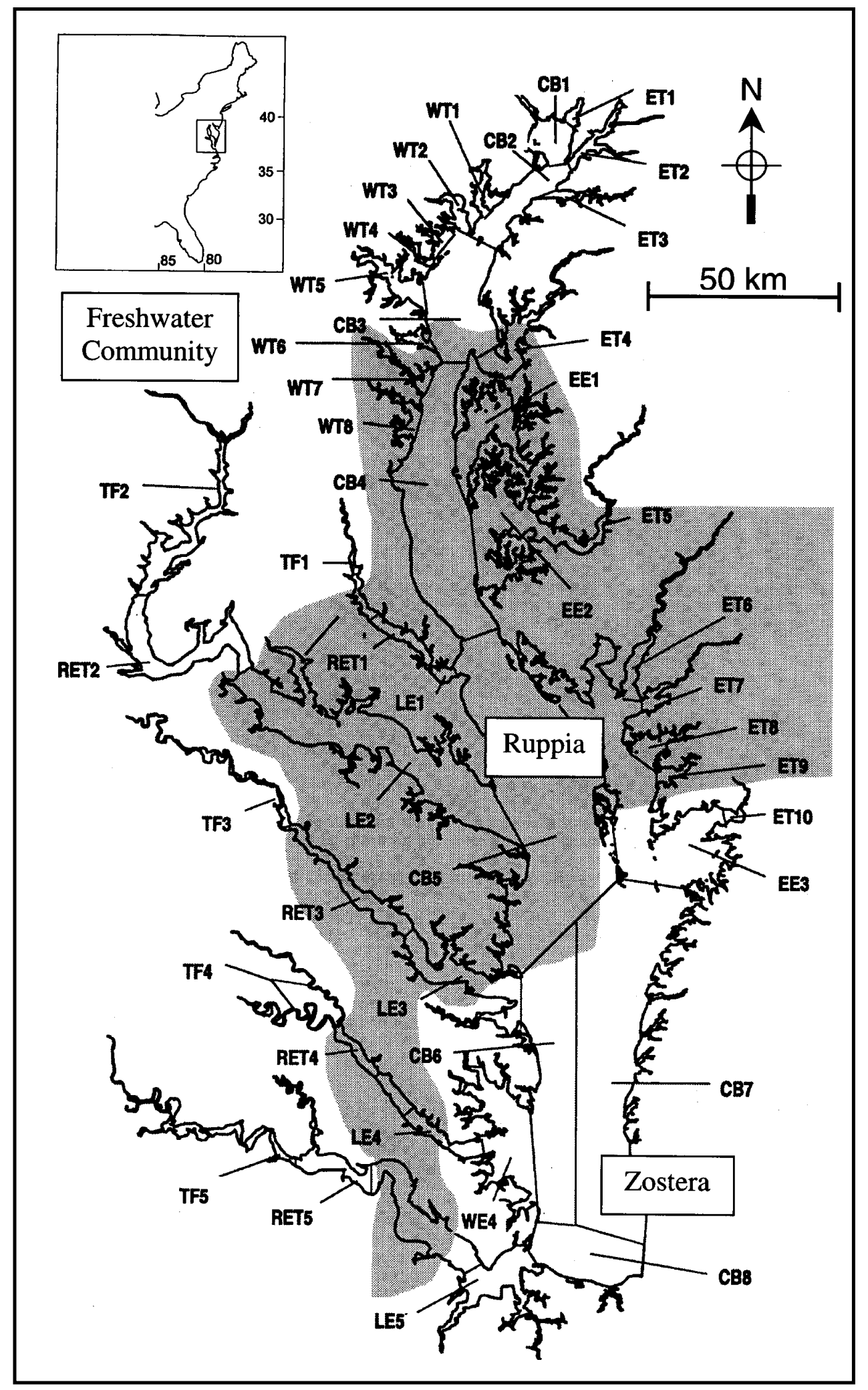

Figure 6. Distribution of SAV community types 


\begin{tabular}{|c|c|c|c|c|c|}
\hline Parameter & Definition & FRESHWATER & RUPPIA & ZOSTERA & Units \\
\hline$A c d w$ & $\begin{array}{l}\text { carbon to dry } \\
\text { weight ratio }\end{array}$ & 0.37 & 0.37 & 0.37 & \\
\hline Acla & $\begin{array}{l}\text { shoot carbon } \\
\text { per unit leaf } \\
\text { area }\end{array}$ & 7.5 & 4.0 & 4.0 & $\begin{array}{l}\mathrm{g} \text { shoot } C \mathrm{~m}^{-2} \\
\text { leaf area }\end{array}$ \\
\hline Fpsr & $\begin{array}{l}\text { fraction of } \\
\text { production } \\
\text { transferred from } \\
\text { shoots to roots }\end{array}$ & 0.12 to 1.0 & 0.1 to 0.85 & 0.1 to 0.85 & \\
\hline Ksh & $\begin{array}{l}\text { light attenuation } \\
\text { by shoots }\end{array}$ & 0.045 & 0.045 & 0.045 & $\mathrm{~m}^{2} \mathrm{~g}^{-1} \mathrm{C}$ \\
\hline Khnw & $\begin{array}{l}\text { half-saturation } \\
\text { concentration } \\
\text { for nitrogen } \\
\text { uptake by } \\
\text { shoots }\end{array}$ & 0.19 & 0.19 & 0.1 & $\mathrm{gN} \mathrm{m}^{-3}$ \\
\hline Khns & $\begin{array}{l}\text { half-saturation } \\
\text { concentration } \\
\text { for nitrogen } \\
\text { uptake by roots }\end{array}$ & 0.95 & 0.95 & 0.4 & $\mathrm{gN} \mathrm{m}^{-3}$ \\
\hline Khpw & $\begin{array}{l}\text { half-saturation } \\
\text { concentration } \\
\text { for phosphorus } \\
\text { uptake by } \\
\text { shoots }\end{array}$ & 0.028 & 0.028 & 0.02 & $\mathrm{gP} \mathrm{m}^{-3}$ \\
\hline Khps & $\begin{array}{l}\text { half-saturation } \\
\text { concentration } \\
\text { for phosphorus } \\
\text { uptake by roots }\end{array}$ & 0.14 & 0.14 & 0.1 & $\mathrm{gP} \mathrm{m}^{-3}$ \\
\hline$P \max$ & $\begin{array}{l}\text { maximum } \\
\text { production at } \\
\text { optimum } \\
\text { temperature } \\
\end{array}$ & 0.1 & 0.08 & 0.06 & $\mathrm{~g} \mathrm{C} \mathrm{g}^{-1} \mathrm{DW} \mathrm{d}^{-1}$ \\
\hline Rsh & $\begin{array}{l}\text { shoot } \\
\text { respiration }\end{array}$ & 0.022 & 0.022 & 0.015 & $\mathrm{~d}^{-1}$ \\
\hline$R r t$ & root respiration & 0.022 & 0.022 & 0.013 & $\mathrm{~d}^{-1}$ \\
\hline$S L$ & sloughing & 0.01 to 0.1 & $\begin{array}{l}0.01 \text { to } \\
0.035 \\
\end{array}$ & \begin{tabular}{|l|}
0.01 to \\
0.035
\end{tabular} & $\mathrm{~d}^{-1}$ \\
\hline Trs & $\begin{array}{l}\text { transfer from } \\
\text { root to shoot }\end{array}$ & 0.0 to 0.05 & 0.0 & 0.0 & $\mathrm{~d}^{-1}$ \\
\hline$\alpha$ & $\begin{array}{l}\text { initial slope of } \\
\text { Photosynthesis } \\
\text { versus } \\
\text { Irradiance } \\
\text { curve }\end{array}$ & 0.0075 & 0.002 & 0.0028 & $\begin{array}{l}\left(\mathrm{g} \mathrm{C} \mathrm{g}^{-1} \mathrm{DW}\right) \\
\left(\mathrm{E} \mathrm{m}^{-2}\right)^{-1}\end{array}$ \\
\hline
\end{tabular}

environments adjacent to the bay (Staver 1984; Twilley et al. 1985). For comparison with the model, reports of in situ accumulation on natural substrates were desirable. The best data sets identified were collected from zostera marina in the lower eastern shore of the bay (Moore et al. 1994), and in Bogue Sound (Penhale 1977), a lagoon situated $300 \mathrm{~km}$ south of the bay. Initial parameters for epiphytes were adapted from the phytoplankton component of the CBEMP. Final parameters (Table 2) were selected to obtain reasonable agreement between computed and observed epiphyte abundance (Figure 10). 


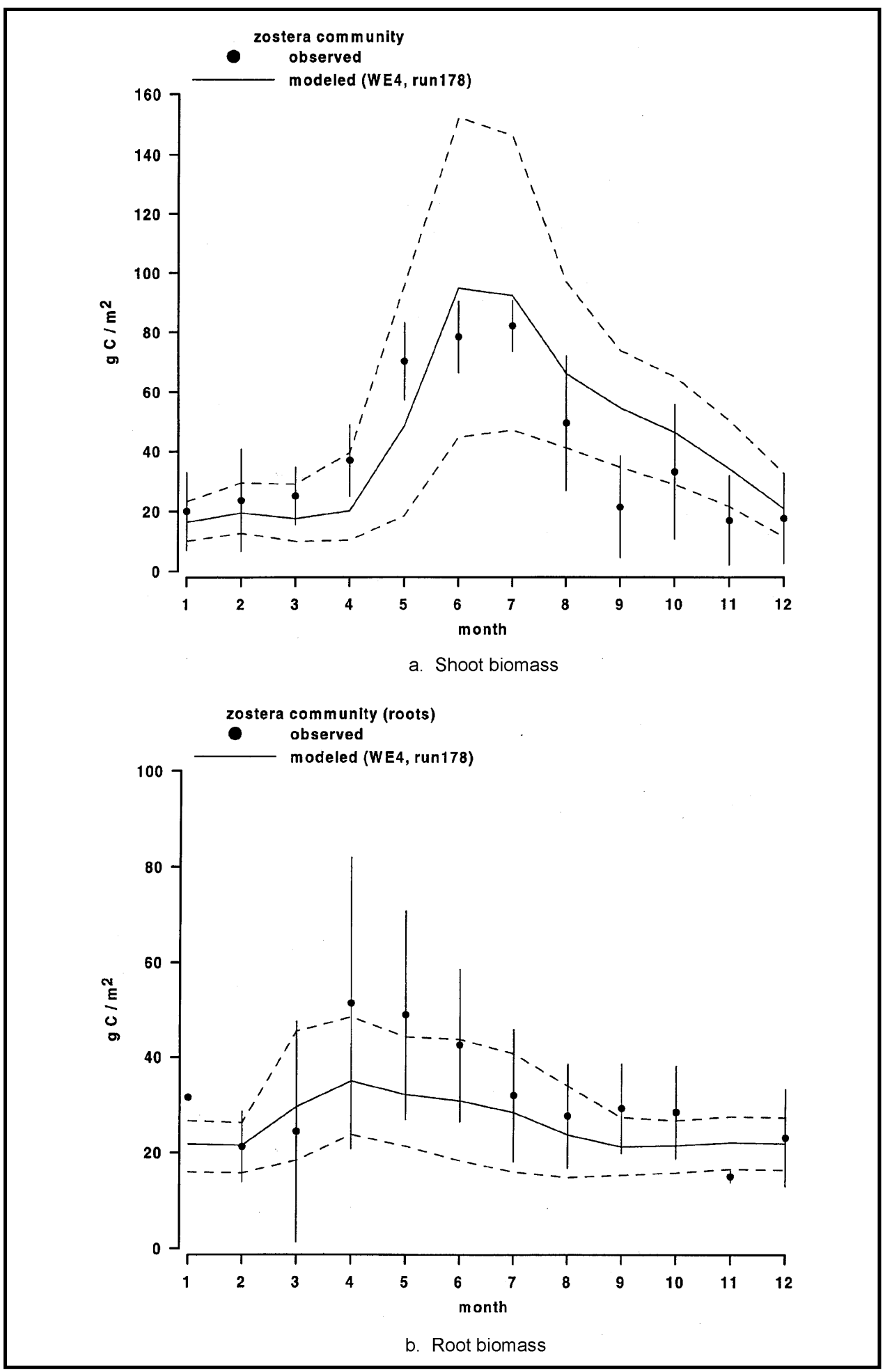

Figure 7. Modeled (mean and interval encompassing 95 percent of computations) and observed (mean and 95 percent confidence interval) ZOSTERA shoot (A) and root (B) biomass. Shoot observations from Moore, Wilcox, and Orth (2000). Root observations assembled from Moore et alia sources. Model results from CBPS WE4 


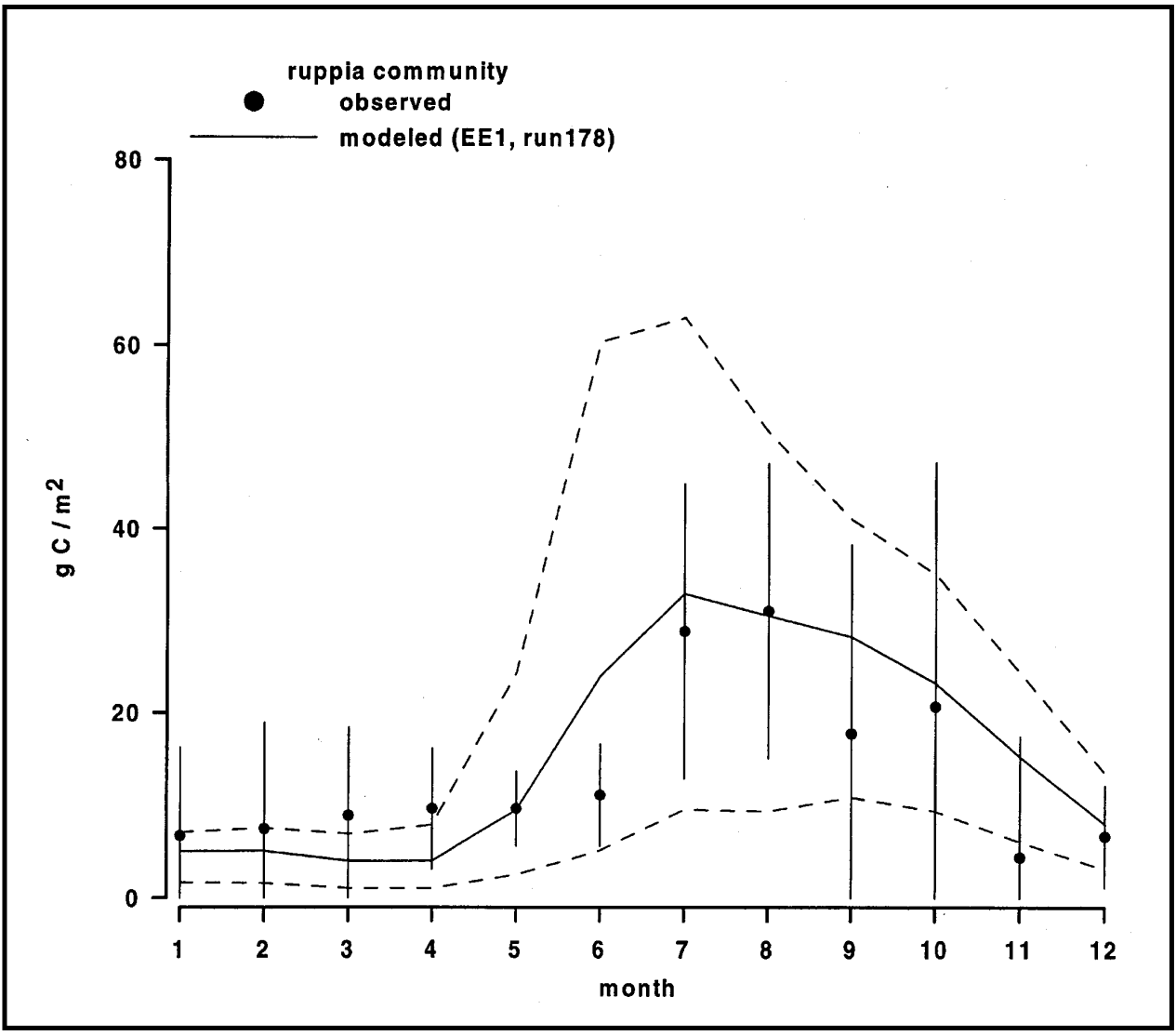

Figure 8. Modeled (mean and interval encompassing 95 percent of computaions) and observed (mean and 95 percent confidence interval) RUPPIA shoot biomass. Observations from Moore, Wilcox, and Orth (2000). Model results from CBPS EE1

\section{Components of light attenuation}

Components of light attenuation in the water column were evaluated for each of the CBPS. Initial parameter values were derived through regression using fixed and volatile solids as independent variates and light attenuation as the dependent variate. Values were refined to improve agreement with observations. Background attenuation ranged from 0.2 to $1.5 \mathrm{~m}^{-1}$. Higher values were assigned at the upper ends of the main stem and tributaries. Lowest values were assigned in the lower bay, consistent with the finding that fresh water is more colored than seawater (Kirk 1994). Application of optical models (Gallegos, Correll, and Pierce 1990; Gallegos 1994) indicates background attenuation in the bay is approximately $0.26 \mathrm{~m}^{-1}$. The range of values employed here results from evaluation of attenuation in individual CBPS rather than to baywide, mean conditions. Assignment of background attenuation also reflects, to some extent, attenuation that cannot be accounted for using computed solids. Attenuation by fixed and volatile solids ranged from 0.055 to $0.117 \mathrm{~m}^{2} \mathrm{~g}^{-1}$. These values agree well with values reported for similar systems (Pennock 1985). 


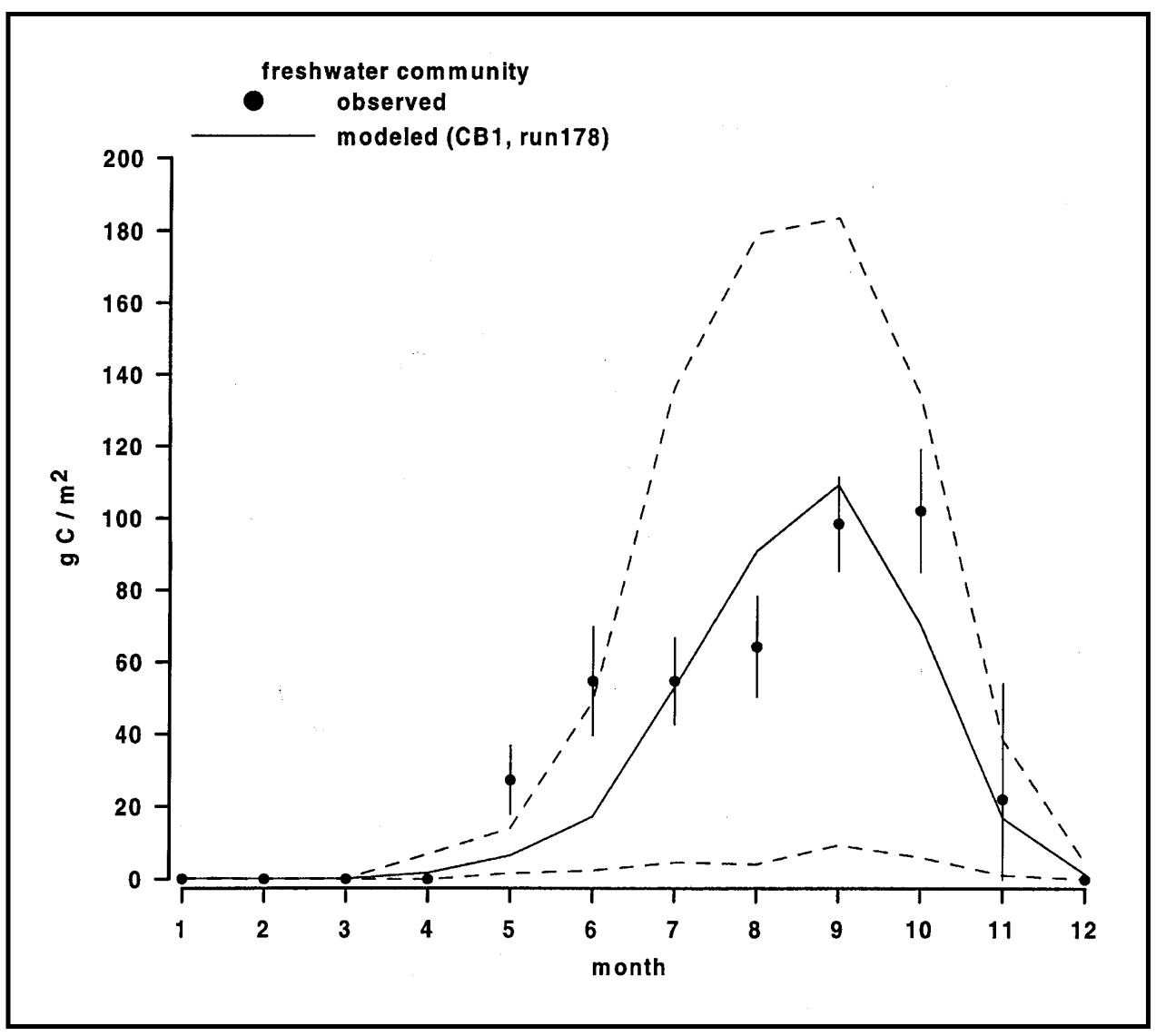

Figure 9. Modeled (mean and interval encompassing 95 percent of computations) and observed (mean and 95 percent confidence interval) FRESHWATER community shoot biomass. Observations from Moore, Wilcox, and Orth (2000). Model results from CBPS CB1

\begin{tabular}{|c|c|c|c|}
\hline Parameter & Definition & Value & Units \\
\hline Acchl & carbon to chlorophyll ratio of viable epiphytes & 75 & $\mathrm{~g} \mathrm{~g} \mathrm{C} \mathrm{g}^{-1} \mathrm{Chl}$ \\
\hline Adwcep & $\begin{array}{l}\text { ratio of epiphyte dry weight to viable epiphyte } \\
\text { carbon }\end{array}$ & 15 & $\mathrm{~g} \mathrm{DW} \mathrm{g}^{-1} \mathrm{C}$ \\
\hline Kep & light attenuation coefficient & 0.1 & $\begin{array}{l}\mathrm{m}^{2} \text { leaf surface } \\
\mathrm{g}^{-1} \text { epiphyte } \mathrm{C}\end{array}$ \\
\hline Khep & density at which growth is halved & 0.1 & $\begin{array}{l}\text { g epiphyte C } \\
\mathrm{g}^{-1} \text { shoot } C\end{array}$ \\
\hline Khn & $\begin{array}{l}\text { half-saturation concentration for nitrogen } \\
\text { uptake }\end{array}$ & 0.025 & $\mathrm{~g} \mathrm{~N} \mathrm{~m}^{-3}$ \\
\hline Khp & $\begin{array}{l}\text { half-saturation concentration for phosphorus } \\
\text { uptake }\end{array}$ & 0.001 & $\mathrm{gP} \mathrm{m}^{-3}$ \\
\hline$P e p$ & maximum production at optimum temperature & 300 & $\mathrm{gC} \mathrm{g}^{-1} \mathrm{Chl} \mathrm{d}^{-1}$ \\
\hline$P R$ & predation rate & 1.0 & $\begin{array}{l}\text { g shoot } C \\
g^{-1} \text { epiphyte } C d^{-1}\end{array}$ \\
\hline $\operatorname{Rep}$ & respiration & 0.25 & $\mathrm{~d}^{-1}$ \\
\hline$\alpha$ & $\begin{array}{l}\text { initial slope of Photosynthesis versus Irradiance } \\
\text { curve }\end{array}$ & 10 & $\begin{array}{l}\left(\mathrm{g} \mathrm{C} \mathrm{g} \mathrm{g}^{-1} \mathrm{Chl}\right) \\
\left(\mathrm{E} \mathrm{m}^{-2}\right)^{-1}\end{array}$ \\
\hline
\end{tabular}




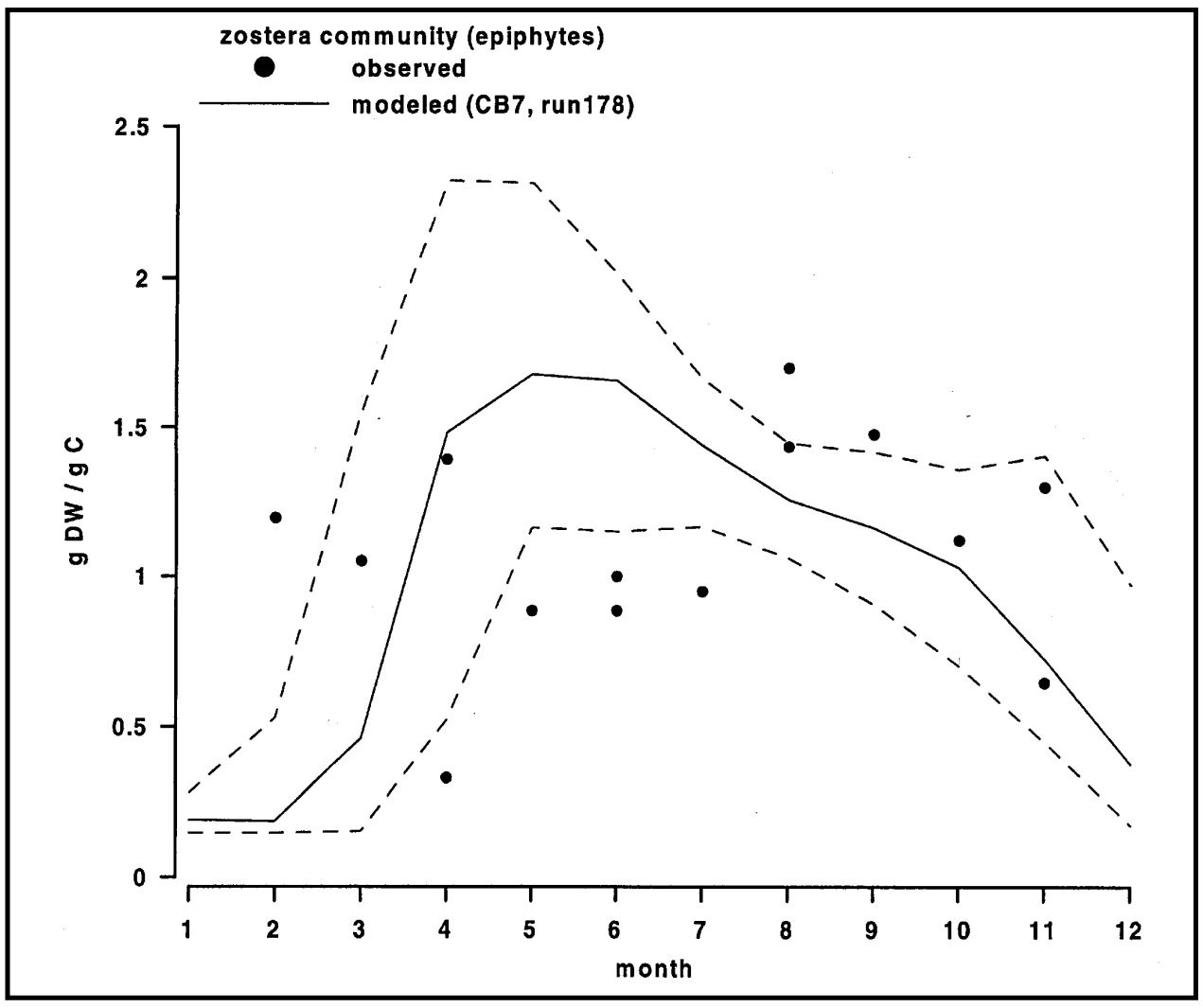

Figure 10. Modeled (mean and interval encompassing 95 percent of computations) and observed biomass of epiphytes on ZOSTERA. Model results from CBPS CB7

The model does not distinguish between attenuation by algae (as chlorophyll) and attenuation by total organic matter (dry weight). Assuming that algae comprise most of the particulate organic matter and utilizing the model ratios dry weight:carbon $=2.5$ and carbon: chlorophyll $=75$, attenuation by volatile solids is equivalent to chlorophyll-specific attenuation of 0.01 to $0.02 \mathrm{~m}^{2} \mathrm{mg}^{-1}$. These values are well within reported ranges (Krause-Jensen and Sand-Jensen 1998).

\section{Model application}

The CBEMP was applied to the 10-year period 1985-1994. It included Phase IV of the CBPO watershed model (Linker et al. 1996), which provided distributed loads of sediments and nutrients, and the Corps' CH3D-WES hydrodynamic model (Johnson et al. 1993), which provided transport. The eutrophication model, including the SAV component, was initialized once and run continuously through the simulated period. Boundary conditions and loads were updated on a daily or monthly basis. Integration time-step was 15 minutes. Output from the model was stored at 10-day increments. 


\section{Results}

\section{Agreement with living-resource parameters}

Living-resource criteria for the survival and propagation of SAV in Chesapeake Bay have been identified by Batiuk et al. (1992). The investigators determined maximum light attenuation for survival of SAV at the 1-m depth to be $2.0 \mathrm{~m}^{-1}$ for freshwater species and $1.5 \mathrm{~m}^{-1}$ for saltwater species. Model results were compared with these criteria by plotting median shoot biomass in each cell for each of ten growing seasons (April-October) against median computed light attenuation. Shoot densities computed by the model clearly conform to the observed criteria (Figure 11). Although computed SAV occasionally survives for a season under conditions that marginally exceed the criteria, the vast majority of computed biomass occurs in cells that meet the criteria. Model regions that substantially exceed the criteria never support SAV.

\section{Effect on suspended solids}

The influence of SAV on total suspended solids (TSS) was determined by collecting suspended solids observations inside and outside SAV beds. The modeled influence was examined by performing analogous observations on the model. Computed solids in cells that supported SAV were compared with computed solids in adjacent cells outside the SAV zone. As with the observations, considerable scatter occurs in the ratio (Figure 12). The relationship (Equation 10) employed to simulate SAV effects on solids clearly works as desired, however, and model results are in reasonable agreement with the trend exhibited by observations.

\section{Spatial distribution of SAV and light attenuation}

SAV abundance is not uniformly distributed in the bay system (Figure 13). Within the main stem bay and its major embayments, SAV is concentrated in CB1, near the confluence with the Susquehanna River, and in the lower half of the bay. Of the tributaries, only the tidal fresh and transitional portions of the Potomac River exhibit substantial abundance although lesser accumulations exist in the lower Rappahannock and York Rivers.

SAV abundance distribution is affected by two factors: area available for SAV growth and conditions suited for SAV growth. A goal of bay management is restoration of SAV to the Tier III level (Batiuk et al. 1992). That is, SAV should be restored to the 2-m depth contour. Using the Tier III areas as a measure of potential habitat, the observed abundance can be normalized into a mass per unit area (Figure 14). This measure provides an indication of regions in which conditions are not suited for SAV growth. If SAV filled potential habitat in all segments, the mass per unit area would be equal in all segments. Instead, mass per unit area roughly follows the abundance distribution. That is, low abundance indicates poor conditions rather than small areas for SAV growth. 


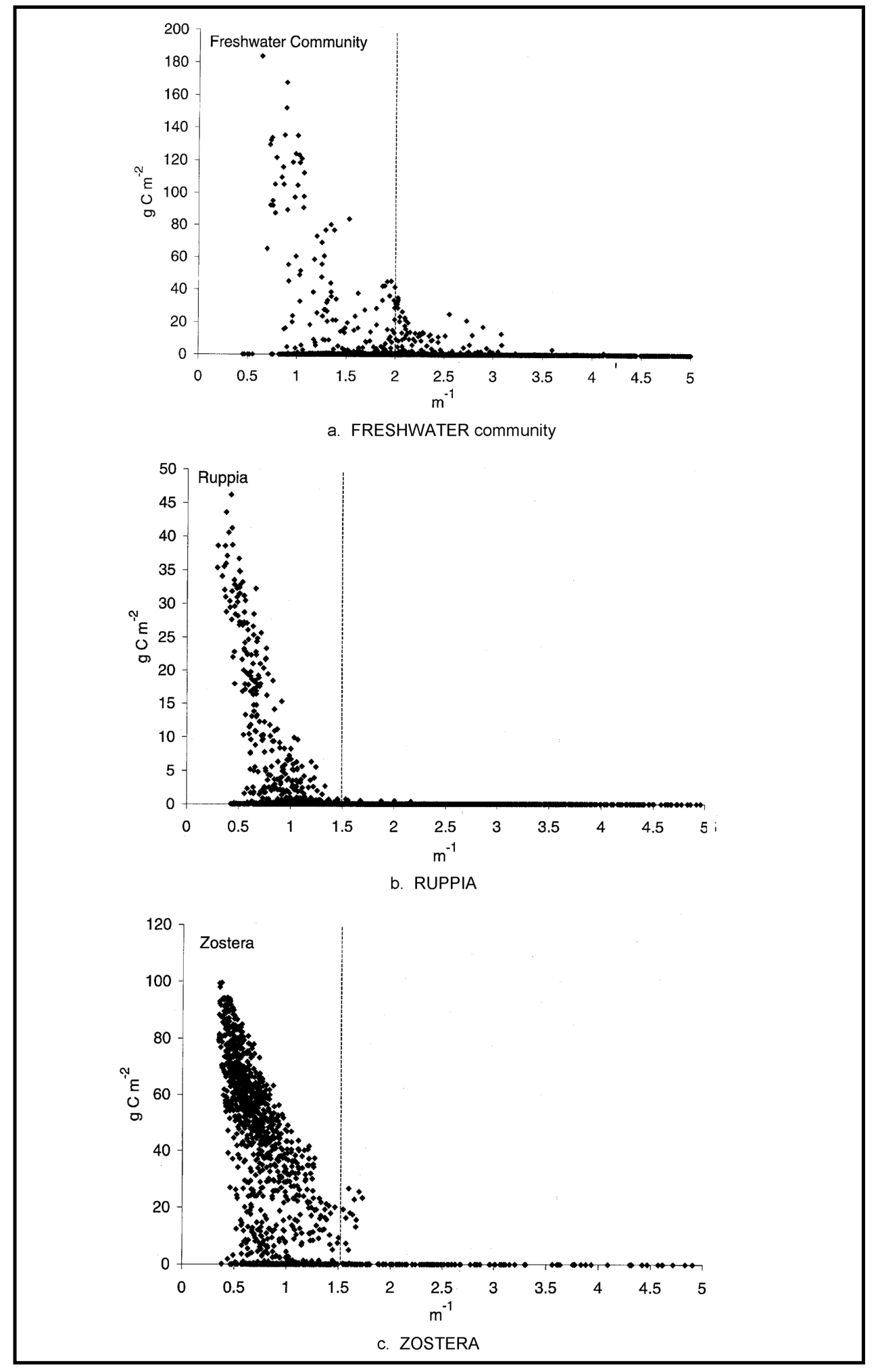

Figure 11. Computed shoot biomass versus light attenuation for (a) FRESHWATER community, (b) RUPPIA, and (c) ZOSTERA. Each point represents seasonal median value in one model cell. Dashed line indicates living-resource criteria for survival at 1-m depth 


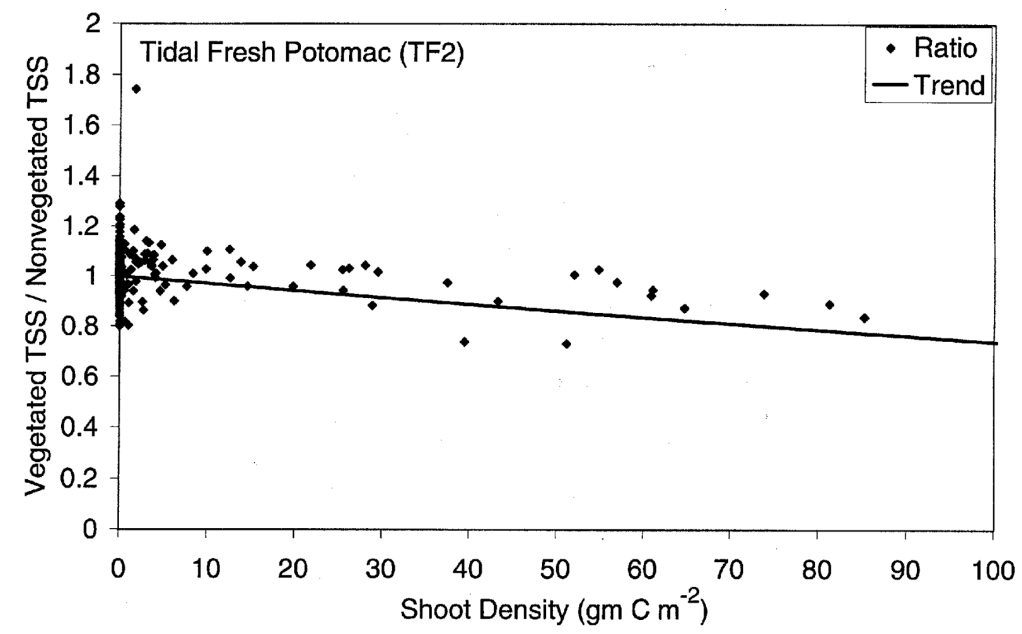

a. FRESHWATER community

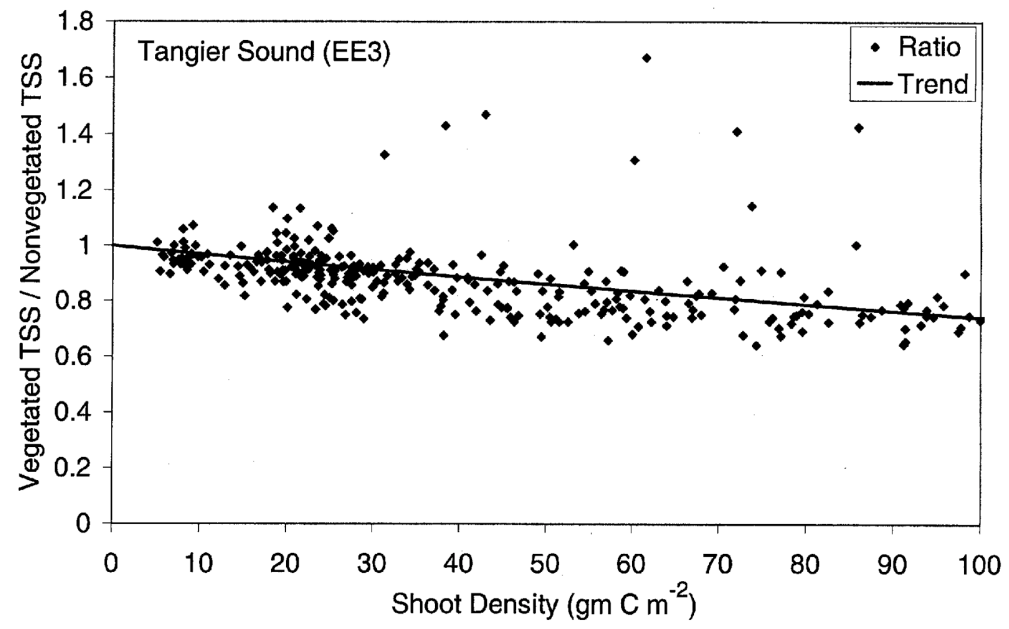

b. RUPPIA

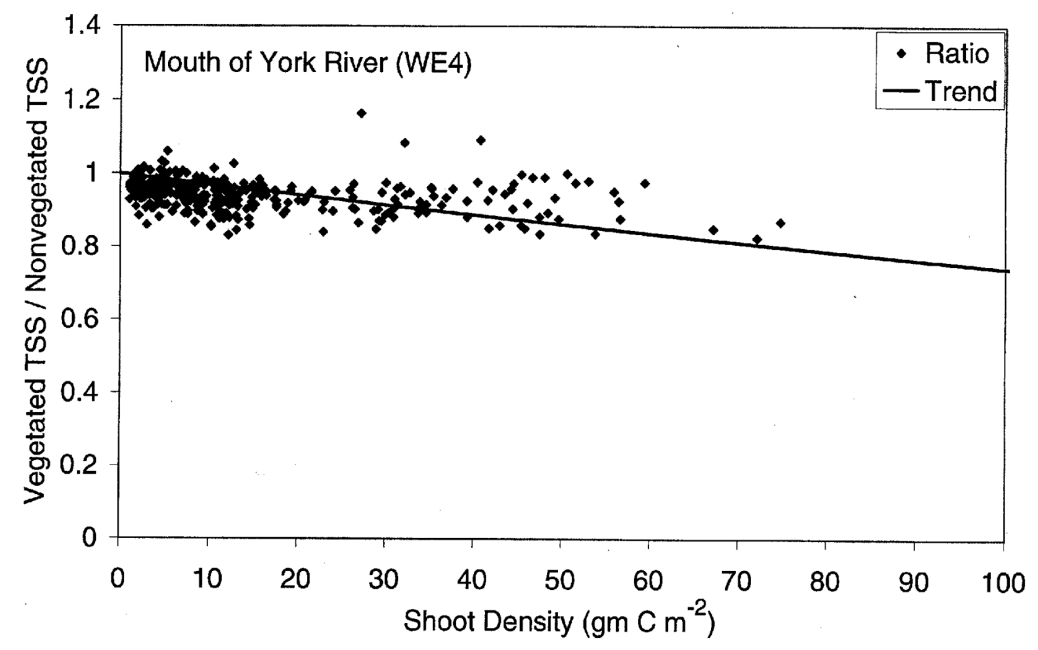

c. ZOSTERA

Figure 12. Modeled ratio of total suspended solids (TSS) in vegetated areas to total suspended solids in adjacent nonvegetated areas for three CBPS. Trend determined by visual comparison with observations 


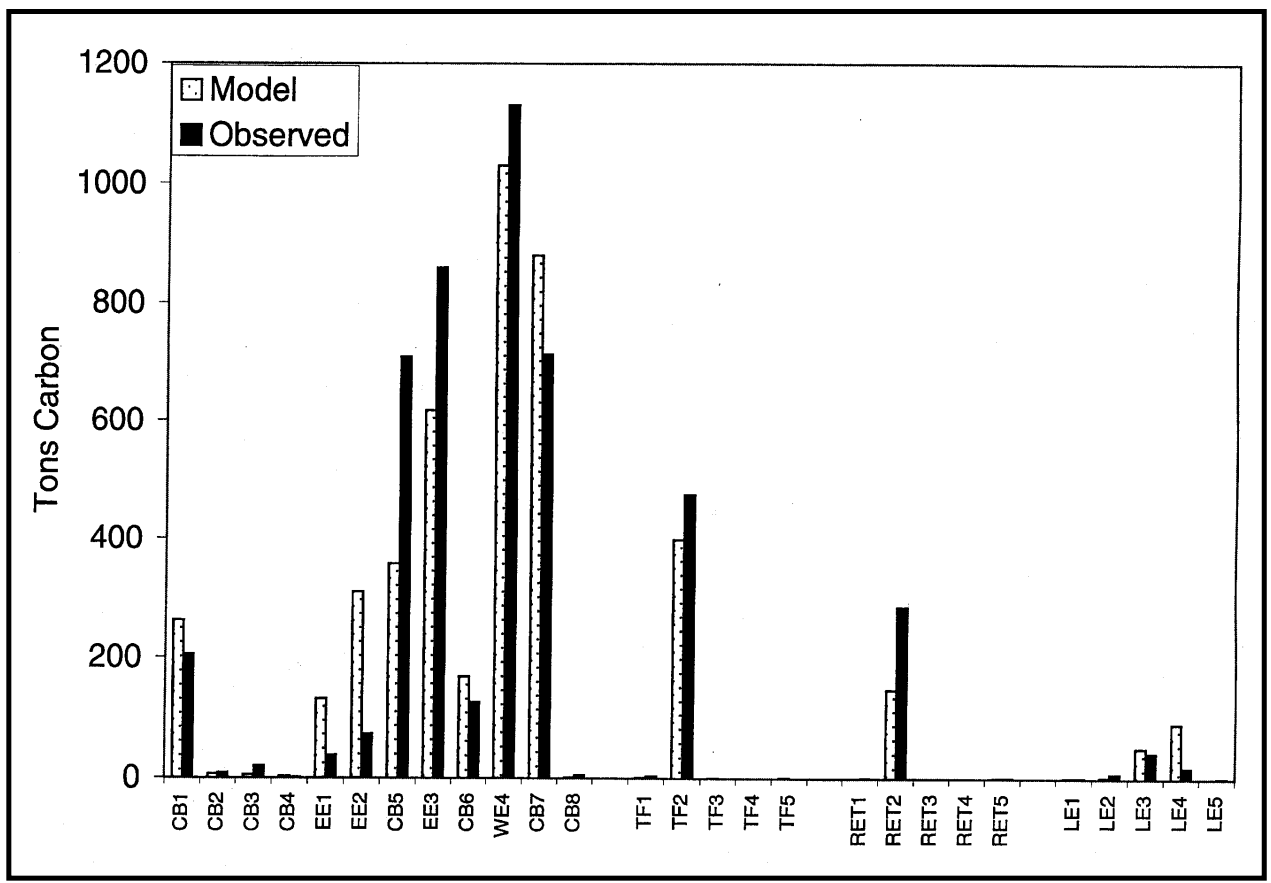

Figure 13. Observed and computed mean abundance, April-October 1985-1994

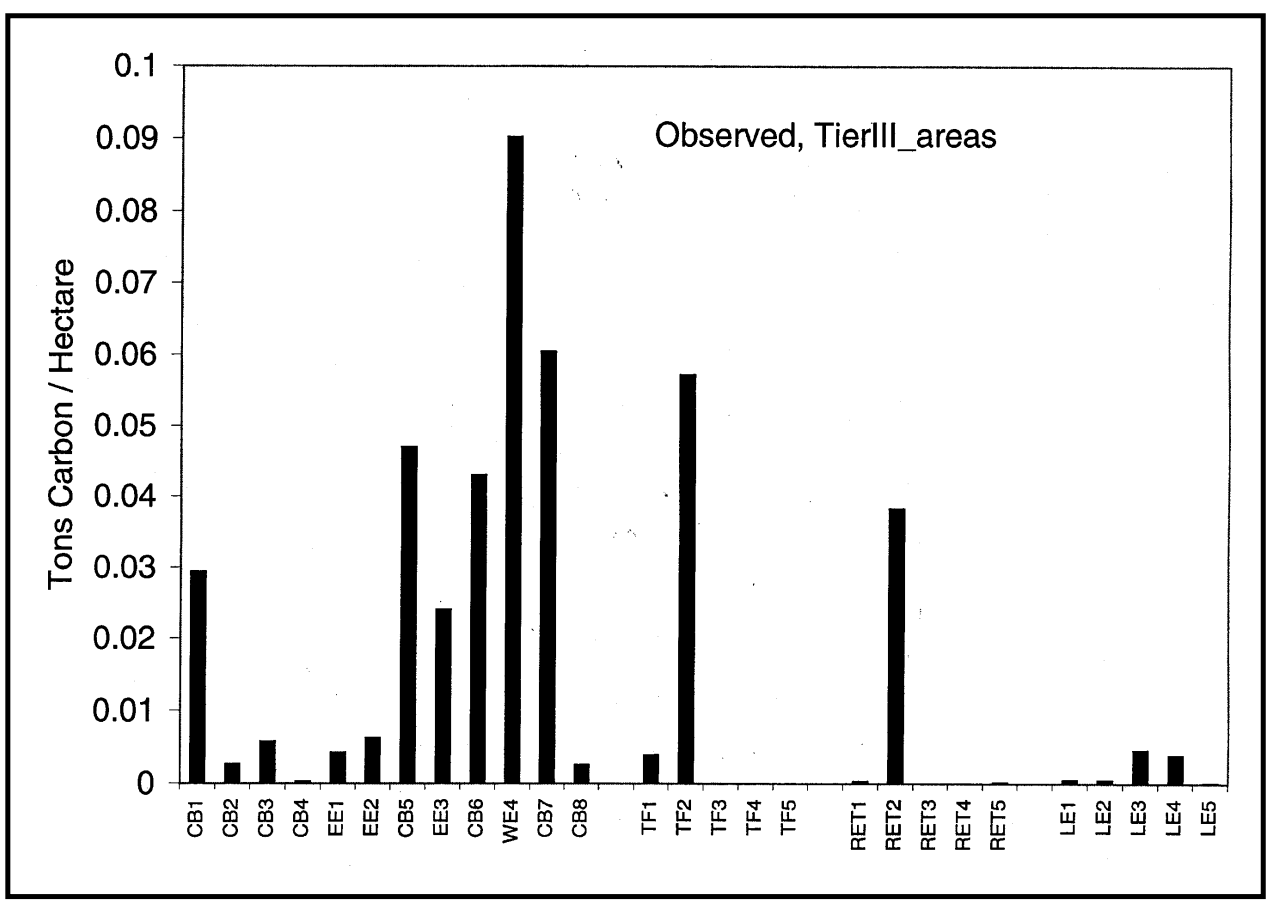

Figure 14. Observed mean abundance, April-October 1985-1994, normalized by Tier III areas 
The observed distribution of SAV largely reflects the distribution of light attenuation (Figure 15). The main stem bay exhibits a classic turbidity maximum (Schubel 1968) that typically occurs in CB2. Less attenuation occurs above and downstream of the maximum. Substantial SAV abundance is restricted to these same areas above and downstream of the maximum. The major tributaries are more turbid than most of the bay and, with the exception of portions of the Potomac, do not support substantial accumulations of SAV.

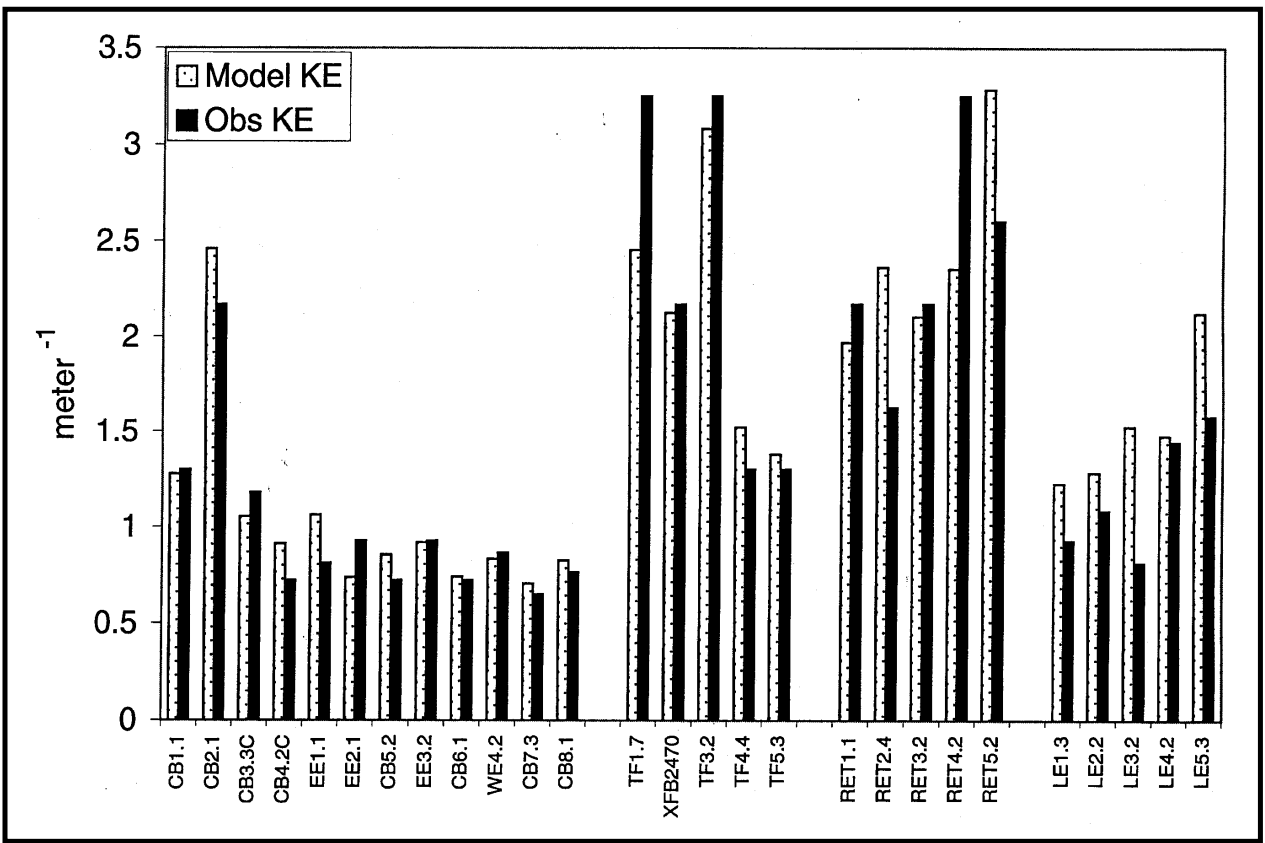

Figure 15. Observed and computed median light attenuation at 27 stations in the bay system, April-October 1985-1994

Qualitatively, the model performs excellently in reproducing the spatial distribution of SAV (Figure 13). Substantial abundance is computed in the Susquehanna Flats, in the lower bay, and in the upper Potomac River. Lesser amounts are computed in the eastern embayments (EE1, EE2), and in the lower Rappahannock and York Rivers. Quantitatively, the median absolute difference between computed and observed abundance is 37 percent of the observed values, with a range from zero to more than 300 percent.

The model also performs excellently in capturing the turbidity maximum in the main stem bay and the characteristic higher turbidity values in the tributaries (Figure 15). Median absolute difference between computed and observed attenuation is $0.19 \mathrm{~m}^{-1}$ or 13 percent of the observed values.

\section{Trends in SAV}

Moore, Wilcox, and Orth (2000) noted a substantial increase in ZOSTERA abundance from the period 1985-1990. Abundance of the other communities was less than ZOSTERA and exhibited no trend. Comparison of model results with time series of observed community abundance (Figure 16) indicates the model 


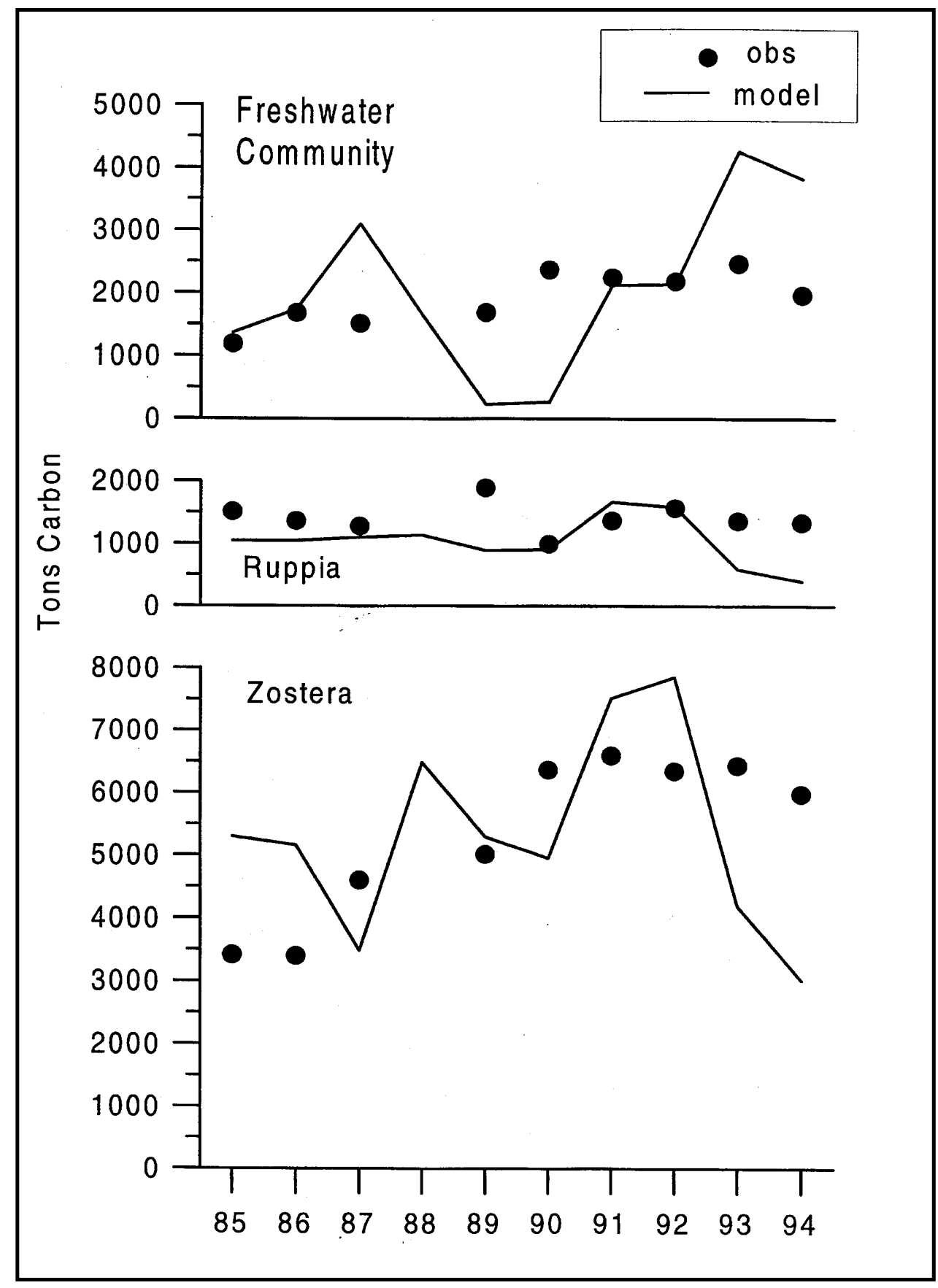

Figure 16. Observed and computed maximum abundance, by community type, 1985-1994

represents correctly the relative abundance in each community. Interannual variability and trends are not well represented, however. The median absolute difference between computed and observed baywide annual abundance, by community type, is 30 percent of observed values, with a range from zero to 240 percent. 


\section{Sensitivity to nutrient and solids loads}

Three model runs were made to examine the sensitivity of SAV to load reductions: 25 percent reduction in nitrogen and phosphorus loads (point-source and distributed); 25 percent reduction in solids loads; 25 percent reduction in both nutrient and solids loads. Nutrient load reductions were adapted as characteristic of present management plans, which call for 20 percent and 35 percent reductions in total nitrogen and phosphorus loads, respectively (Thomann et al. 1994). No goal presently exists for solids reductions. A reduction equivalent to the nutrient reductions was assumed as a reasonable starting point. Results from the sensitivity runs were compared with a base run. The base was identical to the calibration except for initial conditions.

The base and sensitivity runs were initiated by running the model to steadystate under a set of average hydrological conditions and appropriate loads. Following equilibration, the 10-year sequence of actual hydrological conditions was simulated.

The first result of the sensitivity runs is that the greatest abundance gains occur in segments that already support substantial SAV (Figure 17). The second is that nutrient controls alone do little to introduce SAV into areas in which it does not already occur. Solids reductions or solids combined with nutrient reductions are required to reintroduce SAV into the tidal fresh portions of the James, York, and Rappahannock Rivers. The transition regions, which contain the turbidity maxima, of four major tributaries do not support SAV under any of the sensitivity reductions. Multiple segments in the main stem and tributaries show greater improvement from solids control than nutrient control. Almost all segments show greater improvement from combined nutrient and solids reductions than nutrient reductions alone.

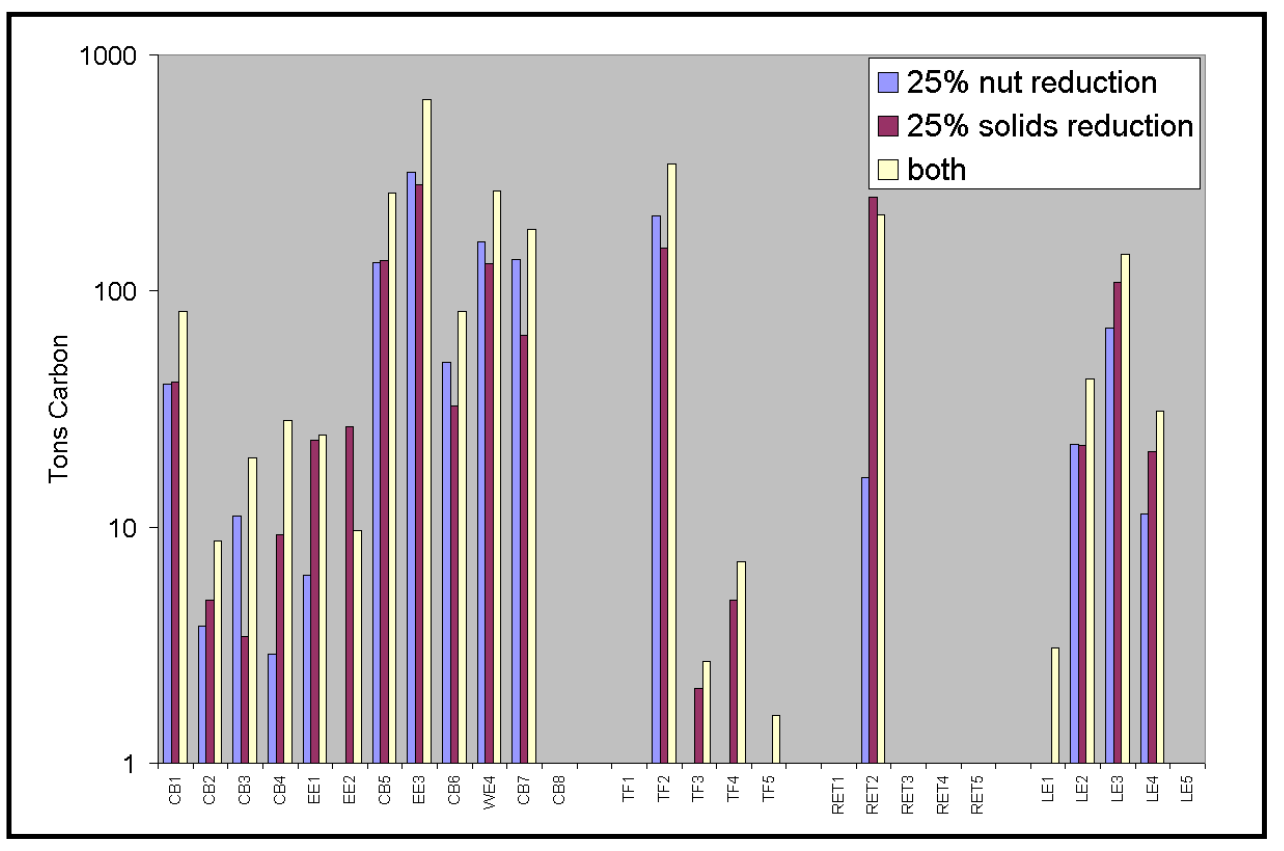

Figure 17. Ten-year mean abundance increase in response to load reductions 
An expected result of the sensitivity runs was that solids reductions alone would decrease SAV in some areas due to relaxed light limitation on epiphytes and phytoplankton. In the turbid portions of the system, the expected increase in attenuation from organic matter did occur. The beneficial effect on SAV of reduced attenuation from fixed solids more than compensated for the increased attenuation from organic matter, however. Consequently, SAV never diminished in response to solids reductions.

Sensitivity to solids reductions can be understood by examining the composition of solids in the system. Extensive solids observations, including total suspended solids, fixed solids, volatile solids, and particulate organic carbon, are available through the monitoring database (U.S. Environmental Protection Agency Chesapeake Bay Program Office, Annapolis, MD). Observations of fixed and volatile solids compose 13 percent of the database. From the remaining observations, volatile solids were estimated as 2.5 times particulate organic carbon (assuming organic matter is composed of carbon, hydrogen, and oxygen in the atomic ratio 1:2:1). Fixed solids were computed as the total less estimated volatile component. Fixed solids exceed volatile solids virtually throughout the system (Figure 18). Consequently, a program that controls volatile solids, through nutrient controls, addresses only a small fraction of solids in the system.

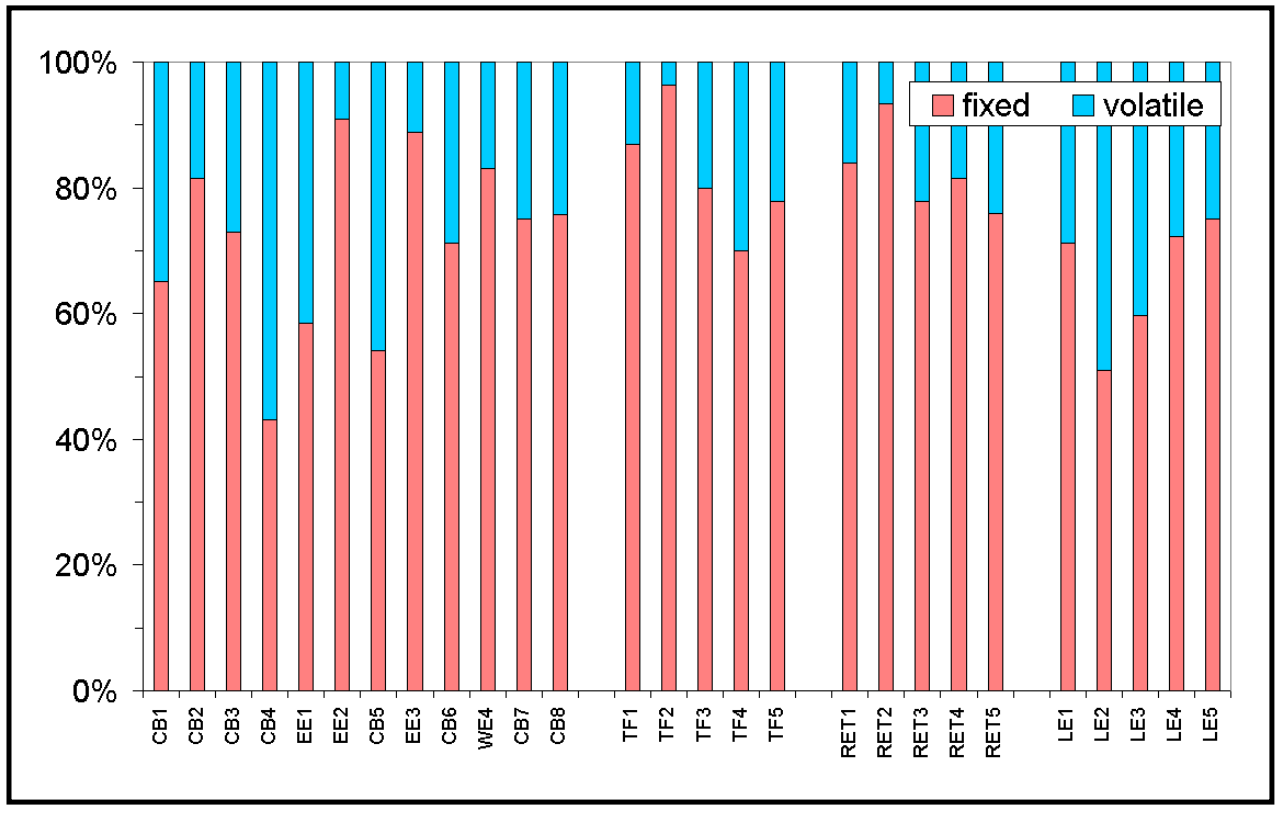

Figure 18. Fixed and volatile fractions of observed total solids concentration, April-October 1985-1994

The components of light attenuation in the system can be examined by using the modeled color, solids distributions, and epiphytes. For this analysis, a mean depth of $1 \mathrm{~m}$ was assumed. Conforming to the distribution of volatile and fixed solids, attenuation from fixed solids exceeds attenuation from volatile solids in almost all regions (Figure 19). The system can be divided into two categories: regions in which attenuation from color and fixed solids exceeds attenuation from organic matter (volatile solids and epiphytes), and regions in which attenuation 


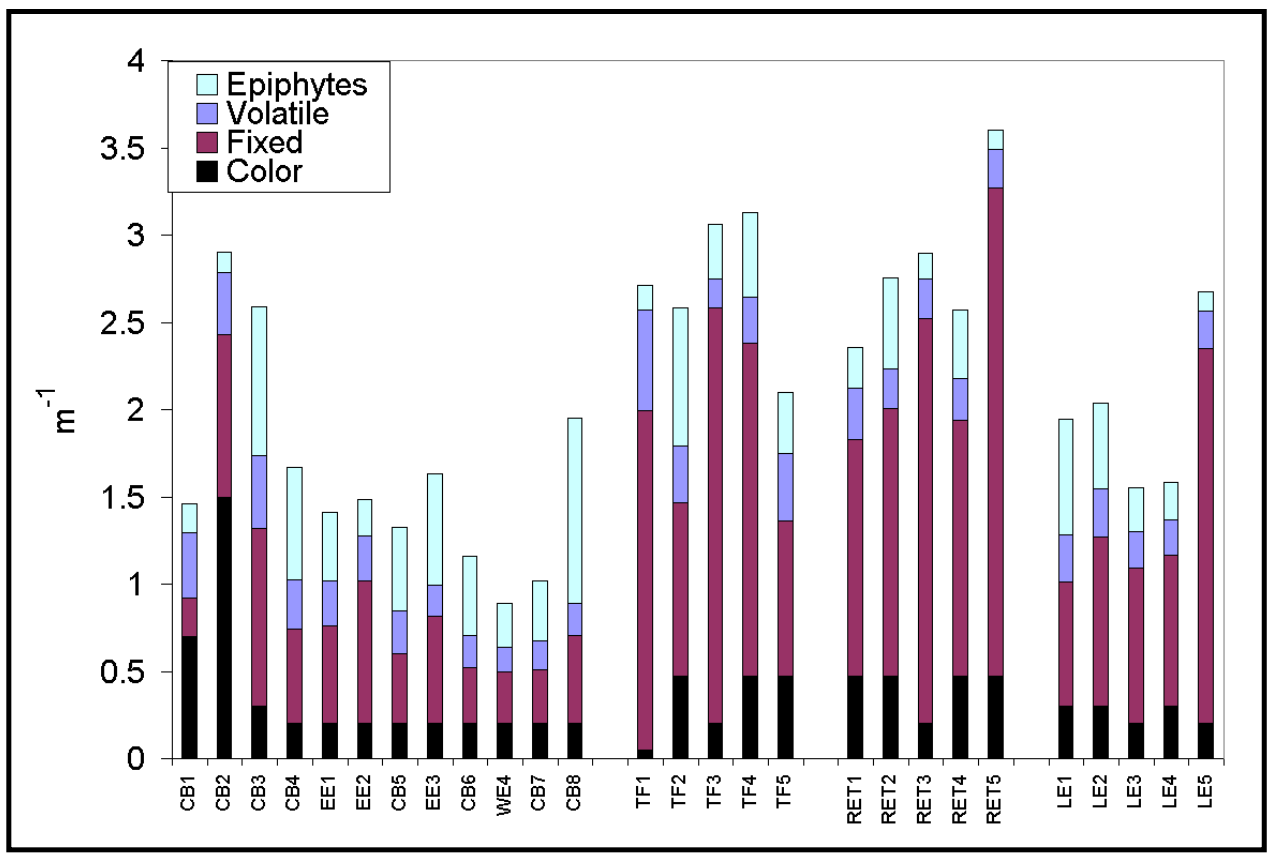

Figure 19. Modeled components of light attenuation at 1-m depth

from organic matter exceeds attenuation from fixed solids. Since organic matter is subject to reduction via nutrient controls, this categorization also divides the system into regions that will benefit most from solids reductions versus nutrient reductions. Color and fixed solids dominate attenuation throughout the major tributaries and in the upper segments of the main stem. Only in the lower portion of the main stem (CB4 downwards) and in adjacent major embayments is attenuation from organic matter dominant.

The components of attenuation alone do not determine the response to nutrient and solids load reductions. Of paramount importance is the requirement to bring total attenuation below levels that support SAV. A more useful classification of the system is into regions subject to nutrient control and regions requiring solids control (Figure 20). Regions subject to nutrient control are areas that presently meet living-resources criteria (Batiuk et al. 1992) and regions in which criteria can be met by reducing attenuation from organic matter. These correspond to regions in which attenuation from color and fixed solids is less than $2 \mathrm{~m}^{-1}$ for freshwater species and less than $1.5 \mathrm{~m}^{-1}$ for other species. Regions in which attenuation from color and solids exceeds $1.5 \mathrm{~m}^{-1}$ (saltwater) to $2 \mathrm{~m}^{-1}$ (freshwater) will never support SAV absent reductions in fixed solids. This classification indicates SAV cannot be restored to large portions of the major tributaries solely via nutrient reduction. Restoration of SAV to the turbidity maximum of the main stem and to the headwaters of several minor tributaries also requires solids reductions. 


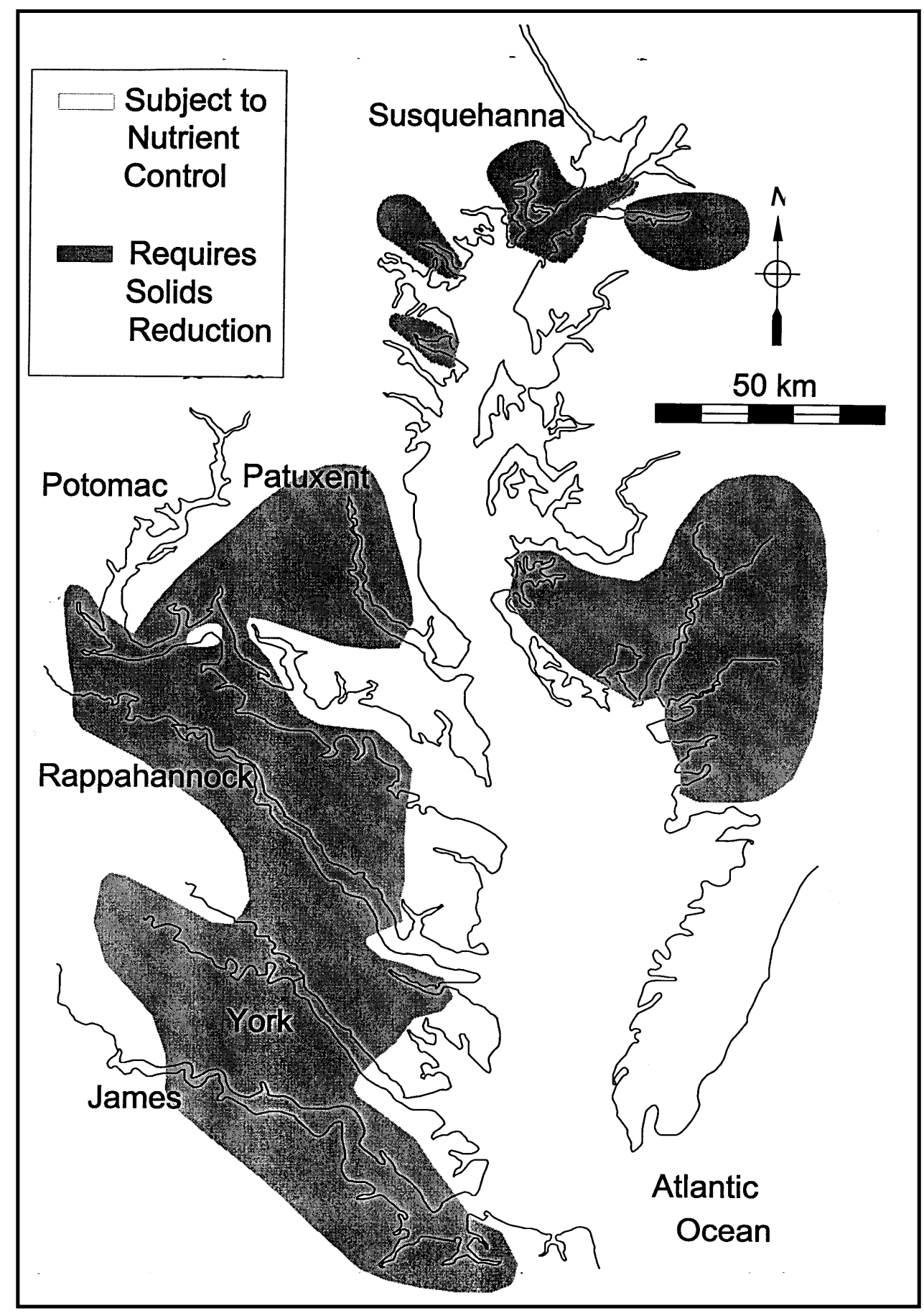

Figure 20. Regions subject to nutrient control versus regions requiring solids control 


\section{Discussion}

\section{Management implications}

First, it must recognized that the present course of nutrient management in the bay and its watershed will benefit the system SAV. On the scale of CBPS, abundance is projected to increase a median of 37 percent in response to 25 percent nutrient reductions (Figure 17). These improvements occur largely in segments that already support SAV, however. Introduction of SAV to areas in which it does not presently occur, notably the tidal fresh portions of the James, Mattaponi, and Rappahannock Rivers, is possible through nutrient controls (Figure 20). These controls must exceed the 25 percent range examined here, however. Through improvements in technology and control of alternate sources (e.g., atmospheric loads), nutrient reductions greater than planned under the 1987 agreement (Baliles et al. 1987) are possible. All that is required is the will to implement them.

Nutrient controls alone, however, are not sufficient to restore a systemwide distribution of SAV. Substantial portions of the major tributaries require solids reductions to support SAV (Figure 20). Solids reductions can also be viewed as an alternative to extreme nutrient controls. Nutrient reductions of 25 percent alone are not sufficient to restore SAV to the tidal fresh reaches of the James, Mattaponi, and Rappahannock Rivers (Figure 17). Solids reductions, alone or in combination with 25 percent nutrient reductions, are projected to support SAV in these areas, however. In viewing the role of solids in SAV restoration, it is worth noting that major declines in SAV occurred following the Tropical Storm Agnes event (Orth and Moore 1984), which introduced massive quantities of suspended solids to the system. Also, sediment accumulation rates in at least one upper bay tributary are higher now than a century or more ago (Brush 1989), suggesting that solids loads are higher at present than in historic times.

\section{The model}

The median error in computing annual community abundance is less than the median error in computing long-term mean abundance in individual CBPS. This statistic belies the obvious conclusion, however, that the model performs well in computing the spatial distribution of SAV (Figure 14) but provides little information regarding interannual variability in abundance (Figure 16). In the long term, the spatial distribution of SAV abundance is determined by the area suited for SAV and by environmental factors, especially light attenuation. The areas are input to the model, and the spatial distribution of environmental factors can be computed with reasonable accuracy. Consequently, the spatial distribution of SAV abundance can be computed with corresponding accuracy.

Interannual variability in SAV abundance is affected by a host of factors. These include environmental influences that vary on numerous time scales and inherent properties of the biota. Short-term or localized events such as storm pulses can have a significant impact on SAV (Moore, Wetzel, and Orth 1997). Consistent, universal simulation of event-scale processes is currently beyond the capability of the CBEMP. Moreover, the response of the plants to events must 
also be represented. Consequently, improvements in computing year-to-year variability await both more accurate environmental models and improved representations of plant physiology.

A high priority for model improvement should be placed on models of plant propagation. This includes local propagation via roots and rhizomes and propagation over distances via seeds and plant fragments. The present model assumes a trace, refuge population in each cell that is available for growth when conditions are favorable. In reality, change in the spatial extent of existing beds is limited by the rates of production and demise of plants at the edges of the beds. The appearance of SAV in new areas depends on the transport of viable plant material or propagules to these areas. The ability to model year-to-year variation in abundance depends partially on the ability to model propagation as well as the ability to model the environment.

Lastly, the ability to model SAV on a subgrid scale should be attained. One feasible approach is to divide the model cell into smaller SAV cells. Since bathymetry and other measures may not be available on the desired scale and since CBEMP computations are not available on the subgrid scale, properties of the SAV cells could be distributed randomly with mean properties determined by the larger model. A second, more advanced approach would be to develop individualbased models of plants and propagate these within model cells.

\section{References}

Baliles, G., Schaefer, W., Casey, R., Thomas, L., Barry, M., and Cole, K. (1987). "Chesapeake Bay Agreement," United States Environmental Protection Agency Chesapeake Bay Program, Annapolis, MD.

Barko, J., and Smart, M. (1981). "Comparative influences of light and temperature on the growth and metabolism of selected freshwater macrophytes," Ecological Monographs 51(2), 219-235.

Batiuk, R., Orth, R., Moore, K., Dennison, W., Stevenson, J., Staver, L., Carter, V., Rybicki, N., Hickman, R., Kollar, S., Bieber, S., and Heasly, P. (1992). "Chesapeake Bay submerged aquatic vegetation habitat requirements and restoration targets: A technical synthesis," CBP/TRS 83/92, United States Environmental Protection Agency Chesapeake Bay Program, Annapolis, MD.

Borum, J. (1985). "Development of epiphytic communities on eelgrass (Zostera marina) along a nutrient gradient in a Danish estuary," Marine Biology 87, 211-218.

Bowes, G., Van, T., Garard, L., and Haller, W. (1977). "Adaptation to low light levels by hydrilla," Journal of Aquatic Plant Management 15, 32-35.

Bowes, G., Holaday, A., and Haller, W. (1979). "Seasonal variation in the biomass, tuber density, and photosynthetic metabolism of hydrilla in three Florida lakes," Journal of Aquatic Plant Management 17, 61-65.

Brush, G. (1989). "Rates and patterns of estuarine sediment accumulation," Limnology and Oceanography 34(7), 1235-1246. 
Carter, V., Paschal, J., and Bartow, N. (1985). "Distribution and abundance of submersed aquatic vegetation in the tidal Potomac River and estuary, Maryland and Virginia, May 1978 to November 1981," Water-Supply Paper 2234-A, U.S. Geological Survey, Alexandria, VA.

Carter, V., Barko, J., Godshalk, G., and Rybicki, N. (1988a). "Effects of submersed macrophytes on water quality in the tidal Potomac River, Maryland," Journal of Freshwater Ecology 4(4), 493-501.

Carter, V., Rybicki, N., Jones, R., Barko, J., Dresler, P., Hickman, R., and Anderson, R. (1988b). "Data on physical, chemical, and biological characteristics of hydrilla beds, mixed vegetation beds, and unvegetated sites in the Tidal Potomac River, 1987,” Open File Report 88-709, U.S. Geological Survey, Alexandria, VA.

Cerco, C., and Cole, T. (1993). "Three dimensional eutrophication model of Chesapeake Bay,” Journal of Environmental Engineering 119, 1006-1025.

Cerco, C., and Meyers, M. (2000). "Tributary refinements to the Chesapeake Bay model," Journal of Environmental Engineering 126(2), 164-174.

Dennison, W., Orth, R., Moore, K., Stevenson, J., Carter, V., Kollar, S., Bergstrom, P., and Batiuk, R. (1993). "Assessing water quality with submersed aquatic vegetation," BioScience 43(2), 86-94.

DiToro, D., and Fitzpatrick, J. (1993). "Chesapeake Bay sediment flux model," Contract Report EL-93-2, U.S. Army Engineer Waterways Experiment Station, Vicksburg, MS.

Evans, A., Webb., K., and Penhale, P. (1986). "Photosynthetic acclimation in two coexisting seagrass systems, Zostera marina L. and Ruppia maritima L.," Aquatic Botany 24, 185-197.

Gallegos, C., Correll, D., and Pierce, J. (1990). "Modeling spectral diffuse attenuation, absorption, and scattering coefficients in a turbid estuary," Limnology and Oceanography 35, 1486-1502.

Gallegos, C. (1994). "Refining habitat requirements of submersed aquatic vegetation: Role of optical models," Estuaries 17, 187-199.

Haller, W., and Sutton, D. (1975). "Community structure and competition between hydrilla and vallisneria," Hyacinth Control Journal 13, 48-50.

Holmes, R. (1970). "The Secchi disk in turbid coastal water," Limnology and Oceanography 15, 688-694.

Jassby, A., and Platt, T. (1976). "Mathematical formulation of the relationship between photosynthesis and light for phytoplankton," Limnology and Oceanography 21, 540-547.

Johnson, B., Kim, K., Heath, R., Hsieh, B., and Butler, L. (1993). "Validation of a three-dimensional hydrodynamic model of Chesapeake Bay," Journal of Hydraulic Engineering 199(1), 2-20.

Keefe, C., Flemer, D., and Hamilton, D. (1976). "Seston distribution in the Patuxent River estuary," Chesapeake Science 17(1), 56-59. 
Kemp, W., Twilley, R., Stevenson, J., Boynton, W., and Means, J. (1983). "The decline of submerged vascular plants in the upper Chesapeake Bay: Summary of results concerning possible causes," Marine Technology Science Journal 17(2), 78-89.

Kirk, J. (1994). Light and photosynthesis in aquatic ecosystems. $2^{\text {nd }}$ ed., Cambridge University Press, Cambridge, 509 pp.

Krause-Jensen, D., and Sand-Jensen, K. (1998). "Light attenuation and photosynthesis of aquatic plant communities," Limnology and Oceanography 43(3), 396-407.

Linker, L., Stigall, C., Chang, C., and Donigian, A. (1996). "Aquatic accounting: Chesapeake Bay watershed model quantifies nutrient loads," Water Environment and Technology 8(1), 48-52.

Madden, C., and Kemp, W. (1996). "Ecosystem model of an estuarine submersed plant community: Calibration and simulation of eutrophication responses," Estuaries 19(2B), 457-474.

Marsh, J., Dennison, W., and Alberte, R. (1986). "Effects of temperature on photosynthesis and respiration in eelgrass (Zostera marina L.)," Journal of Experimental Marine Biology and Ecology 101, 257-267.

Moore, K., Goodman, J., Stevenson, J., Murray, L., and Sundberg, K. (1994). "Chesapeake Bay nutrients, light and SAV: Relations between variable water quality and SAV in field and mesocosm studies, Year 1 Draft Final Report," U.S. Environmental Protection Agency, Chesapeake Bay Program, Annapolis, MD.

Moore, K., Wetzel, R., and Orth, R. (1997). "Seasonal pulses in turbidity and their relations to eelgrass (Zostera marina L.) survival in an estuary," Journal of Experimental Marine Biology and Ecology 215, 115-134.

Moore, K., Wilcox, D., and Orth, R. (2000). "Analysis of the abundance of submerged aquatic vegetation communities in the Chesapeake Bay," Estuaries 23, 115-127.

Neckles, H., Wetzel, R., and Orth, R. (1993). "Relative effects of nutrient enrichment and grazing on epiphyte-macrophyte (zostera marina L.) dynamics," Oecologia 93, 285-295.

Orth, R., and Moore, K. (1984). "Distribution and abundance of submerged aquatic vegetation in Chesapeake Bay: An historical perspective," Estuaries 7(4B), 531-540.

Penhale, P. (1977). "Macrophyte - epiphyte biomass and productivity in an eelgrass (zostera marina L.) community," Journal of Experimental Marine Biology and Ecology 26, 211-224.

Pennock, J. (1985). "Chlorophyll distributions in the Delaware Estuary: Regulation by light limitation," Estuarine, Coastal and Shelf Science 21, 711-725.

Schubel, J. (1968). "Turbidity maximum of the northern Chesapeake Bay," Science 161, 1013-1015. 
Staver, K. (1984). "Responses of epiphytic algae to nitrogen and phosphorus enrichment and effects on productivity of the host plant, potamogeton perfoliatus L., in estuarine waters.” M. S. thesis, University of Maryland, College Park.

Thomann, R., Collier, J., Butt, A., Casman, E., and Linker, L. (1994). "Technical analysis of response of Chesapeake Bay water quality model to loading scenarios," Technical Report Series 101/94, U.S. Environmental Protection Agency, Chesapeake Bay Program Office, Annapolis, MD.

Titus, J., and Adams, M. (1979). "Coexistence and comparative light relations of the submersed macrophytes Myriophyllum spicatum L. and Vallisneria americana Michx," Oecologia (Berl.) 40, 273-286.

Twilley, R., Kemp, W., Staver, K., Stevenson, J., and Boynton, W. (1985). "Nutrient enrichment of estuarine submersed vascular plant communities. 1. Algal growth and effects on production of plants and associated communities," Marine Ecology Progress Series 23, 179-191.

Van, T., Haller, W., and Bowes, G. (1976). "Comparison of the photosynthetic characteristics of three submersed aquatic plants," Plant Physiology 58, 761768 .

Ward, L., Kemp, W., and Boynton, W. (1984). "The influence of waves and seagrass communities on suspended particulate matter in an estuarine embayment," Marine Geology 59, 85-103.

Wetzel, R., and Penhale, P. (1983). "Production ecology of seagrass communities in the lower Chesapeake Bay," Marine Technology Society Journal 17(2), 22-32.

Wetzel, R., and Neckles, H. (1986). "A model of Zostera marina L. photosynthesis and growth: Simulated effects of selected physical-chemical variables and biological interactions," Aquatic Botany 26, 307-323. 


\section{Nutrient and Solids Controls in Virginia's Chesapeake Bay Tributaries}

\section{Introduction}

For nearly 15 years, mathematical models have guided management efforts to reduce eutrophication in Chesapeake Bay and its tributaries. Both models and methodologies have evolved greatly since their first employment. Most recently, models assisted resource agencies in development of "Tributary Strategies" to reduce eutrophication in the major Virginia tributaries to the bay. The objective of this chapter is to (a) describe the models; (b) describe the load-reduction scenarios; (c) report nutrient and solids loads, their origin, and potential for reduction; (d) present results of the scenarios; and (e) interpret the benefits and limits of nutrient and solids controls.

\section{The Virginia Tributaries}

Virginia's western tributaries lie at the southern end of Chesapeake Bay (Figure 1). Their drainage basins compose 22 percent of the system watershed (Figure 2). The James River estuary has the largest drainage basin, the greatest runoff, and the least depth of the three major tributaries (Table 1). Although the upland James watershed is dominated by forest, the tidal James is characterized by major urban and industrial centers including Richmond, Hopewell, and NorfolkNewport News. The York River estuary consists of four water bodies. The tidal fresh Pamunkey and Mattaponi Rivers join at the head of the York River proper. At its mouth, the York opens into Mobjack Bay, which abuts Chesapeake Bay. Nearly 70 percent of the York basin is forested and no major developments are found along the banks of the estuary. The Rappahannock River estuary is comparable to the James in length but drains a smaller watershed and, consequently, has less freshwater flow. The city of Fredericksburg is situated at the head of tide, but the watershed is less developed than the James and no major developments are located below the head of tide. 


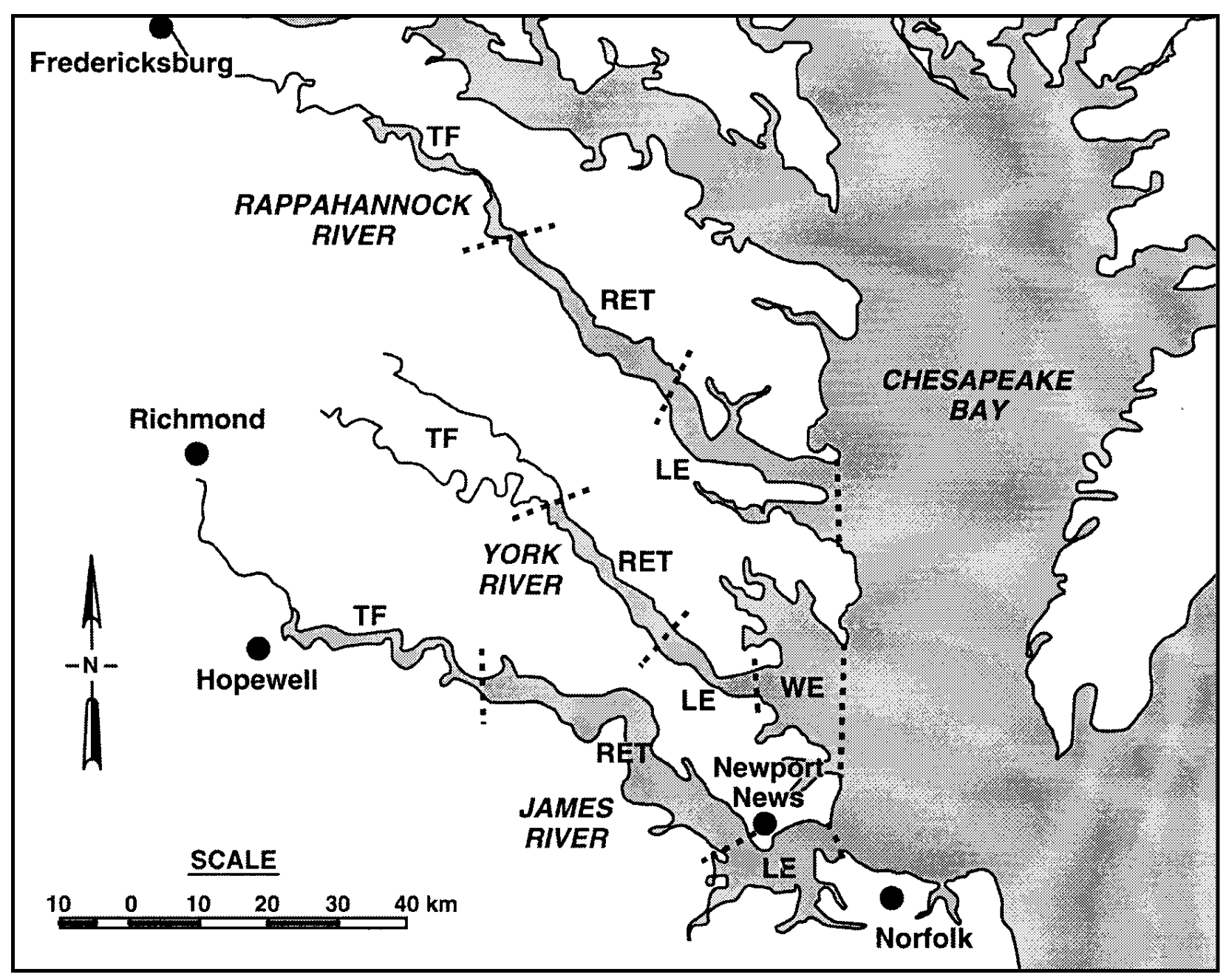

Figure 1. The Virginia tributaries

For purposes of monitoring and reporting, the tributaries are divided into Chesapeake Bay Program Segments (CBPS). The segments (Figure 1) are defined largely according to geometry and salinity regime. Segment designations are Tidal Fresh (TF); River-Estuarine Transition (RET); Lower Estuary (LE); and Western Embayment (WE).

\section{The Models}

A series of four models were employed to quantify loads to the tributaries, to calculate transport within the tributaries, and to represent eutrophication processes.

\section{The watershed model}

The Watershed Model (WSM) simulated the delivery of nutrients and solids to the estuaries. The WSM is based on Hydrologic Simulation Program- 


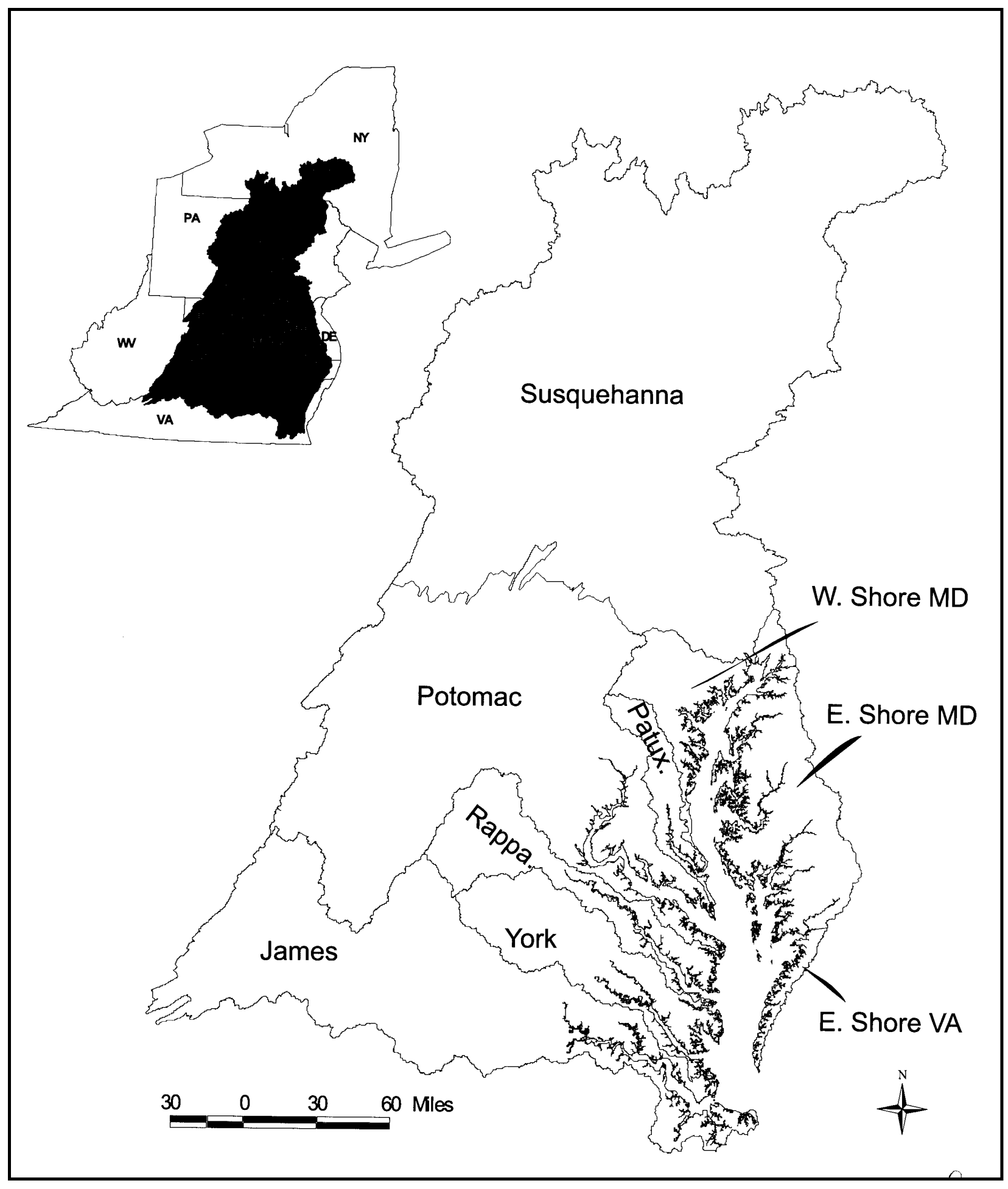

Figure 2. The Chesapeake Bay watershed 


\begin{tabular}{|c|c|c|c|c|}
\hline \multicolumn{5}{|c|}{\begin{tabular}{|l|} 
Table 1 \\
Characteristics of Virginia Tributaries
\end{tabular}} \\
\hline River & Length, km & Mean Depth, m & Drainage Area, $\mathrm{km}^{2}$ & Mean Flow, $\mathrm{m}^{3} \mathrm{~s}^{-1}$ \\
\hline James & 154 & 4.0 & 26,639 & 207 \\
\hline York & 114 & 4.7 & 7,804 & 42 \\
\hline Rappahannock & 157 & 4.7 & 6,972 & 46 \\
\hline
\end{tabular}

FORTRAN Version 11 (Bicknell et al. 1996). The Chesapeake Bay watershed (Figure 2) was divided into 86 segments with an average area of 194,000 hectares. Segmentation was based on topography, rainfall patterns, and river reaches. Within each segment, ten land uses were identified: forest, pasture, mixed open, conventional-tilled cropland, conservation-tilled cropland, cropland in hay, animal waste areas, open water, pervious urban land, and impervious urban land. In addition to loading from various land uses, the WSM incorporated loads from the atmosphere (based on National Atmospheric Deposition Program (NADP) observations), from point sources (based on National Pollution Discharge Elimination System reports), and from septic systems. The model was calibrated through comparison of computed and observed flows (17 stations) and concentrations (15 stations) throughout the watershed for the period 1984-1995. Computed and observed suspended solids, organic phosphorus, dissolved inorganic phosphorus, ammonium, nitrate, and organic nitrogen were compared in a variety of formats including time series and frequency distribution. Formulation and calibration of the WSM are under continuous improvement. Phase 4.1 of the WSM was employed for the Virginia tributaries. Complete calibration documentation may be found at the Chesapeake Bay Program web site http://www.chesapeakebay.net/.

The WSM was employed in two modes. The first mode quantified historic (1985) and present (1996) loading to the system. The second, predictive mode quantified loads that result from various management strategies implemented within the watersheds. Loads were computed on a daily basis for input to the eutrophication model.

\section{The airshed model}

Existing wet deposition of ammonium and nitrate to land and water surfaces within the model domain was derived from NADP observations. Data from 15 stations in the watershed, collected over 11 years, were employed to relate concentration to precipitation, month, and location. For each rainfall event in the calibration period, atmospheric loads were computed as the product of calculated concentration and precipitation volume.

The Regional Acid Deposition Model (RADM) was employed to estimate atmospheric nitrogen loads resulting from various management actions. RADM (Chang et al. 1987) is a three-dimensional model that tracks nitrogen emissions across the eastern United States. Processes considered by RADM include emission inputs, three-dimensional transport, chemical transformations, scavenging, precipitation, and dry deposition. The RADM domain (Figure 3) consists of 


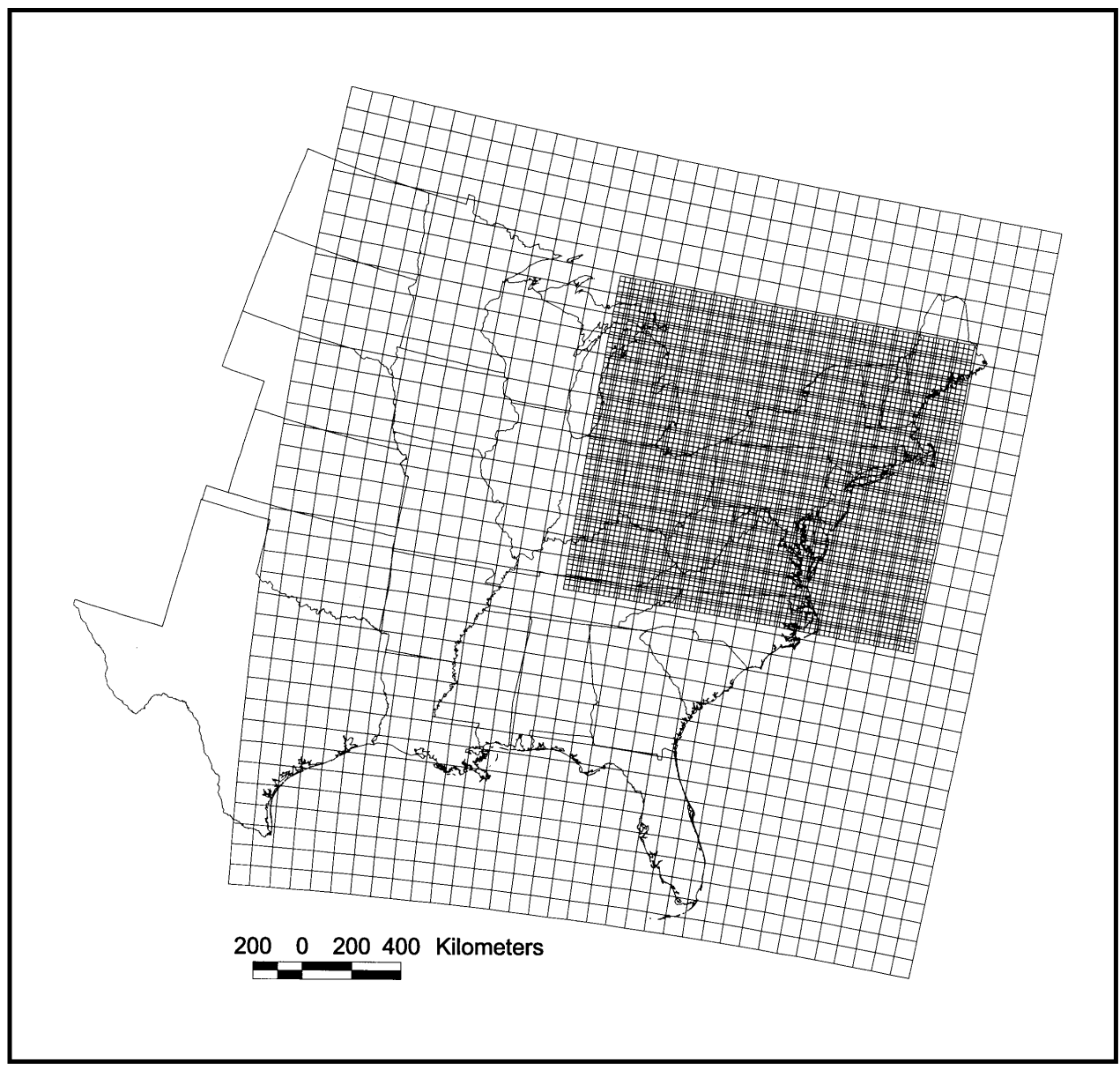

Figure 3. The RADM domain and computational grid

20,000 cells, each $6,400 \mathrm{~km}^{2}$. A nested grid was used in the Chesapeake Bay vicinity consisting of 60,000 cells, each $400 \mathrm{~km}^{2}$.

RADM computed deposition for an annual-average meteorology. Loads corresponding to model hydrology were derived by a ratio method. The percent change in the RADM scenario deposition relative to the RADM base deposition was computed for each RADM cell. This percent change was then applied to the time series of existing loads derived from NADP observations.

Dry deposition of nitrate was derived from wet deposition using ratios calculated by RADM. The atmospheric load of organic nitrogen to water surfaces was determined as the product of concentration and rainfall volume. Deposition of organic and inorganic phosphorus was based on published values.

\section{The hydrodynamic model}

Transport processes within Chesapeake Bay and its tributaries were computed with the Computational Hydrodynamics in Three Dimensions-Waterways Experiment Station (CH3D-WES) model. CH3D-WES (Johnson et al. 1993) is based on 
principles expressed by the equations of motion, conservation of volume, and conservation of mass. Quantities computed by the model include threedimensional velocities, surface elevation, vertical viscosity and diffusivity, temperature, salinity, and density.

CH3D-WES employs the finite-difference method to solve governing equations on a discrete grid. The grid is based on curvilinear coordinates in the horizontal plane and z-coordinates in the vertical direction. The present grid (Cerco and Meyers 2000) included 2,100 cells $\left(\approx 6 \mathrm{~km}^{2}\right.$ each) in the surface plane and up to 20 vertical layers $(\approx 1.5 \mathrm{~m}$ each $)$. Solution time-step was $\approx 5$ minutes.

CH3D-WES was validated against salinity, tide, and current observations collected throughout the Chesapeake Bay system. Examples of model performance were presented by Johnson et al. (1993).

\section{The eutrophication model}

The Corps of Engineers Quality Integrated Compartment Model (CE-QUALICM) was developed for application to Chesapeake Bay (Cerco and Cole 1993). The initial model computed 22 state variables including salinity, temperature, multiple algal groups, multiple forms of carbon, nitrogen, phosphorus and silica, and dissolved oxygen. A distinctive feature of the model was inclusion of a fully predictive sediment diagenesis model that provided computations of sediment oxygen demand and nutrient releases. For employment in the Virginia tributaries, a refined model was developed that incorporated interactive predictive computations of living resources including microzooplankton, mesozooplankton, filterfeeding benthos, deposit-feeding benthos, and submerged aquatic vegetation (SAV). Basics of these computations and examples of results were presented by Cerco and Meyers (2000).

CE-QUAL-ICM employed the same grid as the hydrodynamic model. The time-step for numerical integrations was 15 minutes. CE-QUAL-ICM received inputs from the other models but operated independently of them. Threedimensional flows, surface levels, and vertical diffusivities produced by CH3DWES were stored, at 2-hour intervals, on disk for repetitive use by CE-QUALICM. Daily loads computed by the WSM and RADM, routed to individual cells in the surface plane, were likewise stored and used repetitively by the water quality model.

\section{Scenario Methodology}

Sixteen management scenarios were run (Butt et al. 2000). These examined the present status of the tributaries, response to management actions within the tributary watersheds, and response to management actions within the bay watershed but external to the tributaries. Four primary scenarios are presented here. Each was run for a period of 10 years using observed hydrology from the period 1985-1994. Because benthic sediments require 2 to 10 years to equilibrate to 
loading conditions (Cerco 1995), each scenario was preceded by a 10-year spin-up computation.

\section{Base scenario}

The 1987 Chesapeake Bay Agreement (Baliles et al. 1987) commits the signatories to a 40 percent reduction in controllable nutrient loads to the bay system. The reductions are relative to 1985 point-source loads and nonpoint-source loads in an average rainfall year. The Base Scenario quantifies the base loads against which load reductions are compared. Point-source loads are specified at 1985 levels. Nonpoint-source loads are computed by the WSM using 1985 land use and management practices and the 10-year hydrology. Mean loads from the 10 years are considered equivalent to loads in an average rainfall year. Atmospheric loads are specified at existing levels based on NADP data.

\section{The 1996 Progress Scenario}

Load reductions and their impact on receiving waters are difficult to interpret solely from observations. Lags in response to load alterations and natural hydrologic variability confound the effort to detect trends in water quality and living resource abundance. The 1996 Progress Scenario provided the basis to evaluate load reductions enacted since the signing of the Chesapeake Bay Agreement. This scenario was also interpreted as a characterization of the system under present conditions. Point-source loads for the 1996 Progress Scenario were specified at 1996 levels. Nonpoint-source loads were computed by the WSM based on the 1985-1994 hydrology and 1996 land uses and management practices. Atmospheric loads were from the Base Scenario.

Comparison of the nonpoint-source loads from the Base Scenario and the Progress Scenario provided a quantification of load reductions free from problems associated with lags and hydrologic variability. Comparing two scenarios of computed water quality and living resource abundance provided a quantification of benefits derived from load reductions.

\section{Full Voluntary Program Implementation (FVPI)}

This scenario examined the benefits to be gained by voluntary implementation of load controls at the maximum feasible level. The WSM was used to compute nonpoint-source loads resulting from implementation of a host of management practices (Butt et al. 2000). These included conversion of cropland to conservation till, implementation of streambank buffers, septic system and storm water improvements, urban nutrient management, and other programs for soil and water conservation. Point-source discharges in the watershed and directly to the estuaries were limited to $5.5 \mathrm{mg} / \mathrm{L}$ nitrogen and $0.18 \mathrm{mg} / \mathrm{L}$ phosphorus. Atmospheric deposition of nitrate and ammonium was derived from RADM based on controls of atmospheric emissions by stationary and mobile sources. 


\section{Limit of Technology (LOT)}

This scenario examined the benefits to be gained from maximum load controls and complete participation by landowners and dischargers. The WSM computed nonpoint-source loads based on more extensive application of management practices implemented in the FVPI scenario. Point-source discharges in the watershed and directly to the estuaries were limited to $3.0 \mathrm{mg} / \mathrm{L}$ nitrogen and $0.075 \mathrm{mg} / \mathrm{L}$ phosphorus. Atmospheric deposition of nitrate and ammonium was derived from RADM based on maximum, year-round controls of atmospheric emissions in all states east of the Rocky Mountains.

\section{Loads}

\section{Sources}

Loads reported here are as received in each estuary. The WSM routed loads from their origin in the watershed to receiving streams and then to the tributaries. During the routing, loads were attenuated by settling, periphyton uptake, and other processes. The WSM was employed to estimate the portion of loads originating in each land use that was transmitted to the estuaries. These were combined with loads directly to the estuary to obtain an estimate of the current (1996) percent contribution of each loading source (Table 2).

Estimating the fractional contribution of atmospheric loads is perplexing since these loads are delivered primarily to the land surface and routed to the streambank. During the routing process, the loads are attenuated and combined with other loads to the land. As reported here, loads from each land use include atmospheric loads to that land use. Reported atmospheric loads represent loads directly to the water surface.

Shoreline erosion is a significant source of solids to the estuaries not considered by the WSM. Long-term average loads from erosion of fastland were obtained from the U.S. Army Engineer District, Baltimore (1990). The total volume eroded includes gravel, sand, silt, and clay. Silts and clays, which contribute to suspended solids in the estuaries, were assumed to be 20 percent of the total eroded (Ibison et al. 1990).

In the first application of the model, computed total phosphorus in the main stem bay was less than observed (Cerco and Cole 1993). Omission of phosphorus loads associated with bank erosion was suggested as a source of the discrepancy. For the Virginia Tributaries application, bank loads were introduced in the form of particulate inorganic phosphorus (PIP). The PIP fraction associated with solids, 0.1 percent by weight, was based on observations at tributary load sources.

\section{Nitrogen}

Cropland is the major nitrogen source to the York and Rappahannock estuaries (Table 2). Loads from cropland are two to three times larger than any other 


\begin{tabular}{|c|c|c|c|}
\hline \multicolumn{4}{|c|}{\begin{tabular}{|l} 
Table 2 \\
Sources of Loads to Virginia Tributaries
\end{tabular}} \\
\hline Source & James, \% & York, \% & Rappahannock, \% \\
\hline \multicolumn{4}{|c|}{ Nitrogen } \\
\hline Cropland & 14 & 34 & 48 \\
\hline Pasture & 4 & 5 & 12 \\
\hline Animal Waste & 1 & 1 & 1 \\
\hline Forest & 9 & 15 & 11 \\
\hline Urban Loads & 20 & 16 & 13 \\
\hline Atmospheric & 5 & 12 & 10 \\
\hline Point Source & 48 & 18 & 5 \\
\hline \multicolumn{4}{|c|}{ Phosphorus } \\
\hline Cropland & 19 & 32 & 38 \\
\hline Pasture & 11 & 2 & 12 \\
\hline Animal Waste & 1 & 1 & 1 \\
\hline Forest & 13 & 4 & 1 \\
\hline Urban Loads & 12 & 7 & 7 \\
\hline Atmospheric & 3 & 12 & 7 \\
\hline Point Source & 38 & 24 & 8 \\
\hline Bank Erosion & 2 & 18 & 26 \\
\hline \multicolumn{4}{|c|}{ Sediment } \\
\hline Cropland & 21 & 41 & 33 \\
\hline Pasture & 20 & 6 & 14 \\
\hline Forest & 51 & 22 & 17 \\
\hline Urban Loads & 7 & 3 & 5 \\
\hline Bank Erosion & 2 & 29 & 31 \\
\hline
\end{tabular}

source. After cropland, no single source dominates. In contrast, point sources provide the most nitrogen to the James estuary. Urban loads are a significant secondary source followed by cropland.

\section{Phosphorus}

As with nitrogen, cropland is the major phosphorus source to the York and Rappahannock estuaries (Table 2). In the Rappahannock, bank erosion is the dominant secondary source while in the York, point sources provide a significant fraction of the phosphorus. In the James, point sources are the largest phosphorus source and are double the loading from cropland, the major secondary source. 


\section{Solids}

Consistent with nutrient loads, cropland provides the majority of sediment to the York and Rappahannock estuaries (Table 2). Loads from cropland are rivaled, however, by shoreline erosion. In the James, the majority of solids loads originates in forests. Loads from forests exceed the next two sources, cropland and pasture, combined. Shoreline erosion is a negligible sediment source. The relatively small role played by erosion is due primarily to the enormous solids loading at the fall line although absolute quantities eroded in the James are less than the other tributaries.

\section{Progress by 1996}

Computed daily average nitrogen loads, based on 1996 point sources and land uses, showed declines of 2 to 12 percent from the 1985 base (Table 3). Sources of the reductions varied. In the York and Rappahannock, reductions from distributed sources were partially offset by increases in point-source loading. In the James, major reductions came from point sources although distributed loads were reduced as well. Reductions in computed phosphorus loads, 20 to 35 percent, were much greater than for nitrogen (Table 4). Point-source loads in each estuary were halved, accompanied by reductions in distributed loads as well. Solids loads to the York and Rappahannock were reduced by more than 10 percent while negligible progress was made in reducing solids loads to the James (Table 5).

\section{Full Voluntary Program Implementation}

Implementation of a full voluntary program of load reduction should produce reductions in nitrogen loading, 35 to 49 percent of base loads, much greater than

\begin{tabular}{|c|c|c|c|c|c|}
\hline \multicolumn{6}{|c|}{\begin{tabular}{|l} 
Table 3 \\
Nitrogen Loads to Virginia Tributaries
\end{tabular}} \\
\hline Scenario & $\begin{array}{l}\begin{array}{l}\text { Point Source } \\
\text { kg/day }\end{array} \\
\end{array}$ & \begin{tabular}{|l|} 
Nonpoint \\
Source, $\mathbf{k g} /$ day
\end{tabular} & $\begin{array}{l}\text { Atmospheric } \\
\text { kg/day }\end{array}$ & Total, kg/day & $\begin{array}{l}\text { Reduction } \\
\text { from Base, \% }\end{array}$ \\
\hline \multicolumn{6}{|c|}{ Rappahannock } \\
\hline |Base & 500 & 12,200 & 900 & 13,700 & \\
\hline 1996 Progress & 600 & 10,600 & 900 & 12,100 & 12 \\
\hline FVPI & 200 & 7,200 & 800 & 8,300 & 39 \\
\hline LOT & 100 & 6,200 & 600 & 7,000 & 49 \\
\hline \multicolumn{6}{|c|}{ York } \\
\hline Base & 1,600 & 8,600 & 900 & 11,100 & \\
\hline $\mid 1996$ Progress & 2,000 & 8,000 & 900 & 10,900 & 2 \\
\hline FVPI & 600 & 5,700 & 800 & 7,200 & 35 \\
\hline LOT & 400 & 5,000 & 600 & 6,000 & 46 \\
\hline \multicolumn{6}{|c|}{ James } \\
\hline Base & 27,500 & 23,800 & 1,300 & 52,600 & \\
\hline $\mid 1996$ Progress & 22,300 & 23,200 & 1,300 & 46,800 & 11 \\
\hline FVPI & 7,700 & 18,200 & 1,100 & 27,000 & 49 \\
\hline LOT & 4,600 & 15,300 & 800 & 20,700 & 61 \\
\hline
\end{tabular}




\begin{tabular}{|c|c|c|c|c|c|}
\hline \multicolumn{6}{|c|}{$\begin{array}{l}\text { Table } 4 \\
\text { Phosphorus Loads to Virginia Tributaries }\end{array}$} \\
\hline Scenario & $\begin{array}{l}\text { Point Source, } \\
\text { kg/day }\end{array}$ & \begin{tabular}{|l|} 
Nonpoint \\
Source, kg/day
\end{tabular} & $\begin{array}{l}\text { Atmospheric, } \\
\text { kg/day }\end{array}$ & Total, kg/day & \begin{tabular}{|l|l} 
Reduction \\
from Base, \%
\end{tabular} \\
\hline \multicolumn{6}{|c|}{ Rappahannock } \\
\hline Base & 200 & 1,280 & 70 & 1,570 & \\
\hline 1996 Progress & 100 & 1,100 & 70 & 1,260 & 20 \\
\hline FVPI & 20 & 970 & 70 & 1,060 & 32 \\
\hline LOT & 0 & 870 & 70 & 940 & 40 \\
\hline \multicolumn{6}{|c|}{ York } \\
\hline Base & 520 & 710 & 80 & 1,300 & \\
\hline 1996 Progress & 220 & 610 & 80 & 910 & 30 \\
\hline FVPI & 60 & 560 & 80 & 700 & 46 \\
\hline LOT & 10 & 480 & 80 & 580 & 55 \\
\hline \multicolumn{6}{|c|}{ James } \\
\hline Base & 4,460 & 3,250 & 100 & 7,810 & \\
\hline 1996 Progress & 1,890 & 3,050 & 100 & 5,050 & 35 \\
\hline FVPI & 610 & 2,720 & 100 & 3,430 & 56 \\
\hline LOT & 120 & 2,290 & 100 & 2,520 & 68 \\
\hline
\end{tabular}

\begin{tabular}{|c|c|c|c|c|}
\hline \multicolumn{5}{|c|}{\begin{tabular}{||l} 
Table 5 \\
Solids Loads to Virginia Tributaries \\
\end{tabular}} \\
\hline Scenario & $\begin{array}{l}\text { Nonpoint Source } \\
\mathrm{kg} / \mathrm{day}\end{array}$ & $\begin{array}{l}\begin{array}{l}\text { Bank Loads } \\
\text { kg/day }\end{array} \\
\end{array}$ & Total, kg/day & $\begin{array}{l}\begin{array}{l}\text { Reduction from } \\
\text { Base, \% }\end{array} \\
\end{array}$ \\
\hline \multicolumn{5}{|c|}{ Rappahannock } \\
\hline Base & 900,000 & 330,000 & $1,230,000$ & \\
\hline 1996 Progress & 750,000 & 330,000 & $1,080,000$ & 12 \\
\hline FVPI & 670,000 & 330,000 & $1,000,000$ & 19 \\
\hline LOT & 600,000 & 330,000 & 930,000 & 24 \\
\hline \multicolumn{5}{|c|}{ York } \\
\hline Base & 470,000 & 160,000 & 630,000 & \\
\hline 1996 Progress & 400,000 & 160,000 & 560,000 & 11 \\
\hline FVPI & 370,000 & 160,000 & 530,000 & 16 \\
\hline LOT & 320,000 & 160,000 & 480,000 & 24 \\
\hline \multicolumn{5}{|c|}{ James } \\
\hline Base & $4,980,000$ & 90,000 & $5,070,000$ & \\
\hline 1996 Progress & $4,980,000$ & 90,000 & $5,070,000$ & 0 \\
\hline FVPI & $4,480,000$ & 90,000 & $4,570,000$ & 10 \\
\hline LOT & $4,230,000$ & 90,000 & $4,320,000$ & 15 \\
\hline
\end{tabular}

those achieved by 1996 (Table 3). FVPI calls for reductions in point-source nitrogen loading to a third of 1996 levels, making point-source reductions the largest on a fractional basis. The largest absolute reductions in the York and Rappahannock come from distributed sources, however. On both an absolute and percentage basis, reductions in direct atmospheric nitrogen loads are least of the potential reductions. FVPI reduces phosphorus loads by 32 to 56 percent relative to base (Table 4). The largest fractional reductions are from point sources, which are 
reduced to a third or less of 1996 levels. For the York and James, the largest absolute reductions come from point sources as well. FVPI produces negligible reductions in atmospheric phosphorus loads and 10 to 19 percent reductions in solids loads (Table 5).

\section{Limit of technology}

At the current LOT, nitrogen loads can be reduced by 46 to 61 percent of base levels (Table 3). As with FVPI, the largest fractional reduction comes from point sources, which are reduced to 20 percent of 1996 levels. Reductions in point sources compose the largest absolute nitrogen reduction in the James while reductions in distributed loads dominate in the remaining tributaries. Direct atmospheric loads are reduced by a third from 1996 levels although the absolute amount is small. Phosphorus loads can be reduced by 40 to 68 percent, relative to base, at current LOT (Table 4). Under LOT, point-source phosphorus loads are nearly eliminated while distributed loads are reduced by 30 percent. LOT produces negligible reductions in atmospheric phosphorus loads and 15 to 24 percent reductions in solids loads (Table 5).

\section{Scenario Results}

Results are presented here for nine primary constituents. Surface total nitrogen is reported as an indicator of load reductions and because nitrogen at the surface is available to phytoplankton and epiphytes growing on SAV. Surface total phosphorus is reported for the same reasons. Suspended solids were added to the model primarily to quantify light limitation on SAV. Since SAV exists only in shallow depths $(<2 \mathrm{~m})$ and grows primarily in summer, suspended solids are reported at the surface in summer. Chlorophyll is reported at the surface since the photic zone occupies only a small portion of the water column. Summer is selected to emphasize the season when production is high, water quality is poor, and algae contribute to light limitation of SAV. Mesozooplankton were added to the model as an indicator of food available to fish and other higher-trophic-level organisms. Benthos are reported since they are both a valuable resource in themselves and an indicator of food available to fish and other organisms. Light attenuation is the prime water-quality factor influencing the distribution and abundance of SAV. SAV is reported since assessing the impact of load controls on SAV was a primary objective of the model study. Anoxic volume days (Cerco and Cole 1993) are a space-time integration of the quantity of water with dissolved oxygen less than $1 \mathrm{mg} / \mathrm{L}$.

Results are averaged or summed (SAV biomass) over CBPS (Figure 1) and over the 10-year scenario period. Aside from brevity of presentation, the spatial and temporal aggregations are appropriate because the living-resource models are most reliable over large spatial scales $\left(\approx 100 \mathrm{~km}^{2}\right)$ and multiyear time periods (Cerco and Meyers 2000; Cerco and Moore 2001). 


\section{Surface total nitrogen}

Under present (1996) conditions, the estuaries show a spatial gradient in total nitrogen from highest levels in the tidal fresh regions to lowest levels near the mouths (Figure 4a). The spatial gradient reflects the locations of loads, primarily in the headwaters, and dilution with bay water in the lower estuaries. Segments in the James River show higher nitrogen concentrations than comparable segments in the other estuaries, consistent with relative loading among the estuaries. The response of total nitrogen concentration to load changes is linear. Regression using the fractional change in system loading as an independent variate and fractional change in concentration as the dependent variate results in a slope of 0.91 and a correlation coefficient of 0.98 . Deviations from perfect linearity occur because only surface nitrogen is considered, because loads and load reductions are not uniformly distributed, and because the lower estuaries exchange material with adjacent Chesapeake Bay. Still, a useful rule of thumb is that 90 percent of the fractional change in nitrogen loading is reflected in surface total nitrogen concentration.
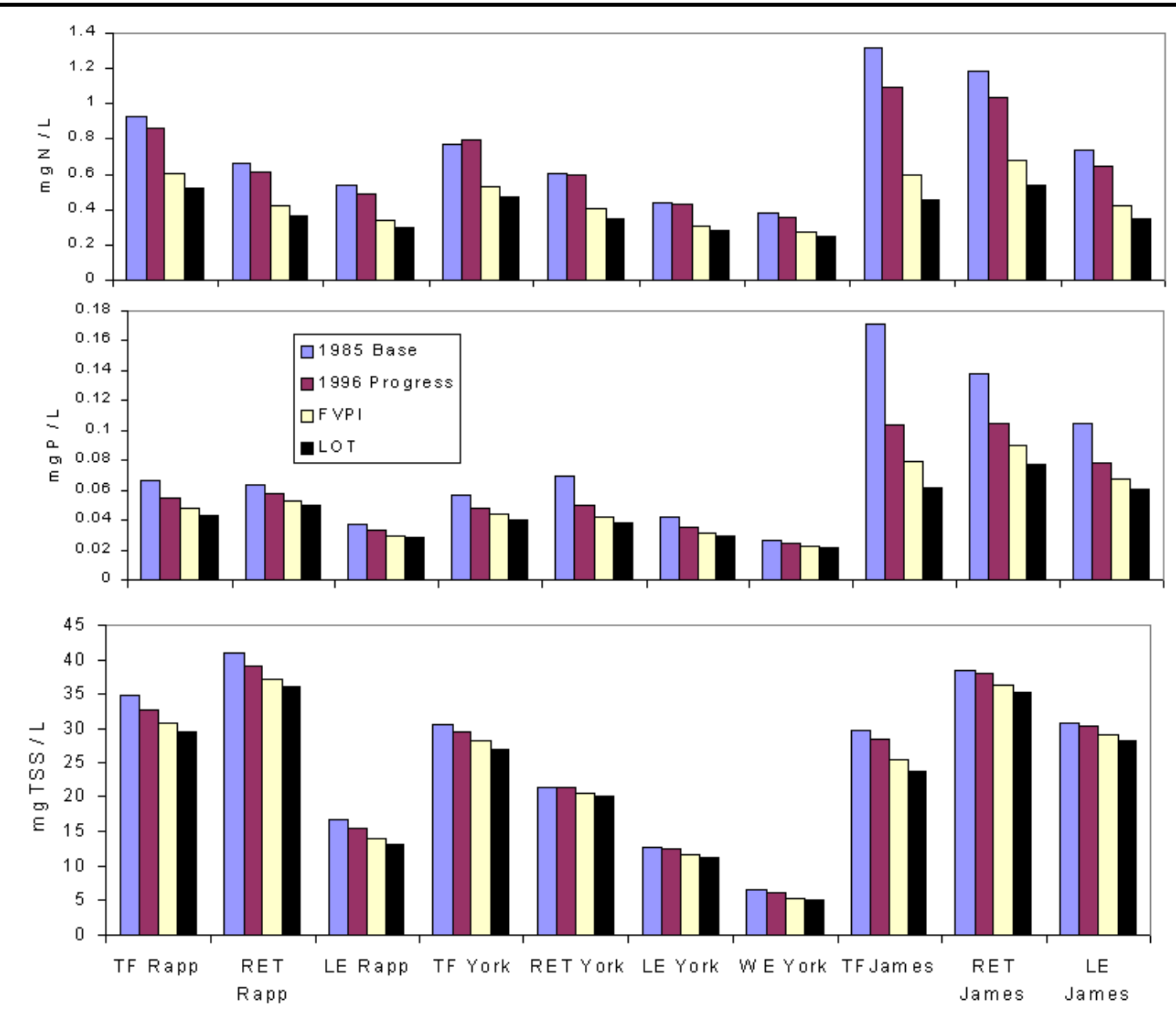

Figure 4. Surface total nitrogen (a), surface total phosphorus (b), and surface total suspended solids (c) computed for four scenarios 


\section{Surface total phosphorus}

Under present conditions, computed total phosphorus in the James River is double the concentration in comparable segments of the other tributaries (Figure 4b). All estuaries exhibit lesser concentrations at their mouths than in their headwaters but little change from the tidal fresh to the river-estuary transition regions. The presence of abundant total phosphorus in the central tributaries, despite diminutive local loading, is due partly to the accumulation of particlebound phosphorus in the estuarine turbidity maxima. The response of total phosphorus concentration to load changes is not so well-behaved as for nitrogen. Regression indicates the slope of fractional concentration change on fractional load reduction is 0.70 with a correlation coefficient of 0.75 . Deviations from perfect linearity occur for the same reasons as for nitrogen. In addition, the local concentration of phosphorus in the turbidity maxima is not related to local phosphorus loads but is affected by changes in solids loading and distribution.

\section{Summer surface total suspended solids}

Under present conditions, computed solids concentrations are comparable in the tidal fresh portions of all tributaries (Figure 4c). The James and the Rappahannock exhibit turbidity maxima at the transitions between the riverine segment and the lower estuary. In the York, the maximum occurs in the region delineated as tidal fresh. The lower estuarine segments of the York and Rappahannock exhibit the least concentrations in their estuaries while solids in the lower James are comparable to the upper James. Correlation between reductions in solids loads and resulting solids concentrations are comparable to phosphorus (multiple $\mathrm{R}=0.62$ ) although the slope is less (0.56). Inspection of results shows nonlinear behavior in several CBPS. Aside from previously offered explanations, solids behavior shows scatter and nonlinearity because solids are generated internally as a result of primary production. Consequently, total solids concentrations are diminished by load reductions and through nutrient reductions, which affect particulate carbon production.

\section{Summer surface chlorophyll}

Under present conditions, chlorophyll in the tidal fresh region of the James is double the concentration computed in any other segments (Figure 5a). All systems show a pattern of higher concentrations near the headwaters and lower concentrations near the mouths, roughly corresponding to nutrient distribution. Reductions in chlorophyll show a high correlation with reductions in nitrogen loads (multiple $\mathrm{R}=0.95$ ) and a lower correlation to reductions in phosphorus loads (multiple $\mathrm{R}=0.82$ ). Correspondence between fractional reductions in nutrient loads and fractional reductions in chlorophyll concentration is nearly one to one.

Because all scenarios involved simultaneous reductions in nitrogen and phosphorus loads, the individual effects of nitrogen and phosphorus load reductions are difficult to isolate. Sensitivity runs with the first version of the model indicated chlorophyll concentrations in Chesapeake Bay are much more sensitive to 

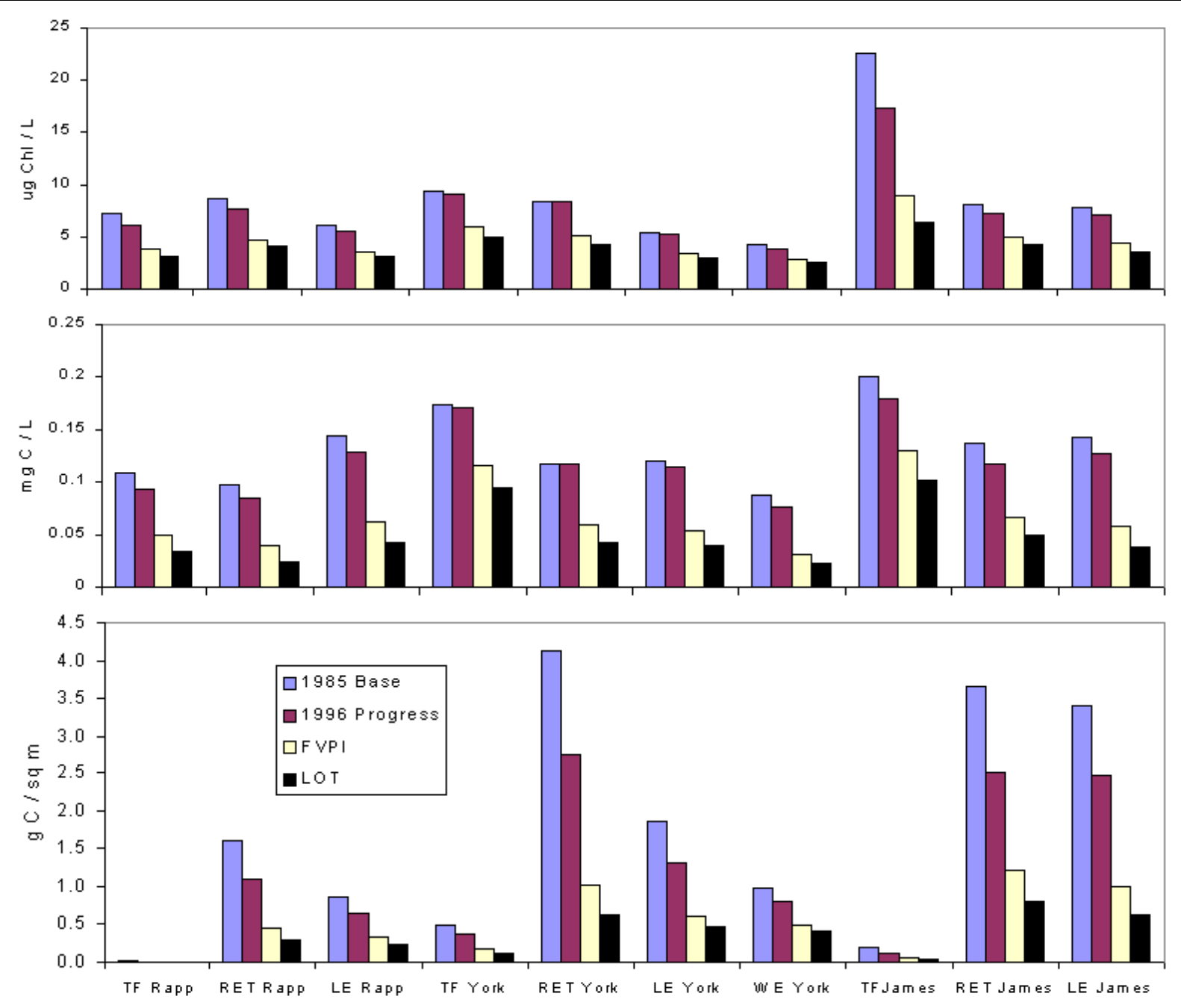

Figure 5. Summer surface chlorophyll (a), mesozooplankton (b), and benthic biomass (c) computed for four scenarios

nitrogen load reductions than phosphorus reductions (Cerco 1995). Analysis with the present model indicates dissolved inorganic phosphorus concentrations in the tidal fresh James are well above limiting levels despite load reductions (Cerco and Meyers 2000). In these scenarios, load reductions from 1985 to 1996, 2 to 12 percent nitrogen reduction versus 26 to 36 percent phosphorus reduction, produced chlorophyll reductions (average less than 10 percent) more representative of nitrogen reductions than phosphorus reductions. Together, these lines of evidence indicate the model chlorophyll is more responsive to nitrogen reductions than phosphorus reductions although sensitivity to phosphorus is present. These results are consistent with bioassays that show, under present conditions, nitrogen is more limiting in summer in the saline portions of the estuaries while light is most limiting in the tidal fresh segments (Fisher et al. 1999). 


\section{Mesozooplankton biomass}

Mesozooplankton biomass holds steady or declines in response to load reductions (Figure 5b). The decline in mesozooplankton is commensurate with corresponding declines in chlorophyll concentration. In the 1996 Progress Run mesozooplankton reductions from base are less than 15 percent while declines of up to 70 percent result from LOT nutrient controls.

\section{Benthic biomass}

Benthic biomass declines throughout the load reduction scenarios (Figure 5c). Computed benthos are much more sensitive than mesozooplankton to changes in chlorophyll, a food source held in common by both groups. Changes from base through 1996 range from an 18 percent loss (WE York) to a 35 percent loss (TF James). Reductions from base of roughly 80 percent characterize nearly all segments under LOT nutrient controls.

\section{Light attenuation}

The spatial distribution of light attenuation under existing conditions (Figure 6a) closely follows the distribution of suspended solids (Figure 4c). Through most of the tributaries, percent reductions in attenuation, up to 20 percent under LOT controls, reflect reductions in solids loads. The tidal fresh portion of the James is distinctive, however. Both solids concentrations (5 percent) and light attenuation (10 percent) decline in the 1996 Progress Run even though solids loads are equivalent to base conditions. The offset persists through LOT load reductions in which 25 percent reductions in attenuation accompany 15 percent reductions in solids loads. The decline in solids and attenuation in excess of solids load reductions indicates the effect of nutrient controls in reducing solids associated with phytoplankton.

\section{Submerged aquatic vegetation}

Load reductions clearly benefit biomass of SAV although the benefits are not uniformly distributed (Figure 6b). Under base conditions, SAV is computed in only three segments, the lower estuarine portions of the Rappahannock and York Rivers and the western embayment of the York. These segments gain biomass (15 to 53 percent) in the 1996 Progress Run, but the distribution of SAV remains limited. Under FVPI, existing beds gain biomass and SAV appears in the tidal fresh portions of the York and James. Incremental improvements from LOT controls over FVPI are minimal. Improvements over base in existing beds through implementation of LOT controls is 32 to 143 percent.

Comparison of biomass in the tidal fresh regions with the lower estuaries can be distorted by the difference in area available for SAV growth. The lower estuaries are characterized by broad shallow shoal areas while the shoals in the tidal fresh regions are much less extensive. Still, normalization of biomass by 

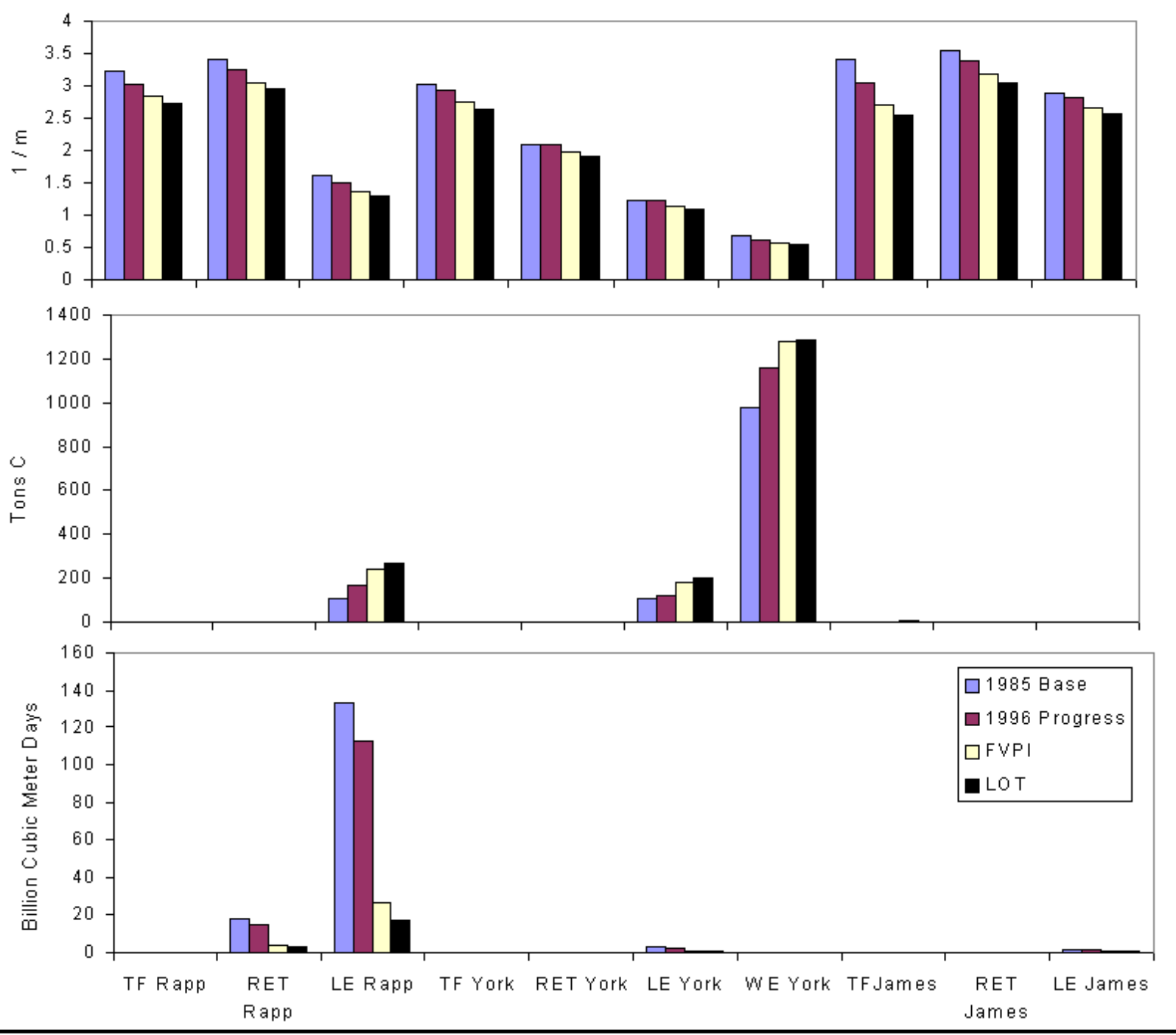

Figure 6. Light attenuation (a), SAV biomass (b), and anoxic volume days (c) computed for four scenarios

potential area for growth shows the resulting density in the tidal fresh regions is less than 3 percent of the density in the lower estuaries.

\section{Anoxic volume days}

Under present conditions, only the RET and LE portions of the Rappahannock River show substantial volumes of anoxic water (Figure 6c). Small anoxic volumes also exist in the LE portions of the York and James. From 11 percent (RET) to 19 percent (LE) of annual volume days are anoxic in the segments of the Rappahannock. Less than 1 percent of annual volume days are anoxic in remaining segments of all estuaries.

Experiments with the initial version of the model indicate anoxic volume in the main stem bay diminishes in greater than one-to-one proportion to nitrogen 
load reductions (Cerco 1995). The proportional reduction in anoxia increases when load reductions approach 50 percent. The Rappahannock behaves in similar fashion. The 12 percent load reductions in the 1996 Progress Run produce 16 percent (RET) to 20 percent (LE) reductions in anoxic volume. The 49 percent load reductions at LOT reduce anoxic volume by more than 80 percent. The increased reduction in anoxia was attributed to a feedback loop in which increased oxygen concentration enhances nitrogen retention in sediments (Harding, Leffler, and Mackiernan 1992; Cerco 1995). For the Rappahannock, a second influence is load reductions elsewhere in the bay watershed which improve oxygen concentration at the mouth of the estuary. A simple model (Kuo, Park, and Moustafa 1991) indicates dissolved oxygen deficit in the Rappahannock is dependent on initial deficit at the mouth of the estuary. Under base conditions, this deficit averages $3.3 \mathrm{mg} / \mathrm{L}$ during summer. This deficit is little changed in the 1996 Progress Run but decreases by $0.5 \mathrm{mg} / \mathrm{L}$ when the entire bay implements LOT controls.

\section{Discussion}

As gauged by the 1996 Progress Run, management efforts have been successful in reducing chlorophyll concentration and anoxic volume in the Virginia tributaries. Additional reductions are possible through implementation of a voluntary program or imposition of limit-of-technology controls. As computed, management efforts have done little to increase the biomass of zooplankton and benthos. Implementation of additional controls is computed to decrease the biomass of both these resources.

A good place to start the discussion is by asking how nutrient reductions are intended to increase biomass of higher trophic levels. The answer is that controls are intended to remove habitat limitations due to low dissolved oxygen concentrations. Controls are intended to reduce algal production, resulting in reduced settling of carbon to bottom waters, lower oxygen demand in bottom waters and sediments, and increased dissolved oxygen concentration. As computed, the controls work as intended. An unavoidable side effect of nutrient controls, however, is reduction in the food supply, algae and algal detritus, to the higher organisms. Consequently, a competition is set up between increased habitat volume and reduced food supply. In portions of the tributaries that exhibit substantial anoxic volume, the model estimates that the detrimental effect of reduced food supply on mesozooplankton and benthos outweighs the benefit of increased habitat.

This model indicates that substantial nutrient load reductions lead to depleted stocks of zooplankton and benthos. These results should be interpreted with great caution. Mass-balance analysis conducted under the auspices of the Chesapeake Bay Program (Kemp et al. 2000) indicates that food supply to the benthos is abundant and will likely remain so. Associated modeling efforts demonstrate the computed response of zooplankton to nutrient reductions is strongly dependent on the formulation and parameterization of the zooplankton feeding function. All living-resource models are approximate and are subject to uncertainty in their parameter assignments. This model (Cerco and Meyers 2000) requires specification of anoxia-induced mortality rates and relation of these rates to dissolved oxygen concentration. It employs simple, quadratic relationships to 
represent predation by fish and other organisms. Potentially, these formulations and/or parameters could be revised so that modeled resources do not decline in the face of food limitation induced by nutrient controls.

Still, it is worthwhile to note that major portions of the tributaries exhibit little or no habitat limitation, as quantified by anoxic volume. Reduction in the food supply to higher organisms in these regions cannot be expected to increase their abundance. And it is worthwhile to note that habitat improvements brought about by nutrient reductions will not necessarily result in more abundant resources.

As with heterotrophs, a good place to start is by asking how nutrient controls are expected to benefit SAV. The conceptual model is that nutrient limitations reduce the biomass of phytoplankton and epiphytic algae. Reduced algae result in reduced light attenuation and more light available to SAV. Increased light results in greater SAV production and restoration to areas that previously supported SAV. As computed, nutrient controls work as intended. Chlorophyll concentrations decrease and SAV biomass increases. The spatial distribution of the benefits is limited, however. Gains occur primarily in regions that already support SAV. Gains are not more widespread because the major fraction of light attenuation in the water column comes from fixed solids, not volatile organic solids that result from primary production (Cerco and Moore 2001). Consequently, attacking light attenuation through nutrient controls addresses the least component of light attenuation in the water column of Virginia tributaries.

Current habitat requirements indicate survival of SAV requires greater than 9 percent of surface light in tidal fresh and oligohaline waters and greater than 15 percent of surface light in more saline waters (U.S. Environmental Protection Agency 2000). The fraction of surface light reaching the leaf surface, after attenuation by modeled components, was computed for the York River (Figure 7). Computations were for the base scenario, a 1-m water column, and an AprilOctober growing season. The $1-\mathrm{m}$ depth was selected since restoration to $1 \mathrm{~m}$ is a prime management goal and since the model SAV beds have an average depth of $1 \mathrm{~m}$. In the tidal fresh region, available light is 62 percent of surface light after attenuation by color in the water and 6 percent of surface light after attenuation by color and fixed solids. Available light is less than 3 percent of surface light after attenuation by color, fixed solids, volatile solids, and epiphytes. Since light is attenuated to less than the 9 percent requirement by color and fixed solids alone, no amount of nutrient control will achieve habitat requirements and restore SAV throughout the tidal fresh region. By contrast, in the western embayment, available light is 34 percent of surface light. SAV is abundant under base conditions. Reduction of attenuation from any component, including volatile solids and epiphytes, should increase current SAV stock.

Summaries presented here are for conditions averaged across CBPS. Conditions computed in these segments are, of course, not uniform. Near the head of tide in the York, for example, computed solids concentrations are much less than the average across the segment. The combined effect of nutrient and solids controls are sufficient to allow trace amounts of SAV to propagate there under the FVPI and LOT scenarios. Trace amounts of SAV are also introduced into the tidal fresh James although, in this region, substantial reductions in chlorophyll also 


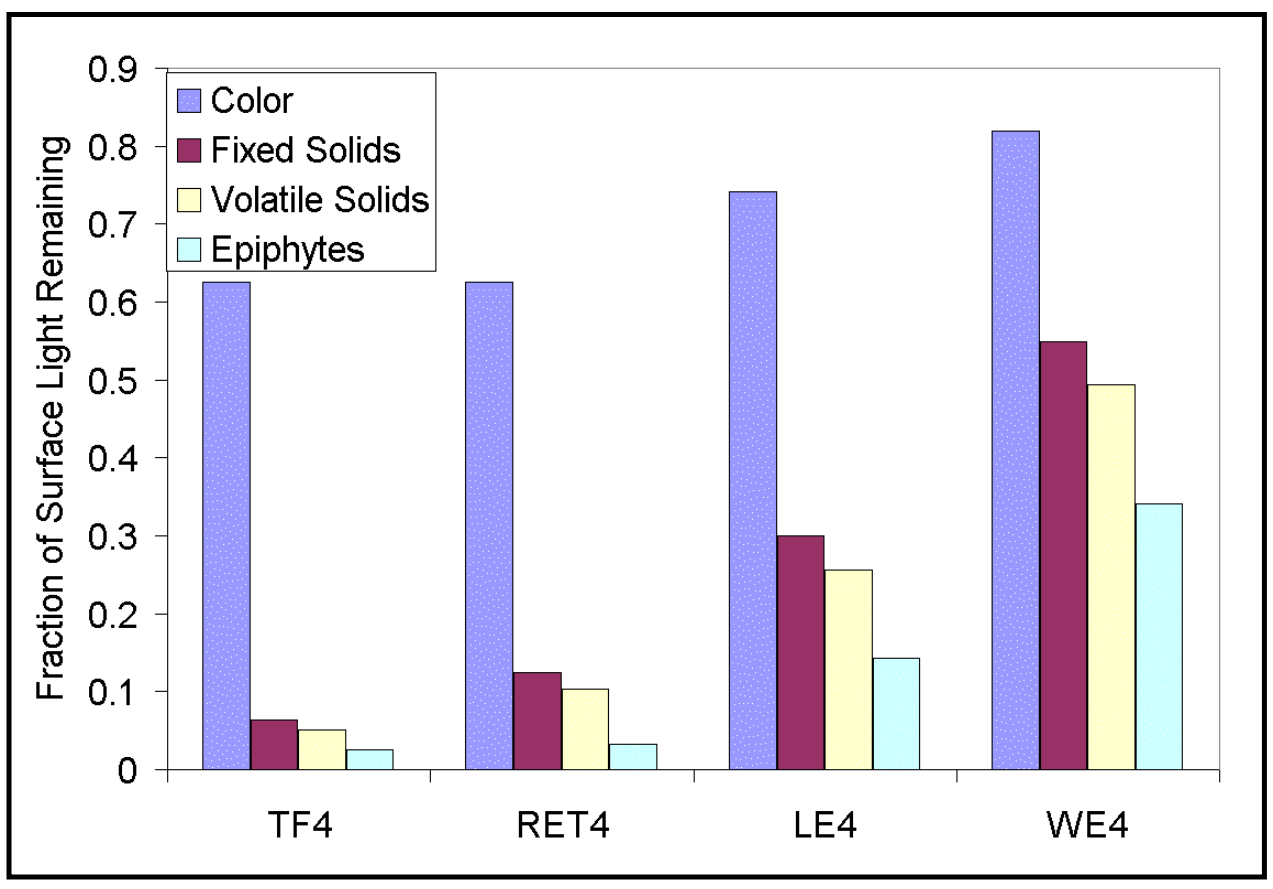

Figure 7. Components of light attenuation in the York River

contribute. Still, the computations indicate that foreseeable nutrient and solids controls will not induce widespread recovery of SAV in the TF and RET segments.

Reductions in solids loads under FVPI and LOT scenarios are roughly half the concurrent reductions in nutrient loads. These results indicate the difficulty in controlling solids loads. For one, they originate as nonpoint-source loads, which are much more difficult to control than point sources. For another, unknown reservoirs of solids exist at the bottom of upland streams and reservoirs and in the estuaries. Consequently, the lag between reductions in solids loads at the land surface and reductions in solids loads to the estuaries is unknown and may be lengthy.

The results presented here indicate that direct actions to benefit living resources should be considered as an alternative to indirect benefits obtained through nutrient control. For example, construction of oyster reefs, delineation of refuges, and fisheries management practices may do more to increase abundance of higher-trophic-level organisms than can be accomplished through nutrient controls alone. Reduction of attenuation through solids controls along with nutrient controls is appropriate since fixed solids are the major component of light attenuation in the water column. Since the ability of filter feeders to clarify a water column is well known (Cohen et al. 1984; Phelps 1994), direct action to increase filter feeders may have a positive feedback on light attenuation, as well. Note that the recently signed "Chesapeake 2000" agreement (Gilmore et al. 2000) calls for a tenfold increase in native oysters in Chesapeake Bay. Concomitant to this agreement, plans are underway to assess the effect on water quality of different population levels of all filter feeders (menhaden, oysters, and clams). In view of the results of these scenarios, this investigation is most worthwhile. 


\section{Conclusions}

Surface total phosphorus concentrations computed under 1996 conditions are lower than 1985 base conditions throughout the Virginia tributaries. Computed surface total nitrogen concentrations for 1996 conditions are lower than base in the Rappahannock and James but have held steady or increased in portions of the York. Changes in computed chlorophyll from 1985 to 1996 are largely consistent with changes in computed nitrogen. As a result of load controls, computed anoxic volume decreased from 1985 to 1996.

Additional reductions in nutrients, chlorophyll, and anoxic volume are possible through Full Voluntary Program Implementation or implementation of Limit of Technology controls.

The benefits of nutrient controls at the 1996 level on computed higher trophic level organisms are limited. Implementation of controls beyond the 1996 level diminishes computed higher trophic level organisms. These results are not definitive but indicate management actions to restore living resources solely through nutrient controls may be insufficient.

Nutrient controls and concurrent solids controls increase computed abundance of SAV primarily in areas in which SAV presently exists. Substantial restoration of SAV to other regions requires major reductions in concentration of fixed solids in the water column.

\section{References}

Baliles, G., Schaefer, W., Casey, R., Thomas, L., Barry, M., and Cole, K. (1987). "Chesapeake Bay Agreement." United States Environmental Protection Agency, Chesapeake Bay Program, Annapolis MD.

Bicknell, B., Imhoff, J., Kittle, J., Donigian, A., Johanson, R., and Barnwell, T. (1996). Hydrologic simulation program - FORTRAN user's manual for release 11," United States Environmental Protection Agency, Environmental Research Laboratory, Athens, GA.

Butt, A., Linker, L., Sweeney, J., Shenk, G., Batiuk, R., and Cerco, C. (2000). "Technical tools used in the development of Virginia's tributary strategies," United States Environmental Protection Agency, Chesapeake Bay Program, Annapolis, MD.

Cerco, C. (1995). "Response of Chesapeake Bay to nutrient load reductions," Journal of Environmental Engineering 121(8), 549-557.

Cerco, C., and Cole, T. (1993). "Three dimensional eutrophication model of Chesapeake Bay," Journal of Environmental Engineering 119(6), 1006-1025.

Cerco, C., and Moore, K. (2001). "System-wide submerged aquatic vegetation model for Chesapeake Bay," Estuaries 24(4), 522-534.

Cerco, C., and Myers, M. (2000). "Tributary refinements to Chesapeake Bay model," Journal of Environmental Engineering 126(2), 164-174. 
Chang, J., Brost, R., Isaksen, I., Madronich, S., Middleton, P., Stockwell, W., and Walcek, C. (1987). "A three-dimensional Eulerian acid deposition model physical concepts and formulation," Journal of Geophysical Research 92, 14681-14700.

Cohen, R., Dresler, P., Phillips, E., and Cory, R. (1984). "The effect of the Asiatic clam, Corbicula fluminea, on the phytoplankton of the Potomac River, Maryland," Limnology and Oceanography 29, 170-180.

Fisher, T., Gustafson, A., Sellner, K., Lacouture, R., Haas, L., Wetzel, R., Magnien, R., Everitt, D., Michaels, B., and Karrh, R. (1999). "Spatial and temporal variation of resource limitation in Chesapeake Bay," Marine Biology $133,763-778$.

Gillmore, J., Glendening, P., Ridge, T., Williams, A., Browner, C., and Bolling, B. (2000). "Chesapeake 2000 Agreement," United States Environmental Protection Agency, Chesapeake Bay Program, Annapolis, MD.

Harding, L., Leffler, M., and Mackiernan, G. (1992). "Dissolved oxygen in Chesapeake Bay: A scientific consensus," Report UM-SG-TS-92-03, Maryland Sea Grant, University of Maryland, College Park, MD.

Ibison, N., Frye, C., Frye, J., Hill, C., and Burger, N. (1990). "Sediment and nutrient contributions of selected eroding banks of the Chesapeake Bay estuarine system," Department of Conservation and Recreation, Division of Soil and Water Conservation, Gloucester Point, VA.

Johnson, B., Kim, K., Heath, R., Hsieh, B., and Butler, L. (1993). "Validation of a three-dimensional hydrodynamic model of Chesapeake Bay," Journal of Hydraulic Engineering 199(1), 2-20.

Kemp, W., Bartleson, R., Blumenshine, S., Hagy, J., and Boynton, W. (2000). "Ecosystem models of the Chesapeake Bay relating nutrient loadings, environmental conditions, and living resources," UMCES[HPL] Contribution 3218, United States Environmental Protection Agency, Chesapeake Bay Program, Annapolis, MD.

Kuo, A., Park, K., and Moustafa, Z. (1991). "Spatial and temporal variabilities of hypoxia in the Rappahannock River, Virginia," Estuaries 14(2), 113-121.

Phelps, H. (1994). "The Asiatic clam (Corbicula fluminea) invasion and systemlevel ecological change in the Potomac River estuary near Washington D.C.," Estuaries 17(3), 614-621.

U.S. Army Engineer District, Baltimore. (1990). "Chesapeake Bay shoreline erosion study feasibility report," Baltimore, MD.

U.S. Environmental Protection Agency. (2000). “Chesapeake Bay submerged aquatic vegetation water quality and habitat-based requirements and restoration targets: A second technical synthesis," Chesapeake Bay Program, Annapolis, MD. 


\section{Incremental Improvements in Virginia Tributary Models}

\section{Introduction}

Three major tributaries of Chesapeake Bay are contained wholly in Virginia: the James, York, and Rappahannock Rivers (Figure 1). These estuaries have been the subject of extensive modeling since the mid-1970's and were included in a systemwide model of Chesapeake Bay (Cerco and Cole 1993). Recently, the systemwide model was revised with the intention of improving representation of the Virginia tributaries (Cerco and Meyers 2000). This chapter provides a quantitative view of the status of the tributary models during multiple states of calibration. The objectives are to document the calibration statistics, for comparison with future models of these and other systems, and to determine the revisions that produced major improvements.

\section{Methods}

Comparisons were based on a continuous simulation of 1985-1986. These years were selected because they were common to all model applications. For salinity, total nitrogen, and total phosphorus, effects of revisions on model performance were examined by computing temporal-volumetric mean concentrations (Table 1) for each tributary. For chlorophyll and light attenuation, surface computations only were examined. Dissolved oxygen concentrations were averaged for bottom cells in summer only since these conditions are of most interest to management. Quantitative statistics were determined through comparison of model computations with observations from 27 stations (Figure 2) sampled at approximately monthly intervals. For salinity, total nitrogen, and total phosphorus, comparisons were made with surface and bottom samples. For chlorophyll and light attenuation, surface samples only were examined while dissolved oxygen comparisons were restricted to bottom samples collected in summer. The number of model-data comparisons ranged from roughly 200 to 1,800 (Table 2).

Statistics computed were mean error, absolute mean error, and relative error: 


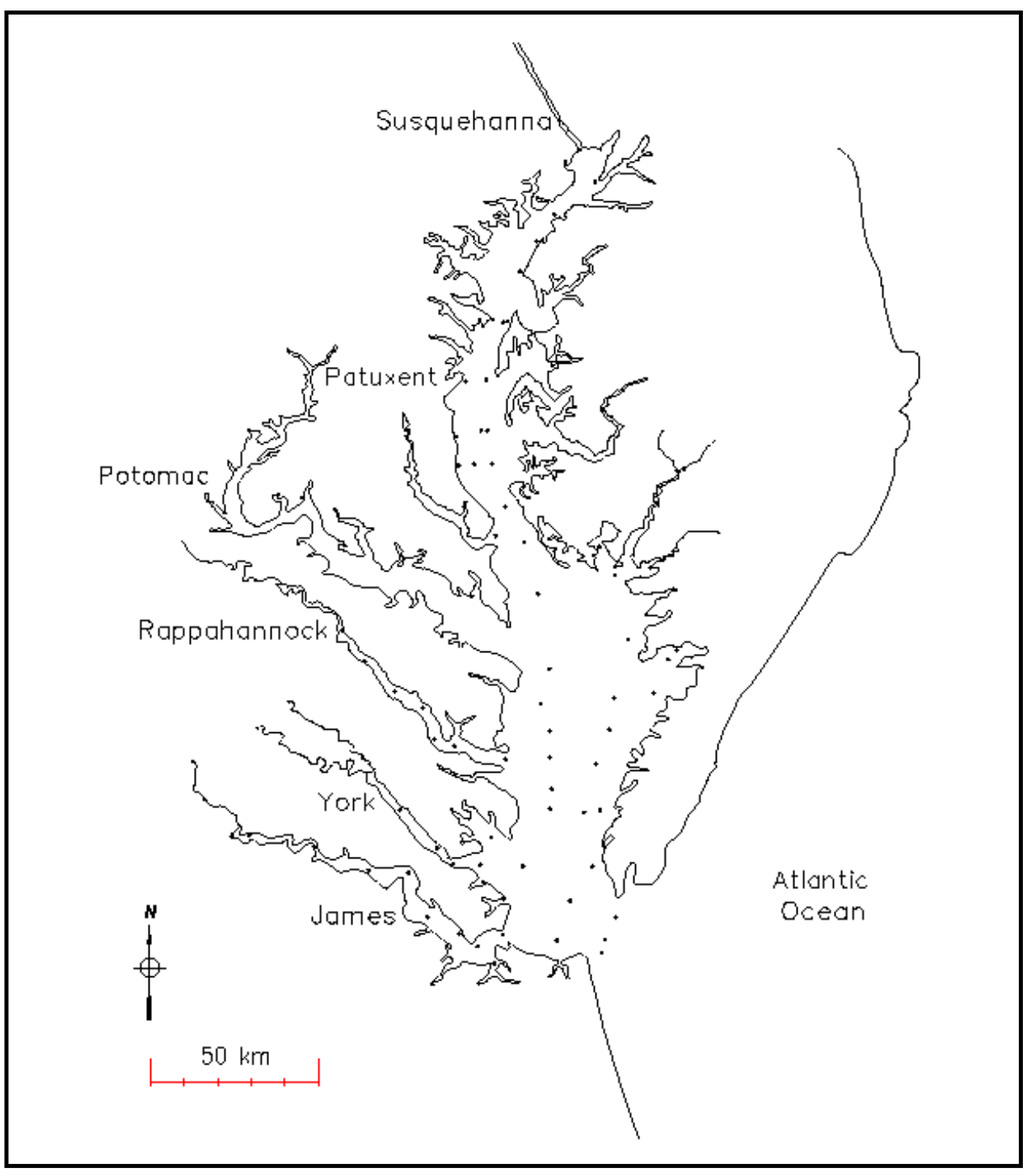

Figure 1. Chesapeake Bay showing sample stations in main stem and Virginia tributaries

$$
\begin{aligned}
& M E=\frac{\Sigma(O-P)}{N} \\
& A M E=\frac{\Sigma|O-P|}{N} \\
& R E=\frac{\Sigma|O-P|}{\Sigma O}
\end{aligned}
$$

in which

$$
\begin{aligned}
M E & =\text { mean error } \\
O & =\text { observation }
\end{aligned}
$$




\begin{tabular}{|c|c|c|c|c|}
\hline Step & Main Stem & James & Rappahannock & York \\
\hline \multicolumn{5}{|c|}{ Salinity } \\
\hline Step 1 & 18.2 & 14.4 & 13.1 & 18.9 \\
\hline Step 2 & 19.3 & 11.3 & 15.6 & 19.3 \\
\hline \multicolumn{5}{|c|}{ Surface Chlorophyll } \\
\hline Step 1 & 9.8 & 9.8 & 11.5 & 8.4 \\
\hline Step 2 & 8.6 & 11.5 & 10.0 & 10.2 \\
\hline Step 3 & 9.3 & 13.1 & 9.3 & 6.8 \\
\hline Step 4 & 9.0 & 12.8 & 8.7 & 6.4 \\
\hline
\end{tabular}

Light Attenuation

\begin{tabular}{||l|l|l|l|l||}
\hline \hline Step 1 & 1.01 & 2.55 & 1.91 & 1.53 \\
\hline Step 2 & 1 & 2.63 & 2.05 & 1.61 \\
\hline Step 3 & 1.16 & 2.73 & 2.49 & 1.45 \\
\hline Step 4 & 1.15 & 2.72 & 2.48 & 1.44 \\
\hline \hline
\end{tabular}

Total Nitrogen

\begin{tabular}{||l|l|l|l|l||}
\hline \hline Step 1 & 0.612 & 0.761 & 0.572 & 0.459 \\
\hline Step 2 & 0.583 & 0.912 & 0.637 & 0.496 \\
\hline Step 3 & 0.659 & 0.953 & 0.682 & 0.538 \\
\hline Step 4 & 0.623 & 0.926 & 0.639 & 0.506 \\
\hline \hline
\end{tabular}

\begin{tabular}{||l|l|l|l|l||}
\hline \hline \multicolumn{5}{|c|}{ Total Phosphorus } \\
\hline \hline Step 1 & 0.0259 & 0.0758 & 0.0274 & 0.0332 \\
\hline Step 2 & 0.0250 & 0.0904 & 0.0310 & 0.0320 \\
\hline Step 3 & 0.0229 & 0.0833 & 0.0255 & 0.0252 \\
\hline Step 4 & 0.0307 & 0.1030 & 0.0437 & 0.0367 \\
\hline \hline
\end{tabular}

Summer, Bottom, Dissolved Oxygen

\begin{tabular}{||l|l|l|l|l||}
\hline \hline Step 1 & 6.020 & 7.830 & 6.820 & 6.280 \\
\hline Step 2 & 6.290 & 7.260 & 6.610 & 6.970 \\
\hline Step 3 & 4.900 & 6.480 & 5.750 & 6.310 \\
\hline Step 4 & 4.950 & 6.500 & 5.800 & 6.330 \\
\hline
\end{tabular}

$$
\begin{aligned}
P & =\text { prediction } \\
N & =\text { number of observations } \\
A M E & =\text { absolute mean error } \\
R E & =\text { relative error }
\end{aligned}
$$

The mean error (Table 3 ) describes whether the model overestimates or underestimates the observations on average. The mean error can achieve its ideal value, zero, while large discrepancies exist between individual observations and 


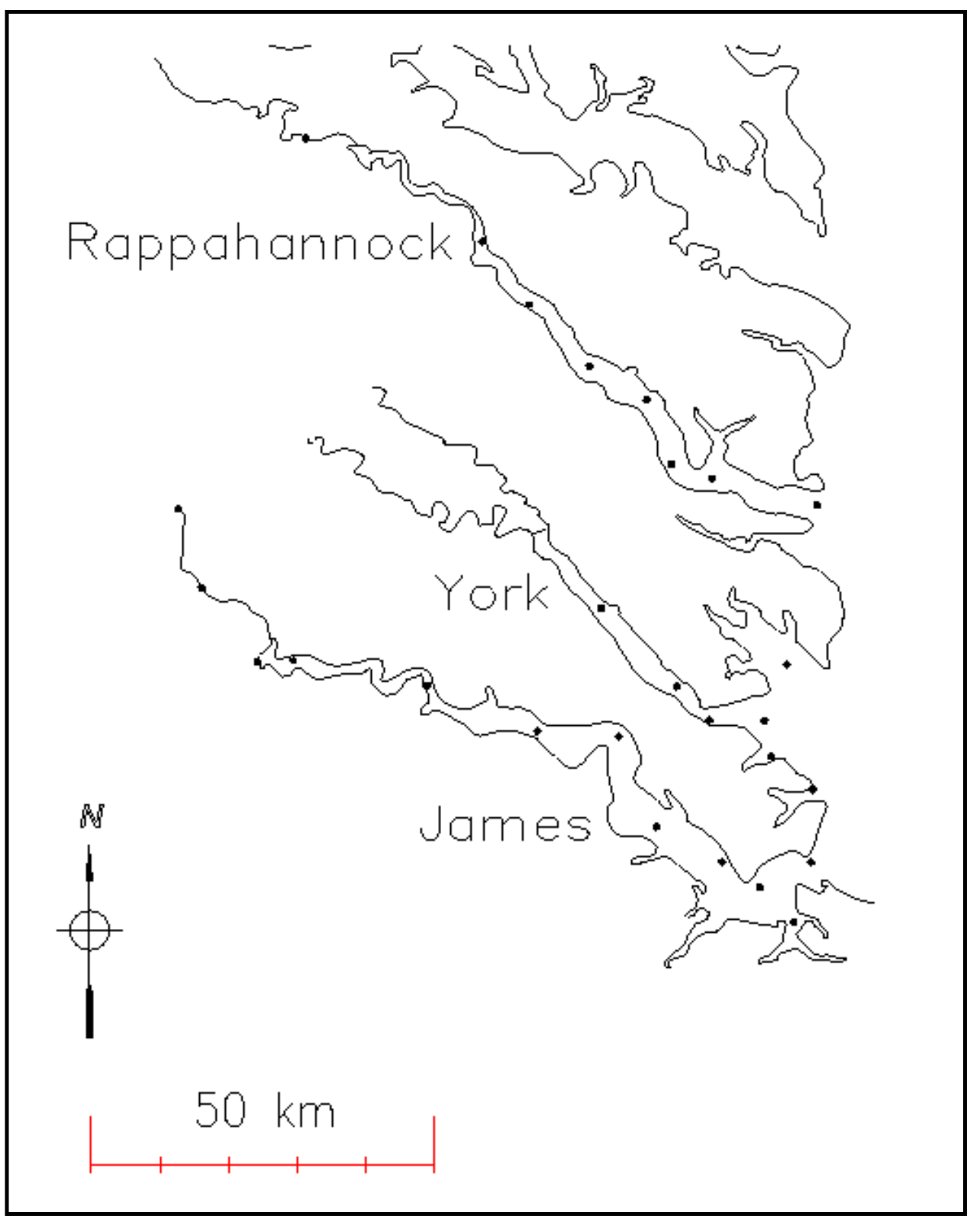

Figure 2. Sample stations in Virginia tributaries

computations. The absolute mean error (Table 4) is a measure of the distance between individual observations and computations. An absolute mean error of zero indicates the model perfectly reproduces observations. The relative error (Table 5) is the absolute mean error normalized by the mean concentration. Relative error provides a statistic suitable for comparison between different variables or systems.

Statistical summaries of model performance were also completed for the main stem of Chesapeake Bay. These are reported in the tabulations but not analyzed further since the study emphasized refinement of the Virginia tributaries. 


\begin{tabular}{||l|l|l||}
\hline \hline $\begin{array}{l}\text { Table } 2 \\
\text { Number of Model-Data Comparisons }\end{array}$ \\
\hline \hline Substance & Main Stem Bay & Virginia Tributaries \\
\hline \hline Salinity & 2761 & 1806 \\
\hline Surface Chlorophyll & 1518 & 928 \\
\hline Light Attenuation & 1204 & 983 \\
\hline Total Nitrogen & 2734 & 1862 \\
\hline Total Phosphorus & 2700 & 1842 \\
\hline Summer, Bottom, Dissolved Oxygen & 327 & 235 \\
\hline
\end{tabular}

\begin{tabular}{|c|c|c|c|c|}
\hline \multicolumn{5}{|c|}{\begin{tabular}{|l} 
Table 3 \\
Mean Errors at Four Steps of Calibration
\end{tabular}} \\
\hline Step & Main Stem & James & Rappahannock & York \\
\hline \multicolumn{5}{|c|}{ Salinity } \\
\hline Step 1 & -0.06 & -0.95 & 2.43 & 0.08 \\
\hline Step 2 & -0.62 & 0.55 & -1.64 & -0.94 \\
\hline \multicolumn{5}{|c|}{ Surface Chlorophyll } \\
\hline Step 1 & -1.59 & 0.24 & 0.54 & -1.19 \\
\hline Step 2 & -0.43 & -0.30 & 2.98 & -0.79 \\
\hline Step 3 & -1.70 & -5.02 & 1.37 & -2.36 \\
\hline Step 4 & -1.19 & -4.84 & 2.25 & -1.66 \\
\hline \multicolumn{5}{|c|}{ Light Attenuation } \\
\hline Step 1 & -0.146 & -0.329 & -0.169 & 0.021 \\
\hline Step 2 & -0.041 & -0.449 & 0.057 & 0.047 \\
\hline Step 3 & -0.219 & -0.430 & -0.605 & 0.205 \\
\hline Step 4 & -0.206 & -0.425 & -0.599 & 0.222 \\
\hline
\end{tabular}

Total Nitrogen

\begin{tabular}{||l|l|l|l|l||}
\hline \hline Step 1 & -0.003 & 0.108 & 0.197 & 0.057 \\
\hline Step 2 & 0.046 & -0.182 & 0.077 & 0.116 \\
\hline Step 3 & -0.025 & -0.197 & 0.080 & 0.060 \\
\hline Step 4 & 0.011 & -0.174 & 0.128 & 0.092 \\
\hline \hline
\end{tabular}

Total Phosphorus

\begin{tabular}{||l|l|l|l|l||}
\hline \hline Step 1 & 0.012 & -0.0077 & 0.0265 & 0.0146 \\
\hline Step 2 & 0.0149 & -0.0332 & 0.0229 & 0.0189 \\
\hline Step 3 & 0.0173 & -0.0278 & 0.0313 & 0.0237 \\
\hline Step 4 & 0.0091 & -0.0456 & 0.0043 & 0.0149 \\
\hline \hline
\end{tabular}

\begin{tabular}{||l|l|l|l|l||}
\hline \multicolumn{7}{|c|}{ Summer, Bottom, Dissolved Oxygen } \\
\hline \hline Step 1 & -0.89 & -1.88 & -2.96 & -0.48 \\
\hline Step 2 & -1.05 & -0.47 & -0.26 & -1.32 \\
\hline Step 3 & 0.63 & 0.29 & 0.88 & -0.03 \\
\hline Step 4 & 0.58 & 0.26 & 0.81 & -0.08 \\
\hline
\end{tabular}




\begin{tabular}{|c|c|c|c|c|}
\hline \multicolumn{5}{|c|}{$\begin{array}{l}\text { Table } 4 \\
\text { Absolute Mean Error at Four Steps of Calibration }\end{array}$} \\
\hline Step & Main Stem & James & Rappahannock & York \\
\hline \multicolumn{5}{|c|}{ Salinity } \\
\hline Step 1 & 1.67 & 1.60 & 2.67 & 2.58 \\
\hline Step 2 & 1.74 & 1.63 & 2.03 & 1.72 \\
\hline \multicolumn{5}{|c|}{ Surface Chlorophyll } \\
\hline Step 1 & 4.93 & 8.64 & 9.50 & 5.02 \\
\hline Step 2 & 4.33 & 11.45 & 7.83 & 5.43 \\
\hline Step 3 & 4.88 & 9.29 & 7.73 & 5.48 \\
\hline Step 4 & 4.60 & 9.17 & 7.39 & 5.19 \\
\hline
\end{tabular}

\begin{tabular}{||l|l|l|l|l||}
\hline \multicolumn{5}{c}{ Light Attenuation } \\
\hline \hline Step 1 & 0.303 & 0.723 & 0.651 & 0.715 \\
\hline Step 2 & 0.276 & 0.986 & 0.800 & 0.789 \\
\hline Step 3 & 0.383 & 1.326 & 1.146 & 0.834 \\
\hline Step 4 & 0.398 & 1.324 & 1.144 & 0.835 \\
\hline \hline
\end{tabular}

Total Nitrogen

\begin{tabular}{||l|l|l|l|l||}
\hline \hline Step 1 & 0.139 & 0.307 & 0.252 & 0.161 \\
\hline Step 2 & 0.132 & 0.442 & 0.227 & 0.163 \\
\hline Step 3 & 0.141 & 0.451 & 0.239 & 0.155 \\
\hline Step 4 & 0.134 & 0.443 & 0.248 & 0.158 \\
\hline \hline
\end{tabular}

\begin{tabular}{||l|l|l|l|l||}
\hline \multicolumn{5}{|c|}{ Total Phosphorus } \\
\hline Step 1 & 0.0170 & 0.0508 & 0.0304 & 0.0203 \\
\hline Step 2 & 0.0184 & 0.0637 & 0.0280 & 0.0256 \\
\hline Step 3 & 0.0190 & 0.0626 & 0.0339 & 0.0263 \\
\hline \hline Step 4 & 0.0155 & 0.0700 & 0.0235 & 0.0217 \\
\hline
\end{tabular}

Summer, Bottom, Dissolved Oxygen

\begin{tabular}{||l|l|l|l|l||}
\hline \hline Step 1 & 1.91 & 2.01 & 3.10 & 1.99 \\
\hline Step 2 & 1.65 & 1.29 & 1.77 & 1.60 \\
\hline Step 3 & 1.36 & 2.45 & 2.33 & 1.26 \\
\hline Step 4 & 1.35 & 2.41 & 2.26 & 1.24 \\
\hline \hline
\end{tabular}

\section{Model Runs}

\section{Step 1}

The Step 1 model was exactly the model completed in 1992 (Cerco and Cole 1993). This model was run on a grid of roughly 4,000 elements and incorporated 22 state variables but no living resources or trophic levels above phytoplankton. 


\begin{tabular}{|c|c|c|c|c|}
\hline \multicolumn{5}{|c|}{$\begin{array}{l}\text { Table } 5 \\
\text { Relative Error at Four Steps of Calibration }\end{array}$} \\
\hline Step & Main Stem & James & Rappahannock & York \\
\hline \multicolumn{5}{|c|}{ Salinity } \\
\hline Step 1 & 9.1 & 19.1 & 24.0 & 17.4 \\
\hline Step 2 & 9.5 & 19.4 & 18.3 & 11.6 \\
\hline \multicolumn{5}{|c|}{ Surface Chlorophyll } \\
\hline Step 1 & 61.6 & 74.1 & 83.4 & 64.0 \\
\hline Step 2 & 54.2 & 98.2 & 68.7 & 69.2 \\
\hline Step 3 & 61.0 & 79.7 & 67.8 & 70.0 \\
\hline Step 4 & 57.6 & 78.6 & 64.8 & 66.2 \\
\hline
\end{tabular}

\begin{tabular}{||l|l|l|l|l||}
\hline \multicolumn{5}{c}{ Light Attenuation } \\
\hline \hline Step 1 & 36.5 & 32.6 & 32.8 & 39.9 \\
\hline Step 2 & 32.9 & 44.5 & 40.3 & 44.0 \\
\hline Step 3 & 45.8 & 59.9 & 57.7 & 46.5 \\
\hline Step 4 & 45.2 & 59.8 & 57.6 & 46.6 \\
\hline \hline
\end{tabular}

\begin{tabular}{||l|l|l|l|l||}
\hline \multicolumn{7}{|c|}{ Total Nitrogen } \\
\hline \hline Step 1 & 22.1 & 31.9 & 32.5 & 20.8 \\
\hline Step 2 & 21.0 & 45.9 & 29.2 & 21.0 \\
\hline Step 3 & 22.4 & 46.9 & 30.8 & 20.0 \\
\hline Step 4 & 21.3 & 46.0 & 31.9 & 20.4 \\
\hline \hline
\end{tabular}

\begin{tabular}{||l|l|l|l|l||}
\hline \multicolumn{5}{|c|}{ Total Phosphorus } \\
\hline \hline Step 1 & 42.5 & 49.3 & 53.4 & 41.0 \\
\hline Step 2 & 45.8 & 61.7 & 49.8 & 51.7 \\
\hline Step 3 & 47.4 & 60.6 & 59.5 & 53.2 \\
\hline Step 4 & 38.5 & 67.9 & 41.2 & 43.9 \\
\hline \hline
\end{tabular}

\begin{tabular}{||l|l|l|l|l||}
\hline Step 4 & 38.5 & 67.9 & 41.2 & 43.9 \\
\hline \hline \multicolumn{5}{|c|}{ Summer, Bottom, Dissolved Oxygen } \\
\hline \hline Step 1 & 44.9 & 31.7 & 63.9 & 41.4 \\
\hline Step 2 & 38.8 & 20.3 & 36.5 & 33.3 \\
\hline Step 3 & 31.9 & 38.6 & 48.0 & 26.2 \\
\hline Step 4 & 31.6 & 38.1 & 46.6 & 25.9 \\
\hline \hline
\end{tabular}

\section{Step 2}

In Step 2, the 1992 model was transferred to the current grid of 10,000 elements (Cerco and Meyers 2000). Concurrent with the new grid, the Lagrangianaverage hydrodynamics (Dortch, Chapman, and Abt 1992) were replaced with intratidal hydrodynamics specified at 2-hour intervals. Fall-line and distributed loads were updated to Phase 4.2 of the watershed model, and point-source estimates were revised. All model parameters and coefficients were maintained at their Step 1 values. 


\section{Step 3}

In Step 3, the new kinetics that incorporated living resources were installed. Of primary importance in this run was the introduction of two zooplankton groups and of filter-feeding benthos to the model state variables (Cerco and Meyers 2000). Addition of living resources necessitated extensive recalibration of the model and revision of parameters and coefficients.

\section{Step 4}

Step 4 incorporated revisions to atmospheric nitrogen loads and to distributed phosphorus loads. Atmospheric loads were revised to reflect National Atmospheric Deposition Program (NADP) data and daily rainfall records. Phosphorus loads included particulate inorganic phosphorus from upland sources and local bank erosion. All model parameters and coefficients were maintained at their Step 3 values.

\section{Loads}

\section{Point source}

An inventory of point sources was conducted by the Chesapeake Bay Program Office and local agencies for the first model study (Cerco and Cole 1993).

Monthly loads were calculated from each source as the product of flow and concentration, when available (Table 6). Otherwise, estimated flows and default concentrations were employed. For the tributary refinement effort, an extensive round of point-source sampling was conducted and computations were reexamined. Sampling conducted in 1994 could not be extrapolated back to the early years, however. Revised point-source loads for 1985-1986 were based largely on new information regarding flows and treatment levels. Nitrogen load estimates in the James were unchanged while phosphorus loads were revised upwards. Pointsource nitrogen and phosphorus loads in the York and Rappahannock were all revised downwards. Revisions were in the range of -19 to 8 percent of original estimates.

\section{Distributed loads}

Distributed loads (Table 6) include loads from the upland portion of the watershed delivered at the fall line and loads delivered at the streambank below the fall line. In all cases, distributed loads were calculated from the U.S. Environmental Protection Agency's (USEPA) Watershed Model (WSM). Loads for Step 1 were generated by Phase 2 of the WSM. Below-fall-line loads in each basin were distributed uniformly from the head of tide to the mouth of the river. Loads for the Tributary Refinements were generated by Phase 4.2 of the WSM. This phase incorporated numerous improvements including better point-source data in the upland watersheds, better information on nutrient loads to the watersheds, more mechanistic simulation of watershed processes, additional 


\begin{tabular}{|c|c|c|c|c|c|c|c|}
\hline \multicolumn{8}{|c|}{$\begin{array}{l}\text { Table } 6 \\
\text { Tributary Loads at Four Steps of Calibration }\end{array}$} \\
\hline \multirow[b]{2}{*}{ River } & \multirow[b]{2}{*}{ Source } & \multicolumn{3}{|c|}{ Nitrogen $(\mathrm{kg} / \mathrm{d})$} & \multicolumn{3}{|c|}{ Phosphorus (kg/d) } \\
\hline & & Step 1 & Steps 2-3 & Step 4 & Step 1 & Steps 2-3 & Step 4 \\
\hline \multirow[t]{4}{*}{ James } & Point Source & 27,270 & 27,806 & 27,806 & 3,907 & 4,233 & 4,233 \\
\hline & Distributed & 20,083 & 20,319 & 20,319 & 3,113 & 3,480 & 6,133 \\
\hline & Atmospheric & 2,126 & 2,459 & 1,256 & 90 & 104 & 104 \\
\hline & Total & 49,479 & 50,584 & 49,381 & 7,110 & 7,817 & 10,471 \\
\hline \multirow[t]{4}{*}{ York } & Point Source & 1,561 & 1,364 & 1,364 & 492 & 398 & 398 \\
\hline & Distributed & 4,151 & 6,573 & 6,573 & 482 & 482 & 628 \\
\hline & Atmospheric & 1,935 & 1,745 & 917 & 82 & 74 & 75 \\
\hline & Total & 7,647 & 9,682 & 8,855 & 1,056 & 954 & 1,101 \\
\hline \multirow[t]{4}{*}{ Rappahannock } & Point Source & 422 & 371 & 371 & 149 & 130 & 130 \\
\hline & Distributed & 6,173 & 9,181 & 9,181 & 595 & 740 & 959 \\
\hline & Atmospheric & 1,520 & 1,699 & 879 & 64 & 72 & 73 \\
\hline & Total & 8,115 & 11,252 & 10,432 & 808 & 941 & 1,161 \\
\hline
\end{tabular}

calibration data, and improved calibration. In addition to the model improvements, below-fall-line loads were distributed according to local drainage area and land use.

Distributed nitrogen loads to the James changed little but were revised upwards substantially in the remaining tributaries. Distributed phosphorus loads were unchanged in the Rappahannock but revised upwards elsewhere. Revisions ranged from 1 to 58 percent for nitrogen and from 0 to 24 percent for phosphorus.

\section{Particulate inorganic phosphorus}

In the first version of the model, total phosphorus predictions in the main stem bay were less than observed (Cerco and Cole 1993). Omission of phosphorus loads associated with bank erosion was suggested as a source of the discrepancy. To investigate this hypothesis, bank loads were introduced in the form of particulate inorganic phosphorus (PIP). Bank solids loads were taken from Corps of Engineers estimates (U.S. Army Engineer District, Baltimore, 1990). Net solids loads to the water column were taken as 20 percent of the total. (The balance is sand that forms beaches along erosion banks (Ibison et al. 1990).) PIP associated with the solids, 0.1 percent by weight, was taken from Keefe (1994). Simultaneously, the inorganic fraction of particulate phosphorus loads provided by the WSM was calculated. Previously, this load fraction was treated as refractory organic matter. PIP thus composed the largest fraction of distributed phosphorus loads (Table 7). Distributed loads increased by 30 to 76 percent over estimates from Phase 4.2 of the WSM alone.

Investigations (Keefe 1994; Conley et al. 1995) suggest little, if any, of the PIP exchanges with the water column. Consequently, PIP was treated as inert 


\begin{tabular}{|c|c|c|c|}
\hline \multicolumn{4}{|c|}{$\begin{array}{l}\text { Table } 7 \\
\text { Distributed Phosphorus Loads to Tributaries } \\
\end{array}$} \\
\hline Phosphorus Fraction & James & York & Rappahannock \\
\hline \begin{tabular}{|l|} 
Dissolved Inorganic and \\
Particulate Organic $\left(\mathrm{kg} \mathrm{d}^{-1}\right)$ \\
\end{tabular} & 1,530 & 249 & 266 \\
\hline Particulate Inorganic $\left(\mathrm{kg} \mathrm{d}^{-1}\right)$ & 4,603 & 378 & 693 \\
\hline Total $\left(\mathrm{kg} \mathrm{d}^{-1}\right)$ & 6,133 & 628 & 959 \\
\hline
\end{tabular}

within the modeled water column. PIP deposited to the sediments was added to the mineral phosphorus pool in the diagenesis model (DiToro and Fitzpatrick 1993). A fundamental distinction within the model was that PIP was transported and deposited identically to fixed solids while particulate organic phosphorus was transported and deposited as with other particulate organic matter.

\section{Atmospheric loads}

Atmospheric loads (Table 6) for the original model were based on USEPA estimates (USEPA 1982) supplemented with available data from the NADP. Loads were estimated on a seasonal basis and incorporated no spatial or intraannual variations. For the tributary refinements, nitrogen loads were based exclusively on more extensive NADP data. Loads varied temporally and spatially, based on daily rainfall records at stations throughout the bay basin. Phosphorus loads in the tributary refinements remained at their original values.

Atmospheric loads were quantified on an areal basis. Owing to the change in surface area, atmospheric loads were altered by the grid refinements, independent of revisions in load estimates. Revisions to the grid altered atmospheric loads by -10 to 16 percent. These were employed in Steps 2 and 3 of the sensitivity runs. The revised load estimates were investigated in Step 4. Atmospheric nitrogen loads diminished 48 percent from original load estimates on equivalent grids. Primary cause of the decrease was revision of the estimated dryfall loads. Dryfall was originally assumed equal to wetfall. Concurrent with the switch to NADP data, estimates of dryfall were revised downwards to 25 percent of wetfall.

\section{Revised Geometry}

The entire bay system was regridded for the tributary refinement effort. The surface plane was determined from maps of the shoreline provided by a USEPA Geographic Information System team. Bathymetry for the model was determined from the National Ocean Service Hydrographic Data Base. Over 2.4 million soundings were employed to determine the model grid. The initial grid dimensions were determined by an automated grid-generation program. The initial grid was subsequently refined by hand to improve computations of salinity and dissolved oxygen. Characteristics of the final grid have been previously defined (Cerco and Meyers 2000). 
As a result of the regridding, all rivers increased in surface area, volume, and maximum depth (Table 8). Mean depth diminished in the James, increased in the York, and was virtually unchanged in the Rappahannock. Length of the York increased substantially due to the inclusion of two tributaries that make up the tidal fresh portion of the estuary.

\begin{tabular}{||l|l|l|l|l|l|l||}
\hline \multicolumn{2}{|l|}{$\begin{array}{l}\text { Table 8 } \\
\text { Tributary Geometry }\end{array}$} \\
\hline \hline \multirow{2}{*}{ River } & Grid & Length, km & $\begin{array}{l}\text { Surface Area } \\
10^{6} \mathrm{~m}^{2}\end{array}$ & $\begin{array}{l}\text { Volume } \\
10^{6} \mathrm{~m}^{3}\end{array}$ & $\begin{array}{l}\text { Mean Depth } \\
\mathrm{m}\end{array}$ & $\begin{array}{l}\text { Maximum } \\
\text { Depth, m }\end{array}$ \\
\hline \hline \multirow{2}{*}{ James } & Step 1 & 150 & 511 & 3,894 & 7.6 & 15.9 \\
\cline { 2 - 8 } & Step 2 & 154 & 591 & 3,906 & 6.6 & 18.9 \\
\hline York & Step 1 & 80 & 167 & 1,175 & 7.0 & 15.9 \\
\cline { 2 - 7 } & Step 2 & 114 & 220 & 1,656 & 7.5 & 20.4 \\
\hline \multirow{2}{*}{ Rappahannock } & Step 1 & 164 & 365 & 3,061 & 8.4 & 14.3 \\
\cline { 2 - 7 } & Step 2 & 157 & 408 & 3,403 & 8.3 & 18.9 \\
\hline \hline
\end{tabular}

\section{Light Attenuation}

Light attenuation in the original model was computed by the relationship:

$$
K e=K e b+\gamma \cdot Q+K e c h l \cdot C h l
$$

in which

$$
\begin{aligned}
K e & =\text { light attenuation } \\
K e b & =\text { base light attenuation } \\
\gamma, K e c h l & =\text { coefficients that relate attenuation to flow and chlorophyll } \\
Q & =\text { fall-line flow } \\
C h l & =\text { chlorophyll concentration }
\end{aligned}
$$

The relationship employed fall-line flow as a surrogate for suspended solids load and the location of the turbidity maximum, two factors that influence extinction. Parameters $K e b$ and $\gamma$ were evaluated via regression at individual monitoring stations and assigned to model cells adjacent to the observations. Parameter Kechl was selected from published values (Pennock 1985).

Since Step 2 was regarded as an interim phase on the way to the complete tributary refinements, the effort to remap attenuation parameters to the new grid was not completed. The relationship to flow was omitted, and instead, background attenuation was assigned, on a monthly basis, to large regions of the system. For the completed tributary refinements, Steps 3 and 4, attenuation was computed as a function of fixed and volatile solids, both of which were model state variables (Cerco and Meyers 2000). 


\section{Revisions to Grid and Loads}

\section{Salinity}

Salinity is the pure measure of the effects of the new grid on transport processes. Grid revisions decreased salinity in the James and increased salinity to greater and lesser degrees in the York and Rappahannock (Figure 3). The mean error statistic (Figure 4) indicates computed salinity in the James was initially higher than observations and became lower than observed. In the Rappahannock and York, grid revisions induced overcomputation of salinity. Grid revisions resulted in negligible change in AME in the James (Figure 5) but noticeable improvements in the Rappahannock and York.

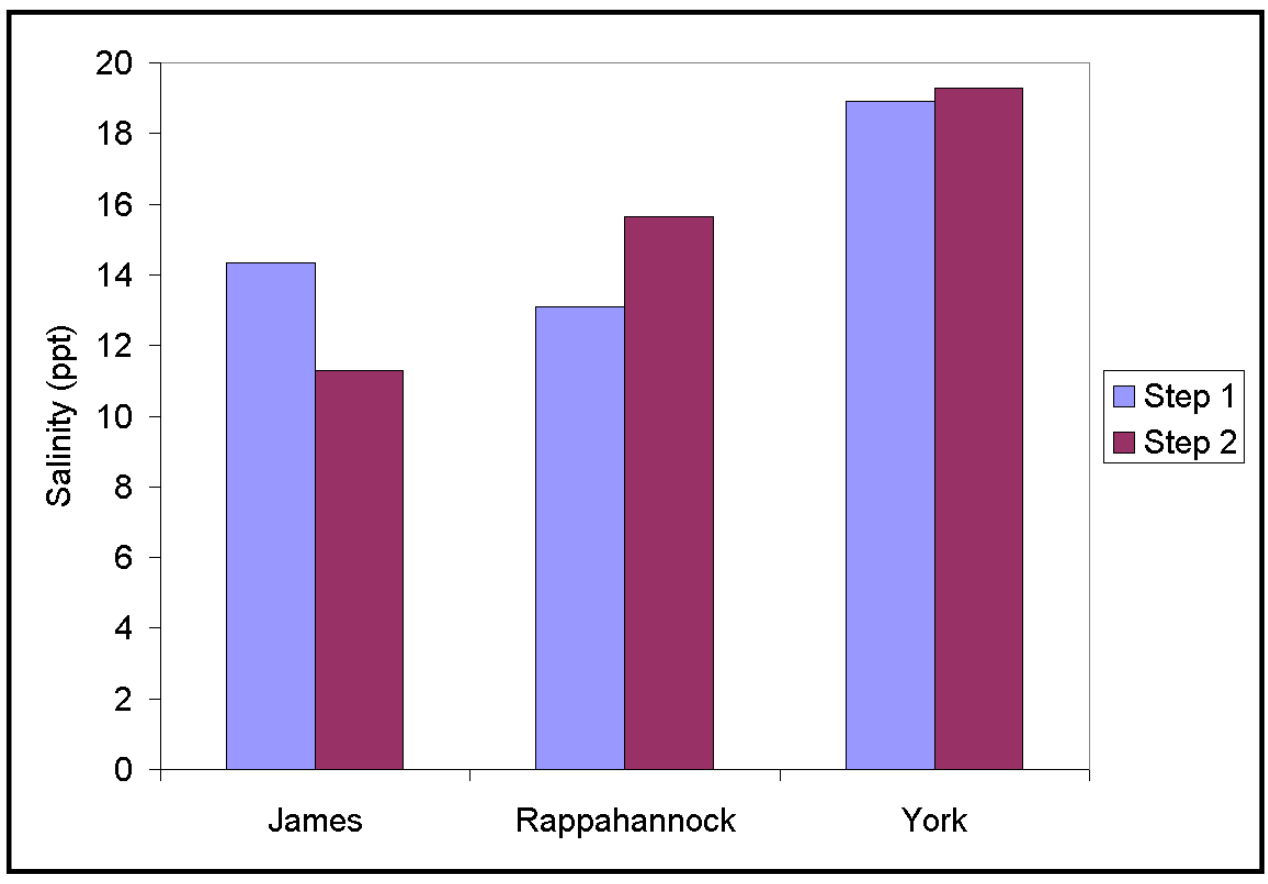

Figure 3. Mean computed salinity in three tributaries

\section{Total nitrogen}

Two factors induce change in computed total nitrogen between Steps 1 and 2. The first is hydrodynamic effects induced by the grid revisions. The second is response to load revisions. In the James, total nitrogen rose from Step 1 to Step 2 (Figure 6). Since loading revisions were negligible (Table 6), the increase is attributable largely to hydrodynamic effects. The concurrent decrease in mean salinity indicates the waters of the James in Step 2 are composed of more freshwater runoff and less ocean water than Step 1. Since runoff is associated with large loads from upland sources, a greater proportion of runoff in the river is expected to increase nitrogen concentrations, all other factors being equal. Circulation effects caused ME (Figure 7) to switch from positive (observations > computations) to negative (computations $<$ observations) and increased AME (Figure 8). 


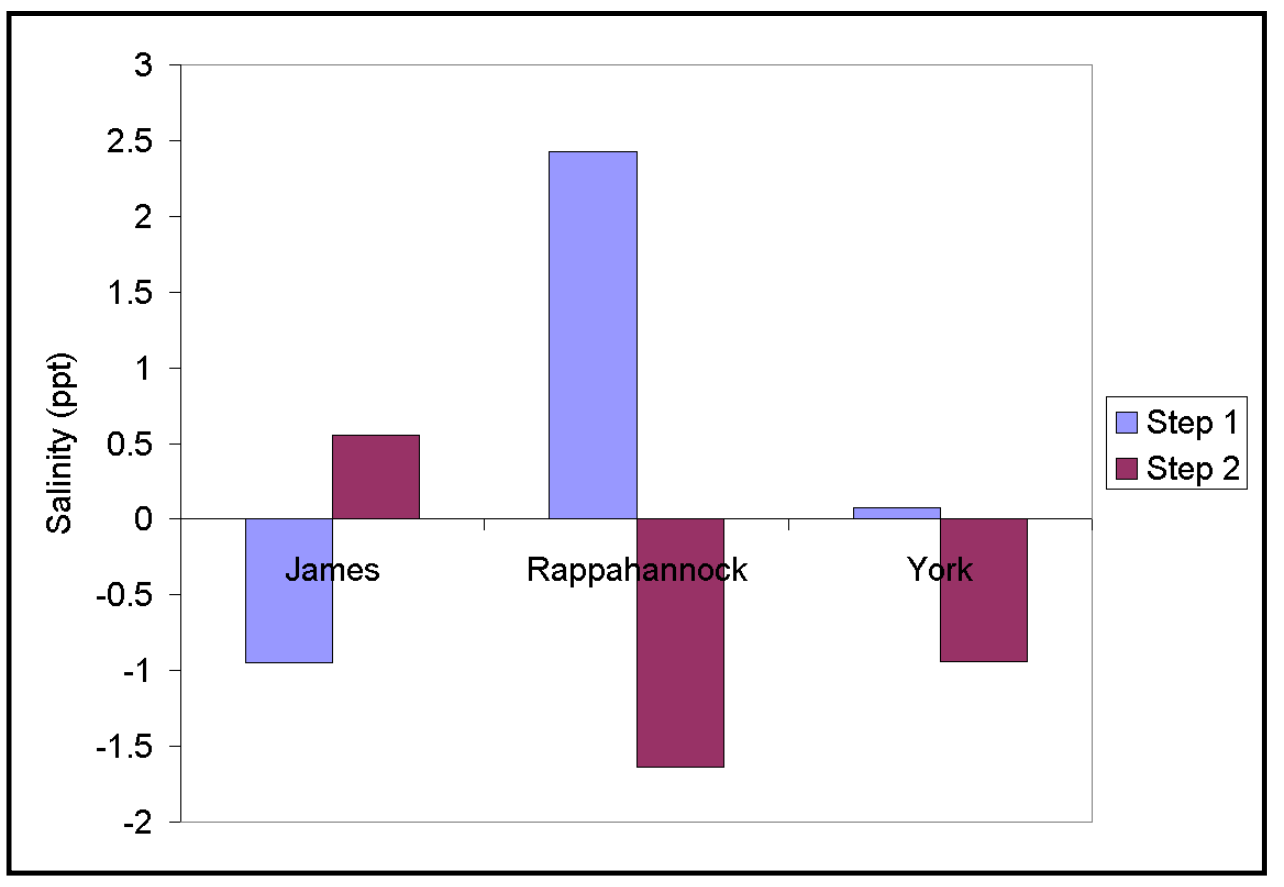

Figure 4. Mean salinity error in three tributaries

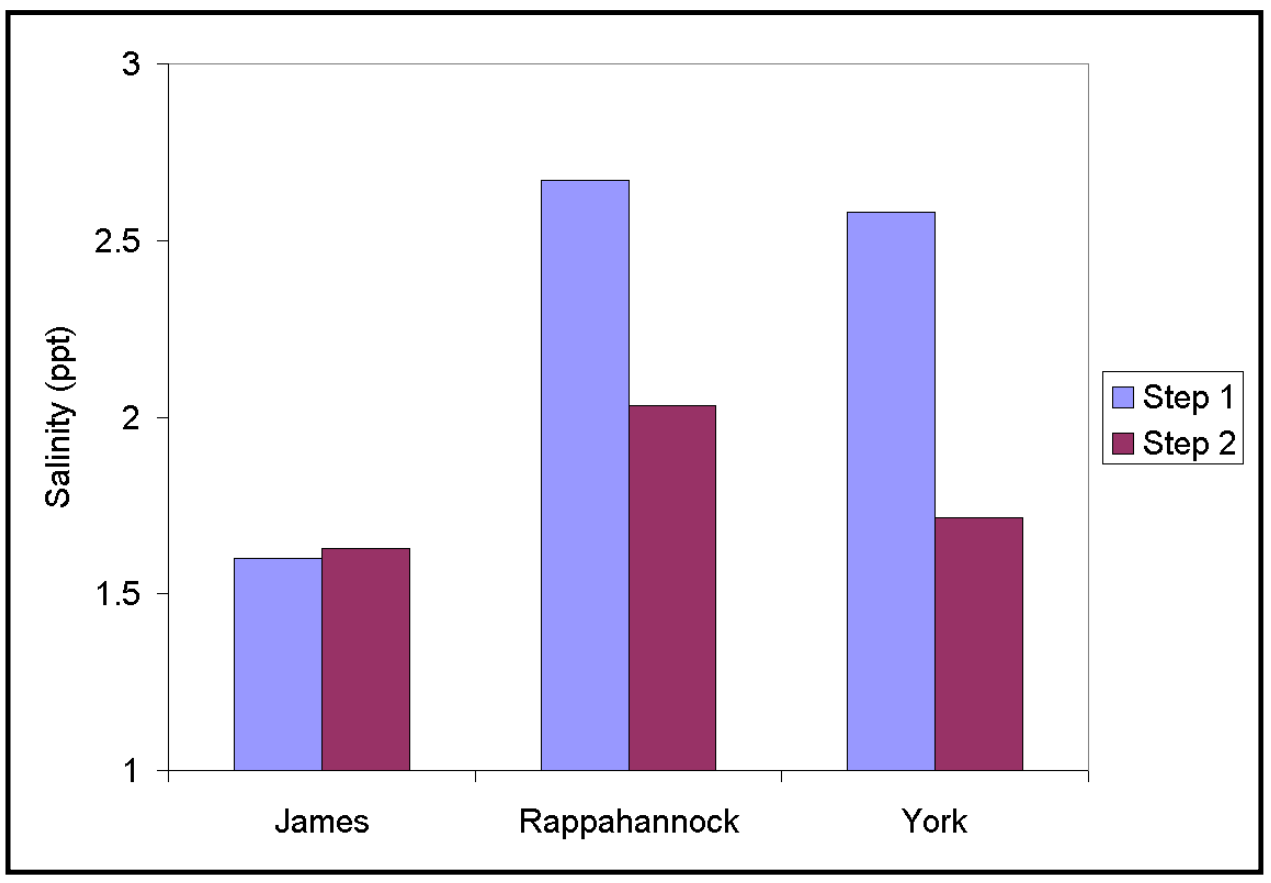

Figure 5. Absolute mean salinity error in three tributaries

For the York and Rappahannock, the decreased fraction of runoff, indicated by increased salinity should decrease total nitrogen. This effect is countered by the increase in estimated loads (Table 6) such that an increase in total nitrogen occurs in both systems. In the Rappahannock, the computations are closer to observed in both ME and AME. In the York, the ME statistic increased, accompanied by negligible change in AME. 


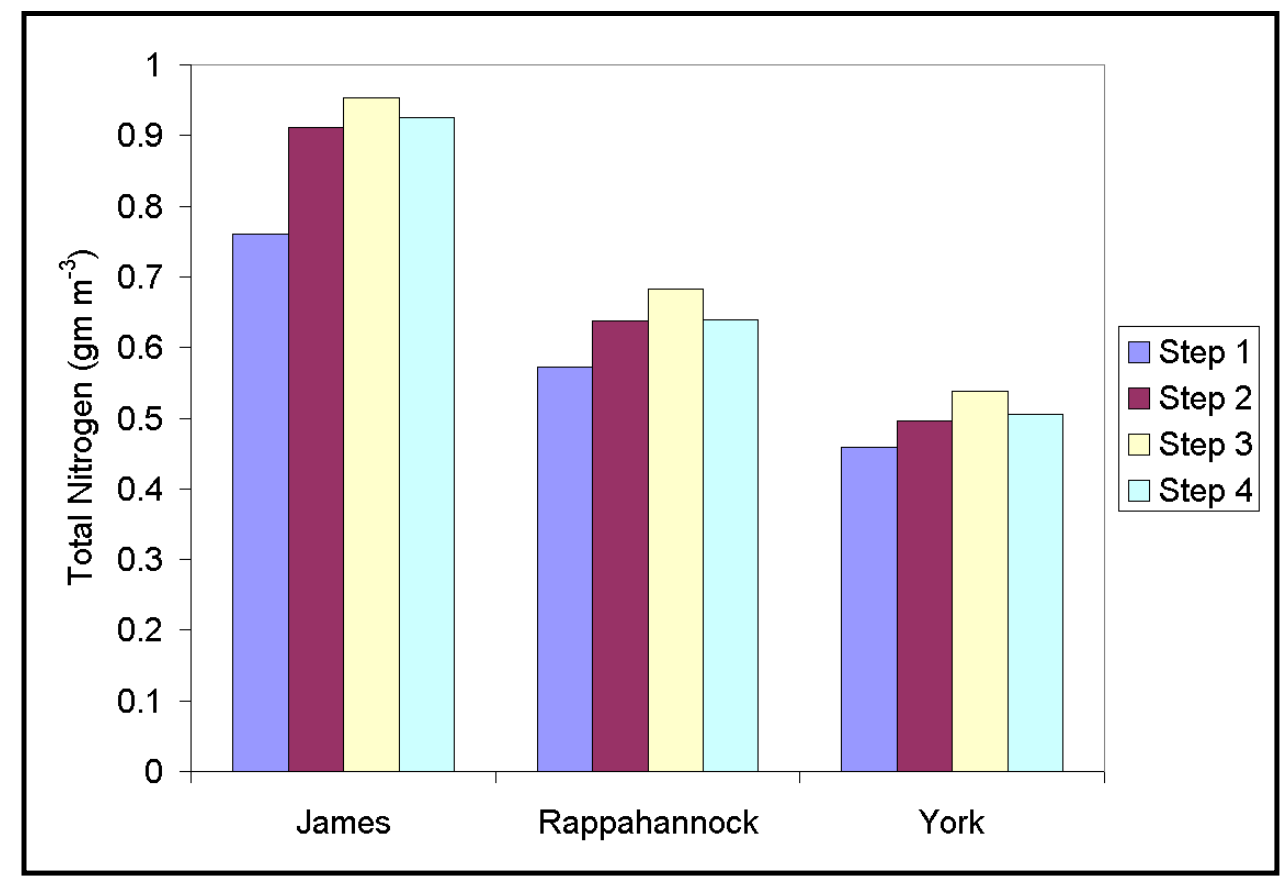

Figure 6. Mean computed total nitrogen in three tributaries

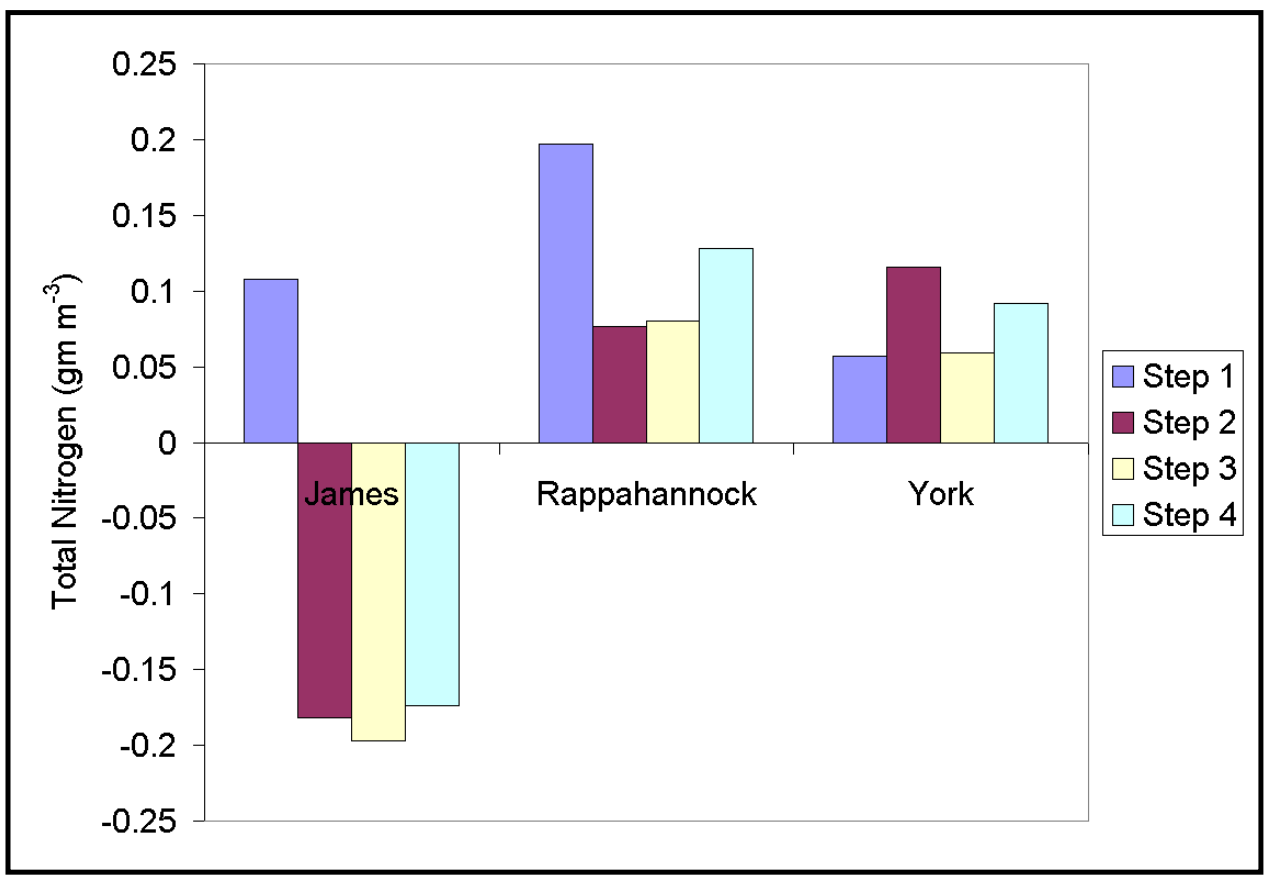

Figure 7. Mean total nitrogen error in three tributaries

\section{Total phosphorus}

Total phosphorus concentration changes (Figure 9) corresponded to load revisions. Increased loads in the James and Rappahannock resulted in increased concentrations while decreased loads in the York resulted in decreased concentrations. Concentrations, which were already high in the James, as indicated by ME 


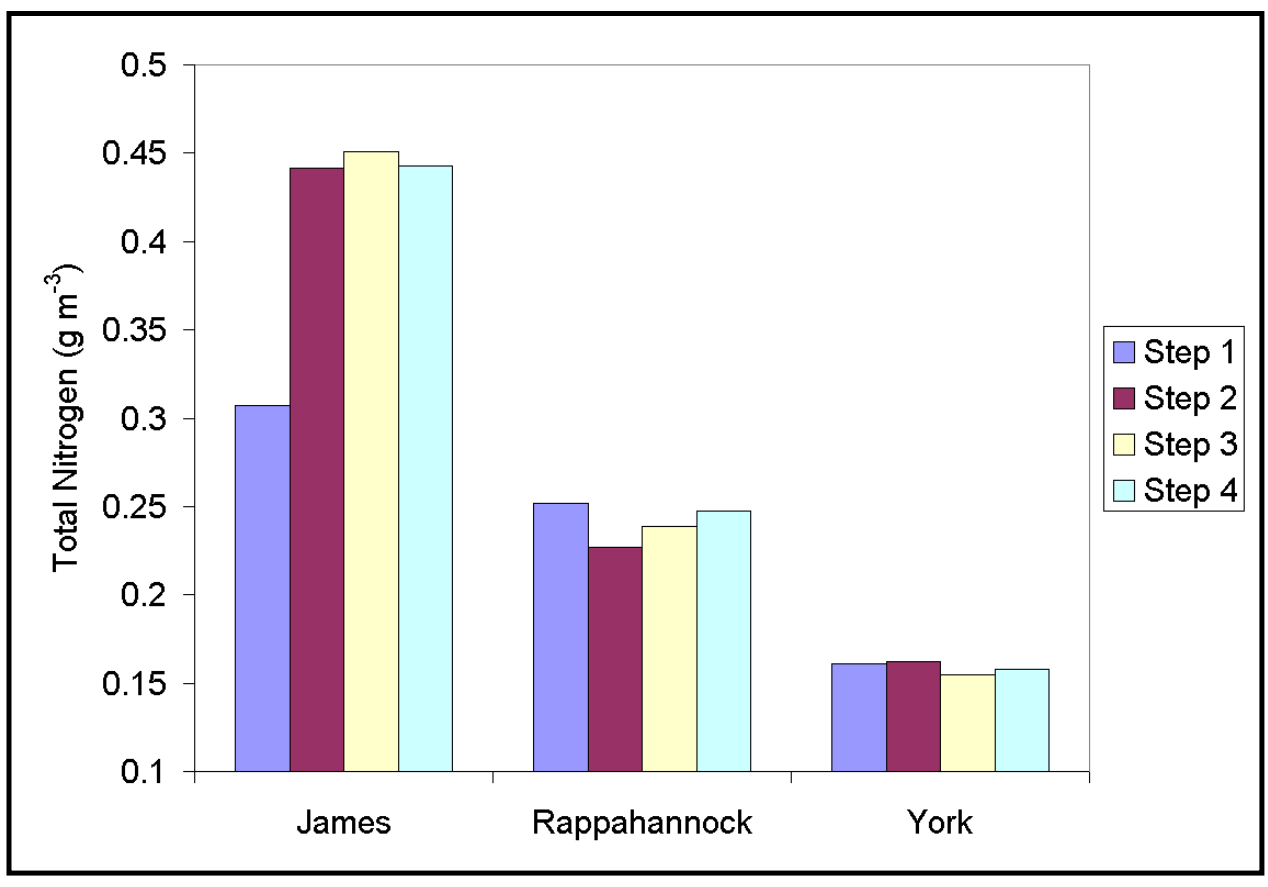

Figure 8. Absolute mean total nitrogen error in three tributaries

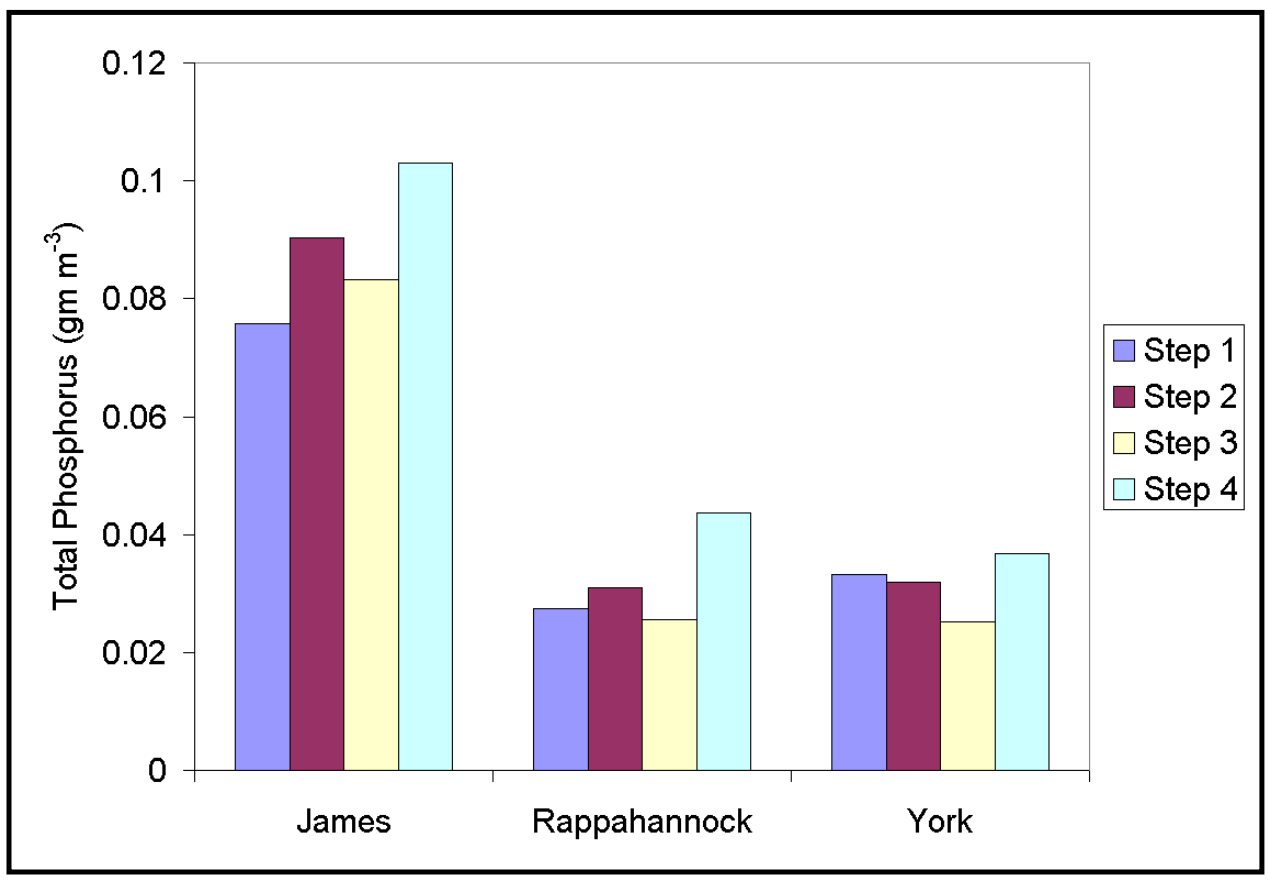

Figure 9. Mean computed total phosphorus in three tributaries

(Figure 10), became higher, accompanied by an increase in AME (Figure 11). In the Rappahannock, the increased concentration brought ME closer to zero and reduced AME. In the York, concentrations that were originally low, on average, became lower, accompanied by an increase in AME. 


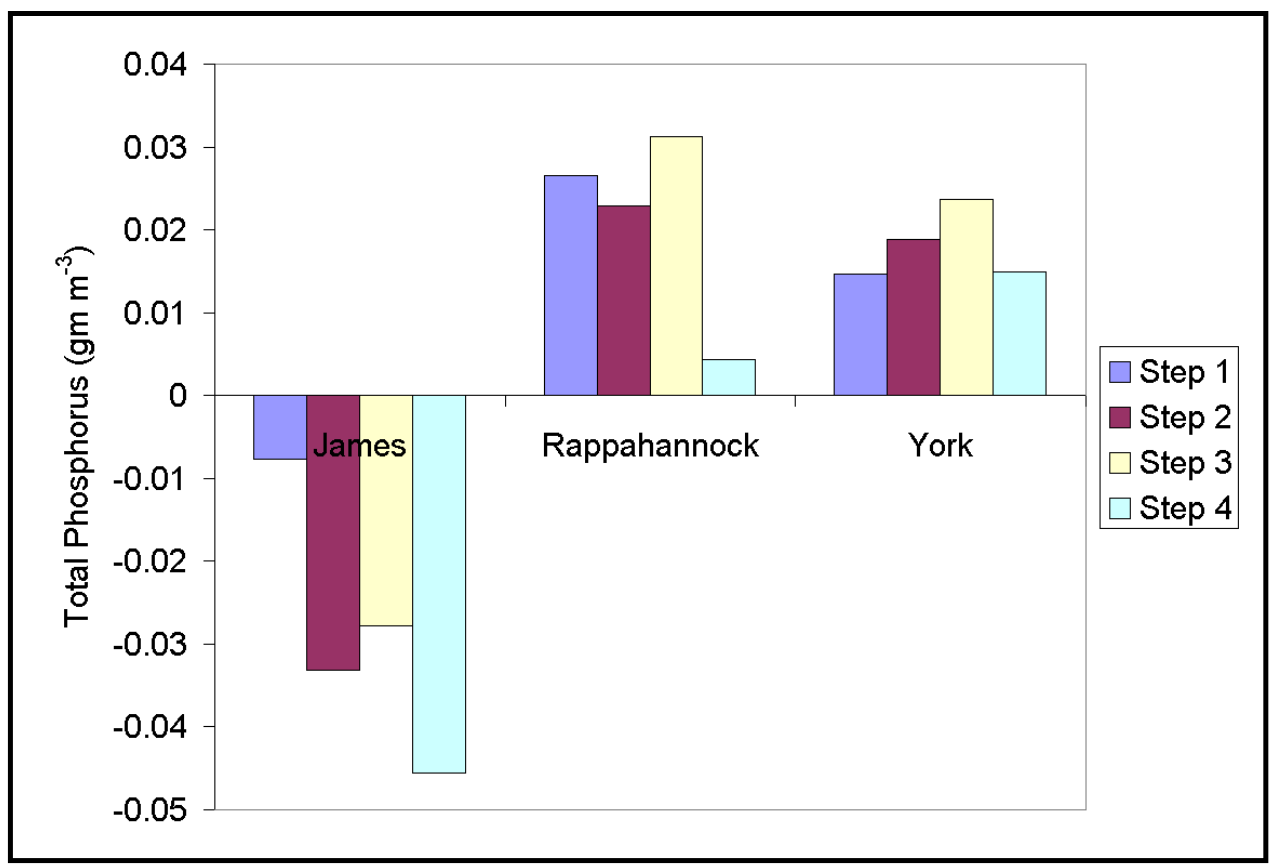

Figure 10. Mean total phosphorus error in three tributaries

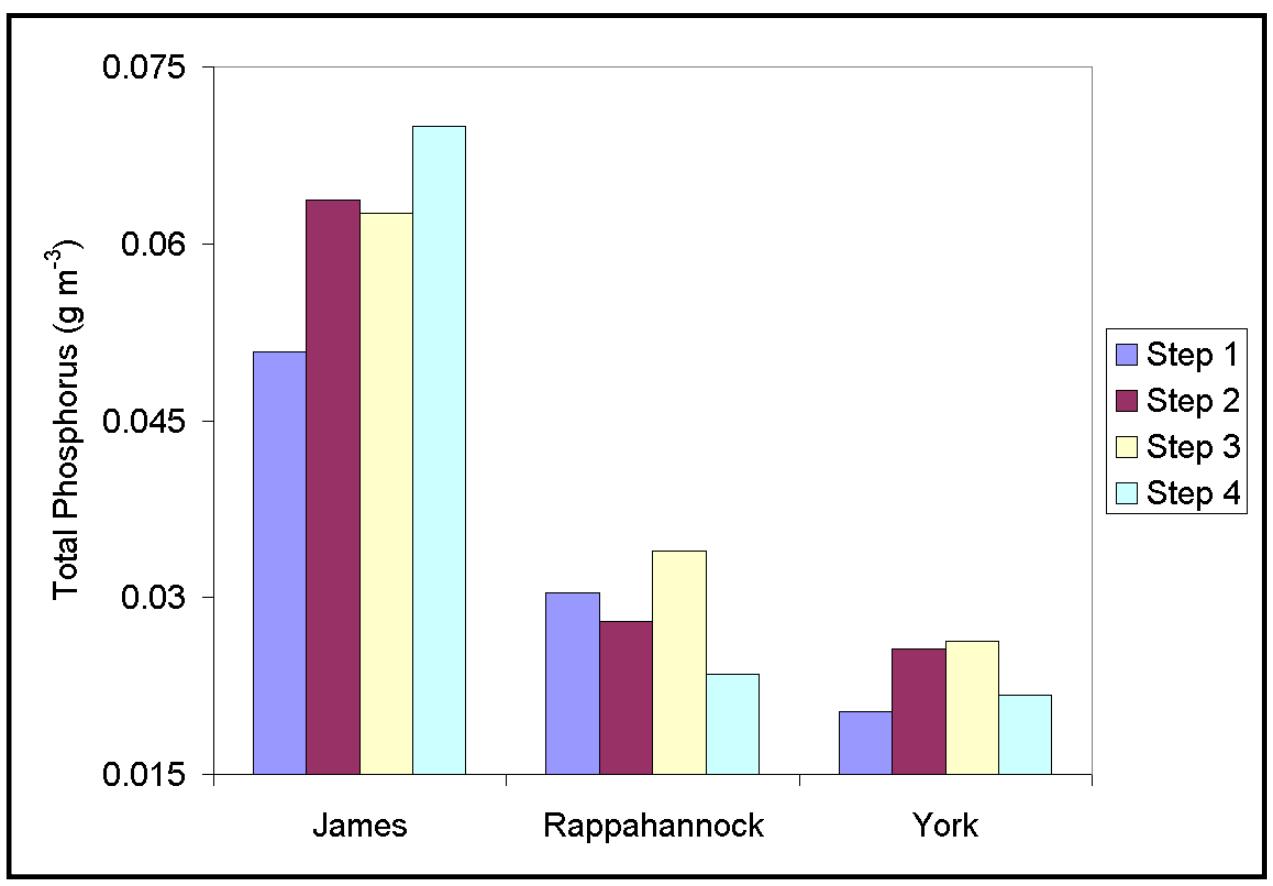

Figure 11. Absolute mean total phosphorus error in three tributaries 


\section{Light attenuation}

In all systems, light attenuation increased from Step 1 to Step 2 (Figure 12). Existing mean errors from Step 1 were exaggerated in the James and York (Figure 13). In the Rappahannock, the initial negative mean error became positive. For all systems, AME increased (Figure 14).

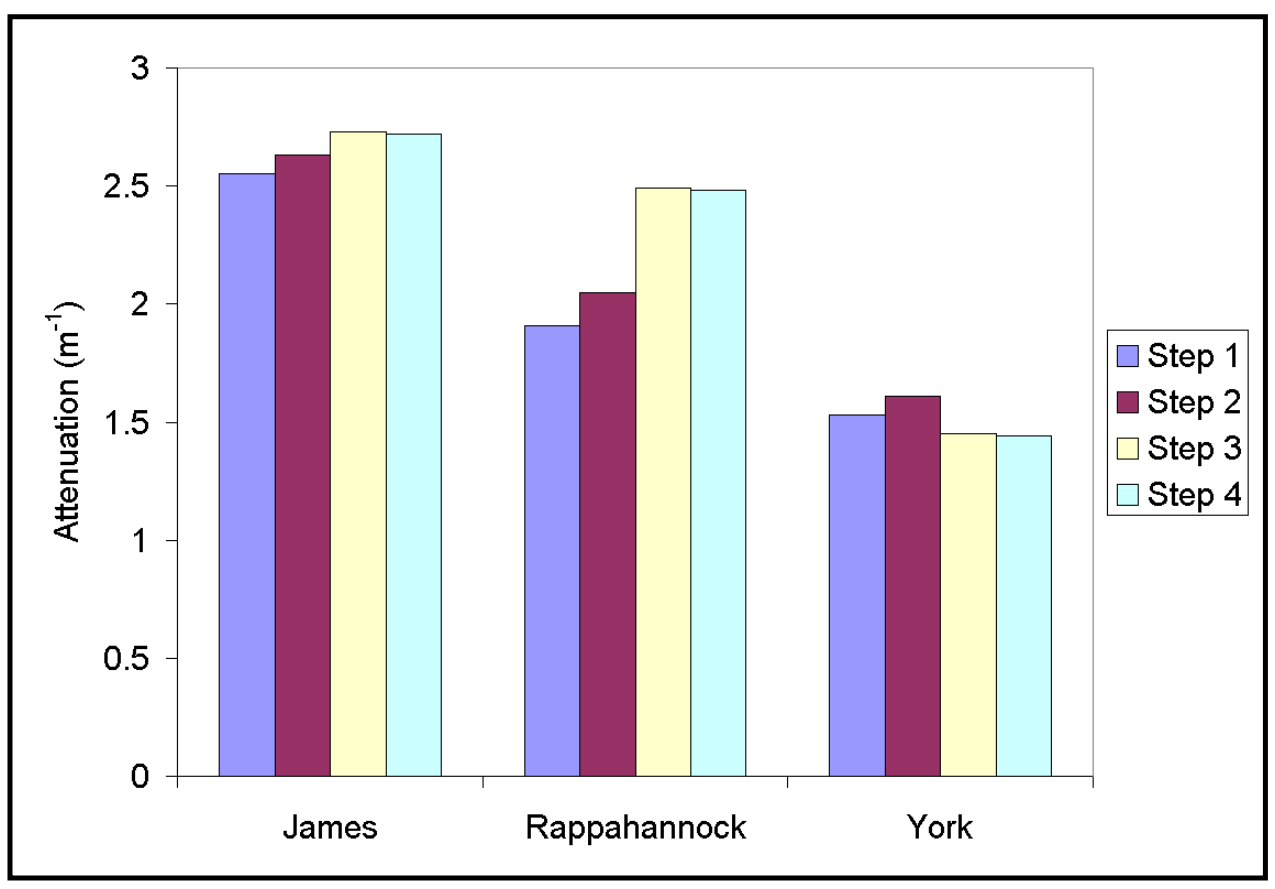

Figure 12. Mean computed light attenuation in three tributaries

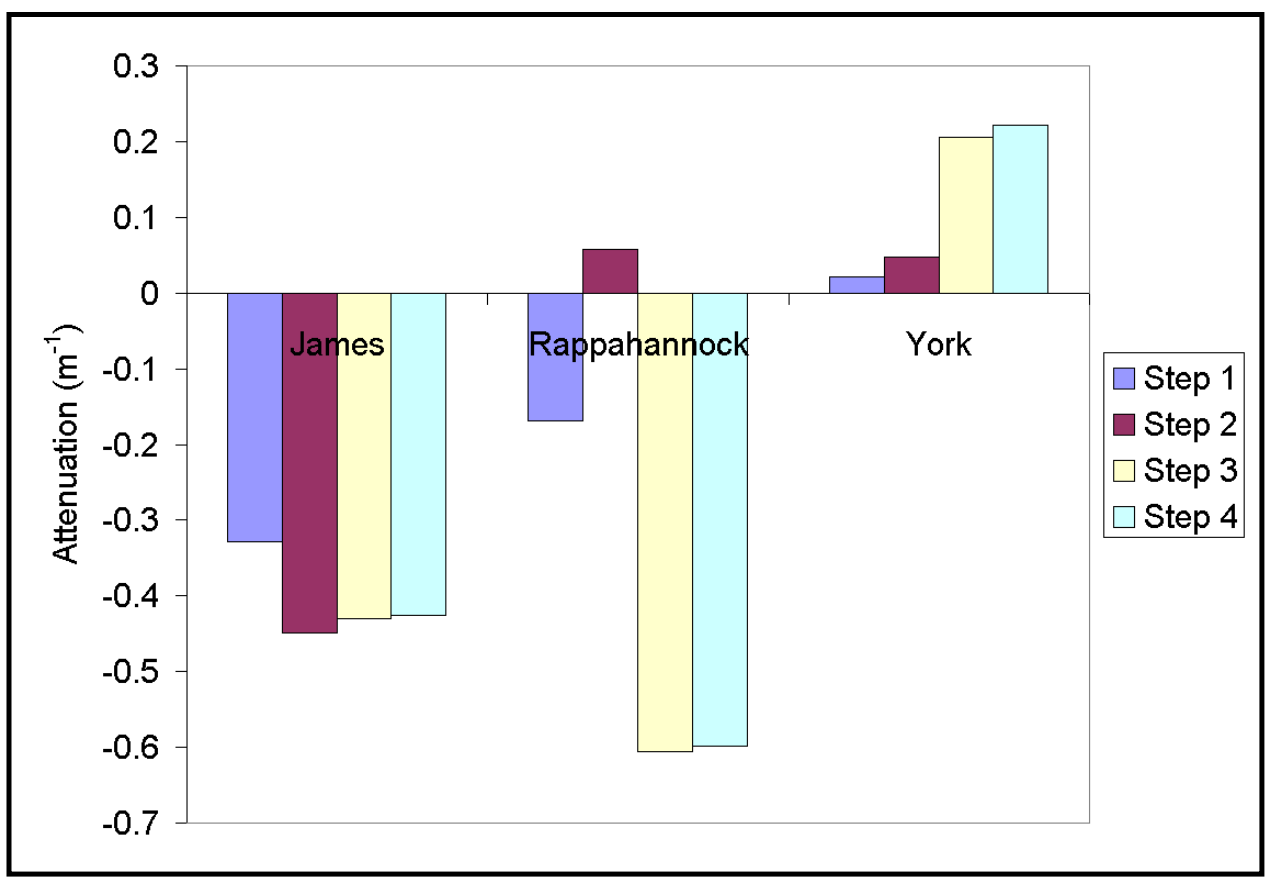

Figure 13. Mean light attenuation error in three tributaries 


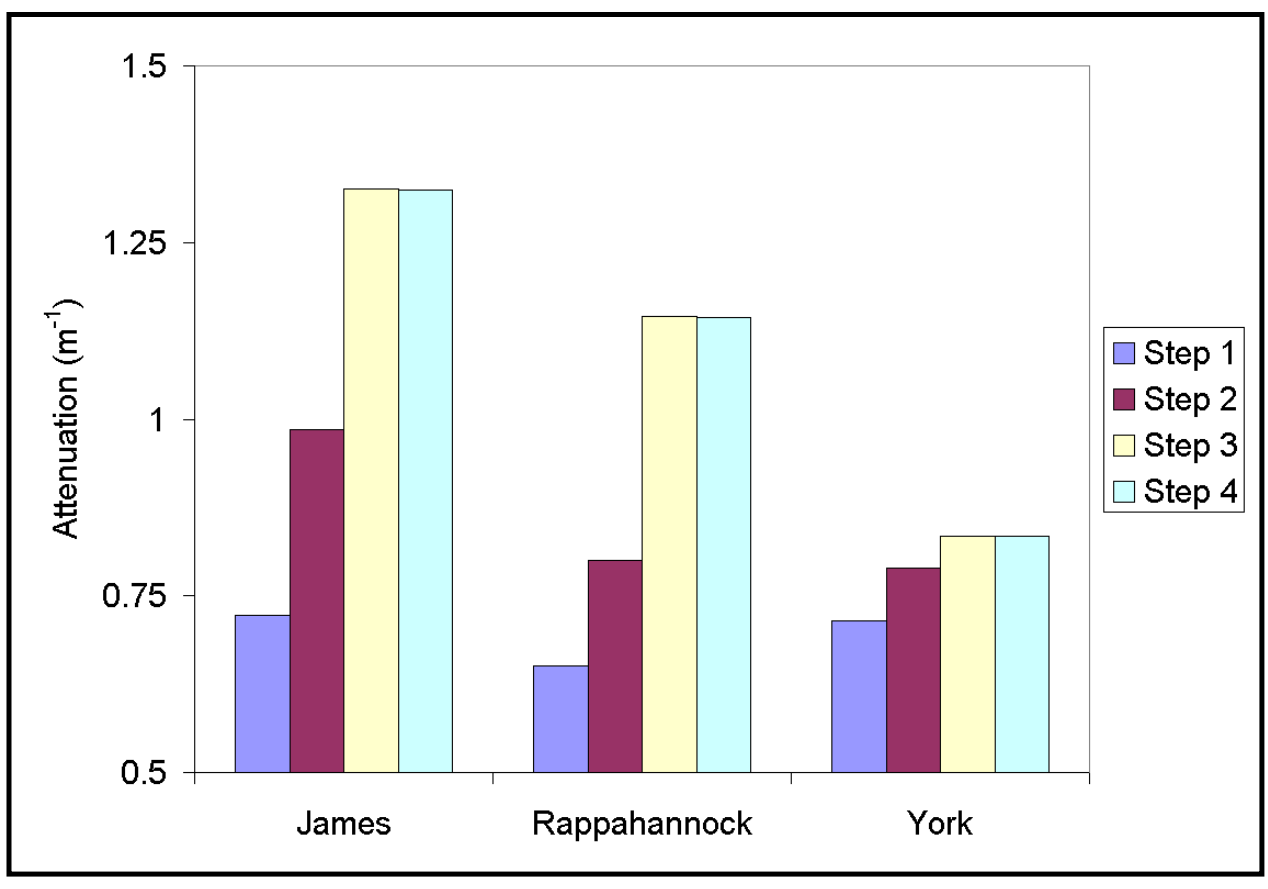

Figure 14. Absolute mean light attenuation error in three tributaries

In two out of three tributaries, mean error grew more distant from the ideal value of zero. In all tributaries, absolute mean error increased. These statistics indicate that less care was taken to specify attenuation for this transitional model run than was taken for the initial model effort.

\section{Chlorophyll}

Mean chlorophyll concentration increased in the James and York and decreased in the Rappahannock (Figure 15). Due to the combined effects of alterations in circulation, loads, and light attenuation, singling out the dominant cause for the chlorophyll change is difficult without analysis of the individual limiting factors. Circulation effects appear to be influential in the James and Rappahannock, however. Increased chlorophyll in the James was accompanied by increased phosphorus loads and diminished exchange with the sea. While increased phosphorus loads would be expected to increase chlorophyll, phosphorus was already abundant. At first appearance, therefore, the increased chlorophyll concentration appears to be a result of increased residence time. From Step 1 to Step 2, nutrient loads to the Rappahannock increased as did flushing with seawater. Diminished chlorophyll concentrations in the presence of increased loads suggest a reaction to decreased residence time although the effect of increased light extinction cannot be dismissed. In the York, nitrogen loads increased, phosphorus loads diminished, and flushing by the sea increased slightly. Since chlorophyll increased, the increased nitrogen load seems to be most responsible.

Mean error in the James switched directions (positive to negative) but with no change in magnitude (Figure 16). Negative mean error in the York remained negative but approached the zero ideal. In the Rappahannock, positive mean error 


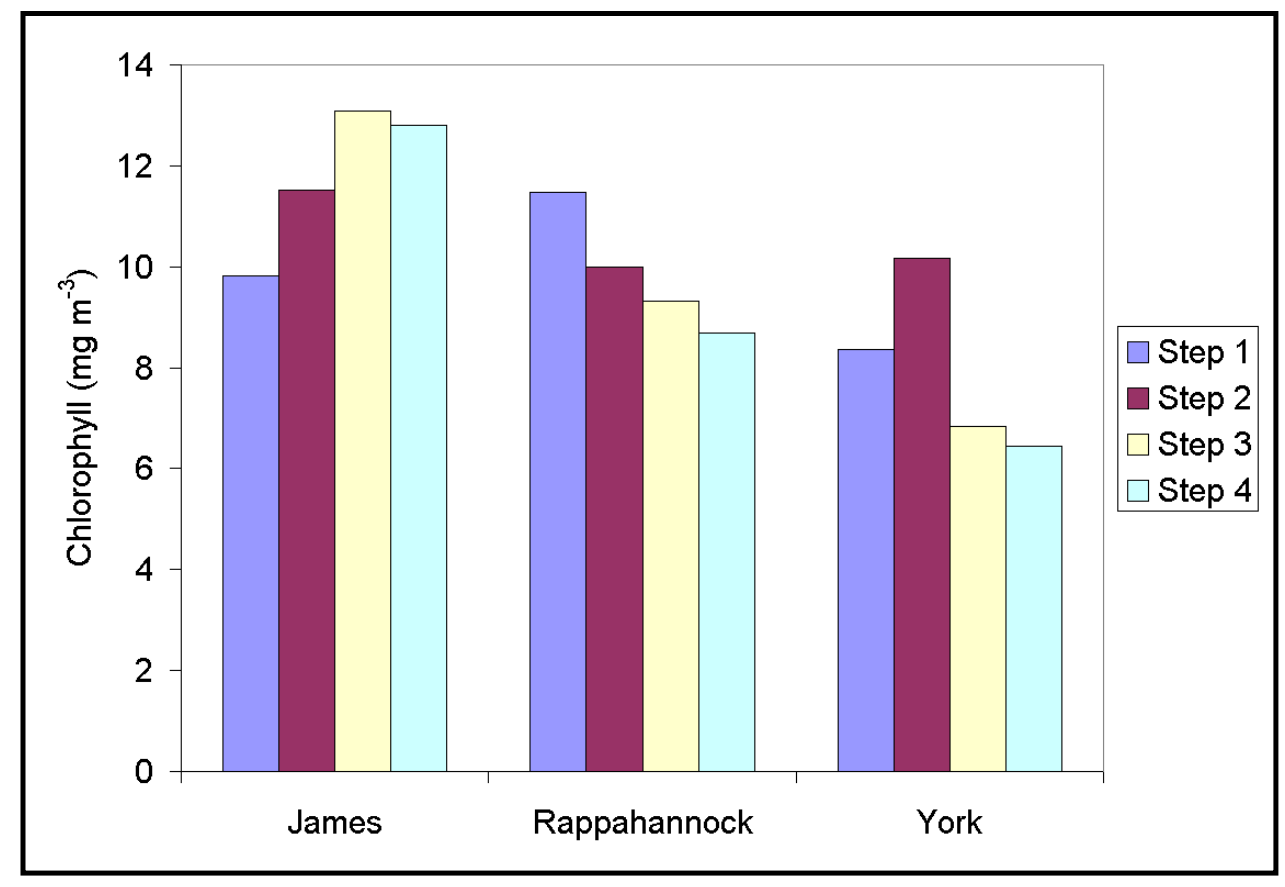

Figure 15. Mean computed chlorophyll in three tributaries

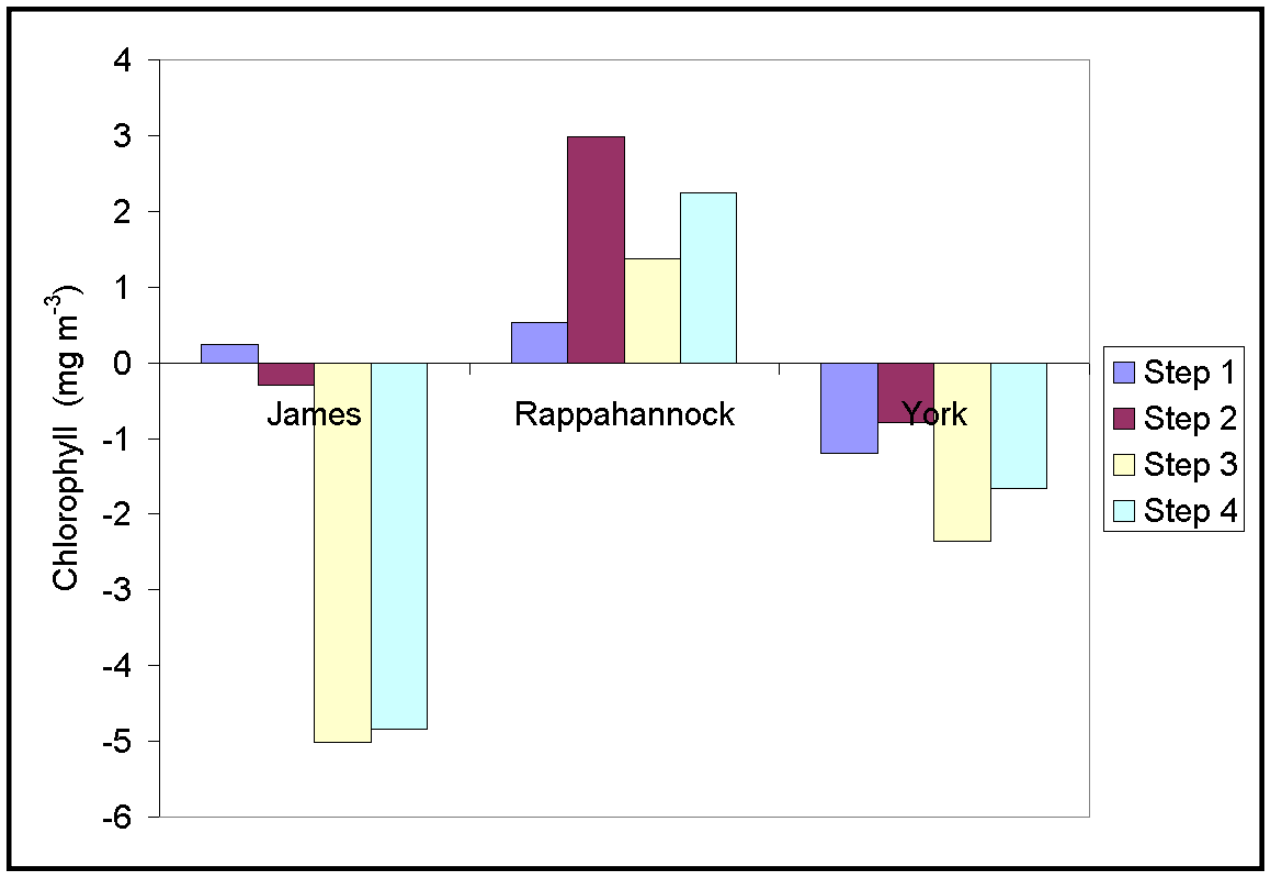

Figure 16. Mean chlorophyll error in three tributaries 
grew larger. AME increased in the James and York and diminished in the Rappahannock (Figure 17).

\section{Dissolved oxygen}

The influences of circulation and mixing on dissolved oxygen in the Virginia tributaries are well understood (Kuo and Neilson 1987). Bottom-water hypoxia is countered by strong gravitational circulation, which replenishes dissolved oxygen in bottom waters. Strong density stratification enhances bottom-water hypoxia while weak stratification diminishes hypoxia. Consequently, grid revisions that result in weaker circulation or stronger stratification are expected to diminish computed dissolved oxygen, especially in bottom waters.

Interpretation of dissolved oxygen changes associated with the grid revision is confounded by the alterations in loads that accompanied the revisions and by interactions in model variables, independent of load changes. Since nutrient loading to the James changed little, this tributary approaches the ideal case of grid changes but no other alterations. Grid revisions to the James resulted in lower computed salinities, indicative of reduced net circulation. As expected, computed bottom-water dissolved oxygen decreased (Figure 18).

The York corresponds to this model also. Computed salinity increased, indicating increased circulation, and bottom-water dissolved oxygen increased. The Rappahannock contradicts the model, however. Salinity increased, indicating increased circulation, but bottom-water dissolved oxygen diminished. Since computed chlorophyll diminished, suggesting a decrease in carbon deposition to

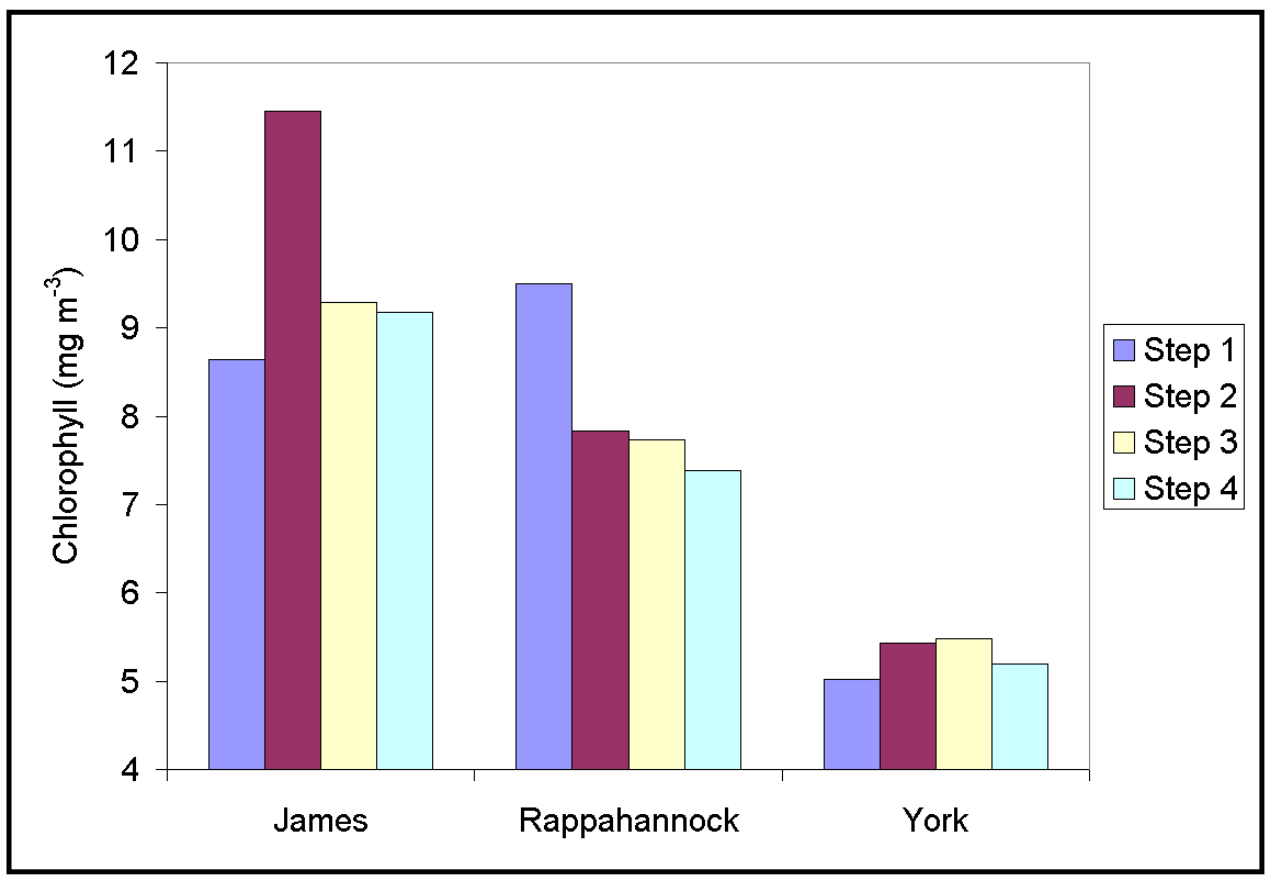

Figure 17. Absolute mean chlorophyll error in three tributaries 


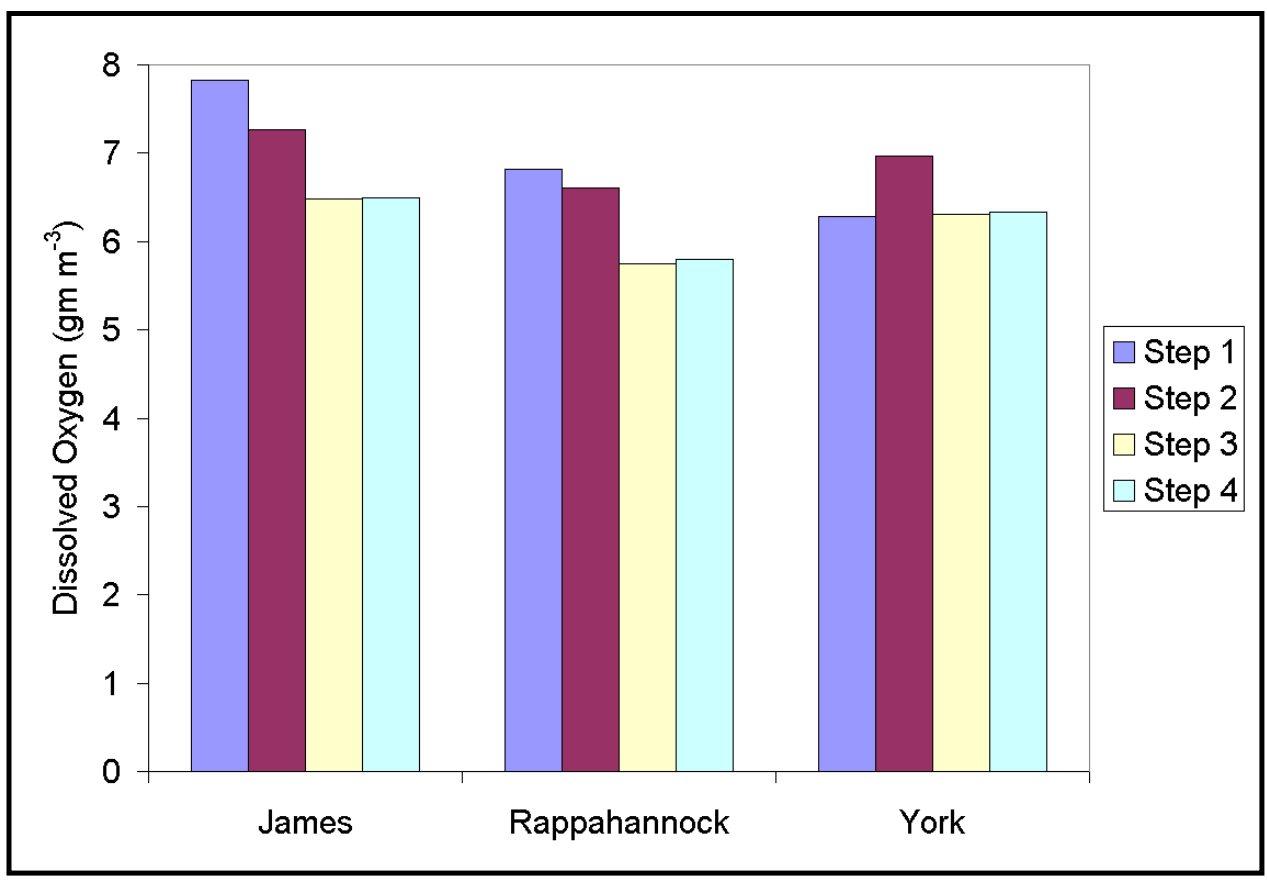

Figure 18. Mean computed summer, bottom, dissolved oxygen in three tributaries

the bottom, the decrease in dissolved oxygen may be indicative of effects of grid resolution independent of circulation.

Mean error in both the James and Rappahannock went from large to negligibly small negative values (Figure 19). Mean error in the York went from a small negative value to a much larger negative value, however. Absolute mean error diminished in all three systems (Figure 20).

\section{Addition of Living Resources and Solids Computations}

Living resources added to the model included microzooplankton, mesozooplankton, filter-feeding benthos, deposit-feeding benthos, and submerged aquatic vegetation (Cerco and Meyers 2000). Addition of these components to the model necessitated a complete recalibration. Calibration was conducted primarily on the basis of visual comparison of computations and observations.

The zooplankton groups and the filter-feeders are the living resources that most impact the computations in the water column. Deposit feeders recycle material in the sediments but do not interact directly with the water column. Submerged aquatic vegetation exists only in littoral zones of limited portions of the tributaries. Computed zooplankton are uniformly distributed within and among the tributaries while filter feeders show strong differences within and among systems (Figure 21). In the tidal fresh portions of the estuaries, computed filter feeders are absent or present at very low levels relative to the remainder of the 


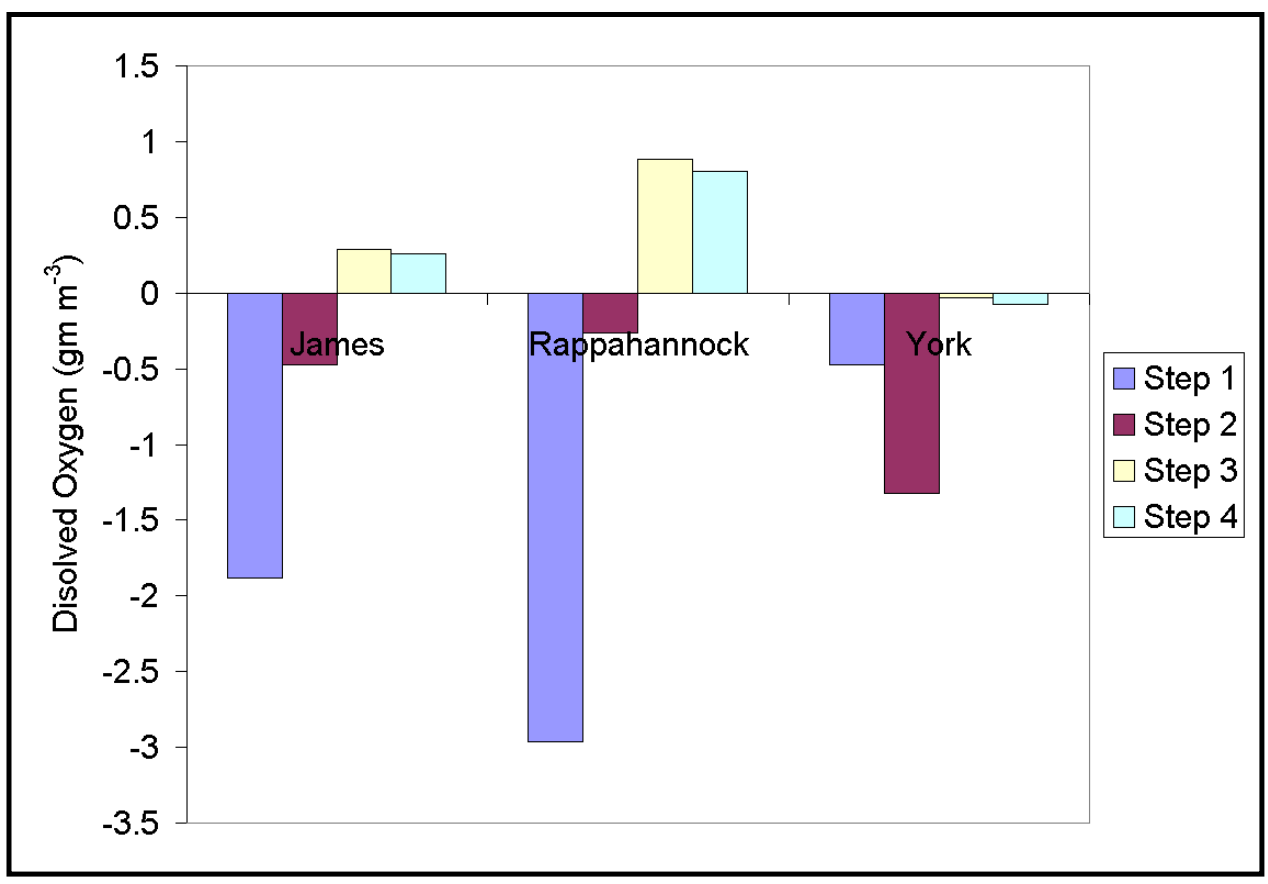

Figure 19. Mean summer, bottom, dissolved oxygen error in three tributaries

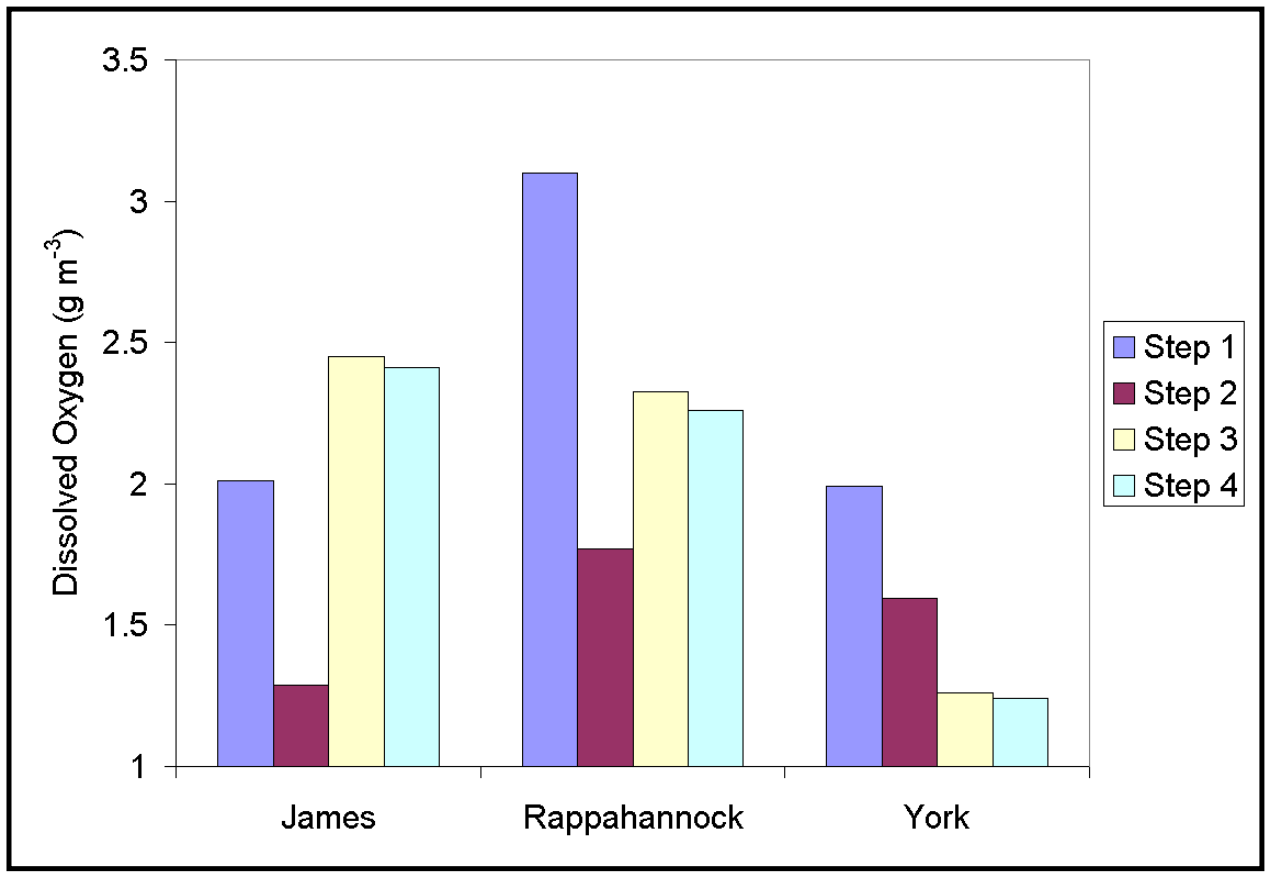

Figure 20. Absolute mean summer, bottom, dissolved oxygen error in three tributaries 


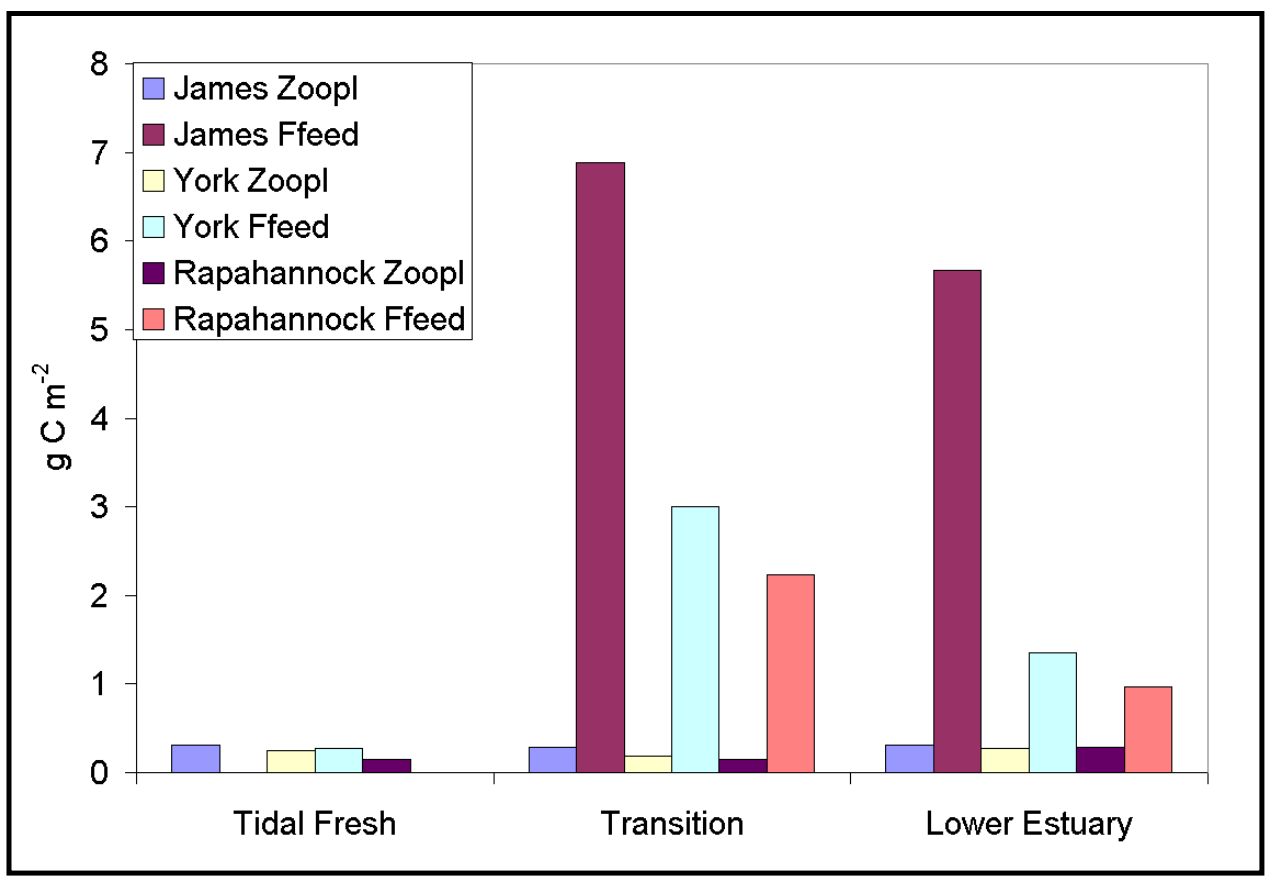

Figure 21. Computed mean zooplankton and filter-feeding benthos in three tributaries

system. In the lower estuaries and in the transition regions between saline and fresh water, filter-feeding biomass is present at levels up to an order of magnitude greater than zooplankton. An interestuary gradient also exists. Filter-feeding biomass is greatest in the James, less in the York, and least in the Rappahannock.

\section{Total nitrogen and total phosphorus}

Addition of living resources increased total nitrogen in all systems (Figure 6). Although this analysis does not identify the process, the increase indicates the addition of living resources diminished transfer of nitrogen from water to bottom sediments. The effect of this unidirectional change on statistics depended on their initial value. Mean error got further from the ideal zero value in the James, was unchanged in the Rappahannock, and got closer to ideal in the York (Figure 7). Absolute mean error increased in the James and Rappahannock and decreased in the York (Figure 8).

Total phosphorus concentrations decreased in all systems (Figure 9) indicating enhanced transfer from water column to benthic sediments. As with nitrogen, the statistical impact of the unidirectional change was dependant on the initial value of the statistics. In the James, mean error got closer to the ideal zero while mean error grew further from the ideal value in the York and Rappahannock (Figure 10). Addition of living resources had little impact on absolute mean error in the James and York (Figure 11) but increased error in the Rappahannock. 


\section{Light attenuation}

Switching to a fully predictive light attenuation model based on computed solids concentration increased attenuation in the James and Rappahannock and decreased attenuation in the York (Figure 12). Mean error became slightly closer to zero in the James but got further from zero in the York and Rappahannock (Figure 13). Absolute mean error grew larger in all three tributaries (Figure 14).

\section{Chlorophyll}

Addition of living resources diminished chlorophyll in the York and Rappahannock and increased chlorophyll in the James (Figure 15). The different responses are difficult to explain from inspection of statistics alone. Filter feeders are absent in the tidal fresh James (Figure 21), however. One possibility is that the model recalibration that accompanied the addition of living resources increased chlorophyll in the tidal fresh James without any filtration to offset the increase.

Mean error got more distant from the ideal zero in the James and York but closer in the Rappahannock (Figure 16). Absolute mean error diminished in the James and changed little elsewhere (Figure 17).

\section{Dissolved oxygen}

Summer, bottom, dissolved oxygen diminished in all systems (Figure 18) with the addition of living resources. This unidirectional change indicates total respiration with living resources exceeds respiration in the previous version of the model. The increased respiration benefited the mean error statistic in the York and James but not in the Rappahannock (Figure 19). Absolute mean error increased in the James and Rappahannock but decreased in the York (Figure 20).

\section{Revisions to Atmospheric and Bank Loads}

\section{Total nitrogen}

As expected, the downward revision to atmospheric nitrogen loads resulted in diminished nitrogen concentrations, roughly $0.03 \mathrm{~g} \mathrm{~m}^{-3}$, in each tributary (Figure 6). The effect on mean error depended on the state of the system prior to the revision. In the James, in which computed total nitrogen was higher than observed, the mean error statistic got closer to zero (Figure 7). In the York and Rappahannock, in which computed total nitrogen was lower than observed, the mean error statistic grew further from zero. Effects on absolute mean error were negligible (Figure 8). 


\section{Total phosphorus}

Addition of bank loads increased total phosphorus by 0.01 to $0.02 \mathrm{~g} \mathrm{~m}^{-3}$ in all systems (Figure 9). As with nitrogen, the effect on mean error depended on the state of the system prior to addition of the loads. In the James, where computed phosphorus concentrations were already high, mean error became more negative (Figure 10). Positive mean error diminished in the York and nearly vanished in the Rappahannock. Corresponding to changes in mean error, absolute mean error grew in the James and diminished in the York and Rappahannock (Figure 11).

\section{Chlorophyll}

Mean chlorophyll concentrations decreased by roughly $0.4 \mathrm{mg} \mathrm{m}^{-3}$ in all systems as a result of the reduction in nitrogen loads (Figure 15). Mean error improved in the James and York but grew larger in the Rappahannock (Figure 16). Absolute mean error diminished in all systems (Figure 17).

\section{Dissolved oxygen}

Summer, bottom, dissolved oxygen rose by 0.02 to $0.05 \mathrm{gm} \mathrm{m}^{-3}$ in all systems as a result of the reduced nitrogen load (Figure 18). This result improved mean error in the James and Rappahannock but forced the error to become more negative in the York (Figure 19). Absolute mean error diminished a negligible amount in all systems (Figure 20).

\section{Relative error}

The relative error statistic is the absolute mean error statistic normalized by the mean observed concentration. Consequently, changes in relative error from step to step correspond to changes in absolute mean error. The value of the relative error statistic is in comparisons across systems or between different variables. Relative error was summarized for Step 4 (Figure 22) since this represents the final calibration state of the model.

Salinity was the substance with the least relative error, 10 to 20 percent. The favorable statistic is the result of two factors. First, salinity is solely the result of transport processes. Second, the range of computed salinity is limited by freshwater and oceanic salinity.

Total nitrogen and dissolved oxygen had relative errors in the range of 20 to 50 percent. Dissolved oxygen relative error reported here is larger than previous analyses. Reported dissolved oxygen relative error in the tributaries for the first version of the study was less than 20 percent (Cerco and Cole 1994). The increase in relative error is due to a change in computation of the statistics. Previously, all oxygen computations were considered. Consideration of computations at the water surface and year round incorporated a large number of observations close to saturation. The model can well reproduce saturation dissolved oxygen. The revised statistic emphasizes dissolved oxygen computations that are influenced by 


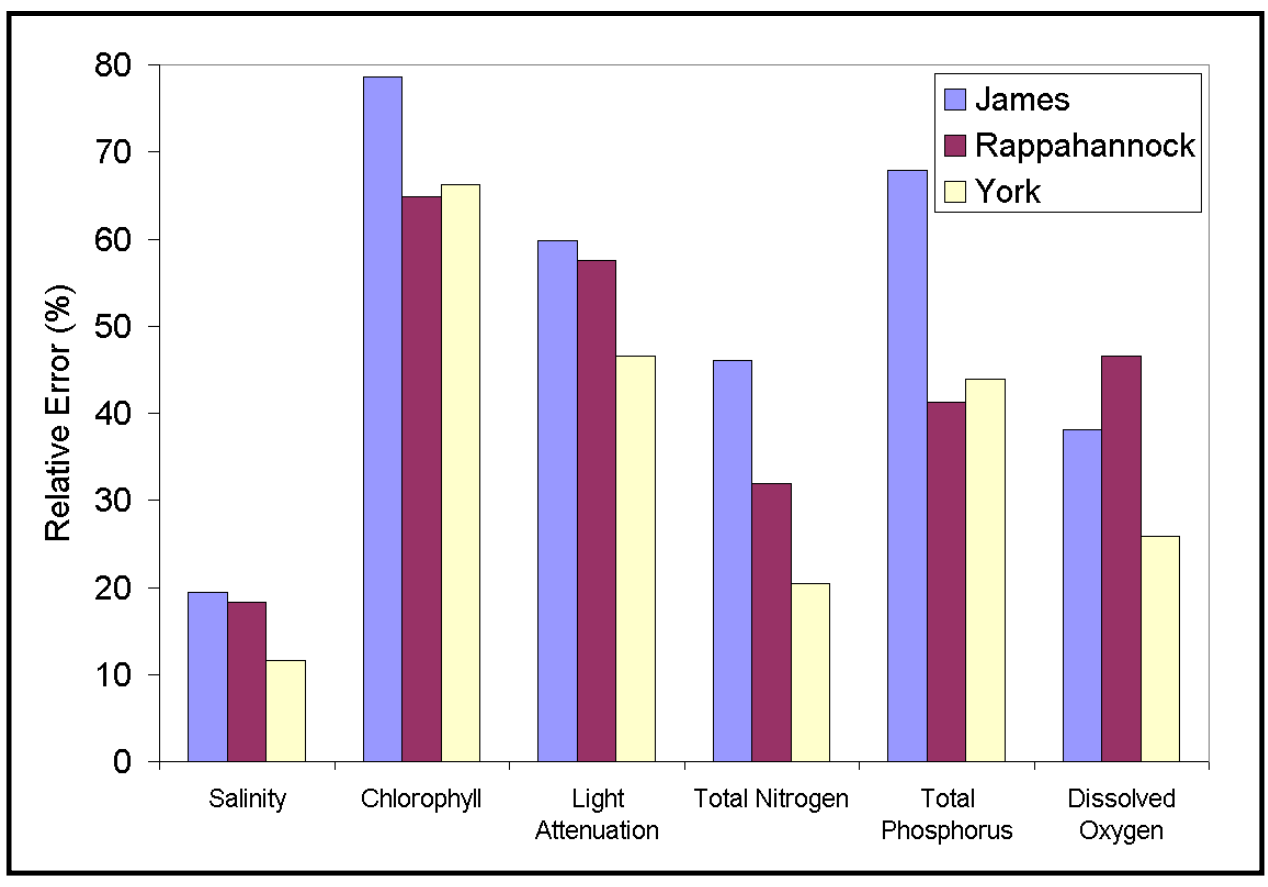

Figure 22. Relative error in three tributaries for final model calibration

transport and by biological sources and sinks. Omission of the readily computed saturated observations adversely affects the relative error statistic.

Relative error for total phosphorus and light attenuation ranged from 40 to 70 percent. The greater error for phosphorus than nitrogen indicates greater uncertainty in loads. Also, transport of PIP is strongly linked to transport of suspended sediment, which is crudely represented in the present model. Uncertainty in solids loads and absence of a true sediment transport model also account for the high relative error in light attenuation.

Relative error for chlorophyll, 65 to 80 percent, was greatest of all parameters. The high error reflected the nonconservative behavior of algal biomass and the approximate nature of mathematical models of biological processes.

With the exception of summer, bottom, dissolved oxygen, relative errors were higher in the James River than in the remaining tributaries. Where substantial differences existed between the two, relative errors were smaller in the York than the Rappahannock. The James River is very heavily loaded relative to the other tributaries (Table 6). Nitrogen loads are five times greater and phosphorus loads are an order of magnitude greater than the York or Rappahannock. Since the model formulation was identical in all three tributaries, the greater relative errors in the James are attributed to uncertainties in loads. Despite the revisions to the point-source loads, data on these for the early years of the study is still sparse. The James River watershed is vast compared to the other two tributaries and major storm loads are common. These loads are especially difficult to simulate with the watershed model. Also, the observations of loads associated with high flows is sparse in earlier years. The years 1985-1986 were selected for analyses here 
because they span multiple model applications. Future analyses should be based on more recent years when better loading information is available.

\section{Summary}

The overarching conclusion from inspection of the summary statistics is that successive revisions to the model did not produce monotonic improvements in the statistical evaluation of the calibration. Statistical response to model revisions was dependent on the system and parameter examined.

Clearly, revisions to the grid resulted in improvement in computed salinity (Figures 4, 5). By inference, the improved salinity computations were accompanied by improved modeling of circulation. The improved representation of circulation, coupled with revised loadings, did not result in universally improved representations of nitrogen (Figures 7, 8), phosphorus (Figures 10,11), or chlorophyll (Figures 16, 17), however. For the most part, summer bottom, dissolved oxygen computations improved (Figures 19,20) and were linked to circulation effects in the James and York. In the Rappahannock, the improvement in computed dissolved oxygen appeared to result from grid alterations but not from circulation effects.

Evaluation of the addition of living resources depends on the purpose of the addition. As with the previous revisions, no universal improvement in statistics was noted. From one perspective, living resources can be added to a conventional eutrophication model with no diminishment in performance. From another perspective, living resources should not be added to a model in the hope that performance will improve.

In terms of the watershed budget, atmospheric nitrogen loads are substantial and should be quantified to the best extent possible. Direct loads to the surface of the tributaries are less significant, however. Revisions of the magnitude explored here had negligible effect on model performance. Incorporation of bank phosphorus loads had more substantial effect and resulted in improved performance in the York and Rappahannock. In the James, in which computed phosphorus was already high, addition of bank loads exacerbated the situation. Although the magnitude of bank loads is uncertain, they do exist in the James. The consistent overprediction of total phosphorus prior to the addition of bank loads indicates point-source and distributed loads to the system for the study years were overestimated. Otherwise, phosphorus sinks have been consistently underestimated.

If the performance statistics of the model did not universally improve after substantial revisions, what was gained from the revisions? The answers are "realism" and "confidence." Certainly, the improved representation of circulation, as indicated by improved salinity statistics, increases the confidence in the model. Addition of living resources provides more realism. The transition to an attenuation model based on computed solids is much more realistic than the previous model, which related attenuation to fall-line flow. 
Statistical examination of model results is no substitute for judgment. In fact, statistics introduce new judgments to be made. The response to a model run in which mean error grows worse while absolute mean error improves is based on judgment, not numbers. Examination of statistics can provide insights, however, not available from conventional visual examination of model-data comparisons.

Statistics are a useful tool and should be produced and examined as part of model evaluation.

\section{References}

Cerco, C., and Cole, T. (1993). "Three-dimensional eutrophication model of Chesapeake Bay," Journal of Environmental Engineering, ASCE, 119(6), 1006-1025.

. (1994). "Three-dimensional eutrophication model of Chesapeake

Bay,” Technical Report EL-94-4, U.S. Army Engineer Waterways

Experiment Station, Vicksburg, MS.

Cerco, C., and Meyers, M. (2000). "Tributary refinements to Chesapeake Bay model," Journal of Environmental Engineering, ASCE, 126(2), 164-174.

Conley, D., Smith, W., Cornwell, J., and Fisher, T. (1995). "Transformation of particle-bound phosphorus at the land-sea interface," Estuarine, Coastal and Shelf Science 40, 161-176.

Cronin, W. (1971). "Volumetric, areal, and tidal statistics of the Chesapeake Bay Estuary and its tributaries," Special Report 20, Chesapeake Bay Institute, Johns Hopkins University, Baltimore, MD.

DiToro, D., and Fitzpatrick, J. (1993). "Chesapeake Bay sediment flux model," Contract Report EL-93-2, U.S. Army Engineer Waterways Experiment Station, Vicksburg, MS.

Dortch, M., Chapman, R., and Abt, S. (1992). "Application of three-dimensional Lagrangian residual transport," Journal of Hydraulic Engineering, ASCE, $118(6), 831-848$.

Ibison, N., Frye, C., Frye, J., Hill, C., and Burger, N. (1990). "Sediment and nutrient contributions of selected eroding banks of the Chesapeake Bay estuarine system," Department of Conservation and Recreation, Division of Soil and Water Conservation, Gloucester Point, VA.

Keefe, C. (1994). "The contribution of inorganic compounds to the particulate carbon, nitrogen, and phosphorus in suspended matter and surface sediments of Chesapeake Bay," Estuaries 17(1B), 122-130.

Kuo, A., and Neilson, B. (1987). "Hypoxia and salinity in Virginia estuaries," Estuaries 10(4), 277-283.

Pennock, J. (1985). "Chlorophyll distributions in the Delaware Estuary: Regulation by light limitation," Estuarine, Coastal and Shelf Science 21, 711-725.

U.S. Army Engineer District, Baltimore. (1990). "Chesapeake Bay shoreline erosion study," Feasibility Report, Baltimore, MD. 
U.S. Environmental Protection Agency. (1982). "Chesapeake Bay program technical studies, a synthesis," Washington, DC, 158-163. 


\section{Appendix A Maps}

This appendix, included on the accompanying CD, presents maps of sample stations and of Chesapeake Bay Program Segments (used in summaries of model and data). 


\section{Appendix B Tributary Calibration}

This appendix, included on the accompanying CD, presents results from the model, exactly as employed to guide management of the tributaries.

\section{Longitudinal Plots}

The spatial distributions of observed and computed properties, at water surface and bottom, are compared for the main stem bay and major tributaries. Distance is measured from the mouth of each water body, headed upstream. For comparisons, four seasons were defined:

Winter: December to February.

Spring: March to May.

Summer: June to August.

Fall: September to November.

Next, year groups were created:

1985 to 1988: The period prior to major phosphorus load controls in Virginia.

1989 to 1992: The period following major phosphorus load controls in

Virginia.

1993 to 1994: Two unusually wet years.

Medians and range were taken for all model values and all observations within the season and year groups. Twelve seasonal year groupings resulted.

\section{Time Series by Program Segments}

The system was divided into levels as follows:

Level 1: Depth $<6.7 \mathrm{~m}$.

Level 2: $6.7 \mathrm{~m}<$ Depth $<12.8 \mathrm{~m}$.

Level 3: Depth $>12.8 \mathrm{~m}$. 
All model cells and all observations within Chesapeake Bay Program Segments were averaged by layer. Data were averaged on a monthly basis. Model averages were taken every 10 days.

\section{Time series at stations}

Surface and bottom observations at selected stations were averaged by month. These were compared to 10-day model averages at sample locations.

\section{Vertical profiles}

At selected stations, observed vertical distributions of water quality parameters were interpolated into uniform 1-m increments. This was done for each vertical cast. Next, the interpolated observations were averaged into seasonal year groupings (medians) as with the longitudinal observations. These were compared to seasonal year groupings of model results.

Salinity, temperature, and dissolved oxygen are usually observed at 1-m depth increments. The interpolation and averaging procedure provides a reasonable representation of the observations of these substances on a seasonal basis. Remaining parameters are observed at two to four locations in the water column. The validity of the interpolation and averaging procedure for the remaining observed quantities has not been examined. These model-data comparisons are provided "for the record." More extensive examination of the vertical component of model performance is required.

\section{Submerged Aquatic Vegetation (SAV) time series}

Time series of the following computed quantities are provided for Chesapeake Bay Program Segments:

Shoot density $\left(\mathrm{g} \mathrm{C} \mathrm{m}^{-2}\right)$.

Shoot biomass $(\mathrm{kg})$.

Limitations to SAV production.

Light extinction $\left(\mathrm{m}^{-1}\right)$.

Epiphyte density (g epiphyte $\mathrm{C}^{-1}$ shoot $\mathrm{C}$ ).

Limitations to epiphyte production. 


\section{Appendix C Maryland Minor Tributaries}

Immediately upon completion of the work in Virginia tributaries, the model team was instructed to examine model results and optimize the model for use in Maryland minor tributaries. The model team and sponsors concluded that model resolution was insufficient to provide meaningful results in extensive portions of these smaller water bodies. A refined, detailed grid was constructed, and the model on this grid is presently under development. Documentation of the earlier results is presented in this appendix, included on the accompanying CD, for comparison with results to be produced on the refined grid. 


\section{Appendix D Particulate Inorganic Phosphorus}

The earliest phase of the Chesapeake Bay model identified particulate inorganic phosphorus (PIP) as a significant component of the total phosphorus in the water column. Virtually no observations of this substance were available from the Chesapeake Bay program, however. Consequently, a sampling campaign was conducted in 1994 to collect PIP observations. These observations are available from the Chesapeake Bay Program and have been incorporated into the model database. These observations have not been otherwise presented or extensively examined, however. This appendix presents a data summary, presented on the accompanying $\mathrm{CD}$. The summary includes, at each station, annual mean salinity (ppt), fixed solids concentration $(\mathrm{mg} / \mathrm{L})$, PIP concentration $(\mathrm{mg} / \mathrm{L})$, PIP as a fraction of fixed solids $(\mathrm{mg} / \mathrm{g})$, and dissolved inorganic phosphorus concentration $(\mathrm{mg} / \mathrm{L})$. 


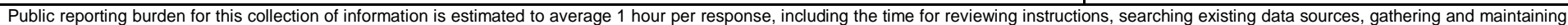

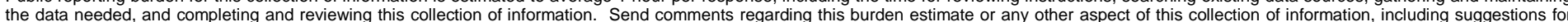

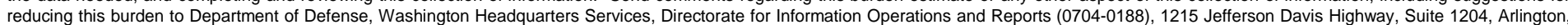

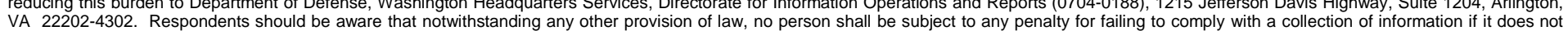
VA 22202-4302. Respondents should be aware that notwithstanding any other provision of law, no person shall be $s$.
display a currently valid OMB control number. PLEASE DO NOT RETURN YOUR FORM TO THE ABOVE ADDRESS.

\begin{tabular}{l|c} 
1. REPORT DATE (DD-MM- $Y Y Y Y)$ & $\begin{array}{c}\text { 2. REPORT TYPE } \\
\text { Fpril } 2002\end{array}$ \\
\hline
\end{tabular}

\section{TITLE AND SUBTITLE}

Tributary Refinements to the Chesapeake Bay Model

\begin{tabular}{|l|l} 
& 3. \\
\hline
\end{tabular}

3. DATES COVERED (From - To)

\section{5a. CONTRACT NUMBER}

5b. GRANT NUMBER

5c. PROGRAM ELEMENT NUMBER

\section{AUTHOR(S)}

\section{5d. PROJECT NUMBER}

Carl F. Cerco, Billy H. Johnson, Harry V. Wang

5e. TASK NUMBER

5f. WORK UNIT NUMBER

\section{PERFORMING ORGANIZATION NAME(S) AND ADDRESS(ES)}

8. PERFORMING ORGANIZATION REPORT

U.S. Army Engineer Research and Development Center

Environmental Laboratory and Coastal and Hydraulics Laboratory

3909 Halls Ferry Road, Vicksburg, MS 39180-6199;

Virginia Institute of Marine Science, P.O. Box 1346, Route 1208, Greate Road

Gloucester Point, VA 23062-1346

\section{SPONSORING / MONITORING AGENCY NAME(S) AND ADDRESS(ES)}

U.S. Army Corps of Engineers

Washington, DC 20314-1000

$$
\text { NUMBER }
$$

ERDC TR-02-4

10. SPONSOR/MONITOR'S ACRONYM(S)

11. SPONSOR/MONITOR'S REPORT NUMBER(S)

\section{DISTRIBUTION / AVAILABILITY STATEMENT}

Approved for public release; distribution is unlimited.

\section{SUPPLEMENTARY NOTES}

Appendices A-D are included on the accompanying CD.

\section{ABSTRACT}

The Tributary Refinements phase of the Chesapeake Bay model study had two objectives: (a) to improve resolution and accuracy within the major Virginia tributaries and (b) to incorporate living resources into the model package. The report includes monographs that (a) summarize the hydrodynamic model; (b) summarize the water quality model; (c) detail the phytoplankton kinetics; (d) describe the submerged aquatic vegetation model; (e) present results of management scenarios; and (f) present statistical summaries of model performance.

\begin{tabular}{|c|c|c|c|c|c|}
\hline \multirow{3}{*}{\multicolumn{2}{|c|}{$\begin{array}{l}\text { 15. SUBJECT TERMS } \\
\text { Chesapeake Bay } \\
\text { Eutrophication }\end{array}$}} & \multicolumn{2}{|l|}{ James River } & \\
\hline & & \multirow{2}{*}{\multicolumn{2}{|c|}{$\begin{array}{l}\text { Mathematical models } \\
\text { Rappahannock River }\end{array}$}} & \multicolumn{2}{|c|}{ York River } \\
\hline & & & & & \\
\hline \multicolumn{3}{|c|}{ 16. SECURITY CLASSIFICATION OF: } & $\begin{array}{l}\text { 17. LIMITATION } \\
\text { OF ABSTRACT }\end{array}$ & $\begin{array}{l}\text { 18. NUMBER } \\
\text { OF PAGES }\end{array}$ & $\begin{array}{l}\text { 19a. NAME OF RESPONSIBLE } \\
\text { PERSON }\end{array}$ \\
\hline $\begin{array}{l}\text { a. REPORT } \\
\text { UNCLASSIFIED }\end{array}$ & $\begin{array}{l}\text { b. ABSTRACT } \\
\text { UNCLASSIFIED }\end{array}$ & $\begin{array}{l}\text { c. THIS PAGE } \\
\text { UNCLASSIFIED }\end{array}$ & & 215 & $\begin{array}{l}\text { 19b. TELEPHONE NUMBER (include } \\
\text { area code) }\end{array}$ \\
\hline
\end{tabular}


Destroy this report when no longer needed. Do not return it to the originator. 